\title{
Migraine and anti-migraine drugs
}

Citation for published version (APA):

de Hoon, J. N. J. M. (2000). Migraine and anti-migraine drugs: focus on cardiovascular aspects. [Doctoral Thesis, Maastricht University]. Universiteit Maastricht. https://doi.org/10.26481/dis.20000928jh

Document status and date:

Published: 01/01/2000

DOI:

10.26481/dis.20000928jh

Document Version:

Publisher's PDF, also known as Version of record

\section{Please check the document version of this publication:}

- A submitted manuscript is the version of the article upon submission and before peer-review. There can be important differences between the submitted version and the official published version of record.

People interested in the research are advised to contact the author for the final version of the publication, or visit the DOI to the publisher's website.

- The final author version and the galley proof are versions of the publication after peer review.

- The final published version features the final layout of the paper including the volume, issue and page numbers.

Link to publication

\footnotetext{
General rights rights.

- You may freely distribute the URL identifying the publication in the public portal. please follow below link for the End User Agreement:

www.umlib.nl/taverne-license

Take down policy

If you believe that this document breaches copyright please contact us at:

repository@maastrichtuniversity.nl

providing details and we will investigate your claim.
}

Copyright and moral rights for the publications made accessible in the public portal are retained by the authors and/or other copyright owners and it is a condition of accessing publications that users recognise and abide by the legal requirements associated with these

- Users may download and print one copy of any publication from the public portal for the purpose of private study or research.

- You may not further distribute the material or use it for any profit-making activity or commercial gain

If the publication is distributed under the terms of Article $25 \mathrm{fa}$ of the Dutch Copyright Act, indicated by the "Taverne" license above, 


\section{MigRAINE AND ANTI-MigRAINE DRUGS}

Focus on Cardiovascular Aspects 
Cover illustration: Indirect immunohistochemistry highlighting the presence of calcitonin gene-related peptide containing perivascular sensor-motor nerves in a whole mount preparation of a mesenteric resistance artery of the rat. Courtesy of Gregorio Fazzi and Jo De Mey, Vascular Pharmacology Unit, Dept. of Pharmacology and Toxicology, Cardiovascular Research Institute Maastricht (CARIM), Universiteit Maastricht, The Netherlands.

Migraine and anti-migraine drugs: focus on cardiovascular aspects / Jan Nelly Jozef Maria de Hoon ISBN 90-9014076-X NUGI $741 / 746$

The financial support of the following companies and organisations is gratefully acknowledged:

Belgium: AstraZeneca (main sponsor for publication), Boehringer Ingelheim, Organon, Pfizer, Servier R\&D Benelux. The Netherlands: Anglo-Dutch Migraine Association, GlaxoWellcome, Merck Sharp \& Dohme, Pie Medical Benelux. France: Institut de Recherche Pierre Fabre. 


\section{MigRAINE AND ANTI-MIGRAINE DRUGS}

\section{Focus on Cardiovascular Aspects}

\section{PROEFSCHRIFT}

ter verkrijging van de graad van doctor aan de Universiteit Maastricht

op gezag van de Rector Magnificus,

Prof. dr. A.C. Nieuwenhuijzen Kruseman,

volgens het besluit van het College van Decanen, in het openbaar te verdedigen

op donderdag 28 september 2000 om 10.00 uur

\section{door \\ JAN NELLY JOZEF MARIA DE HOON}

Geboren te Turnhout op 8 mei 1964 


\section{Promotores:}

Prof. dr. H.A.J. Struijker-Boudier

Prof. dr. J. Troost

\section{Co-promotor:}

Dr. L.M.A.B. Van Bortel

\section{Beoordelingscommissie:}

Prof. dr. P.J.E.M. Kitslaar (voorzitter)

Prof. dr. J.G.R. De Mey

Prof. dr. P.J. Goadsby (Institute of Neurology, London, UK)

Prof. dr. A.P.G. Hoeks

Prof. dr. P.R. Saxena 
Aan Ann, ons kindje en mijn auders 
Het is met het leven als met een proefschrift, het komt meer op de inhoud dan op de lengte aan.

(naar E. Laurillard, ter nagedachtenis aan nonkel Joe, 1928-1985) 


\section{Table of Contents}

\section{Part I: Introduction}

Chapter 1: General introduction: migraine and anti-migraine drugs 13

$\begin{array}{ll}1.1 \text { Epidemiology of migraine } & 13\end{array}$

1.2 Clinical features and diagnostic criteria 13

1.3 Pathophysiology of migraine: a historical overview $\quad 15$

1.4 Anti-migraine drugs 23

1.5 Migraine and cardiovascular disease $\quad 33$

Outline and aims of the present thesis $\quad 49$

Chapter 2: Methods for haemodynamic assessments used in the present thesis 51

2.1 Blood pressure, pulse pressure and heart rate 51

2.2 Large artery wall properties: a "novel" approach 52

2.3 Blood flow and vascular resistance $\quad 59$

2.4 In vivo assessment of endothelial function 61

2.5 Cardiac output and systemic vascular resistance 63

2.6 Intima-media thickness 64

2.7 Minimal forearm vascular resistance $\quad 64$

Part II: The pathophysiology of migraine: focus on vascular aspects

Chapter 3: Migraine patients display interictal changes in large artery wall properties $\quad 71$

3.1 Introduction $\quad 72$

3.2 Subjects and methods $\quad 73$

$\begin{array}{ll}3.3 \text { Results } & 77\end{array}$

3.4 Discussion

Chapter 4: Vascular responsiveness to nitric oxide and calcitonin gene-related peptide in migraine patients $\quad 89$

4.1 Introduction $\quad 90$

4.2 Subjects and methods $\quad 91$ 
Chapter 5: Mechanism of action of the vasodilator response to calcitonin gene-related peptide in human

\section{Part III: Vascular effects of anti-migraine drugs}

Chapter 6: Vascular effects of 5-HT $\mathrm{H}_{1 \mathrm{~B} / 1 \mathrm{D}}$-receptor agonists in migraine patients 131 6.1 Introduction 132

6.2 Subjects and methods 133

6.3 Results 137

6.4 Discussion

Chapter 7: Dihydroergotamine: discrepancy between arterial, arteriolar and pharmacokinetic data

7.1 Introduction $\quad 150$

7.2 Subjects and methods $\quad 151$

7.3 Results 154

$\begin{array}{ll}7.4 \text { Discussion } & 159\end{array}$

\section{Part IV: Discussion and synopsis}

Chapter 8: General discussion and conclusions

8.1 Interictal functional and structural arterial changes in migraine patients

8.2 Migraine pathophysiology:

8.3 Cardiovascular effects of anti-migraine drugs $\quad 172$

8.4 From facts to future 
Chapter 9: Summary - Samenvatting

Curriculum vitae

Bibliography

List of abbreviations 

Part I

\author{
Introduction
}

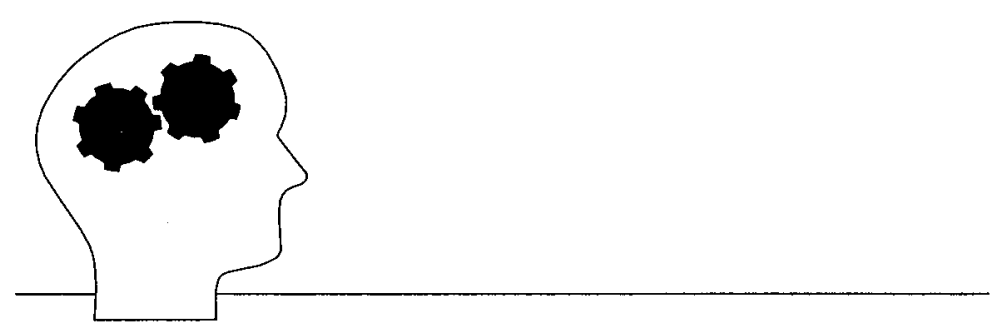


"... there was given to me a thorn in the flesh, the messenger of Satan to buffet me ..."

(Saint Paul, 4-64) 


\section{Chapter 1}

\section{General Introduction: Migraine and Anti-Migraine Drugs}

\subsection{Epidemiology of migraine}

As migraine is a highly prevalent syndrome affecting up to $10 \%$ of the general population it comprises a major public health problem [1]. Among females the incidence of migraine peaks between 12 and 17 years of age, among males between 5 and 11 [2]. Migraine affects about $18 \%$ of women and $6 \%$ of men. It is 2 to 3 times more frequent in females compared to males and has the highest prevalence in persons aged 25 to 55 years $[3,4]$.

\subsection{Clinical features and diagnostic criteria}

One of the first major treatises on the subject of migraine was written by Edward Liveing in 1873 [5]. In his book "On megrim, sick-headache and some allied disorders" he compared migraine with epilepsy and referred to it as "the pathology of nerve-storms". By carefully observing his patients Liveing meticulously described the clinical features of migraine as it was reported by his patients:

"... Every three or four weeks I am liable to an attack, coming on for the most part in consequence of some unhealthy influence, such as long fasting, a fatiguing evening entertainment, and so forth. I thereupon awake the next morning with a general feeling of disorder, and a slight pain in the region of the right temple, ... reaching its greatest intensity at mid-day; towards evening it usually passes off. While at rest the pain is bearable, but it is increased by motion to a high degree of violence. ... It responds to every beat of the temporal artery.... At the height of the attack there is nausea, ... it has only once occasioned vomiting." 


\section{Chapter 1}

Table 1.1 Classification and diagnostic criteria for migraine according to the Headache Classification Committee of the International Headache Society (1988) [6].

\section{Migraine without aura:}

A. At least 5 attacks fulfilling B-D.

B. Headache attacks, lasting 4-72 hours (untreated or unsuccessfully treated).

C. Headache has at least two of the following characteristics:

1. Unilateral localisation

2. Pulsating quality

3. Moderate or severe intensity (inhibits or prohibits daily activities)

4. Aggravation by walking stairs or similar routine physical activity

D. During headache at least one of the following:

1. Nausea and/or vomiting

2. Photophobia and phonophobia

E. At least one of the following:

1. History, physical- and neurological examinations do not suggest association with head trauma, vascular or non-vascular intracranial disorders, use of or withdrawal from noxious substances, non-cephalic infections, metabolic disorders or disorder of cranial or facial structures.

2. History and/or physical- and/or neurological examinations do suggest such disorder, but it is ruled out by appropriate investigations.

3. Such disorder is present, but migraine attacks do not occur for the first time in close temporal relation with the disorder.

Migraine with aura:

A. At least 2 attacks fulfilling B.

B. At least 3 of the following 4 characteristics:

1. One or more fully reversible aura symptoms indicating focal cerebral cortical - and/or brain stem dysfunction.

2. At least one aura symptom develops gradually over more than 4 minutes or, 2 or more symptoms occur in succession.

3. No aura symptom lasts more than 60 minutes. If more than one aura symptom is present, accepted duration is proportionally increased.

4. Headache follows aura with a free interval of less than 60 minutes. (It may also begin before or simultaneously with the aura).

C. (See above under E. for migraine without aura). 
To improve the diagnosis and scientific study of migraine, the Headache Classification Committee of the International Headache Society formulated diagnostic criteria in 1988 (Table 1.1) [6]. According to these criteria, migraine is characterised by attacks of moderate to severe headache accompanied by autonomic and neurological symptoms. Typical migraine headache lasts 4 to 72 hours and presents as unilateral, pulsating pain worsening upon physical activity. In case of migraine without aura (previously referred to as common migraine) headache is associated with nausea and vomiting as well as photophobia and phonophobia. However, in up to onethird of patients migraine headache is preceded by aura symptoms (previously referred to as classical migraine) which last up to one hour. Aura symptoms mainly consist of visual symptoms such as scintillating scotomas and visual field defects, but may also include sensory and motor symptoms such as paresthesia and paresis [7].

\subsection{Pathophysiology of migraine: a historical overview}

About hundred years ago, Freud's theories on the pathogenesis of migraine focused on neurophysiological hypotheses [8]. He stated "that migraine represents a toxic effect produced by sexual stimulating substances when this cannot find sufficient discharge". Since that time the pathophysiology of migraine has been much debated with the pendulum of interest swinging between a primary vascular and a primary neuronal theory (Table 1.2) [9]. However, recent findings indicate that elements of both theories can be reconciled in a unifying hypothesis which regards migraine as a neurovascular disorder.

\section{The primary vascular theory}

The concept of migraine being due to an inappropriate vasodilatation and increased arterial pulsations of cranial blood vessels dominated the thinking of migraine pathophysiology for several centuries. It was first recognised by the Swiss physician Wepfer [10] in the 17th century and confirmed by Graham and Wolff in 1938 [11]. 
Table 1.2 Migraine pathophysiology: a historical overview.

$\begin{array}{lll}\text { 55-56 } & \text { Il Corinthians 12:7 } & \text { Was St Paul's thorn in the flesh ... migraine? } \\ 1727 & \text { J. Wepfer } & \text { Arterial distension and perivascular oedema? } \\ 1873 & \text { E. Liveing } & \text { Megrim: The pathology of "nerve storms". } \\ 1895 & \text { S. Freud } & \text { Neurophysiological hypotheses. } \\ 1937 & \text { J. Graham \& H. Wolff } & \text { Increased arterial pulsations causing pain. } \\ 1944 & \text { A. Leão } & \text { Cortical spreading depression causing aura. } \\ 1969 & \text { H. Heyck } & \text { Shunting through arteriovenous anastomoses. } \\ 1979 & \text { M. Moskowitz } & \text { Activation of the trigeminovascular system. } \\ 1988 & \text { P. Goadsby } & \text { Release of calcitonin gene-related peptide. } \\ 1998 & \text { M. Ferrari } & \text { Cerebral calcium channelopathy? }\end{array}$

In their pioneer work Graham and Wolff observed an increase in the amplitude of the superficial temporal artery pulsations during the headache phase of migraine, while after the administration of ergotamine the amplitude was reduced and pain was often relieved [11]. From these data they reasoned that migraine headache is caused by stretching of branches of the external carotid artery and that it is alleviated by vasoconstriction. In 1969, during the headache phase Heyck observed a decreased arteriovenous oxygen difference in the extracranial circulation which normalised after the administration of dihydroergotamine [12]. Thus he postulated that the increased blood flow in the extracranial circulation might result from the shunting of blood through arteriovenous anastomoses which are predominantly present in the skin of the scalp and in the dura mater $[13,14]$. This would also explain the paleness frequently observed during a migraine attack and is in line with recent research demonstrating that many acute anti-migraine drugs constrict arteriovenous anastomoses by $5-\mathrm{HT}_{\mathrm{IB}^{-}}$ receptor activation in the porcine carotid circulation $[15,16]$.

Only recently adequate tools became available to investigate the vascular changes during migraine headache in more detail. Based on indirect measurements Drummond and co-workers [17] concluded that only in a minority of patients 
dilatation of the superficial temporal artery contributes to migraine headache. In contrast, using ultrasound Iversen et al. [18] showed that the diameter of the temporal artery is significantly larger on the symptomatic than on the non-symptomatic side during an attack. Although conflicting results were obtained, it is likely that in a substantial number of migraine patients headache is associated with extracranial arterial vasodilatation.

Intracranial changes in arterial diameter cannot be measured directly $[19,20]$. Only relative changes can be estimated by the combination of regional cerebral blood flow (rCBF) measurements, which refer to tissue perfusion controlled by resistance vessels, and transcranial Doppler sonography (TCD), which measures blood flow velocity in large arteries. If $\mathrm{rCBF}$ is unaffected it is assumed that a decrease or increase in arterial blood flow velocity reflects vasodilatation or vasoconstriction, respectively. Friberg et al. [21] reported that both in patients with and without aura, migraine headache is associated with a decreased blood flow velocity in the middle cerebral artery while $\mathrm{rCBF}$ was unaffected, indicating intracranial arterial vasodilatation. In addition, sumatriptan increased blood flow velocity, suggesting reversal of middle cerebral artery vasodilatation. Thus taken together, both intra- and extracranial arterial vasodilatations have been reported during an acute migraine attack. These observations support the primary vascular theory which states that vasodilatation causes headache by the activation of perivascular sensory nerves [22].

The transient neurological symptoms preceding headache during migraine with aura, have been proposed to result from cerebral hypoperfusion secondary to intracranial vasoconstriction [20]. In the early phase of migraine with aura, Olesen et al. [23] reported focal posterior cerebral hypoperfusion which was proportional to the severity of aura symptoms. Using novel functional magnetic resonance imaging techniques (fMRI) a decrease in cerebral blood flow in the occipital cortex was recently confirmed in migraine with aura $[24,25]$. If due to hypoperfusion, transient ischaemia would affect neuronal function these data would favour a primary vascular event.

Although attractive, several lines of evidence cast doubt on the vascular theory. Firstly, in migraine patients without aura at no point in time focal changes in cerebral 


\section{Chapter 1}

blood flow are observed and there is no consistent relationship between arterial diameter, cerebral blood flow and headache $[26,27]$. Secondly, some cranial vasodilators (e.g. nitrates and histamine) $[28,29]$ are capable of inducing headache, while others are not (e.g. papaverine) [30] suggesting that vasodilatation per se does not cause headache. Although nitric oxide (NO) donors (e.g. nitroglycerine and nitroprusside) can induce headache which resembles migraine [31, 32], this does not prove arterial vasodilatation to be the primary event. On the contrary, recent animal studies by Wei and co-workers demonstrated that vasodilatation by NO-donors results from the activation of perivascular sensory nerves and the subsequent release of calcitonin gene-related peptide (CGRP) [33]. If the same is true for man, this might explain the delayed onset of headache after the administration of nitrates. Thirdly, vasodilatation cannot only be the cause of perivascular nerve stimulation, but it can also be caused by it [22].

\section{The primary neuronal theory}

Clinical practice shows that up to 24 hours before the actual attack, migraine patients report prodromes including craving for foods, mood changes, yawning and fatigue which all indicate hypothalamic dysfunction [34]. In case of migraine with aura, both visual disturbances and sensor-motor symptoms are clearly of a neuronal origin. According to the neuronal theory the aura might be caused by "cortical spreading depression" (CSD) which was first reported by Leão in 1944 [35]. He described the phenomenon of CSD as a slow-moving wave of depressed cortical activity which can be induced in animals by a variety of stimuli. The speed at which the neuronal depression wave moves across the cortex $(2-3 \mathrm{~mm} / \mathrm{min})$ corresponds well with the spreading of cerebral hypoperfusion which moves from occipital to frontal regions during the aura phase [36]. In line with these observations, the primary neuronal theory states that depressed neuronal activity causes the aura symptoms while arteriolar vasoconstriction, resulting in reduced cerebral perfusion, is merely an epiphenomenon due to the reduced metabolic demand. However, proof of the existence of CSD in human is not yet available [37]. 


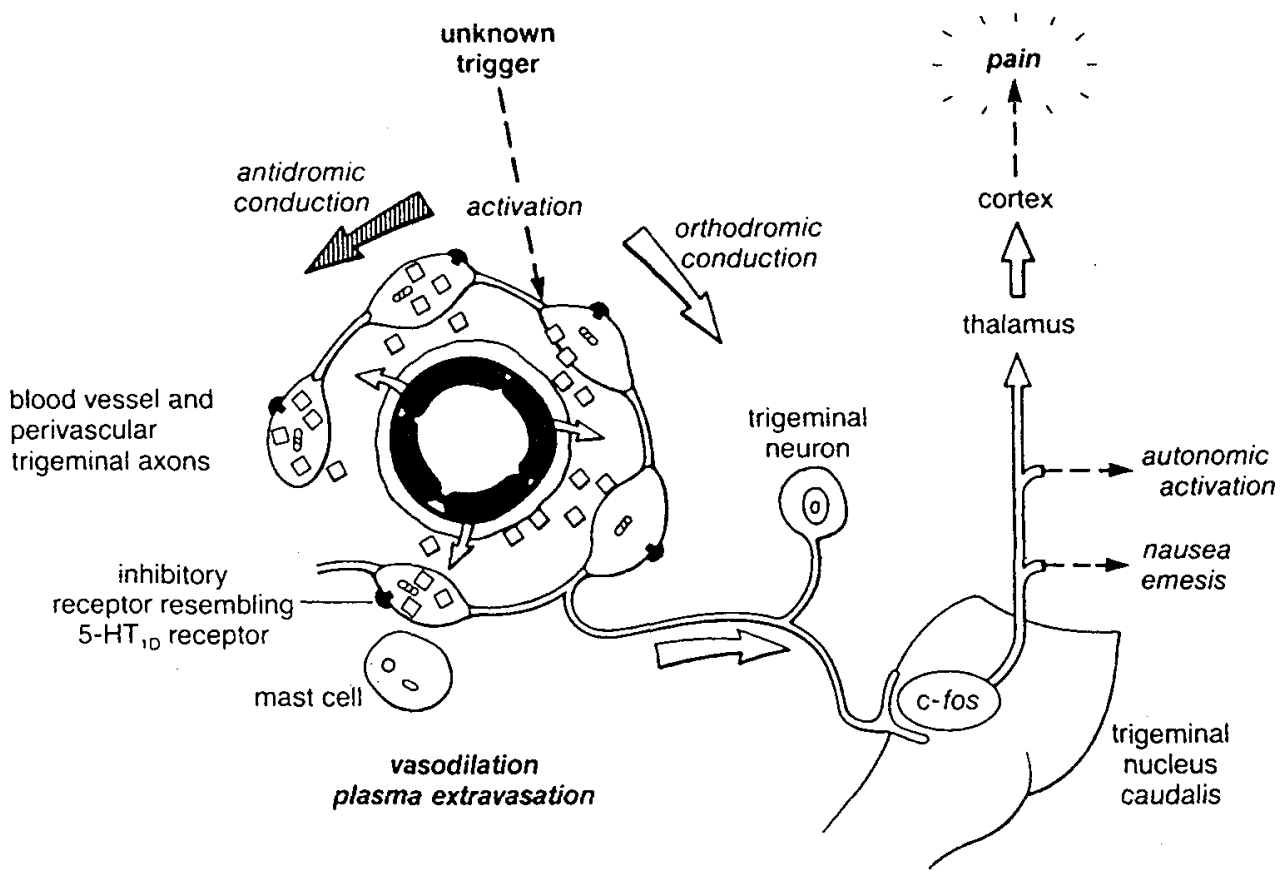

Figure 1.1 Pathophysiological mechanism of migraine (Reproduced with permission from Moskowitz MA, Trends Pharmacol Sci 1992; 13: 307-311).

The unifying hypothesis: the trigeminovascular system

The current view is that migraine is a neurovascular disorder of which the trigeminovascular system is the anatomical substrate [38]. The trigeminovascular system comprises of pain sensitive intracranial structures (i.e. meninges and blood vessels) and the major afferent pathway for transmitting pain from these structures constituted by the first division of the trigeminal nerve and its central projections into the trigeminocervical complex (i.e. the trigeminal nucleus caudalis and the $\mathrm{C}_{1}-\mathrm{C}_{2}$ superficial dorsal horns). From these brainstem regions nociceptive information is transmitted to the thalamus and cortical areas to produce pain while projections into the nucleus tractus solitarius mediate autonomic symptoms including nausea and vomiting [39]. 


\section{Chapter 1}

In 1979, Moskowitz hypothesised that activation of the trigeminovascular system is essential for the generation of migraine headache (Fig. 1.1) [40]. Both in animal and in human it has been shown that the activation of this system, by stimulation of the trigeminal ganglion, results in the central transmission of pain and the retrograde release of neurotransmitters [41, 42]. These neurotransmitters including CGRP, substance P (SP) and neurokinin A (NKA) are vasodilator neuropeptides contained within unmyelinated perivascular sensory nerves [38]. The effects of SP and NKA, which also promote plasma protein extravasation, are mediated by interaction with $\mathrm{NK}_{1}$ and $\mathrm{NK}_{2}$ receptors, respectively [43]. Activation of these receptors is coupled to the stimulation of phospholipase $\mathrm{C}$ and involves the endothelial release of NO. CGRP exerts its biological effects by interaction with CGRP-receptors ( $\mathrm{CGRP}_{1}$ and $\left.\mathrm{CGRP}_{2}\right)$ which, based on in vitro data, involves both endothelium-dependent and endothelium-independent mechanisms [44]: (i) activation of vascular smooth muscle cell adenylate cyclase [45-47]; (ii) the endothelial release of NO [48, 49] and (iii) the activation of adenosine-5'-triphosphate-sensitive

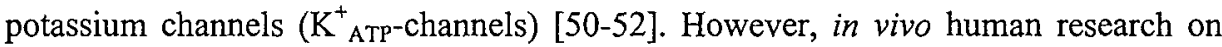
the vasodilator mechanism of action of CGRP is still lacking (see Chapter 5).

In animal experiments, neuropeptide release promotes neurogenic inflammation which is characterised by vasodilatation, plasma protein extravasation, platelet aggregation and mast cell degranulation $[22,41]$. Although neurogenic inflammation is suggested to be a defence mechanism to noxious stimuli, the substances released by it might sensitise sensory nerves and induce sustained headache. Recently, Goadsby and co-workers were the first to demonstrate that during migraine headache the trigeminovascular system is indeed turned on and CGRP is released into the cranial circulation [53]. However, plasma protein extravasation has not yet been shown to constitute an important component in the pathophysiology of migraine [54].

Taken together, according to the neurovascular theory, activation of the trigeminal pathway is the primary event in migraine headache and results in the secondary perivascular release of vasodilating neuropeptides (e.g. CGRP and SP) initiating neurogenic inflammation. Alternatively, the centrally projecting $\mathrm{C}$-fibres release neurotransmitters (e.g. CGRP, SP and glutamate) which activate second order 
neurones within the trigeminal nucleus and result in the central transmission of pain [22]. In this cascade, recent evidence indicates an important role for glutamate and $\mathrm{N}$ methyl-D-aspartate (NMDA) receptor activation for the transmission of nociceptive information within the trigeminocervical complex [55-58].

Although the trigeminovascular theory provides a sound framework for linking the neuronal and vascular changes observed in migraine headache, the coupling mechanism between cerebral events (i.e. aura symptoms) and the activation of the trigeminovascular system remains uncertain. One of the potential links is NO. During CSD, glutamate is released and NMDA receptor-operated calcium channels are activated [59]. The resulting influx of calcium is responsible for the propagation of spreading depression and the calcium-dependent activation of NO-synthase [60]. Interestingly, $\mathrm{NO}$ has been shown to activate perivascular sensory nerves and plays a regulatory role in the release of neuropeptides $[33,61]$.

\section{The trigger initiating migraine}

To date, none of the previously discussed hypotheses has been able to identify the trigger initiating the vascular and/or neuronal changes associated with migraine headache. As an isolated migraine attack can occur in any subject, it is not the individual attack but the repeated occurrence of it which is considered abnormal and defines migraine as a disease [1]. Therefore, it is suggested that migraine patients are either susceptible subjects with a low "migraine threshold" or are exposed to frequent and/or strong migraine-inducing triggers.

Based on epidemiological data, many environmental factors have been reported to precipitate migraine [62]. Among these stress, weather changes, hormonal fluctuations, exposure to bright light, hunger and fatigue are most frequently mentioned. In addition, about $30 \%$ of patients report food-induced migraine and commonly refer to alcohol (red wine in particular), chocolate and certain cheeses (containing tyramine or phenylethylamine) as precipitants for headache [63]. In view of the ease and safety with which these triggers can be manipulated, their role in the management of migraine should not be forgotten. 


\section{Chapter I}

According to Olesen and co-workers [64, 65] NO (or endothelium derived relaxing factor, EDRF) is a likely candidate for the triggering molecule initiating migraine headache. It was demonstrated that migraine patients suffer a more intense migraine-like headache and display an increased vasodilatation of the middle cerebral artery after the administration of NO-donors (i.e. nitrates) compared to healthy subjects [66]. Based on these data it was concluded that migraine patients display an arterial supersensitivity to NO. This view is supported by the observation that other substances including prostacyclin, methacholine and adenosine which are known to induce the endothelial release of NO, can also induce migraine headache [67-69]. Although NO is likely to be involved in the pathophysiology of migraine, it remains unknown whether it exerts its effects predominantly at the level of the blood vessel wall, at the level of perivascular nerves or both. However, the latency period between the exposure to organic nitrates and the onset of migraine-like headache suggests that NO initiates a slow pathological process which eventually leads to the attack [65]. This pathological process could well be the activation of the trigeminovascular system (see Chapter 4).

With regard to the "migraine threshold", biochemical [70], neurophysiological [71] and magnetic resonance spectroscopic [72] data suggest an increased cortical excitability and increased responses during the interictal period. In this context, there is increasing evidence that genetic factors might set the scene for migraine [73]. For instance, in familial hemiplegic migraine, a rare autosomal dominant type of migraine with aura which is associated with hemiparesis, mutations have been reported in the $C A C N \alpha 1 A$ gene encoding the $\alpha_{1 \mathrm{~A}}$-subunit of a brain specific voltage-gated P/Q-type calcium channel [74]. Mutations in the $C A C N \alpha 1 A$ gene alter calcium channel function and are likely to be involved in typical migraine both with and without aura $[75,76]$. As mutant calcium channels might be implicated in CSD and abnormal neurotransmitter release, Ferrari states that migraine can be regarded as a "cerebral calcium channelopathy" [1].

Finally, studies using positron emission tomography (PET) have identified a brainstem region which is activated during migraine headache and remains activated after pain relief by sumatriptan [77]. These data are suggestive for the existence of a 
central "migraine generator" triggering the attack and persisting after successful treatment which alleviates symptoms without affecting the "migraine generator" itself.

\subsection{Anti-migraine drugs}

The physiological mechanisms by which anti-migraine drugs relieve migraine headache are still not fully elucidated. Thinking of migraine in terms of an activation of the trigeminovascular system, three distinct pharmacological sites of action can be identified: (i) the cranial blood vessels (both meningeal and cerebral), (ii) the peripheral trigeminal sensory nerves innervating these vessels, and (iii) the central projections of the trigeminal nerve and the trigeminocervical complex [78]. The desired pharmacological effects at each of these levels comprise of (i) vasoconstriction, (ii) inhibition of perivascular nerve activation and/or neurogenic inflammation and (iii) attenuation of the excitability of trigeminal neurones, respectively. In the present overview the pharmacology of drugs used in the acute treatment of migraine is discussed. Attention is focused on both anti-migraine activity and cardiovascular effects.

\section{Non-specific drugs}

Using a stepped-care approach, migraine patients should first be treated with nonspecific drugs including simple analgesics (e.g. paracetamol and acetylsalicylic acid) and non-steroidal anti-inflammatory drugs (NSAIDs, e.g. ibuprofen and naproxen) [79]. Because gastric stasis often accompanies migraine attacks, anti-emetics are frequently associated to increase drug absorption and enhance the effectiveness of the treatment [80]. Compared to specific anti-migraine drugs, several non-specific drug regimens (e.g. the combination acetylsalicylic acid and metoclopramide) have been shown to be equally effective [81]. The mode of action of NSAIDs probably relates to their ability to block neurogenic inflammation by inhibiting plasma protein extravasation [82]. 


\section{Chapter 1}

\section{Ergot alkaloids}

The ergot alkaloids were the first specific compounds reported to be successful in the acute treatment of migraine [83]. Ergotamine was isolated in 1918 from the fungus Claviceps purpurea and reported effective as an anti-migraine drug in 1926. However, because of its unfavourable side effect profile the dihydrogenated derivative dihydroergotamine (DHE, Fig. 1.2) was developed and became available in 1945 [84]. Both ergotamine and DHE are non-selective pharmacological compounds interacting with serotonergic (5-HT $\mathrm{H}_{1}$ and $5-\mathrm{HT}_{2}$-receptors), adrenergic ( $\alpha_{1}$ and $\alpha_{2}$-receptors) and dopaminergic receptors $\left(\mathrm{D}_{2}\right.$-receptors) $[84,85]$. DHE differs form ergotamine in that it is less toxic, less emetic and claimed to display a decreased peripheral vasoconstrictor activity $[84,86]$.

Despite their wide acceptance as anti-migraine drugs, ergot alkaloids have a very low oral and rectal bioavailability ( $5 \%$ or less) and limited placebo-controlled data are available on their clinical efficacy [87]. The anti-migraine activity of the ergot alkaloids results from cranial vasoconstriction and inhibition of plasma protein extravasation $[88,89]$. The low incidence of headache recurrence observed in clinical practice has been attributed to their long lasting vasoconstrictor effects [90].

Because of sustained systemic and coronary vasoconstriction ergot alkaloids are contraindicated in patients with cardiovascular disease [91-93]. The vasopressor effects of the ergot alkaloids are the combined result of actions on (i) pre-synaptic $\alpha_{2}$ and $\mathrm{D}_{2}$-receptors, inhibiting noradrenaline efflux, (ii) post-synaptic $\alpha_{1}, 5-\mathrm{HT}_{1 \mathrm{~B}}$ and $5-\mathrm{HT}_{2 \mathrm{~A}}$ receptors, mediating vasoconstriction, and (iii) central blood pressure control mechanisms [94]. Concerning arterial effects, in vitro data show that ergotamine and DHE induce a sustained contraction of human arteries [93, 95, 96]. For ergotamine, long lasting arterial contractions and a discrepancy between plasma concentrations and arterioconstrictor activity have also been reported in human [91]. Both in animal [97] and in human [98-100] the same discrepancy has been demonstrated for the venoconstrictor activity of DHE. In contrast, data on the arterial and arteriolar effects of DHE in human are scarce. Although based on indirect measurements, Andersen et al. [101] concluded that DHE lacks peripheral arterial effects, direct assessments of the arterial effects of DHE have never been performed in human (see Chapter 7). 
Name

F 11356

Sumatriptan

Zolmitriptan

Rizatriptan<smiles>N#Cc1ccc(N2CCN(C(=O)COc3ccc4[nH]cc(CCN)c4c3)CC2)cc1</smiles><smiles>CNS(=O)(=O)Cc1ccc2[nH]cc(CCN(C)C)c2c1</smiles><smiles>CN(C)CCc1c[nH]c2ccc(CC3COC(=O)N3)cc12</smiles><smiles>CN(C)CCc1c[nH]c2ccc(Cn3cncn3)cc12</smiles>

Naratriptan

Avitriptan<smiles>CNS(=O)(=O)Cc1ccc2[nH]cc(CCCN3CCN(c4ncncc4OC)CC3)c2c1</smiles>

Eletriptan<smiles>CN1CCCC1Cc1c[nH]c2ccc(CCS(=O)(=O)c3ccccc3)cc12</smiles>

Frovatriptan<smiles>CN[C@H]1CCc2[nH]c3ccc(C(N)=O)cc3c2C1</smiles>

Almotriptan

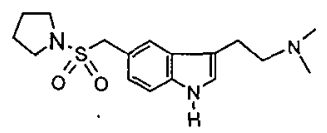

Dihydroergotamine

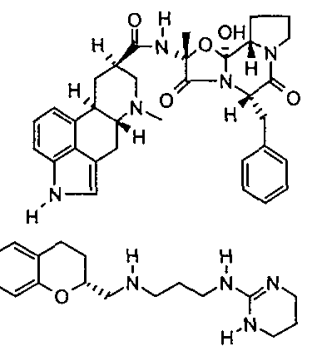

Figure 2.1 Chemical structures of anti-migraine drugs. 


\section{Chapter 1}

\section{Sumatriptan}

Prior to the development of sumatriptan, attention focused on the role of the disturbance in 5-hydroxytryptamine (5-HT, serotonin) metabolism in migraine patients [102]. Compared to healthy control subjects, between attacks 5-HT plasma concentrations are lower in migraine patients [103]. During migraine headache, platelet 5-HT content falls while plasma 5-HT concentration and urinary 5-hydroxyindole-3-acetic acid (5-HIAA) secretion, a metabolite of 5-HT, are increased [104]. The ictal rise in plasma 5-HT concentration probably reflects a selfdefence mechanism. This is supported by the observations that reserpine, which lowers plasma 5-HT concentrations, can induce migraine in susceptible subjects while the intravenous administration of 5-HT can abort the attack [105]. In view of these data, it was hypothesised that compounds might be designed which retain the efficacy of 5-HT in the treatment of migraine headache but are devoid of its unacceptable side effects (e.g. platelet aggregation, bronchoconstriction and generalised vasoconstriction).

As a result of this research in the early 1990s sumatriptan (GR 43175) was the first selective $5-\mathrm{HT}_{1 \mathrm{~B} / 1 \mathrm{D}}$-receptor agonist to become available as an anti-migraine drug and still is one of the most effective and generally well tolerated treatments [106, 107]. Disadvantages include its poor oral bioavailability, hydrophilicity limiting central nervous system penetration and short plasma half-life responsible for frequent headache recurrence in patients who initially respond well (Table 1.3) [108-111]. However, the major limitation for the use of sumatriptan are chest symptoms which are reported by up to $15 \%$ of patients [112-114]. Although coronary vasoconstriction is an unlikely cause for these chest symptoms in most patients, sumatriptan has occasionally been associated with both myocardial infarction and sudden death [115, 116]. In addition to coronary vasoconstriction, the systemic vasoconstrictor effects of sumatriptan have also clearly been demonstrated in human and rendered the drug contraindicated in patients with cardiovascular disease [93, 117-119]. Therefore, recent research aimed at the development of "sumatriptan-like" drugs which should be at least equally effective but display increased cardiovascular safety and an improved pharmacokinetic profile. 


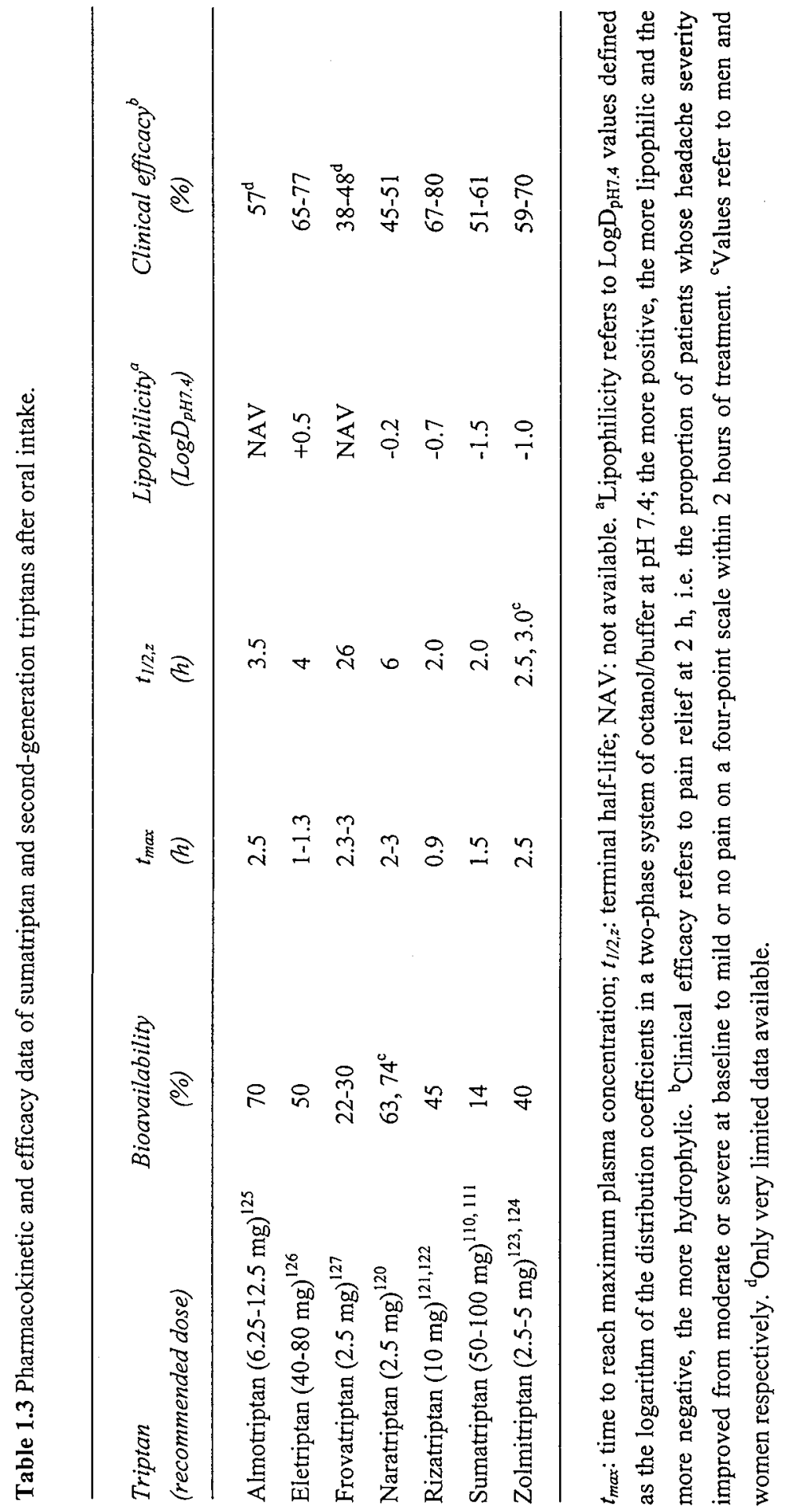




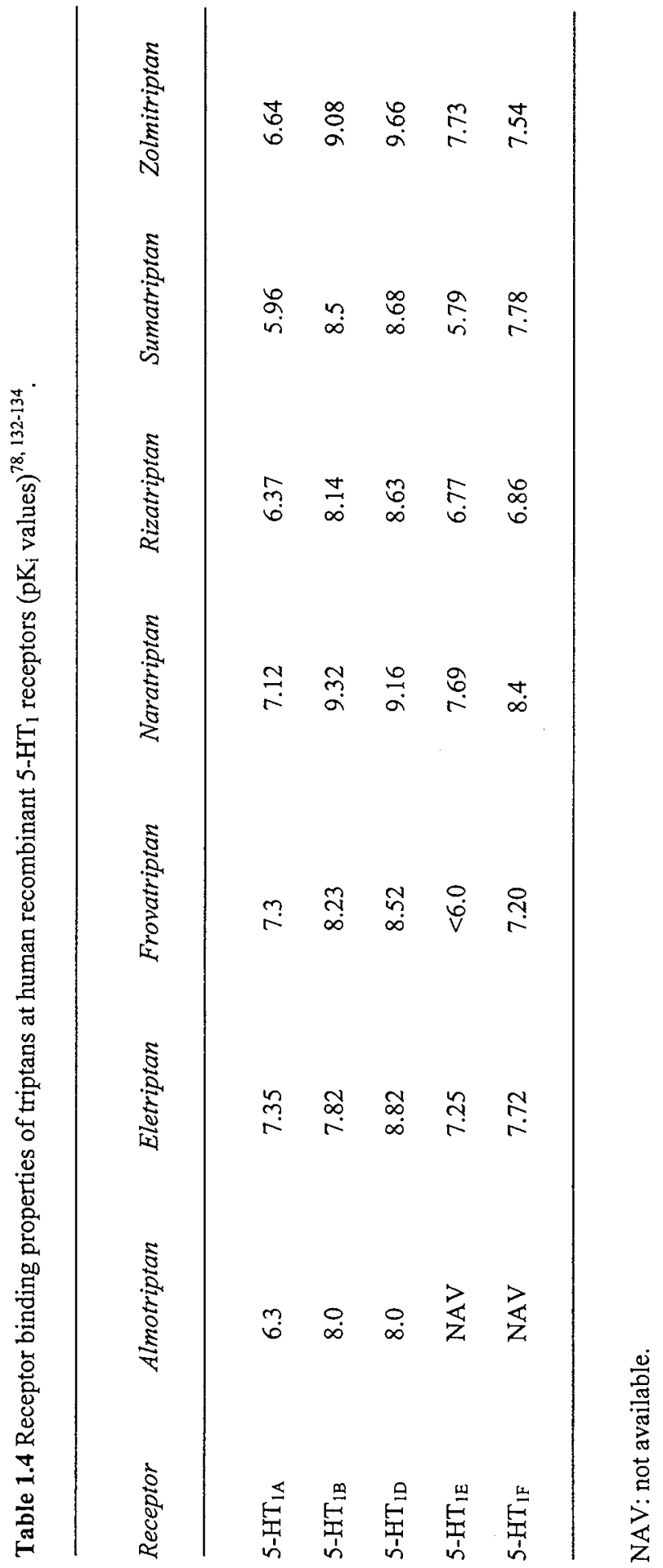




\section{Second generation triptans: the "triptan war"}

Together with sumatriptan, the majority of the more recently developed 5- $\mathrm{HT}_{1 \mathrm{~B} / 1 \mathrm{D}}$ receptor agonists are tryptamine derivatives which are collectively referred to as "triptans" (Fig. 1.2) [78]. Naratriptan (GR 85548) [120], rizatriptan (MK 462) [121, 122] and zolmitriptan (311C90) [123, 124] were recently marketed while almotriptan (LAS 31416) [125], eletriptan (UK 116044) [126] and frovatriptan (VML 251/SB 209509) [127] will shortly become available. Although these triptans have a higher bioavailability, longer plasma half-life and increased lipophilicity compared to sumatriptan (Table 1.3), their clinical efficacy increased only marginally and headache recurrence has not decreased substantially [79, 111, 128]. F 11356 [129] and IS-159 [130] are in clinical development whereas, despite their effectiveness, avitriptan (BMS 180048) [131] and alniditan ( $R$ 091274, a non-indole derivative) [132] will not be commercialised.

\section{Triptans: pharmacology and mode of action}

Based on their pharmacological profile the triptans as a class can be regarded as

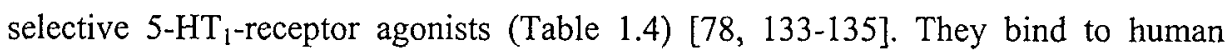
$5-\mathrm{HT}_{\mathrm{IB}}$ (previously known as $5-\mathrm{HT}_{\mathrm{IDB}}$ ) [136] and $5-\mathrm{HT}_{1 \mathrm{D}}$ (previously known as 5-HT $\left.\mathrm{T}_{1 \mathrm{D} \alpha}\right)$ [136] receptors with high affinity, and to a lesser extent to $5-\mathrm{HT}_{\mathrm{lF}}$ receptors. The triptans have virtually no affinity to the other classes of 5-HT receptors $\left(5-\mathrm{HT}_{2-7}\right)$. Notable exceptions are zolmitriptan and F 11356 which display affinity to the 5- $\mathrm{HT}_{7}$ $\left(\mathrm{pK}_{\mathrm{i}} 7.02\right)$ and $5-\mathrm{HT}_{2 \mathrm{~A}}\left(\mathrm{pK}_{\mathrm{i}} 6.57\right)$ receptor, respectively. A higher affinity to the $5-\mathrm{HT}_{2 \mathrm{~B}}$ receptor is noted for zolmitriptan $\left(\mathrm{pK}_{\mathrm{i}} 7.19\right)$ and rizatriptan $\left(\mathrm{pK}_{\mathrm{i}} 6.59\right)$.

The distribution of 5- $\mathrm{HT}_{1 \mathrm{~B}}$ and $5-\mathrm{HT}_{1 \mathrm{D}}$ receptors and their functional involvement in the anti-migraine activity of triptans have been clarified by pharmacological, immunocytochemical and molecular techniques [137-140]. It was demonstrated that within the trigeminovascular system $5 \mathrm{HT}_{\mathrm{IB}}$ receptors are only present on meningeal smooth muscle cells while $5-\mathrm{HT}_{\mathrm{ID}}$ receptors are expressed on trigeminal sensory neurones and their peripheral and central projections. It is now generally accepted that the anti-migraine activity of both sumatriptan and second-generation triptans is the combined result of cranial vasoconstriction by $5-\mathrm{HT}_{1 \mathrm{~B}}$-receptor activation and 


\section{Chapter 1}

inhibition of neuropeptide release by presynaptic $5-\mathrm{HT}_{1 \mathrm{D}}$-receptor activation [141143]. In addition, there is convincing evidence that increased lipophilicity permits second-generation triptans to penetrate into the brain and suppress neuronal activity within the trigeminal nuclei by $5-\mathrm{HT}_{1 \mathrm{D}}$-receptor stimulation [144-146]. As a consequence, central pain transmission is interrupted and autonomic symptoms are reduced.

Although sumatriptan has also been suggested to interfere with central pain transmission, because of its hydrophylic nature it is not expected to penetrate into the brain. However, it cannot be excluded that during the process of neurogenic inflammation the blood-brain barrier is disrupted and access is gained into the central nervous system $[147,148]$.

\section{Triptans: focus on cardiovascular effects}

Most second-generation triptans are selective $5-\mathrm{HT}_{1 \mathrm{~B} / 1 \mathrm{D}}$-receptor agonists characterised by an in vitro pharmacology comparable to that of sumatriptan in terms of receptor selectivity, potency and efficacy (Table 1.4) [78]. Thus, from a pharmacological point of view, there is little reason to expect that second-generation triptans will display a profoundly different cardiovascular profile.

Which are the receptors involved in the vascular effects of the triptans? The vascular effects of 5-HT and its derivatives are determined by interactions with 5-HT receptors both on vascular smooth muscle cells, including $5-\mathrm{HT}_{1 \mathrm{~B}}, 5-\mathrm{HT}_{2 \mathrm{~A}}$ and $5-\mathrm{HT}_{7}$ receptors, and on the endothelium, mainly $5-\mathrm{HT}_{1 \mathrm{~B}}$ and $5-\mathrm{HT}_{2 \mathrm{~B}}$ receptors [149-151]. The $5-\mathrm{HT}_{1}$ receptor subtypes are coupled with inhibition of adenylate cyclase, $5-\mathrm{HT}_{2}$ receptor subtypes with stimulation of phospholipase $\mathrm{C}$ and the $5-\mathrm{HT}_{7}$ receptor with enhancement of adenylate cyclase activity. Endothelial 5-HT receptors mediate the release of vasodilator substances, including $\mathrm{NO} / \mathrm{EDRF}$, resulting in vasodilatation [152]. Interactions with $5-\mathrm{HT}_{1 \mathrm{~B}}$ and $5-\mathrm{HT}_{2 \mathrm{~A}}$ receptors on smooth muscle cells mediate vasoconstriction whereas $5-\mathrm{HT}_{7}$ receptors probably induce vasodilatation in the absence of endothelium [149, 153].

Thus, 5-HT and 5-HT analogues interact in a complex way with different 5-HT receptors which display opposite functional effects in the regulation of vasomotor 
tone. If the endothelium plays a pivotal role in providing a counteractive mechanism for the vasoconstrictor effects of triptans, this constitutes a sound rational why patients with endothelial dysfunction are at increased risk for unwanted coronary vasoconstriction after the intake of 5-HT-receptor agonists $[154,155]$.

In contrast with cerebral blood vessels in which $5-\mathrm{HT}_{1 \mathrm{~B}}$ receptors predominate, there is a low expression of $5-\mathrm{HT}_{1 \mathrm{~B}}$ receptors in peripheral and coronary arteries [141]. In these vessels $5-\mathrm{HT}_{2 \mathrm{~A}}$ receptors play a more important role in 5-HT-induced vasoconstriction $[156,157]$. This differential anatomical distribution of $5-\mathrm{HT}_{1 \mathrm{~B}}$ receptors provides a pharmacological basis for the craniovascular selectivity of 5- $\mathrm{HT}_{1 \mathrm{~B} / \mathrm{ID}}$-receptor agonists which display a low affinity for $5-\mathrm{HT}_{2 \mathrm{~A}}$ receptors. However, as the clinical efficacy of the currently available triptans is at least in part related to their ability to constrict cranial vessels, they are all likely to cause peripheral and coronary vasoconstriction as well by $5-\mathrm{HT}_{1 \mathrm{~B}}$ receptor activation. Thus, although second-generation triptans are often claimed to display an increased cranioselectivity it is not entirely clear how to gain this increased selectivity.

In vitro data indicate that many second generation triptans contract both human coronary and cranial arteries with a potency and maximal effect comparable with that of sumatriptan $[93,141,158,159]$. However, as the clinical relevance of these in vitro data remains speculative, in vivo human research is needed to better define the cardiovascular profile of these drugs by comparing their vascular effects at clinically relevant plasma concentrations. Thus, until proven otherwise, peripheral and coronary vasoconstriction can be regarded a class effect of the triptans (see Chapter 6).

\section{Beyond the triptans}

To date, the clinical use of all acute anti-migraine drugs is limited by their potential to induce systemic and coronary vasoconstriction by $5-\mathrm{HT}_{\mathrm{IB}}$ receptor activation [93]. Therefore, current research is aimed at the development of effective drugs devoid of $5-\mathrm{HT}_{1 \mathrm{~B}}$ receptor affinity which could, if proven clinically effective, represent a neuronal site of action and display an increased cardiovascular safety [138].

The development of selective $5-\mathrm{HT}_{1 \mathrm{~F}}$-receptor agonists (referred to as

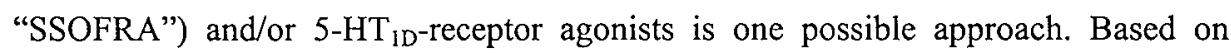




\section{Chapter 1}

studies with the selective 5- $\mathrm{HT}_{1 \mathrm{~F}}$-receptor agonist LY 334370 , these receptors most likely inhibit neurotransmitter release within the trigeminal nucleus caudalis [160, 161]. Presynaptic inhibition of neurotransmitter release probably blocks the activation of second-order neurones and the central transmission of nociceptive stimuli. Both in vitro data and preliminary human data indicate that LY 334370 lacks vasoconstrictor properties while it was proven to be clinically effective at high dose [162, 163]. However, as alniditan and rizatriptan are clinically effective triptans with a low affinity for $5-\mathrm{HT}_{1 \mathrm{~F}}$-receptors, the role of $5-\mathrm{HT}_{\mathrm{IF}}$-receptor activation in the treatment of migraine remains obscure $[78,164]$. In contrast with selective $5-\mathrm{HT}_{\mathrm{IF}}$-receptor agonists, the selective $5-\mathrm{HT}_{1 \mathrm{D}}$-receptor agonist $\mathrm{CP}-122,288$ was ineffective in the treatment of migraine [165], questioning the potential of this approach.

A second approach might be the development of inhibitors of plasma protein extravasation. However, many compounds which potently inhibit plasma protein extravasation in animal experiments do not abort migraine attacks in clinical practice. These compounds include CP-122,288 [165], bosentan (endothelin-receptor antagonist) [166] and the $\mathrm{NK}_{1}$-receptor antagonists RPR 100893 [79] and lanepitant (LY 303870) [167]. Surprisingly, avitriptan [131] and BMS-181885 [168], which are effective drugs, do not reduce dural plasma protein extravasation. These observations indicate that inhibition of plasma protein extravasation in animal models may not be related to clinical efficacy [78].

As indicated, $\mathrm{NK}_{1}$-receptor antagonists interfering with neurogenic inflammation, did not prove to be clinically effective. In contrast with SP, CGRP and NO are considered much more important in initiating neurogenic vasodilatation [22]. Consequently, the development of both CGRP-receptor antagonists and NO-synthase inhibitors became a major field of research which recently resulted in the first potent, selective non-peptidergic CGRP antagonist (BIBN4096BS) [169]. BIBN4096BS completely inhibits neurogenic vasodilatation in animal experiments and is currently being evaluated for its clinical efficacy as an anti-migraine drug.

Alternatively, NO-synthase inhibitors are being developed as well. As previously discussed, NO might be involved at several stages of migraine pathophysiology: (i) as a triggering molecule initiating migraine [170], (ii) as a 
coupling mechanism between CSD and activation of the trigeminovascular system [60], (iii) as a regulator of neuropeptide release [33] and (iv) as EDRF mediating the vasodilating effects of CGRP and SP [43]. Although selective NO-synthase inhibitors are not yet available for clinical use, preliminary results obtained in migraine patients with $\mathrm{L}-\mathrm{N}^{\mathrm{G}}$-methylarginine $(546 \mathrm{C} 88)$ suggest that NO-synthase inhibition may represent a promising therapeutic principle in the treatment of migraine [171].

Finally, the role of NMDA-receptor mediated activation of the trigeminocervical complex by glutamate is gaining increasing interest as a potential target for future anti-migraine drugs. Obviously, in addition to selective $5-\mathrm{HT}_{1 \mathrm{~F}}$-receptor agonists, selective NMDA-receptor antagonists might offer an alternative approach for interrupting the central transmission of pain [59].

\subsection{Migraine and cardiovascular disease}

During a migraine attack vascular changes are not limited to the cranial circulation. Iversen et al. [18] reported that a migraine attack is characterised by a generalised peripheral vasoconstriction and concluded that migraine headache is accompanied by abnormal reactions of the arterial system. In addition, the association of migraine with angina pectoris due to coronary artery vasospasm (i.e. Prinzmetal's angina) [172-174] and the increased frequency of Raynaud's syndrome in migraine patients [175], suggest that migraine might be part of a generalised vasospastic disorder [172]. Furthermore, migraine patients have repeatedly been reported to be at increased risk for the development of ischaemic stroke [176-178], supporting the notion of migraine being associated with vascular abnormalities. As vascular endothelial mechanisms and autonomic transmission are intimately linked, it has even been suggested that migraine might be an "endotheliopathy" [179]. Indeed, many vasoactive substances including adenosine-5'-triphosphate (ATP), SP, CGRP, 5-HT and acetylcholine (ACh) have a role in the autonomic nervous system and each of them interacts with endothelial receptors mediating the release of NO. 


\section{Chapter 1}

Taken together, it cannot be excluded that migraine is accompanied by vascular changes which extend beyond the cranial circulation and are also present during the interictal period. However, neither the structural nor the functional vascular properties and endothelial function have ever been investigated in vivo in migraine patients (see Chapters 3 and 4 ).

\subsection{References}

1. Ferrari MD. Migraine. Lancet 1998;351(9108):1043-1051.

2. Silberstein SD, Lipton RB. Headache epidemiology. Neurol Clin 1996;14(2):421-434.

3. Lipton RB, Silberstein SD, Stewart WF. An update on the epidemiology of migraine. Headache 1994;34:319-328.

4. Lipton R, Stewart WF. Migraine headaches: epidemiology and comorbidity. Clin Neurosci 1998;5:2-9.

5. Liveing E. On megrim, sick-headache, and some allied disorders: a contribution to the pathology of nerve storms. London: Arts \& Boeve Nijmegen; 1873.

6. Headache Classification Committee of the International Headache Society. Classification and diagnostic criteria for headache disorders, cranial neuralgias and facial pain. Cephalalgia 1988;8:1-96.

7. Russell MB, Olesen $\mathbf{J}$. A nosographic analysis of the migraine aura in a general population. Brain 1996;119:355-361.

8. Karwautz A, Wober-Bingol C, Wober C. Freud and migraine: the beginning of a psychodynamically oriented view of headache a hundred years ago. Cephalalgia 1996;16:22-26.

9. Schoenen J. The pathophysiology of migraine: a review based on the literature and on personal contributions. Func Neurol 1998;13:7-15.

10. Wepfer JJ. Observationes medico-practicae de affectibus capitis internis et externis. Schaffhausen 1727.

11. Graham JR, Wolff HG. Mechanism of migraine headache and action of ergotamine tartrate. Arch Neurol Psych 1938;39:737-763.

12. Heyck H. Pathogenesis of migraine. Res Clin Stud Headache 1969;2:1-28.

13. Sherman JL. Normal arteriovenous anastomoses. Medicine 1963;42:247-267. 
14. Kerber CW, Newton TH. The macro- and microvasculature of the dura mater. Neuroradiology 1973;6:175-179.

15. Saxena PR. Cranial arteriovenous shunting, an in vivo animal model for migraine. In: Olesen J, Moskowitz MA, editors. Experimental headache models. Philadelphia New York: Lippincott-Raven; 1995. p. 189-198.

16. De Vries P, Willems EW, Heiligers JPC, Villalón CM, Saxena PR. Investigation of the role of 5-HT1B and 5-HT1D receptors in the sumatriptan-induced constriction of porcine carotid arteriovenous anastomoses. Br J Pharmacol 1999;127:405-412.

17. Drummond PD, Lance JW. Extracranial vascular changes and the source of pain in migraine headache. Ann Neurol 1983;13:32-37.

18. Iversen $\mathrm{HK}$, Nielsen TH, Olesen J, Tfelt-Hansen P. Arterial responses during migraine headache. Lancet 1990;336:837-839.

19. Friberg L. Cerebral blood flow changes in migraine: methods, observations and hypotheses. J Neurol 1991;238:S12-S17.

20. Olesen J. Cerebral and extracranial circulatory disturbances in migraine: pathophysiological implications. Cerebrovasc Brain Metab Rev 1991;3(1):1-28.

21. Friberg L, Olesen J, Iversen HK, Sperling B. Migraine pain associated with middle cerebral artery dilatation: reversal by sumatriptan. Lancet 1991;338:13-17.

22. Moskowitz MA, Macfarlane R. Neurovascular and molecular mechanisms in migraine headaches. Cerebrovasc Brain Metab Rev 1993;5(3):159-177.

23. Olesen J, Larsen B, Lauritzen M. Focal hyperemia followed by spreading oligemia and impaired activation of rCBF in classic migraine. Ann Neurol 1981;9:344-352.

24. Cutrer FM, Sorensen AG, Weisskoff RM, Ostergaard L, Sanchez del Rio M, Lee EJ, et al. Perfusion-weighted imaging defects during spontaneous migrainous aura. Ann Neurol 1998;43:25-31.

25. Sanchez del Rio M, Bakker D, Wu O, Agosti R, Mitsikostas DD, Ostergaard L, et al. Perfusion weighted imaging during migraine: spontaneous visual aura and headache. Cephalalgia 1999;19:701-707.

26. Andersen AR, Friberg L, Olsen TS, Olesen J. Delayed hyperemia following hypoperfusion in classic migraine. Arch Neurol 1988;45:154-159.

27. Zwetsloot CP, Caekebeke JFV, Jansen JC, Odink J, Ferrari MD. Blood flow velocity changes in migraine attacks-a transcranial Doppler study. Cephalalgia 1991;11:103107. 


\section{Chapter 1}

28. Iversen $\mathrm{H}$, Olesen $\mathrm{J}$, Tfelt-Hansen $\mathrm{P}$. Intravenous nitroglycerin as an experimental model of vascular headache. Basic characteristics. Pain 1989;38:17-24.

29. Lassen LH, Thomsen LL, Olesen J. Histamine induces migraine via the H1-receptor. Support for the NO hypothesis of migraine. NeuroReport 1995;6:1475-1479.

30. Olesen $J$, Paulson $O B$. The effect of intra-arterial papaverine on the regional cerebral blood flow in patients with stroke or intracranial tumor. Stroke $1971 ; 2: 148-159$.

31. Thomsen LL, Kruuse C, Iversen HK, Olesen J. A nitric oxide donor (nitroglycerin) triggers genuine migraine attacks. Eur $J$ Neurol 1994;1:73-80.

32. Iversen HK. Experimental headache in humans. Cephalalgia 1995;15:281-287.

33. Wei EP, Moskowitz MA, Boccalini P, Kontos HA. Calcitonin gene-related peptide mediates nitroglycerin and sodium nitroprusside-induced vasodilation in feline cerebral arterioles. Circ Res 1992;70:1313-1319.

34. Blau JN. Migraine prodromes separated from the aura: complete migraine. $\mathrm{Br} \mathrm{Med} J$ 1980;281:658-660.

35. Leão AAP. Spreading depression of activity in cerebral cortex. $J$ Neurophysiol 1944;7:359-390.

36. Lauritzen M, Olsen ST, Lassen NA, Paulson OB. Changes in regional cerebral blood flow during the course of classic migraine attacks. Ann Neurol 1983;13:633-641.

37. Lauritzen M. Pathophysiology of the migraine aura: the spreading depression theory. Brain 1994;117:199-210.

38. Moskowitz MA, Buzzi GM, Sakas DE, Linnik MD. Pain mechanisms underlying vascular headaches. Rev Neurol 1989;145(3):181-193.

39. Moskowitz MA. Basic mechanisms in vascular headache. Headache 1990;8:801-815.

40. Moskowitz MA, Reinhard JFJ, Romero J, Melamed E, Pettibone DJ. Neurotransmitters and the fifth cranial nerve: Is there a relationship to the headache phase of migraine? Lancet $1979 ; 2: 883-885$.

41. Markowitz S, Saito K, Moskowitz MA. Neurogenically mediated leakage of plasma protein occurs from blood vessels in dura mater but not brain. $J$ Neurosci 1987; 7:41294136.

42. Goadsby PJ, Edvinsson L, Ekman R. Release of vasoactive peptides in the extracerebral circulation of humans and the cat during activation of the trigeminovascular system. Ann Neurol 1988;23:193-196. 
43. Lundberg JM. Pharmacology of cotransmission in the autonomic nervous system: integrative aspects on amines, neuropeptides, adenosine triphosphate, amino acids and nitric oxide. Pharmacol Rev 1996;48(1):113-178.

44. Bell D, McDermott BJ. Calcitonin gene-related peptide in the cardiovascular system: characterization of receptor populations and their (patho)physiological significance. Pharmacol Rev 1996;48(2):253-288.

45. Edvinsson L, Fredholm B, Hamel E, Jansen I, Verrechia C. Perivascular peptides relax cerebral arteries concomitant with stimulation of cyclic adenosine monophosphate accumulation or release of an endothelium-derived relaxing factor in the cat. Neurosci Lett 1985;58:213-217.

46. Greenberg B, Rhoden $\mathrm{K}$, Barnes P. Calcitonin gene-related peptide (CGRP) is a potent non-endothelium-dependent inhibitor of coronary vasomotor tone. $\mathrm{Br} J$ Pharmacol 1987;92:789-794.

47. Franco-Cereceda A. Calcitonin gene-related peptide and human epicardial coronary arteries: presence, release and vasodilator effects. Br J Pharmacol 1991;102:506-510.

48. Thom SM, Hughes AD, Goldberg P, Martin G, Schachter M, Sever P. The actions of calcitonin gene-related peptide and vasoactive intestinal peptide as vasodilators in man in vivo and in vitro. Br J Clin Pharmacol 1987;24:139-144.

49. Gray DW, Marshall I. Human alfa-calcitonin gene-related peptide stimulates adenylate cyclase and guanylate cyclase and relaxes rat thoracic aorta by releasing nitric oxide. Br J Pharmacol 1992;107:691-696.

50. Nelson MT, Huang Y, Brayden JE, Hescheler J, Standen NB. Arterial dilations in response to calcitonin gene-related peptide involve activation of $\mathrm{K}^{+}$channels. Nature 1990;344:770-773.

51. Kitazono T, Heistad DD, Faraci FM. Role of ATP-sensitive $\mathrm{K}^{+}$channels in CGRPinduced dilatation of basilar artery in vivo. Am J Physiol 1993;34:H581-H585.

52. Luu TN, Dashwood MR, Tadjkarimi S, Chester AH, Yacoub MH. ATP-sensitive potassium channels mediate vasodilation produced by calcitonin gene-related peptide in human internal mammary but not gastroepiploic arteries. Eur $J$ Clin Invest 1997;27:960-966.

53. Goadsby PJ, Edvinsson L, Ekman R. Vasoactive peptide release in the extracerebral circulation of humans during migraine headache. Ann Neurol 1990;28:183-187. 


\section{Chapter I}

54. May A, Shepheard SL, Knorr N, Effert R, Wessing A, Hargreaves RJ, et al. Retinal plasma extravasation in animals but not in humans: implications for the pathophysiology of migraine. Brain 1998;121:1231-1237.

55. Mitsikostas DD, Sanchez del Rio M, Cutrer FM, Moskowitz MA, Waeber C. Glutamate and 5-HT1F receptors modulate trigeminal pain in rats. Cephalalgia 1999;19:314.

56. Goadsby PJ, Classey J. Blood flow responses in trigeminocervical complex involve glutamate. Cephalalgia 1999;19:315.

57. Classey JD, Knight YE, Goadsby PJ. MK-801 reduces Fos-like immunoreactivity in trigeminocervical complex of cat. Cephalalgia 1999;19:394.

58. Storer RJ, Goadsby PJ. Trigeminovascular nociceptive transmission involves $\mathrm{N}$ methyl-D-aspartate and non-N-methyl-D-aspartate glutamate receptors. Neuroscience 1999;90(4):1371-1376.

59. Choi DW, Koh J, Peters S. Pharmacology of glutamate neurotoxicity in cortical cell culture attenuation by NMDA antagonists. $J$ Neurosci 1988;8:185-196.

60. Dawson VL, Dawson TM, London ED, Bredt DS, Snyder SH. Nitric oxide mediates glutamate neurotoxicity in primary cortical culture. Proc Natl Acad Sci USA 1991;88:7797-7801.

61. Holzer $\mathrm{P}$, Jocic $\mathrm{M}$. Cutaneous vasodilatation induced by nitric oxide-evoked stimulation of afferent nerves in the rat. Br J Pharmacol 1994;112:1181-1187.

62. Robbins L. Precipitating factors in migraine: a retrospective review of 494 patients. Headache 1994;34:214-216.

63. Vaughan TR. The role of food in the pathogenesis of migraine headache. Clin Rev Allergy 1994;12:167-180.

64. Olesen $\mathbf{J}$, Thomsen LL, Iversen $\mathrm{H}$. Nitric oxide is a key molecule in migraine and other vascular headaches. Trends Pharmacol Sci 1994;15:149-153.

65. Olesen J, Thomsen LL, Lassen LH, Olesen IJ. The nitric oxide hypothesis of migraine and other vascular headaches. Cephalalgia 1995;15:94-100.

66. Thomsen LL, Iversen HK, Brinck TA, Olesen J. Arterial supersensitivity to nitric oxide (nitroglycerin) in migraine sufferers. Cephalalgia 1993;13:395-399.

67. Peatfield RC, Gawel MJ, Rose FC. The effect of infused prostacycline in migraine and cluster headache. Headache 1981;21:190-195.

68. Carratala C, Gea JG, Aguar CM, Grau S, Espadaler-Medina JM, Broquetas JM. Methacholine induced headache. Thorax 1995;50:319. 
69. Brown SGA, Waterer GW. Migraine precipitated by adenosine. Med $J$ Australia 1995; 162:389-391.

70. Welch KMA, Ramadan NM. Mitochondria, magnesium and migraine. $J$ Neurol Sci 1995;134:9-14.

71. Schoenen J. Clinical neurophysiology studies in headache: a review of data and pathophysiological hints. Funct Neurol 1992;7:191-204.

72. Sappey-Marinier D, Calabrese G, Fein G, Hugg JW, Biggins C, Weiner MW. Effect of photic stimulation on human visual cortex lactate and phosphates using $1 \mathrm{H}$ and $31 \mathrm{P}$ magnetic resonance spectroscopy. J Cereb Blood Flow Metab 1992;12:584-592.

73. Haan J, Terwindt GM, Ferrari MD. Genetics of migraine. Adv Headache 1997;15:4360 .

74. Ophoff RA, Terwindt GM, Vergouwe MN, van Eijk R, Oefner PJ, Hoffman SMG, et al. Familial hemiplegic migraine and episodic ataxia type- 2 are caused by mutations in the Ca2+ channel gene CACNL1A4. Cell 1996;87(3):543-552.

75. Kraus RL, Sinegger MJ, Glossmann H, Hering S, Striessnig J. Familial hemiplegic migraine mutations change alfa1A Ca2+ channel kinetics. J Biol Chem 1998;273:55865590 .

76. Kors EE, Haan J, Ferrari MD. Genetics of primary headaches. Curr Opin Neurol 1999;12:249-254.

77. Weiller C, May A, Limmroth V, Juptner M, Kaube H, Schayck RV, et al. Brain stem activation in spontaneous human migraine attacks. Nat Med 1995;1:658-660.

78. Pauwels PJ, John GW. Present and future of 5-HT receptor agonists as antimigraine drugs. Clin Neuropharmacol 1999;22:123-136.

79. Diener H-C, Limmroth V. Acute management of migraine: triptans and beyond. Curr Opin Neurol 1999;12(3):261-267.

80. Welch KMA. Drug therapy of migraine. N Engl J Med 1993;329:1476-1483.

81. Tfelt-Hansen P, Henry P, Mulder LJ, Schaeldewaert RG, Schoenen J, Chazot G. The effectiveness of combined oral lysine acetylsalicylate and metoclopramide compared with oral sumatriptan for migraine. Lancet 1995;346:923-926.

82. Buzzi MG, Sakas DE, Moskowitz MA. Indomethacin and acetylsalicylic acid block neurogenic plasma protein extravasation in rat dura mater. Eur $J$ Pharmacol 1989;165:251-258. 


\section{Chapter 1}

83. Silberstein SD, Young WB. Safety and efficacy of ergotamine tartrate and dihydroergotamine in the treatment of migraine and status migrainosus. Neurology 1995;45:577-584.

84. Silberstein SD. The pharmacology of ergotamine and dihydroergotamine. Headache 1997;37:S15-S25.

85. Saxena PR, Den Boer MO. Pharmacology of antimigraine drugs. $J$ Neurol 1991;238:S28-S35.

86. The Dihydroergotamine Nasal Spray Multicentre Investigators. Efficacy, safety and tolerability of dihydroergotamine nasal spray as monotherapy in the treatment of acute migraine. Headache 1995;35:177-184.

87. Perrin VL. Clinical pharmacokinetics of ergotamine in migraine and cluster headache. Clin Pharmacokinet 1985;10:334-352.

88. Markowitz S, Saito K, Moskowitz MA. Neurogenically mediated plasma extravasation in dura mater: effect of ergot alkaloids. A possible mechanism of action in vascular headache. Cephalalgia 1988;8:83-91.

89. Saito K, Markowitz S, Moskowitz MA. Ergot alkaloids block neurogenic extravasation in dura mater: proposed action in vascular headaches. Ann Neurol 1988;24:732-737.

90. Winner P, Ricalde O, Le Force B, Saper J, Margul B. A double-blind study of subcutaneous dihydroergotamine versus subcutaneous sumatriptan in the treatment of acute migraine. Arch Neurol 1996;53:180-184.

91. Tfelt-Hansen P, Paalzow L. Intramuscular ergotamine: plasma levels and dynamic activity. Clin Pharmacol Ther 1985;37:29-35.

92. Galer BS, Lipton RB, Solomon S, Newman LC, Spierings ELH. Myocardial ischemia related to ergot alkaloids: a case report and literature review. Headache 1991;31:446451.

93. Maassen van den Brink A, Reekers M, Bax WA, Ferrari MD, Saxena PR. Coronary side-effect potential of current and prospective antimigraine drugs. Circulation 1998;98:25-30.

94. Clark BJ, Chu D, Aellig WH. Actions on the heart and circulation. In: Berde B, Schild $\mathrm{HO}$, editors. Ergot alkaloids and related compounds. Berlin, Heidelberg, New York: Springer-Verlag; 1978. p. 321-420.

95. Ostergaard JR, Mikkelsen E, Voldby B. Effects of 5-hydroxytryptamine and ergotamine on human superficial temporal artery. Cephalalgia 1981;1:223-228. 
96. Muller-Schweinitzer $\mathrm{E}$. What is known about the action of dihydroergotamine on the vasculature in man? Int J Clin Pharmacol Ther Toxicol 1984;22(12):677-682.

97. Muller-Schweinitzer E, Rosenthaler J. Ex vivo studies after oral treatment of the beagle with dihydroergotamine. Eur J Pharmacol 1983;89:1-8.

98. Aellig WH. A new technique for recording compliance of human hand veins. Br J Clin Pharmacol 1981;11:237-243.

99. de Marees H, Welzel D, de Marees A, Klotz U, Tiedjen KU, Knaup G. Relationship between the venoconstrictor activity of dihydroergotamine and its pharmacokinetics during acute and chronic oral dosing. Eur J Clin Pharmacol 1986;30:685-689.

100. Aellig WH, Rosenthaler J. Venoconstrictor effects of dihydroergotamine after intranasal and intramuscular administration. Eur J Clin Pharmacol 1986;30:581-584.

101. Andersen AR, Tfelt-Hansen P, Lassen NA. The effect of ergotamine and dihydroergotamine on cerebral blood flow in man. Stroke 1987;18:120-123.

102. Ferrari MD, Saxena PR. On serotonin and migraine: a clinical and pharmacological review. Cephalalgia 1993;13:151-156.

103. Ferrari MD, Odink J, Tapparelli C, Van Kempen GMJ, Pennings EJM, Bruyn GW. Serotonin metabolism in migraine. Neurology 1989;39:1239-1242.

104. Deanovic A, Iskric S, Duplj M. Fluctuation of 5-hydroxy-indole compounds in the urine of migrainous patients. Biomedicine 1975;23:346-349.

105. Kimball RW, Friedman AP, Valeejo E. Effect of serotonin in migraine patients. Neurology 1960;10:107-111.

106. Humphrey PPA, Feniuk W, Marriott AS, Tanner RJN, Jackson MR, Tucker ML. Preclinical studies on the anti-migraine drug, sumatriptan. Eur Neurol 1991;31:282290.

107. Humphrey PPA, Feniuk W. Mode of action of the anti-migraine drug sumatriptan. Trends Pharmacol Sci 1991;12:444-446.

108. Plosker GL, McTavish D. Sumatriptan: a reappraisal of its pharmacology and therapeutic efficacy in the acute treatment of migraine and cluster headache. Drugs 1994;47:622-651.

109. Visser WH, Jaspers NMWH, de Vriend RHM, Ferrari MD. Risk factors for headache recurrence after sumatriptan: a study in 366 migraine patients. Cephalalgia 1996; 16:264-269. 
110. Tfelt-Hansen P. Efficacy and adverse events af subcutaneous, oral and intranasal sumatriptan used for migraine treatment: a systemic review based on number needed to treat. Cephalalgia 1998;18:532-538.

111. Goadsby PJ. A triptan too far? J Neurol Neurosurg Psychiatry 1998;64:143-147.

112. Visser WH, Jaspers NMWH, de Vriend RHM, Ferrari MD. Chest symptoms after sumatriptan: a two-year clinical practice review in 735 consecutive migraine patients. Cephalalgia 1996;16:554-559.

113. Ottervanger JP, Van Witsen TB, Valkenburg HA, Grobbee DE, Stricker BHC. Adverse reactions attributed to sumatriptan. A post-marketing study in general practice. Eur $J$ Clin Pharmacol 1994;47:305-309.

114. Brown EG, Endersby CA, Smith RN, Talbot JC. The safety and tolerability of sumatriptan: an overview. Eur Neurol 1991;31:339-344.

115. Main ML, Ramaswamy K, Andrews TC. Cardiac arrest and myocardial infarction immediately after sumatriptan injection. Ann Intern Med 1998;128:874.

116. Ottervanger JP, Paalman HJ, Boxma GL, Stricker BH. Transmural myocardial infarction with sumatriptan. Lancet 1993;341:861-862.

117. Macintyre PD, Bhargava B, Hogg KJ, Gemmill JD, Hillis WS. The effect of I.V. sumatriptan, a selective 5-HT1-receptor agonist on central haemodynamics and the coronary circulation. Br J Clin Pharmacol 1992;34:541-546.

118. Macintyre PD, Bhargava B, Hogg KJ, Gemmill JD, Hillis WS. Effects of subcutaneous sumatriptan, a selective 5HT1 agonist, on the systemic, pulmonary, and coronary circulation. Circulation 1993;87:401-405.

119. Hood S, Birnie D, Hillis S. The haemodynamic effects of subcutaneous sumatriptan, a 5HT1-receptor agonist. Br J Clin Pharmacol 1997;43:327-328.

120. Mathew NT, Asgharnejad M, Peykamian M, Laurenza A. Naratriptan is effective and well tolerated in the acute treatment of migraine. Results of a double-blind, placebocontrolled, crossover study. Neurology 1997;49:1485-1490.

121. Sciberras DG, Polvino WJ, Gertz BJ, Cheng H, Stepanavage M, Wittreich J, et al. Initial human experience with MK-462 (rizatriptan): a novel 5-HT1D agonist. $\mathrm{Br} J \mathrm{Clin}$ Pharmacol 1997;43:49-54.

122. Teall J, Tuchman M, Cutler N, Gross M, Willoughby E, Smith B, et al. Rizatriptan (MAXALT) for the acute treatment of migraine and migraine recurrence. A placebocontrolled, outpatient study. Headache 1998;38(4):281-287. 
123. Seaber E, On N, Gibbens M, Leavens WJ, Liptrot J, Chittick G, et al. The absolute bioavailability and metabolic disposition of the novel antimigraine compound zolmitriptan (311C90). Br J Clin Pharmacol 1997;43:579-587.

124. Rapoport AM, Ramadan NM, Adelman JU, Mathew NT, Elkind AH, Kudrow DB, et al. Optimizing the dose of zolmitriptan (Zomig, *311C90) for the acute treatment of migraine. A multicenter, double-blind, placebo-controlled, dose range-finding study. Neurology 1997;49(5):1210-1218.

125. Holm KJ, Spencer CM. Almotriptan. CNS Drugs 1999;11(2):159-165.

126. Goadsby PJ, Ferrari MD, Olesen J, Stovner LJ, Senard JM, Jackson NC, et al. Eletriptan in acute migraine: a double-blind, placebo-controlled comparison to sumatriptan. Neurology 2000;54:156-163.

127. Buchan P, Keywood C, Ward C. Pharmacokinetics of frovatriptan (VML 251/SB 209509) in healthy young and elderly male and female subjects. 12th Migraine Trust International Symposium London, UK;September: 1998.

128. Meloche J. Triptans and migraine: which drug for which patient? Can J Diagn 1999;16(1):67-77.

129. John GW, Pauwels PJ, Perez M, Halazy S, Le Grand B, Verscheure Y, et al. F11356, a novel 5-hydroxytryptamine (5-HT) derivative with potent, selective, and unique high intrinsic activity at $5-\mathrm{HT} 1 \mathrm{~B} / 1 \mathrm{D}$ receptors in models relevant to migraine. $J$ Pharmacol and Exp Ther 1999;290:83-95.

130. Van Giersbergen PLM, Dingemanse J. Multiple-dose pharmacokinetics and tolerability of IS-159, a new serotonin 1B/1D receptor agonist. Br J Clin Pharmacol 2000; (in press).

131. Ryan RE, Elkind A, Goldstein J. Twenty-four-hour effectiveness of avitriptan in the acute treatment of migraine headaches. Headache 1997;37:245-248.

132. Goldstein J, Schellens R, Diener HC, Dahlof C, Olesen J, Senard JM, et al. Alniditan, a novel nonindole 5-HTID receptor agonist. A subcutaneous dose-finding trial in acute migraine. In: Olesen J, Tfelt-Hansen P, editors. Headache treatment. Trial methodology and new drugs. Philadelphia, New York: Lippincott-Raven; 1997. p. 279-285.

133. Napier C, Stewart M, Melrose H, Hopkins B, McHarg A, Wallis R. Characterisation of the 5-HT receptor binding profile of eletriptan and kinetics of $[3 \mathrm{H}]$ eletriptan binding at human 5-HT1B and 5-HT1D receptors. Eur J Pharmacol 1999;368:259-268.

134. Bou J, Domenech T, Gras J, Beleta J, Ienas JI, Fernandez AG, et al. Pharmacological profile of almotriptan, a novel antimigraine agent. Cephalalgia 1997;17:421-422. 
135. Brown AM, Parsons AA, Raval P, Porter R, Tilford NS, Gager TL, et al. SB 209509 (VML 251), a potent constrictor of rabbit basilar artery with high affinity and selectivity for human 5-HTID receptors. Br J Pharmacol 1996;119:110P.

136. Hartig PR, Hoyer D, Humphrey PPA, Martin GR. Alignment of receptor nomenclature with the human genome: classification of 5-HT1B and 5-HT1D receptor subtypes. Trends Pharmacol Sci 1996;17:103-105.

137. Nilsson T, Longmore J, Shaw D, Jansen-Olesen I, Edvinsson L. Contractile 5-HT1B receptors in human cerebral arteries: pharmacological characterization and localization with immunocytochemistry. Br J Pharmacol 1999;128:1133-1140.

138. Bouchelet I, Case B, Olivier A, Hamel E. No contractile effect for 5-HT1D and 5-HT1F receptor agonists in human and bovine cerebral arteries: similarity with human coronary artery. Br J Pharmacol 2000;129:501-508.

139. Longmore J, Shaw D, Smith D, McAllister G, Pickard JD, Sirinathsinghji DJS, et al. Differential distribution of 5HT1D- and 5HT1B-immunoreactivity within the human trigemino-cerebrovascular system: implications for the discovery of new antimigraine drugs. Cephalalgia 1997;17:833-842.

140. Hamel E, Fan E, Linville D, Ting V, Villemure JG, Chia LS. Expression of mRNA for the serotonin 5-hydroxytryptamine 1D beta receptor subtype in human and bovine cerebral arteries. Mol Pharmacol 1993;44:242-246.

141. Longmore J, Razzaque Z, Shaw D, Davenport AP, Maguire J, Pickard JD, et al. Comparison of the vasoconstrictor effects of rizatriptan and sumatriptan in human isolated cranial arteries: immunohistological demonstration of the involvement of 5-HT1B-receptors. Br J Clin Pharmacol 1998;46:577-582.

142. Verheggen R, Hundeshagen AM, Brown AM, Schindler M, Kaumann AJ. 5-HT1B receptor-mediated contractions in human temporal artery: evidence from selective antagonists and 5-HT receptor mRNA expression. $\mathrm{Br} J$ Clin Pharmacol 1998;124:1345-1354.

143. Buzzi MG, Moskowitz MA. The antimigraine drug sumatriptan (GR43175), selectively blocks neurogenic plasma extravasation from blood vessels in dura mater. $\mathrm{Br} J$ Pharmacol 1990;99:202-206.

144. Cumberbatch MJ, Hill RG, Hargreaves RJ. Rizatriptan has central antinociceptive effects against durally evoked responses. Eur J Pharmacol 1997;328:37-40. 
145. Goadsby $\mathrm{PJ}$, Knight $\mathrm{Y}$. Inhibition of trigeminal neurones after intravenous administration of naratriptan through an action at 5-hydroxytryptamine 5-HT1B/1D receptors. Br J Pharmacol 1997;122:918-922.

146. Goadsby PJ, Hoskin KL. Inhibition of trigeminal neurons by intravenous administration of the serotonin (5-HT)-1B/D receptor agonist zolmitriptan (311C90): are brain stem sites a therapeutic target in migraine? Pain 1996;67:355-359.

147. Kaube $\mathrm{H}$, Hoskin KL, Goadsby PJ. Inhibition by sumatriptan of central trigeminal neurons only after blood-brain barrier disruption. Br J Pharmacol 1993;109:788-792.

148. Hoskin KL, Kaube H, Goadsby PJ. Sumatriptan can inhibit trigeminal afferents by an exclusively neural mechanism. Brain 1996;119:1419-1428.

149. Hoyer D, Clarke DE, Fozard JR, Hartig PR, Martin GR, Mylecharane EJ, et al. International Union of Pharmacology classification of receptors for 5-hydroxytryptamine (serotonin). Pharmacol Rev 1994;46(2):157-203.

150. Ullmer C, Schmuck K, Kalkman HO, Lubbert H. Expression of serotonin receptor mRNAs in blood vessels. FEBS letters 1995;370:215-221.

151. Nilsson T, Longmore J, Shaw D, Pantev E, Bard JA, Branchek $T$, et al. Characterisation of 5HT receptors on human coronary arteries by molecular and pharmacological techniques. Eur J Pharmacol 1999;372(1):49-56.

152. Schmuck K, Ullmer C, Kalkman HO, Probst A, Lübbert H. Activation of meningeal 5-HT2B receptors: an early step in the generation of migraine headache? Eur $J$ Neurosci 1996;8:959-967.

153. Bard JA, Zgombick J, Adham N, Vaysse P, Branchek TA, Weinshank RL. Cloning of a novel human serotonin receptor (5-HT7) positively linked to adenylate cyclase. $J$ Biol Chem 1993;268:23422-23426.

154. Golino P, Piscione F, Willerson JT, Cappelli-Bigazzi M, Focaccio A, Villari B, et al. Divergent effects of serotonin on coronary-artery dimensions and blood flow in patients with coronary atherosclerosis and control patients. N Engl J Med 1991;324:641-648.

155. Ellwood AJ, Curtis MJ. Mechanism of actions of sumatriptan on coronary flow before and after endothelial dysfunction in guinea-pig isolated heart. Br J Pharmacol 1997; 120:1039-1048.

156. Connor HE, Feniuk W, Humphrey PPA. 5-Hydroxytryptamine contracts human coronary arteries predominantly via 5-HT2 receptor activation. Eur $J$ Pharmacol 1989;161:91-94. 
157. Verheggen R, Freudenthaler S, Meyer-Dulheuer F, Kaumann AJ. Participation of 5-HT1-like and 5-HT2A receptors in the contraction of human temporal artery by 5-hydroxytryptamine and related drugs. Br J Pharmacol 1996;117:283-292.

158. Maassen van den Brink A, Van den Broek RWM, De Vries R, Saxena PR. Human middle meningeal and coronary artery contraction to eletriptan and sumatriptan. Cephalalgia 1999;19:399.

159. Longmore J, Hargreaves RJ, Razzaque Z, Schofield WN, Shaw D, Smith D, et al. Rizatriptan selectively contracts human isolated middle meningeal artery over coronary artery: comparisons with sumatriptan. Cephalalgia 1997;17:388.

160. Pascual J, Castro ME, Romon T, del Arco C, del Olmo E, Pazos A. Anatomical distribution of 5HT1F receptors in the human brain suggests role in migraine pathophysiology. Cephalalgia 1997;17:341.

161. Shepheard S, Edvinsson L, Cumberbatch M, Williamson D, Mason G, Webb J, et al. Possible antimigraine mechanisms of action of the 5-HT1F receptor agonist $\mathrm{LY} 334370$. Cephalalgia 1999;19:851-858.

162. Goldstein DJ; Roon KI, Offen WW, Phebus LA, Johnson KW, Schaus JM, et al. Migraine treatment with the selective 5-HT1F receptor agonist (SSOFRA) LY334370. Cephalalgia 1999;19:318.

163. Goldstein DJ, Gossen D, Granier L. Clinical experience with LY334370, a selective 5-HT1F receptor agonist (SSOFRA): absence of cardiovascular effects. Cephalalgia 1999;19:366-367.

164. Leysen JE, Gommeren W, Heylen L, Luyten WH, Van de Weyer I, Vanhoenacker P, et al. Alniditan, a new 5-hydroxytryptamine1D agonist and migraine-abortive agent: ligand binding properties of human 5-hydroxytryptaminelD alpha, human 5-hydroxytryptamine $1 \mathrm{D}$ beta, and calf 5-hydroxytryptaminelD receptors investigated with [3H]5-hydroxytryptamine and [3H]alniditan. Mol Pharmacol 1996;50(6):15671580.

165. Roon KI, Diener HC, Ellis P, Hettiarachchi J, Poole P, Christiansen I, et al. CP-122,288 blocks neurogenic inflammation, but is not effective in aborting migraine attacks: results of two controlled clinical trials. Cephalalgia 1997;17:245.

166. May A, Gijsman HJ, Wallnofer A, Jones R, Diener HC, Ferrari MD. Endothelin antagonist bosentan blocks neurogenic inflammation, but is not effective in aborting migraine attacks. Pain 1996;67:375-378. 
167. Goldstein DJ, Wang O, Saper JR, Stoltz R, Silberstein ST, Mathew NT. Ineffectiveness of neurokinin-1 antagonist in acute migraine: crossover study. Cephalalgia 1997; 17:785-790.

168. Yocca FD, Gylys JA, Smith DW, Ruediger E, Yevich JP, Mahle C, et al. BMS-181885: a clinically effective migraine abortive with peripherovascular and neuronal 5HT1D antagonistic properties. Cephalalgia 1997;17:404.

169. Doods H, Hallermayer G, Wu D, Entzeroth M, Rudolf K, Engel W, et al. Pharmacological profile of BIBN4096BS, the first selective small molecule CGRP antagonist. Br J Pharmacol 2000;129:420-423.

170. Fozard JR. The 5-hydroxytryptamine-nitric oxide connection: the key link in the initiation of migraine? Arch Int Pharmacodyn 1995;329:111-119.

171. Lassen LH, Ashina M, Christiansen I, Ulrich V, Olesen J. Nitric oxide synthase inhibition in migraine. Lancet 1997;349:401-402.

172. Lafitte C, Even C, Henry-Lebras F, de Toffol B, Autret A. Migraine and angina pectoris by coronary artery spasm. Headache 1996;36:332-334.

173. Heupler FA. Syndrome of symptomatic coronary arterial spasm with nearly normal coronary arteriograms. Am J Cardiol 1980;45:873-881.

174. Miller D, Waters DD, Warnica W, Szlachcic J, Kreeft J, Theroux P. Is variant angina the coronary manifestation of a generalized vasospastic disorder? $N$ Engl J Med 1981;304:763-766.

175. Zahavi I, Chagnac A, Hering R, Davidovich S, Kuritzky A. Prevalence of Raynaud's phenomenon in patients with migraine. Arch Intern Med 1984;144:742-744.

176. Carolei A, Marini C, De Matteis G. History of migraine and risk of cerebral ischaemia in young adults. The Italian National Research Council Study Group on Stroke in the Young. Lancet 1996;347:1503-1506.

177. Merikangas KR, Fenton BT, Cheng SH, Stolar MJ, Risch N. Association between migraine and stroke in a large-scale epidemiological study of the United States. Arch Neurol 1997;54(4):362-368.

178. Chang CL, Donaghy M, Poulter N. Migraine and stroke in young women: case-control study. The World Health Organisation Collaborative Study of Cardiovascular Disease and Steroid Hormone Contraception. Br Med J 1999;318:13-18.

179. Appenzeller O. Pathogenesis of migraine. Med Clin N Am 1991;75(3):763-789. 
"The ability to convert ideas to things is the secret of outward succes".

(Henry Ward Beecher) 


\section{Outline and Aims of the Present Thesis}

Migraine is a neurovascular disorder in which the trigeminovascular system plays a pivotal role. Consequently, research has focused on the central nervous system, cranial blood vessels and the connection between both provided by the trigeminal nerve. Although structural and functional extracranial vascular research has hardly ever been performed in migraine patients, peripheral vascular disorders are probably associated with it, vascular changes are at least part of the headache phase, and acute antimigraine drugs affect the cardiovascular system as a whole. Therefore, the objective of the present thesis was to study migraine and its treatment by performing cardiovascular research on migraine pathophysiology and acute anti-migraine drugs. The specific aims were the following:

1. To make an inventory of the cardiovascular properties of migraine patients during the interictal period compared to those of matched control subjects (Chapter 3).

2. To challenge the concept of nitric oxide (NO) supersensitivity and to assess the vascular reactivity to calcitonin gene-related peptide (CGRP) in migraine patients (Chapter 4).

3. To investigate the vasodilator mechanism of action of CGRP at clinically relevant plasma concentrations in vivo in human (Chapter 5).

4. To compare the effects of selective 5-HT $1 \mathrm{~B} / 1 \mathrm{D}$-receptor agonists on large artery wall properties, resistance vessels and endothelial function in migraine patients (Chapter 0).

5. To investigate the time-course of the peripheral vascular effects of dihydroergotamine and its pharmacokinetics after a single subcutaneous administration to healthy subjects (Chapter 7). 
All research was performed in migraine patients during the interictal period or in healthy volunteers. The most important techniques for haemodynamic assessments used in the present thesis (Chapter 2) comprise of non-invasive ultrasound measurements of cardiovascular parameters and venous occlusion plethysmography applied to the "perfused forearm model". In the last part (Chapters 8 and 9) the research results are discussed in terms of their implications for migraine pathophysiology and for the future development of anti-migraine drugs. 


\title{
Chapter 2
}

\section{Methods for Haemodynamic Assessments Used in the Present Thesis}

\begin{abstract}
All haemodynamic assessments reported in this thesis, were performed in a quiet and temperature controlled room. The subjects had been lying in the supine position for at least 15 and 30 minutes before assessments were started in the non-invasive and invasive study protocols, respectively.
\end{abstract}

\subsection{Blood pressure, pulse pressure and heart rate}

Oscillometric measurements

Using a semi-automated oscillometric device (Dinamap ${ }^{\circledR}$ 950, Critikon Inc., Florida) resting heart rate (beats per min, bpm), brachial artery systolic blood pressure (SBP, $\mathrm{mmHg}$ ) and diastolic blood pressure (DBP, $\mathrm{mmHg}$ ) were measured at the left upper arm [1]. Depending on the study, every 1 to 3 minutes recordings were made in order to obtain at least 3 measurements within the available time frame; the mean of these recordings was taken as the subject's reading. Brachial artery pulse pressure was calculated as SBP-DBP.

\section{Applanation tonometry}

Using applanation tonometry, pressure waveforms were recorded at the common carotid, brachial and femoral artery (Chapters 3, 6 and 7). The applanation tonometer (Micro-tip ${ }^{\circledast}$ transducer, Millar Instruments Inc., Texas) is a pencil-like probe incorporating a small pressure sensitive transducer which is placed in contact with the skin and permits continuous and accurate recording of pressure waveforms of 


\section{Chapter 2}

superficial arteries [2]. Although, applanation tonometry has been proposed for local pulse pressure measurement, the accuracy of absolute pulse pressure values obtained with this technique remains a matter of debate. Therefore, an alternative approach was developed for local non-invasive pulse pressure assessment at peripheral arteries in human by calibrating the original pressure waveforms (see section 2.2) [3].

Invasive blood pressure measurements

Invasive blood pressure measurements were performed during those studies in which the "perfused forearm model" was used (see section 2.3 and Chapters 4 and 5).

\subsection{Large artery wall properties: a novel approach}

\section{Arterial diameter and distension}

In the studies presented in this thesis the echo-tracking system developed by Hoeks and collaborators [4] was used to measure arterial diameter and distension. The system consists of an ultrasound device (Scanner 350, Pie Medical, The Netherlands) equipped with a $7.5 \mathrm{MHz}$ linear-array transducer connected to a data acquisition and processing unit (Wall Track System ${ }^{\otimes}$, Pie Medical, The Netherlands). For a detailed description of the principles of the vessel wall movement detector system we refer to the paper by Hoeks et al. [4]. In brief, the system makes use of Doppler signal processing to assess non-invasively (transcutaneous) the displacement of arterial walls during the cardiac cycle. The resulting distension waveform, i.e. the diameter as a function of time, allows for the off-line calculation of the change in arterial diameter during the cardiac cycle (distension) relative to its initial end diastolic diameter for each heart beat. The system has previously been validated and has shown acceptable reproducibility for the measurement of large artery wall properties of the common carotid, brachial and common femoral artery [5]. In addition, because of its putative importance in the pathophysiology of migraine (see Chapter 1), the variability of temporal artery diameter measurements was assessed during the preparation of the protocols presented in this thesis. The intra- and inter-session coefficients of variation (expressed as percentage) averaged $5.6 \pm 2.1$ and $5.0 \pm 3.1 \%$, respectively. 
All data on arterial measurements presented in this thesis are the mean of at least 3 recordings of diameter and distension; at the temporal artery diameter was recorded at least 5 times. As each recording lasted approximately 5 seconds (about 5 heart beats), data refer to the mean of about 15 heart beats ( 25 for the temporal artery). If within one recording of approximately 5 heart beats diameter or distension was unstable (i.e. standard deviation $>10 \%$ of the mean), the recording was discarded and repeated.

At the common carotid artery, ipsilateral vessel wall movements and pressure waveforms were recorded consecutively as a function of time. At the brachial and femoral artery recordings were performed simultaneously. Therefore, after obtaining a satisfactory image of the artery under investigation for vessel wall tracking, the ultrasound transducer was fixed with a robotic arm (without touching the skin) while pressure waveforms were recorded at the contralateral side. In order to minimise motion artifacts, temporal artery diameter measurements were also obtained by fixing the ultrasound transducer.

\section{Vessel wall properties: the "classical" approach}

Distensibility, a measure of elasticity, and cross-sectional compliance, a measure of buffering capacity, are parameters which refer to local mechanical vessel wall properties [6]. Using end diastolic diameter $(\mathrm{D}, \mathrm{mm})$ and distension $(\Delta \mathrm{D}, \mu \mathrm{m})$ the end diastolic cross-sectional area (CSA, equation 2.1) and the change in cross-sectional area during the cardiac cycle ( $\triangle \mathrm{CSA}$, equation 2.2 ) were calculated:

$$
\begin{array}{ll}
\mathrm{CSA}=\pi(\mathrm{D} / 2)^{2} & \mathrm{~mm}^{2} \\
\Delta \mathrm{CSA}=\pi((\mathrm{D}+\Delta \mathrm{D}) / 2)^{2}-(\mathrm{D} / 2)^{2} & \mathrm{~mm}^{2}
\end{array}
$$

Subsequently, the distensibility coefficient (DC, equation 2.3) and cross-sectional compliance (CC, equation 2.4) were calculated by making use of the local pulse pressure $(\triangle \mathrm{P})[7]$ :

$$
\begin{array}{ll}
\mathrm{DC}=(\Delta \mathrm{CSA} / \mathrm{CSA}) / \Delta \mathrm{P} & \mathrm{kPa}^{-1} \\
\mathrm{CC}=\Delta \mathrm{CSA} / \Delta \mathrm{P} & \mathrm{mm}^{2} / \mathrm{kPa}
\end{array}
$$

In man, pulse pressure as measured at the level of the brachial artery (i.e. $\Delta \mathrm{P}_{\mathrm{BA}}=\mathrm{SBP}$ DBP), has often been used to calculate vessel wall properties of different peripheral 
arteries. This approach will be further referred to as the "classical" approach. However, as pulse pressure increases centrifugally because of a significant increase in SBP [8], this results in an overestimation of pulse pressure for more central arteries (e.g. carotid artery) and an underestimation for more peripheral arteries (e.g. radial artery). Therefore, an algorithm was developed which permits to calculate local pulse pressure by making use of pressure waveforms recorded with applanation tonometry and calibrating them with DBP and MAP [3].

\section{Vessel wall properties: a "novel" approach}

In order to assess the pulse pressures of the common carotid $\left(\Delta \mathrm{P}_{\mathrm{CCA}}\right)$, brachial $\left(\Delta \mathrm{P}_{\mathrm{BA}}\right)$ and femoral artery $\left(\Delta \mathrm{P}_{\mathrm{FA}}\right)$ the pressure waveforms recorded with the applanation tonometer were calibrated [3]. By definition, $\Delta \mathrm{P}_{\mathrm{BA}}$ as measured with applanation tonometry equals pulse pressure as measured with the oscillometric device at the upper arm. Thus at the brachial artery the nadir and peak of the pressure waveform can be equalled to DBP and SBP, respectively. Subsequently, by integrating the area under the pressure-time curve of the brachial artery and dividing it by the duration of the cardiac cycle, MAP was calculated. As MAP and DBP hardly change throughout the arterial tree [9], the nadir and mean (assessed by integration) of the pressure waveforms of the common carotid and femoral artery were equalled to DBP and $\mathrm{MAP}$, respectively. Finally, the corresponding local $\mathrm{SBP}, \Delta \mathrm{P}_{\mathrm{CCA}}$ and $\triangle \mathrm{P}_{\mathrm{FA}}$ were calculated.

Table 2.1 summarises the data (obtained by one investigator) on reproducibility and variability of absolute values of pulse pressures as measured with applanation tonometry $\left(\Delta \mathrm{P}_{\text {tono }}\right)$ compared to calculated pulse pressures $\left(\Delta \mathrm{P}_{\text {cal }}\right)$ according to the approach outlined in the previous paragraph. The data were obtained in a group of ten young, healthy volunteers ( 8 males, 2 females). Analysis was performed by calculating repeatability coefficients (RC, according to Bland-Altman [10]) and coefficients of variation (CV, expressed as percentage) for two sets of 3 recordings each. Compared to $\Delta \mathrm{P}_{\text {tono, }}$, these data show that $\Delta \mathrm{P}_{\text {cal }}$ is more reproducible. In addition, as illustrated by figure 2.1 , in our hands calculated pulse pressures as obtained by the method outlined above, result in values which are in agreement with the known centrifugal increase in pulse pressure. 


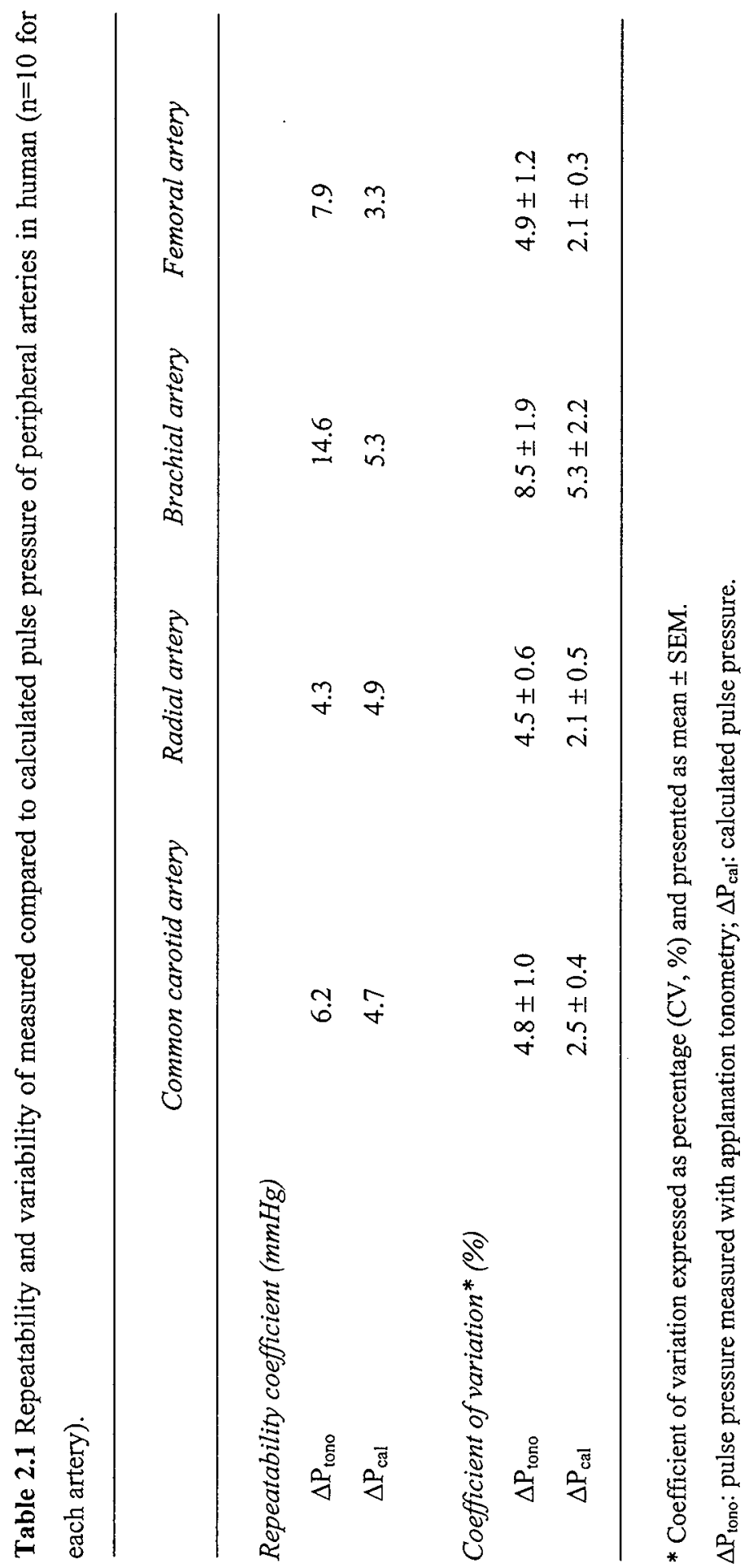




\section{Chapter 2}

Based on these observations we decided to use this "novel" approach for calculating vessel wall properties in the studies presented in this thesis (Chapters 3,6 and 7).

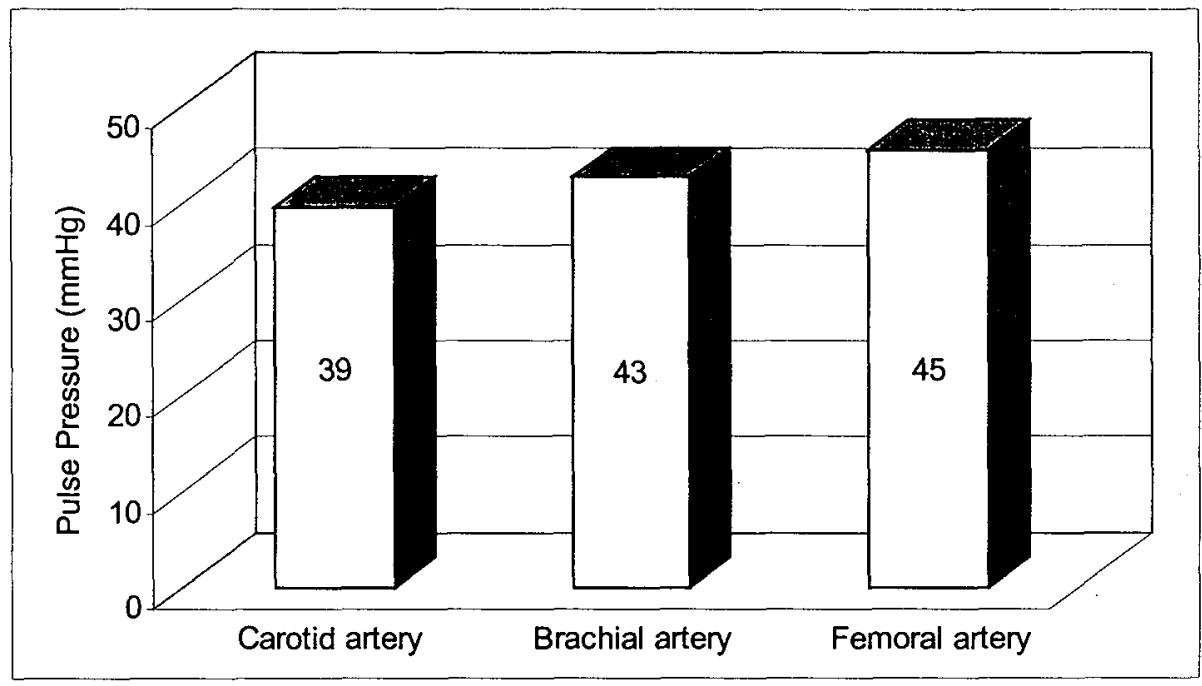

Figure 2.1 Calculated pulse pressures (mean) of the carotid, brachial and femoral artery in a group of 50 migraine patients by using the "novel" approach outlined in detail in the text (for the complete data, see Chapter 3).

Diameter-time recordings (ultrasound) and pressure-time recordings (applanation tonometry) were simultaneously analysed off-line using a custom made Matlab $^{\circledR}$ script developed by the biophysics department of the university. Because of different phase-characteristics between the echo-tracking algorithm and the pressure amplifier, a phase shift between both signals was prevented by multiplying the signals coming out of both systems by each others phase-characteristics during the analysis. In addition, on merging the separately recorded diameter and pressure signals of the common carotid artery, both signals were aligned at the start of their up-slope (i.e. the beginning of systole, Fig. 2.2). By doing so, vessel wall properties can be calculated both over the operating pressure (i.e. local pulse pressure) and over a pre-defined fixed pressure interval (e.g. $85-95 \mathrm{mmHg}$ ). The latter are referred to as vessel wall 
properties obtained under isobaric conditions: isobaric distensibility coefficient $\left(\mathrm{DC}_{\text {iso }}\right)$ and isobaric cross-sectional compliance $\left(\mathrm{CC}_{\text {iso }}\right)$ [6]. This approach is particularly useful to investigate changes in vessel wall properties after the administration of drugs influencing blood pressure. In such case, changes in vessel wall properties resulting from drug-induced changes in the pressure-diameter relation can be differentiated from changes resulting from a change is blood pressure (cfr. Chapters 6 and 7).

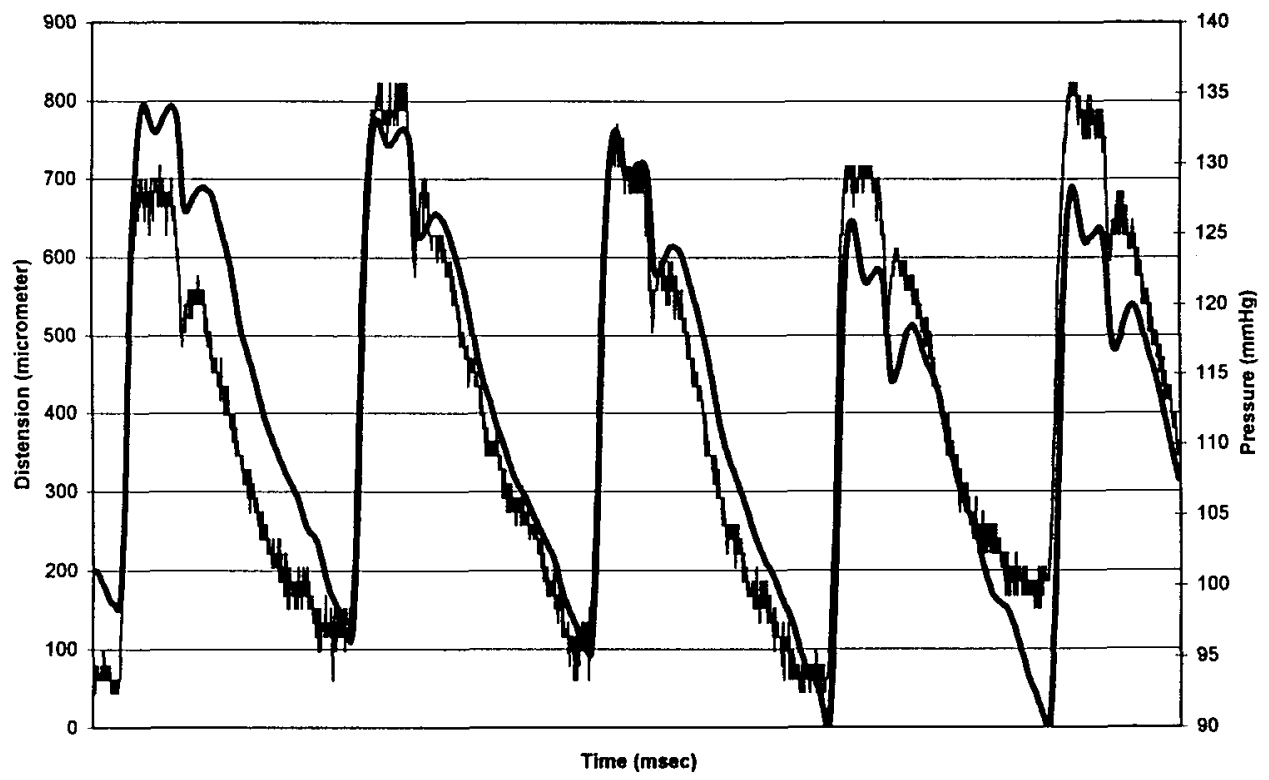

Figure 2.2 Example of aligned diameter-time (echo-tracking, fat line) and pressure-time recording (applanation tonometry, thin line) at the common carotid artery.

Using the "novel" approach as presented in the previous paragraphs, the variability of large artery wall properties was assessed in a group of young, healthy volunteers ( 8 males, 2 females) and compared to that of a previous study [5] using the "classical" approach (Table 2.2). These data show that by (i) making use of a robotic arm to measure vessel wall movements, (ii) calculating local pulse pressures and (iii) simultaneously analysing diameter-time and pressure-time recordings, in our hands 


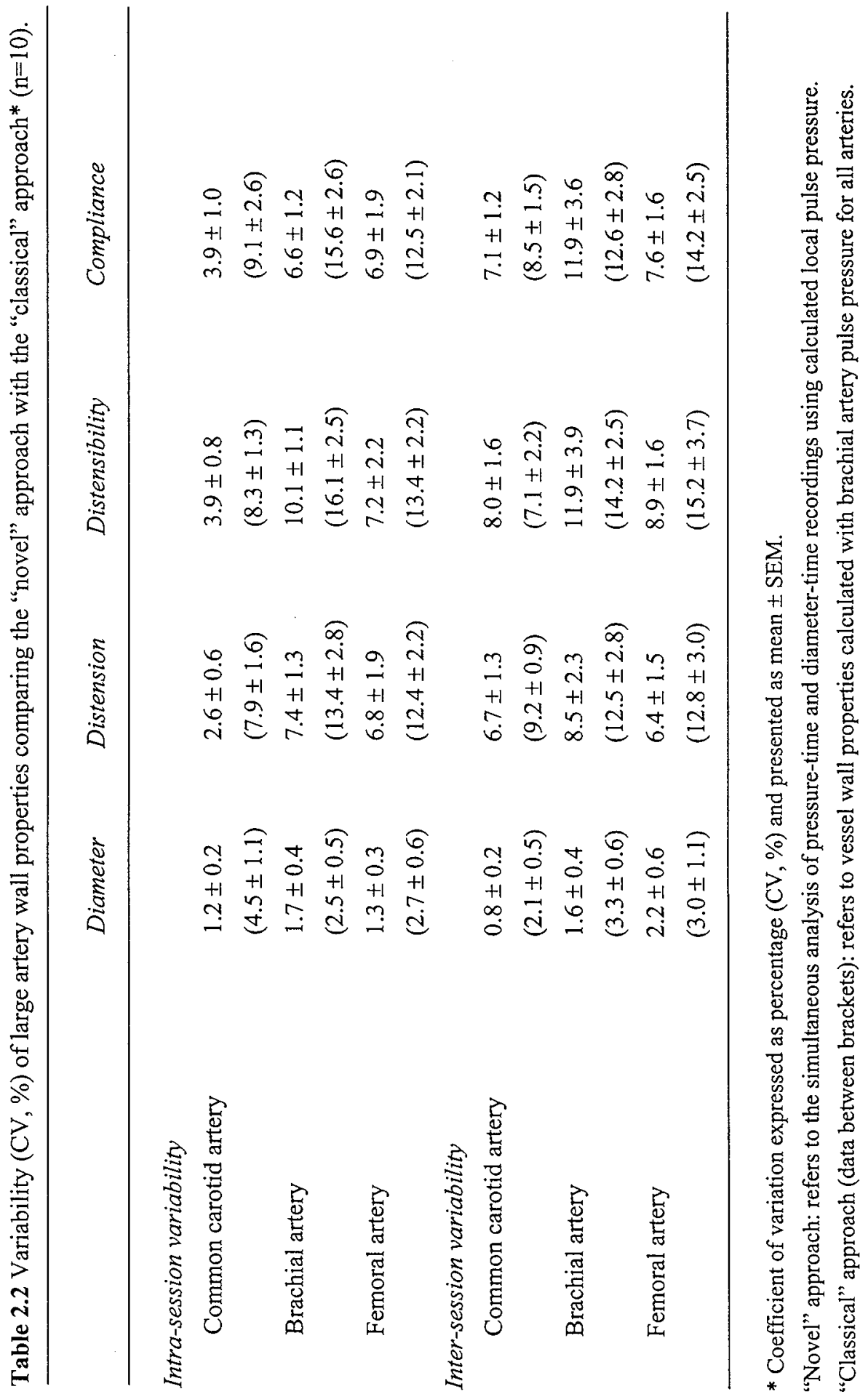


the variability of the data was at least as good as previously reported whereas large artery wall properties might be calculated more accurately.

In summary, the outlined approach offers the following potentials: (i) a reproducible calculation of local pulse pressures, (ii) a more accurate calculation of large artery wall properties and (iii) the possibility to calculate isobaric distensibility and cross-sectional compliance.

\subsection{Blood flow and vascular resistance}

\section{Ultrasound}

Doppler ultrasound provides a non-invasive and reproducible technique to measure blood flow in conduit arteries [11]. Centre stream velocity profiles in the common carotid, temporal and brachial artery were measured using $(7.5 \mathrm{MHz})$ pulsed-Doppler at a $70^{\circ}$ angle to the vessel and a sampling volume in the centre of the artery. For each cardiac cycle the mean flow velocity was calculated electronically by multiplying the area under the velocity profile curve (corrected for angle) by the heart rate. Of each artery at least 8 velocity profiles were recorded; the mean of these recordings was taken as the subject's reading. Blood flow $(\mathrm{ml} / \mathrm{min})$ was calculated by multiplying the mean flow velocity by the end diastolic cross-sectional area (CSA) as measured with the echo-tracking system. Vascular resistance of the vascular bed distal of the artery under investigation was calculated as MAP divided by local blood flow and expressed as $\mathrm{kPa} . \mathrm{l}^{-1} . \mathrm{s}$.

\section{Venous occlusion plethysmography}

Venous occlusion plethysmography offers an alternative technique to study limb blood flow [12]. Whereas early studies mainly involved measurements of the lower limb, the forearm is currently most frequently used in pharmacological studies [13]. The underlying principle of the technique is straightforward: the rate of swelling of a limb during obstruction of the venous return is proportional to the rate of arterial inflow. Using mercury-in-rubber strain gauge devices, changes in limb circumference are detected as changes in electrical resistance of the gauge. As changes in limb 
circumference are measured, a measure of blood flow per unit volume of tissue (e.g. $\mathrm{ml} / \mathrm{min} / 100 \mathrm{ml}$ of tissue) is obtained. Absolute blood flow can be calculated by measuring limb volume, for instance by water displacement, and multiplying it with blood flow per unit volume of tissue. For more detailed information on venous occlusion plethysmography we refer to recent excellent reviews by Webb [13] and Benjamin [14].

In the present thesis, venous occlusion plethysmography was used to measure forearm arterial blood flow (FBF). Total FBF consists of blood flow through skeletal muscle ( 50 to $70 \%$ of total $\mathrm{FBF}$ under resting conditions) and skin perfusion. Blood flow through skin varies markedly with temperature and has a different physiology and pharmacology compared with skeletal muscle perfusion. Therefore, hand perfusion, which predominantly refers to skin perfusion, is usually excluded during FBF measurements [15]. In practice, we measured FBF with ECG-triggered venous occlusion plethysmography using mercury-in-Silastic strain gauges. Venous outflow was obstructed by intermittently inflating upper arm cuffs to a pressure of $45 \mathrm{mmHg}$. Hand perfusion was excluded by wrist cuffs inflated to $240 \mathrm{mmHg}$ one minute before FBF measurements were started.

Venous occlusion plethysmography is used in different settings [13, 14]. First, it is used to assess changes in limb perfusion after the systemic administration of drugs (e.g. dihydroergotamine, Chapter 7). This approach takes into account drug-induced systemic haemodynamic effects which make the direct vascular effects of drugs more difficult to interpret. Alternatively, venous occlusion plethysmography is used to investigate the direct vascular effects of vasoactive drugs during local intra-arterial infusion (e.g. into the brachial artery). Obviously, the major advantage of this technique, referred to as the "perfused forearm model", is that local high dosages of vasoactive substances can be administered without causing any systemic side effects. In addition, by simultaneously measuring FBF both in the infused and non-infused arm, the latter provides an internal control which takes into account short-term changes in FBF affecting both arms and being unrelated to the drug under investigation. For a detailed description of the experimental set-up of the "perfused forearm model" we refer to the methods sections of Chapters 4 and 5 . 


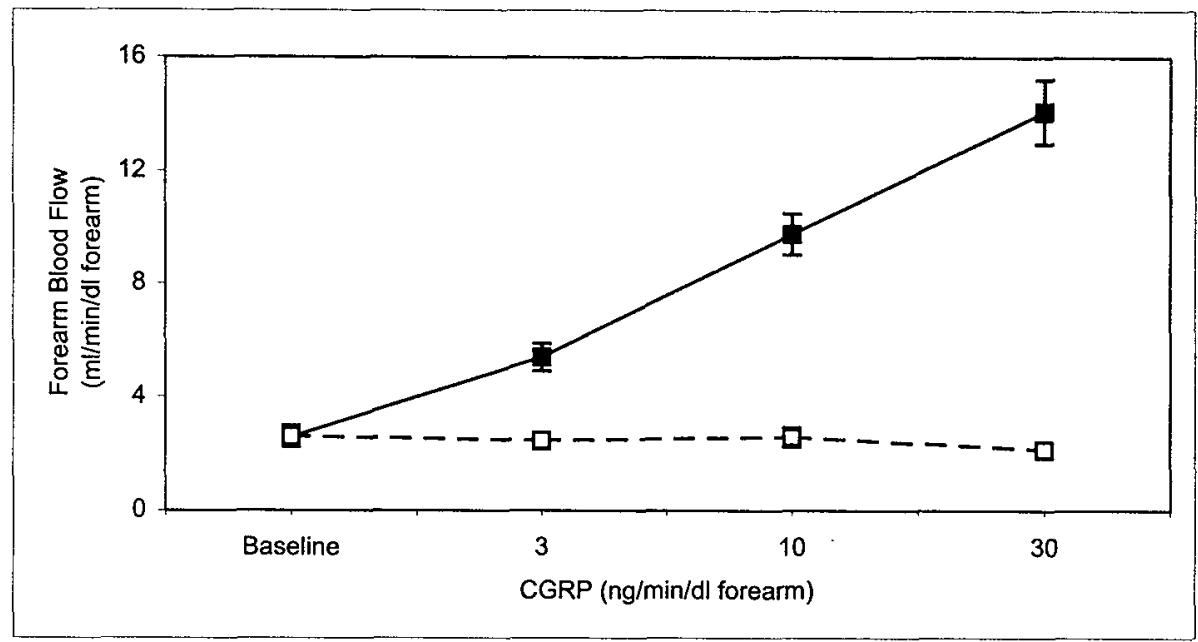

Figure 2.3 Calcitonin gene-related peptide (CGRP) induced changes in forearm blood flow (mean \pm SEM) simultaneously measured in the infused ( $\square$, solid line) and non-infused ( $\square$, dashed line) arm in healthy subjects $(n=40)$. (For the complete data, see Chapter 5).

Provided that perfusion pressure (arterial blood pressure) is constant, changes in FBF reflect changes in smooth muscle tone of resistance vessels and measurements can be expressed as FBF per unit of forearm volume (Fig. 2.3). However, small alterations in perfusion pressure or sympathetic arousal which influence FBF have to be taken into account $[14,16]$. Therefore, FBF measurements are either expressed in terms of calculated forearm vascular resistance (FVR) defined as perfusion pressure divided by FBF and expressed as arbitrary units (AU) or, if FBF is being measured simultaneously in both arms, results are expressed as the ratio in FBF in the infused over the control arm (FBF-ratio).

\subsection{In vivo assessment of endothelial function}

After Furchgott and Zawadzki [17] demonstrated the obligatory role of the endothelium in modulating vascular tone, numerous studies have evaluated 


\section{Chapter 2}

endothelial function using invasive [18-21] and non-invasive [22-27] techniques in both normal and disease states. Healthy endothelium releases endothelium-derived relaxing factor (EDRF or nitric oxide, NO) which is a potent vasodilator and is generated through the action of endothelial nitric oxide synthase (eNOS or NOSIII) on its substrate L-arginine [28]. Endothelial NOS can be activated both by chemical stimuli (e.g. acetylcholine, histamine, serotonin, bradykinin and substance P) via receptor-mediated mechanisms and by the physical stimulus of shear stress via mechanoreceptors. However, many cardiovascular diseases have been shown to be associated with a decreased endothelium-dependent vasodilatation which is referred to as endothelial "dysfunction" and is regarded as an early stage of atherosclerosis. Consequently, techniques investigating endothelial function, in particular noninvasive approaches, are gaining increasing interest.

\section{Non-invasive approach}

Flow-mediated vasodilatation of the brachial artery is currently a frequently used noninvasive technique to assess endothelial function in human $[26,29,30]$. Flowmediated vasodilatation of the brachial artery depends on the endothelial release of NO [31], resulting from an increase in shear stress, and correlates well with coronary endothelial function [32].

In the present thesis (Chapters 4 and 6 ) flow-mediated vasodilatation of the brachial artery was measured with the echo-tracking system (see section 2.2) using a protocol comparable with the one described by Celermajer and collaborators [27]. In practice, the brachial artery was scanned over a longitudinal section about $5 \mathrm{~cm}$ proximal of the elbow. When a satisfactory picture was obtained, both the position of the arm and the transducer remained fixed throughout the experiment. At baseline, 5 diameter measurements (each consisting of 4 to 5 cardiac cycles) and 8 velocity profiles of the arterial blood flow were recorded. These measurements were followed by inflation of a blood pressure cuff placed around the forearm to a pressure of 240 $\mathrm{mmHg}$ for 5 minutes. Thereafter, the cuff was released and the maximum velocity profile during the first 15 seconds was recorded, followed by a diameter measurement after 45 seconds of deflation. Finally, depending on the study protocol (Chapters 4 
and 6), from 1 until 5 minutes after cuff deflation brachial artery diameter was measured at regular time intervals.

In the analysis the diameter change caused by flow-mediated vasodilatation was expressed as the percentage change relative to the mean baseline diameter. Basal blood flow was calculated by multiplying the basal mean flow velocity by the crosssectional area of the artery at rest. Maximal blood flow (reactive hyperaemia) was calculated by multiplying the mean flow velocity upon reperfusion by the crosssectional area of the artery 45 seconds after deflation of the cuff and was expressed as percentage change relative to the basal blood flow. From cuff deflation $(t=0)$ until 5 minutes after reperfusion the area under the diameter-time curve $\left(\mathrm{AUC}_{0 \rightarrow 5}\right)$ was calculated.

\section{Invasive approach}

By using the "perfused forearm model", both basal and stimulated endothelial NO production can be assessed in vivo in man [13]. Basal NO production can be evaluated by using the competitive NOS inhibitor $\mathrm{L}-\mathrm{N}^{\mathrm{G}}$-monomethyl-arginine (L-NMMA); stimulated NO production can be investigated by the local infusion of substances inducing forearm vasodilatation by eNOS activation (Chapters 4 and 5).

In both the invasive and the non-invasive approach, endothelium-independent vasodilatation induced by an exogenous NO-donor (e.g. nitroprusside or organic nitrates) should be included as a control experiment to exclude that differences in endothelium-dependent vasodilatation are due to structural changes limiting the vasodilator capacity of the vascular bed under investigation.

\subsection{Cardiac output and systemic vascular resistance}

Cardiac output was measured using echocardiography (Vingmed CFM 750, Sonotron, Norway). Measurements were performed in the left lateral position. Aortic diameter was measured at least 3 times using pulsed ultrasound $(2.5 \mathrm{MHz})$ from a standard twodimensional long-axis parasternal view at the site of the aortic annulus; the mean of these readings was used in the subsequent calculations. Aortic blood velocity profiles 
(at least 8) were obtained with continuous ultrasound using an apical window. Stroke volume was calculated from aortic cross-sectional area multiplied by the mean blood velocity across the aortic valve during systole. Cardiac output was calculated electronically by multiplying stroke volume and heart rate, as determined from the duration of the cardiac cycle [33]. Systemic vascular resistance (SVR, $\mathrm{kPa} . \mathrm{I}^{-1} . \mathrm{s}$ ) was defined as MAP divided by cardiac output.

\subsection{Intima-media thickness}

Using an established ultrasound method [34] posterior wall intima-media thickness (IMT) of the right common carotid artery (1-2 cm proximal of the bulb) and brachial artery (at the level of the elbow) was assessed. The raw radio frequency (RF) signals from $\mathrm{M}$-mode were used to measure local IMT. For this purpose sample volumes were placed at the blood-intima and media-adventitia interface of the amplitude signal of the end-diastolic RF-line displayed on the computer monitor. IMT was measured with an accuracy of two decimals (in $\mathrm{mm}$ ) whereas the RF-line is discretised in steps of 35 $\mu \mathrm{m}$. At each artery at least 5 measurements were performed; the mean was taken as the subject's reading.

\subsection{Minimal forearm vascular resistance}

Minimal forearm vascular resistance (minimal FVR, defined as MAP/maximal FBF) was calculated as a functional correlate of the morphological status of the forearm resistance vessels and expressed as arbitrary units (AU) [35, 36]. Maximal (postischaemic) FBF of the arm was measured using venous occlusion plethysmography (Periflow, Janssen Scientific Instruments, Belgium). After 3 minutes of basal FBF measurements, arterial occlusion of the left upper arm was obtained for 13 minutes by inflating a blood pressure cuff to a pressure of $240 \mathrm{mmHg}$. During the last minute of ischaemia dynamic exercise (10 to 20 hand contractions) was added. After release of the cuff FBF was measured for 2 minutes. Both the maximum FBF and the time to 
reach maximum were used in the analysis. During FBF measurements, both at baseline and during reactive hyperaemia, 3 oscillometric MAP measurements were obtained (with 1-minute intervals) at the right upper arm to calculate minimal FVR.

\subsection{References}

1. Meldrum SJ. The principles underlying Dinamap - a microprocessor based instrument for the automatic determination of mean arterial pressure. J Med Eng Tech 1978;2(5):243-244.

2. Kelly R, Hayward C, Ganis J, Daley J, Avolio A, O'Rourke M. Noninvasive registration of the arterial pressure pulse waveform using high-fidelity applanation tonometry. $J$ Vasc Med Biol 1989;1(3):142-149.

3. de Hoon JNJM, Hoeks APG, Willigers JM, Van Bortel LMAB. Non-invasive assessment of pulse pressure at different peripheral arteries in man. Neth $J$ Med 1998;52:A36.

4. Hoeks APG, Brands PJ, Smeets FAM, Reneman RS. Assessment of the distensibility of superficial arteries. Ultrasound Med Biol 1990;16:121-128.

5. Kool MJF, van Merode T, Reneman RS, Hoeks APG, Struyker-Boudier HAJ, Van Bortel LMAB. Evaluation and reproducibility of a vessel wall movement detector system for assessment of large artery properties. Cardiovasc Res 1994;28:610-614.

6. Laurent S, Caviezel B, Beck L, Girerd X, Billaud E, Boutouyrie P, et al. Carotid artery distensibility and distending pressure in hypertensive humans. Hypertension 1994;23:878-883.

7. Reneman RS, Van Merode T, Hick P, Muytjens AMM, Hoeks APG. Age-related changes in carotid artery wall properties in men. Ultrasound Med Biol 1986;12:465471.

8. Safar ME, London GM, Asmar R, Frohlich ED. Recent advances on large arteries in hypertension. Hypertension 1998;32:156-161.

9. O'Rourke MF. Relative importance of blood pressure components on cardiovascular integrity: systolic, diastolic, mean or pulse pressure. In: Hansson L, Birkenhager WH, editors. Handbook of Hypertension: Elsevier Science B.V.; 1997. p. 1-27.

10. Bland MJ, Altman DG. Statistical methods for assessing agreement between two methods of clinical measurement. Lancet 1986;i:307-310. 


\section{Chapter 2}

11. Rimoy GH, Bhaskar NK, Rubin PC. Reproducibility of Doppler blood flow velocity waveform measurements: study on variability within and between day and during haemodynamic intervention in normal subjects. Eur J Clin Pharmacol 1991;41:125129.

12. Whitney RJ. The measurement of volume changes in human limbs. $J$ Physiol Camb 1953;121:1-27.

13. Webb DJ. The pharmacology of human vessels in vivo. $J$ Vasc Res 1995;32:2-15.

14. Benjamin N, Calver A, Collier J, Robinson B, Vallance P, Webb D. Measuring forearm blood flow and interpreting the responses to drugs and mediators. Hypertension 1995;25:918-923.

15. Lenders $J$, Janssen G-J, Smits $P$, Thien $T$. Role of the wrist cuff in forearm plethysmography. Clin Sci 1991;80:413-417.

16. Chin-Dusting JPF, Cameron JD, Dart AM, Jennings GLR. Human forearm venous occlusion plethysmography: methodology, presentation and analysis. Clin Sci 1999;96:439-440.

17. Furchgott R, Zawadzki D. The obligatory role of endothelial cells in the relaxation of arterial smooth muscle by acetylcholine. Nature 1980;288:373-376.

18. Creager MA, Cooke JP, Mendelsohn ME, Gallagher SJ, Coleman SM, Loscalzo J, et al. Impaired vasodilation of forearm resistance vessels in hypercholesterolemic humans. $J$ Clin Invest 1990;86:228-234.

19. Calver A, Collier J, Vallance P. Inhibition and stimulation of nitric oxide synthesis in the human forearm arterial bed of patients with insulin-dependent diabetes. $J$ Clin Invest 1992;90:2548-2554.

20. Katz SD, Schwartz M, Yuen J, LeJemtel TH. Impaired acethylcholine-mediated vasodilation in patients with congestive heart failure: Role of endothelium-derived vasodilating and vasoconstricting factors. Circulation 1993;88:55-61.

21. Cockcroft JR, Chowienczyk PJ, Benjamin N, Ritter JM. Preserved endotheliumdependent vasodilatation in patients with essential hypertension. $N$ Engl $J$ Med 1994;330:1036-1040.

22. Celermajer DS, Sorensen KE, Gooch VM, Spiegelhalter DJ, Miller OI, Sullivan ID, et al. Non-invasive detection of endothelial dysfucntion in children and adults at risk of atherosclerosis. Lancet 1992;340:1111-1115.

23. Chowienczyk PJ, Watts GF, Cockcroft JR, Ritter JM. Impaired endothelium-dependent vasodilation of forearm resistance vessels in hypercholesterolaemia. Lancet 1992;340:1430-1432. 
24. Celermajer DS, Sorensen KE, Georgakopoulos D, Bull C, Thomas O, Robinson J, et al. Cigarette smoking is associated with dose-related and potentially reversible impairment of endothelium-dependent dilation in healthy young adults. Circulation 1993;88:21492155.

25. Drexler H, Hayoz D, Munzel T, Just H, Zelis R, Brunner HR. Endothelial function in congestive heart failure. Am Heart $J$ 1993;126:761-764.

26. Sorensen KE, Celermajer DS, Spiegelhaiter DJ, Georgakopoulos D, Robinson J, Thomas $\mathrm{O}$, et al. Non-invasive measurement of human endothelium dependent arterial responses: accuracy and reproducibility. Br Heart $J$ 1995;74:247-253.

27. Celermajer DS, Adams MR, Clarkson P, Robinson J, McCredie R, Donald A, et al. Passive smoking and impaired endothelium-dependent arterial dilatation in healthy young adults. $N$ Engl $J$ Med 1996;334:150-154.

28. Moncada S, Palmer RMJ, Higgs EA. Nitric oxide: physiology, pathophysiology, and pharmacology. Pharmacol Rev 1991;43(2):109-142.

29. Corretti MC, Plotnick GD, Vogel RA. Technical aspects of evaluating brachial artery vasodilatation using high-frequency ultrasound. Am J Physiol 1995;268:H1397-H1404.

30. Leeson P, Thorne S, Donald A, Mullen M, Clarkson P, Deanfield J. Non-invasive measurement of endothelial function: effect on brachial artery dilatation of graded endothelial dependent and independent stimuli. Heart 1997;78:22-27.

31. Joannides R, Haefeli WE, Linder L, Richard V, Bakkali EH, Thuillez C, et al. Nitric oxide is responsible for flow-dependent dilatation of human peripheral conduit arteries in vivo. Circulation 1995;91:1314-1319.

32. Anderson TJ, Uehata A, Gerhard MD, Meredith IT, Knab S, Delagrange D, et al. Close relation of endothelial function in the human coronary and peripheral circulations. $J \mathrm{Am}$ Coll Cardiol 1995;26:1235-1241.

33. Huntsman LL, Stewart DK, Barnes SR, Franklin SB, Colocousis JS, Hessel EA. Noninvasive doppler determination of cardiac output in man. Circulation $1983 ; 67(3): 593-602$.

34. Willekes C, Hoeks APG, Bots ML, Brands PJ, Willigers JM, Reneman RS. Evaluation of off-line automated intima-media thickness detection of the common carotid artery based on M-line signal processing. Ultrasound Med Biol 1999;25(1):57-64.

35. Pedrinelli $R$, Taddei S, Spessot $M$, Salvetti A. Maximal post-ischaemic forearm vasodilation in human hypertension: a re-assessment of the method. $J$ Hypertens 1987;5(Suppl. 5):S431-S433. 
Chapter 2

36. Pedrinelli R, Spessot M, Salvetti A. Reactive hyperemia during short-term blood flow and pressure changes in the hypertensive forearm. J Hypertens 1990;8:467-471. 
The Pathophysiology of Migraine:

Focus on Vascular Aspects

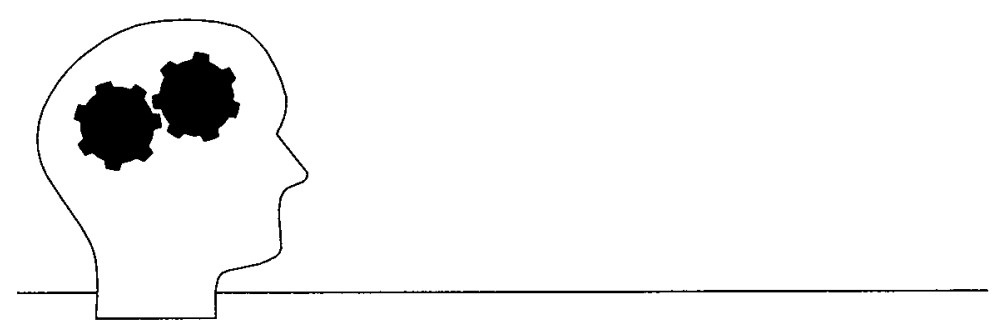


"The art of life is the avoiding of pain."

(Thomas Jefferson, 1743-1826) 


\title{
Chapter 3
}

\section{Migraine Patients Display Interictal Changes in Large Artery Wall Properties}

\begin{abstract}
Background: Migraine has been suggested to be part of a generalised vasospastic disorder. Therefore it was hypothesised that migraine patients may display functional and/or structural vascular changes which extend beyond the cranial circulation and are present outside the headache phase. Methods: During the interictal period, in 50 migraine patients (with or without aura) and 50 matched control subjects vascular measurements were performed at the common carotid, temporal, brachial and common femoral artery. Using ultrasound and applanation tonometry arterial diameter, distension, intima-media thickness, blood flow velocity and pressure waveforms were recorded. Using echocardiography, cardiac output was measured. Subsequently, large artery wall properties and systemic vascular resistance were calculated. Results: Vascular parameters of the common carotid arteries, cardiac output and systemic vascular resistance did not differ between both groups. Right temporal artery diameter was larger $(P=0.03)$ in migraine patients (mean difference $101 \mu \mathrm{m}$ with $95 \%$ confidence interval $(95 \% \mathrm{CI})$ of $9 / 194 \mu \mathrm{m})$ compared to control subjects. At the brachial artery migraine patients displayed a smaller $(P=0.02)$ distension (difference $-24 \mu \mathrm{m}$ and $95 \% \mathrm{CI}-45 /-4 \mu \mathrm{m}$ ) and isobaric compliance (difference $-0.025 \mathrm{~mm}^{2} / \mathrm{kPa}$ and $95 \% \mathrm{CI}$ $\left.0.047 /-0.003 \mathrm{~mm}^{2} / \mathrm{kPa}\right)$ whereas intima-media thickness tended $(P=0.07)$ to be increased

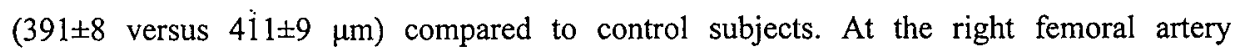
distensibility tended to be smaller $(P=0.10)$ in migraine patients.
\end{abstract}

\footnotetext{
Based on: J.N.J.M. de Hoon ${ }^{(1)}$, J.M. Willigers ${ }^{(2)}$, J. Troost $^{(3)}$, H.A.J. Struijker-Boudier ${ }^{(1)}$, L.M.A.B. Van Bortel ${ }^{(1)}$. Migraine patients display interictal changes in large artery wall properties. (submitted).
}

${ }^{(1)}$ Dept. of Pharmacology and Toxicology and (2) Dept. of Biophysics, Cardiovascular Research Institute Maastricht, Maastricht University, Maastricht; ${ }^{(3)}$ Dept. of Neurology, University Hospital Maastricht, Maastricht, The Netherlands. 


\section{Chapter 3}

Conclusions: During the interictal period migraine patients display both cranial and peripheral vascular changes, supporting the hypothesis that migraine might be part of a more generalised vascular disorder.

\subsection{Introduction}

The original concept of migraine being due to a vasodilatation of cranial blood vessels as postulated by Graham and Wolff [1] has shifted towards a more complex theory regarding migraine as a neurovascular disorder of the trigeminovascular system [2]. Although this theory highlights the activation of pain-producing perivascular sensory nerves, the concept of vascular changes taking place during a migraine attack is still generally accepted $[3,4]$. These vascular changes comprise of cranial vasoconstriction and cerebral hypoperfusion during the aura phase followed by vasodilatation and hyperperfusion during the headache phase.

Studies on the pathophysiology of migraine have focused on the dilatation and increased pulsations of the external carotid artery and its branches, including the temporal artery $[5,6]$. However, during a migraine attack vascular changes are not limited to the cranial circulation. Iversen et al. [5] reported that a migraine attack is characterised by a generalised peripheral vasoconstriction and concluded that migraine is accompanied by abnormal reactions of the arterial system. Moreover, the association of migraine with angina pectoris due to coronary artery vasospasm (i.e. Prinzmetal's angina) [7-9] and the increased frequency of Raynaud's syndrome in migraine patients [10], suggest that migraine might be part of a generalised vasospastic disorder [7]. In addition, migraine patients have repeatedly been reported to be at increased risk for the development of ischaemic stroke [11-13]. As each of these conditions might be the result of a common vascular abnormality, it cannot be excluded that migraine is accompanied by vascular changes which extend beyond the cranial circulation and are present outside the headache phase.

Based on these observations, the present study was designed to compare the cardiovascular properties of migraine patients with those of a matched control group of non-migraineurs. To this end, arterial structure and function of cranial (common 
carotid and superficial temporal artery) and peripheral (brachial and common femoral artery) blood vessels were assessed and cardiac measurements were performed during the interictal period.

\subsection{Subjects and methods}

\section{Subjects and subject selection}

The cardiovascular parameters of 50 migraine patients (as defined by the International Headache Society migraine criteria [14]) were compared to those of 50 healthy control subjects (Table 3.1). Both populations were matched for gender, age, body mass index, blood pressure, cholesterol and smoking habits. Migraine patients were recruited from the neurology outpatient clinic and control subjects from among hospital and laboratory staff. Based on medical history, physical examination and routine laboratory tests, all participants were in good health. Major exclusion criteria were: history of cerebrovascular or cardiovascular disease, arterial hypertension (blood pressure $>160 / 95 \mathrm{mmHg}$ ), diabetes mellitus, hyperlipidaemia (total cholesterol $>6.5 \mathrm{mmol} / \mathrm{l}$ ), pregnancy or lactation. The regular use of vasoactive drugs was not allowed. After approval by the ethics committee of the academic hospital of Maastricht this research was carried out in accordance with the Declaration of Helsinki (1989). All subjects gave written informed consent to participate.

\section{Study protocol}

After screening, eligible subjects were invited to return to the hospital for cardiovascular assessments. Before examination subjects were asked not to use any drug for at least 3 days and to abstain from caffeine or alcohol-containing beverages and from smoking for at least 12 hours. All measurements were performed by one investigator in a quiet, temperature controlled room with the subject lying comfortably in the supine position. Measurements started after 15 minutes of supine rest and lasted approximately 1.5 hour. Systolic blood pressure (SBP), diastolic blood pressure (DBP) and heart rate were recorded at the left upper arm using a semi-automated 


\section{Chapter 3}

oscillometric device (Dinamap ${ }^{\boxplus 5}$ 950, Critikon Inc., Florida). Blood pressures and heart rate were measured every 3 minutes for at least 15 minutes. The mean of these readings was used as the subject's haemodynamic parameters.

Table 3.1 Subject characteristics at screening*.

Characteristic Control subjects $(n=50) \quad$ Migraine patients $(n=50)$

$\begin{array}{lcc}\text { Sex }(\text { male/female) } & 12 / 38 & 12 / 38 \\ \text { Smoker/non-smoker } & 14 / 36 & 14 / 36 \\ \text { Age (years) } & 38.4 \pm 9.9 & 38.3 \pm 10.3 \\ \text { Body mass index }\left(\mathrm{kg} / \mathrm{m}^{2}\right) & 24.0 \pm 3.3 & 24.2 \pm 2.5 \\ \text { Systolic blood pressure }(\mathrm{mmHg}) & 118 \pm 12 & 114 \pm 11 \\ \text { Diastolic blood pressure }(\mathrm{mmHg}) & 70 \pm 9 & 69 \pm 9 \\ \text { Heart rate }(\mathrm{bpm}) & 65 \pm 7 & 63 \pm 8 \\ \text { Total cholesterol }(\mathrm{mmol} / \mathrm{l}) & 5.1 \pm 0.8 & 5.2 \pm 1.0\end{array}$

*Data presented as number or mean $\pm \mathrm{SD}$.

Vascular measurements were consecutively performed at the common carotid artery (bilateral), superficial temporal artery (bilateral) and at the right brachial and common femoral artery using an echo-tracking system (Wall Track System ${ }^{\circledR}$ combined with Scanner 350, Pie Medical, The Netherlands) and an applanation tonometer (Micro-tip ${ }^{\circledR}$ transducer, Millar Instruments Inc., Texas). Cardiac measurements were performed using echocardiography (Vingmed CFM 750, Sonotron, Norway).

\section{Measurements}

At the common carotid, brachial and femoral artery both pressure waveforms and vessel wall movements (i.e. arterial end diastolic diameter, $\mathrm{D}$ and diameter change, $\Delta \mathrm{D}$ or distension) were recorded non-invasively using applanation tonometry [15] 
and an echo-tracking system [16], respectively. At the temporal artery only D was measured. At the common carotid artery vessel wall movements and pressure waveforms were recorded ipsilateral and consecutively. At the brachial and femoral artery vessel wall movements (right) and pressure waveforms (left) were recorded contralateral and simultaneously. In the analysis, mean arterial pressure (MAP), local pulse pressures of the common carotid $\left(\triangle \mathrm{P}_{\mathrm{CCA}}\right)$, brachial $\left(\Delta \mathrm{P}_{\mathrm{BA}}\right)$ and femoral artery $\left(\Delta \mathrm{P}_{\mathrm{FA}}\right)$ and large artery wall properties were calculated [17]. Therefore, diameter-time recordings (ultrasound) and pressure-time recordings (applanation tonometry) were simultaneously analysed off-line using a custom made Matlab $^{\circledR}$ script developed by the biophysics department of the university as previously reported [17]. By constructing diameter-pressure curves, distensibility coefficients (DC) and crosssectional compliance (CC) were calculated over the operating pressure.

Using ultrasound, in the common carotid and temporal arteries centre stream velocity was measured in order to calculate local blood flow and vascular resistance. At the right common carotid artery and brachial artery posterior wall intima-media thickness was assessed using an established ultrasound method [18]. Finally, using echocardiography cardiac output and systemic vascular resistance were determined.

For a detailed description on all the measurements which were performed and the subsequent data analysis, we refer to Chapter 2.

\section{Statistical analysis}

It was calculated that with a significance level of 0.05 and a power of $80 \%, 40$ subjects per group were required to detect between group differences of $20 \%$ in distensibility of the femoral artery, which is the artery with the lowest reproducibility. Comparison of clinical characteristics and cardiovascular parameters between both groups was done with the unpaired Student's $t$-test. Except for subject characteristics, which are presented as mean $\pm \mathrm{SD}$, data are presented as mean \pm SEM. $P<0.05$ was considered statistically significant. 


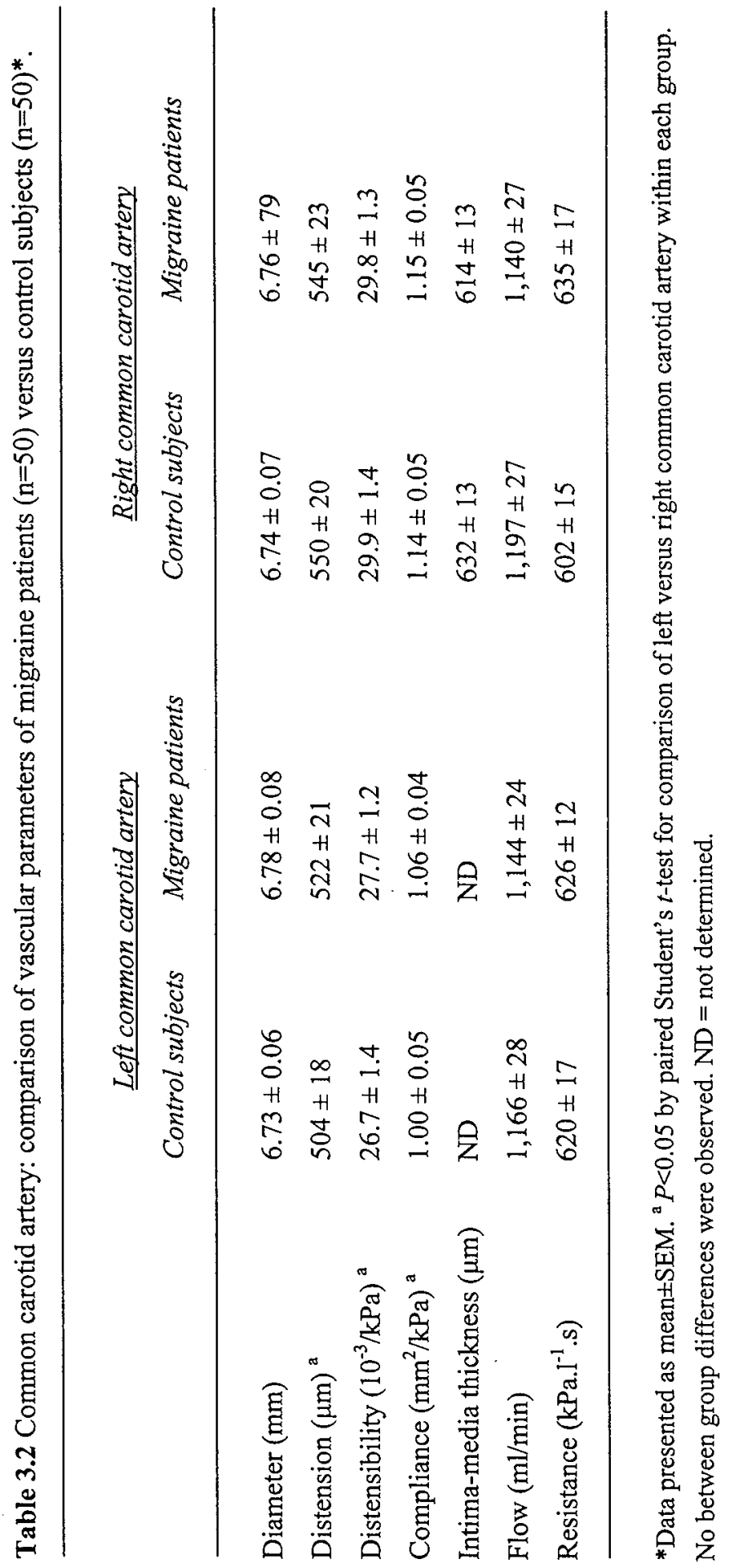




\subsection{Results}

\section{Subject characteristics}

Clinical characteristics of migraine patients (aged 19 to 58 year) and control subjects (aged 21 to 59 year) did not differ (Table 3.1). Migraine patients had been suffering from migraine for on average $15 \pm 1$ year. Eleven patients had a history of recurrent migraine with aura (classic migraine), 39 without aura (common migraine). Migraine attacks recurred with a frequency of $2.6 \pm 0.4$ per month and lasted on average $1.4 \pm 0.1$ days. Headache was one-sided in 43 patients: either left-sided $(n=15)$, right-sided $(n=16)$ or alternating $(n=12)$. Nausea or vomiting $(n=39)$ and photophobia or phonophobia $(\mathrm{n}=46)$ were frequently associated with it. As an abortive drug triptans $(n=21)$, analgesics $(n=20)$ and anti-inflammatory drugs $(n=15)$ were most frequently used. Only 3 patients mentioned the use of ergot alkaloids. Oral contraceptives or hormonal replacement therapy were used by a comparable number of migraine patients $(n=13)$ and control subjects $(n=14)$.

\section{Haemodynamic data}

Mean arterial pressure did not differ between control subjects $(88 \pm 1 \mathrm{mmHg})$ and migraine patients $(88 \pm 1 \mathrm{mmHg})$. Pulse pressures of the common carotid, brachial and femoral artery of control subjects $(41 \pm 1,44 \pm 1$ and $47 \pm 1 \mathrm{mmHg}$, respectively) were comparable with those of migraine patients $(39 \pm 1,43 \pm 1$ and $46 \pm 1 \mathrm{mmHg}$, respectively).

\section{Vascular measurements}

At the common carotid artery (Table 3.2 and Fig. 3.1) vascular parameters did not differ between migraine patients and control subjects. In both groups distension, distensibility and compliance were smaller at the left common carotid artery compared to the right one. In a subgroup of 31 migraine patients who consistently reported unilateral migraine on the same side of the head, the vascular parameters of the "diseased" and "healthy" side were compared. At the level of the common carotid artery this subgroup analysis revealed no differences. 


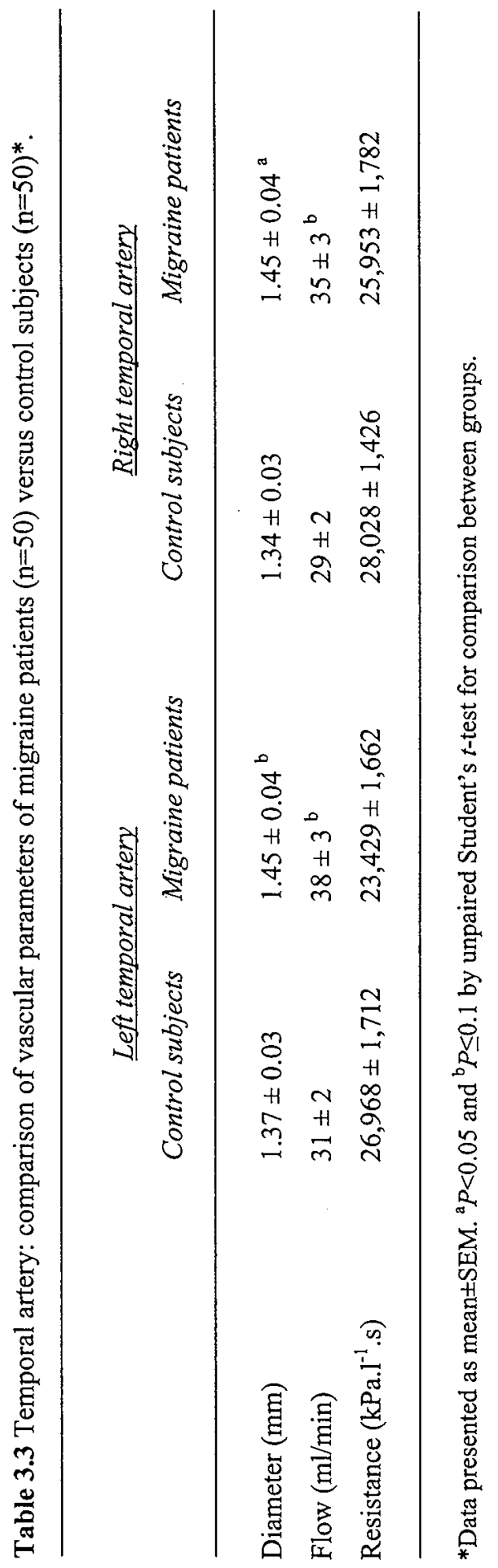




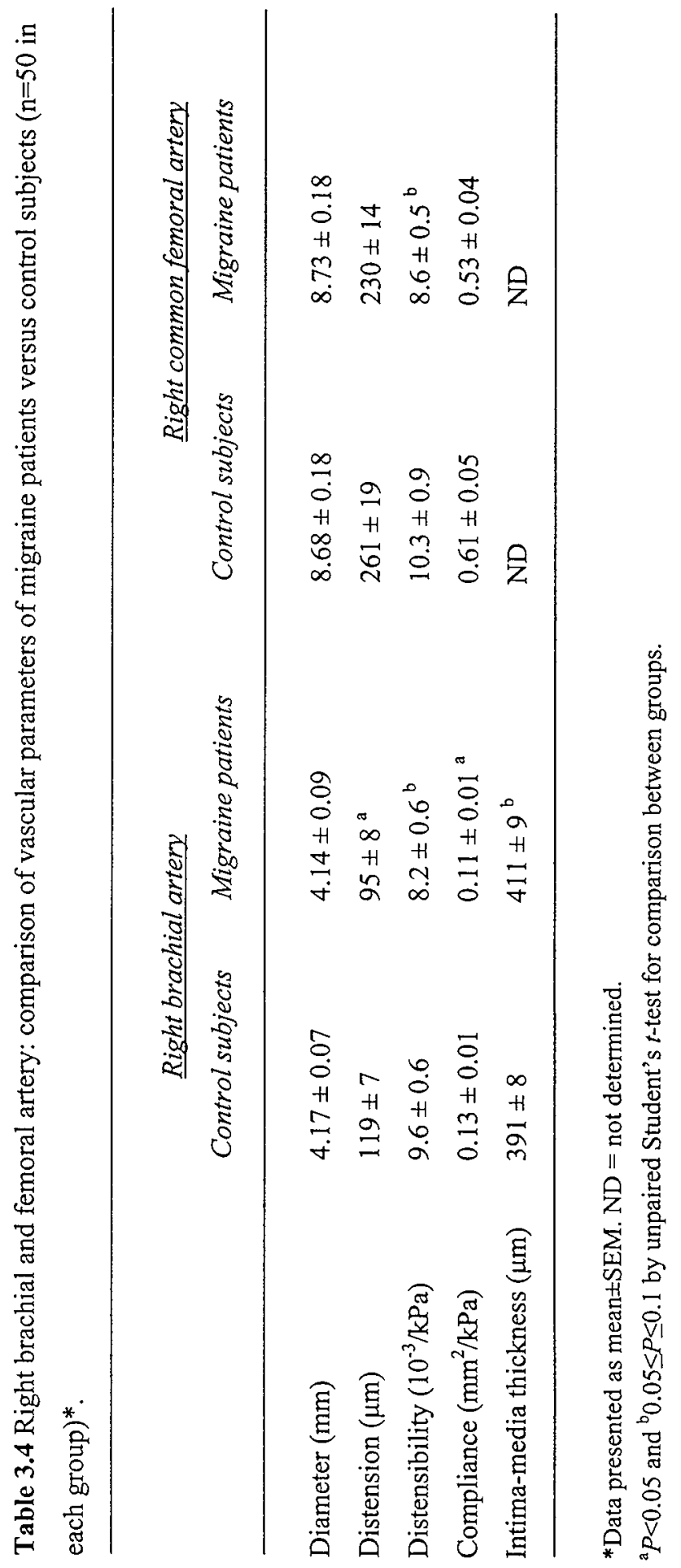




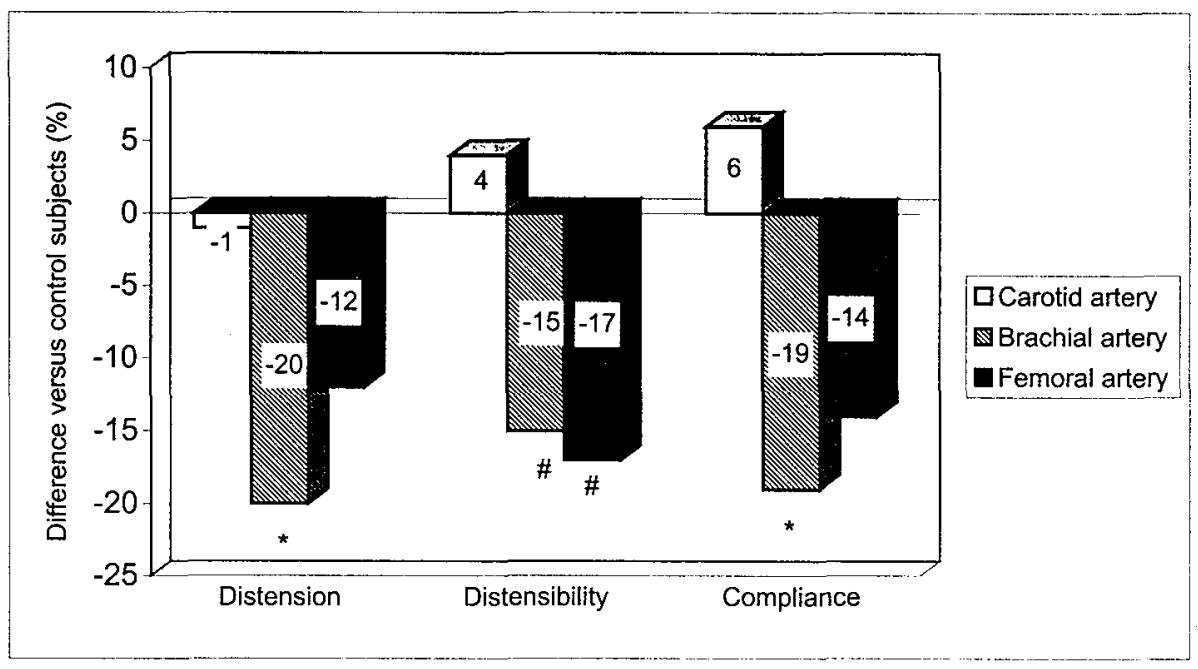

Figure 3.1 Comparison of the vascular parameters of the right common carotid, brachial and common femoral artery of migraine patients with those of control subjects. Differences are expressed as percentage difference versus control subjects. ${ }^{*} P<0.05$ and ${ }^{\#} P \leq 0.1$ by unpaired Student's $t$-test versus control subjects.

Temporal artery diameter (Table 3.3 and Fig. 3.2) was larger ( $P=0.03$, right) or tended to be larger ( $P=0.1$, left $)$ in migraine patients compared to control subjects. Likewise, temporal artery blood flow tended to be larger $(P \leq 0.1)$ in migraine patients while local vascular resistance did not differ significantly. A subgroup analysis comparing the temporal artery parameters of the "diseased" and "healthy" side of the head of migraine patients showed no differences.

At the brachial artery (Table 3.4 and Fig. 3.1) distension and compliance were smaller $(P=0.02)$ in migraine patients compared to control subjects. In addition, distensibility tended to be smaller $(P=0.10)$ and intima media thickness tended to be larger $(5.3 \%$ versus control subjects, $P=0.07)$ in migraine patients. At the femoral artery (Table 3.4 and Fig. 3.1) no differences were demonstrated between both groups. 


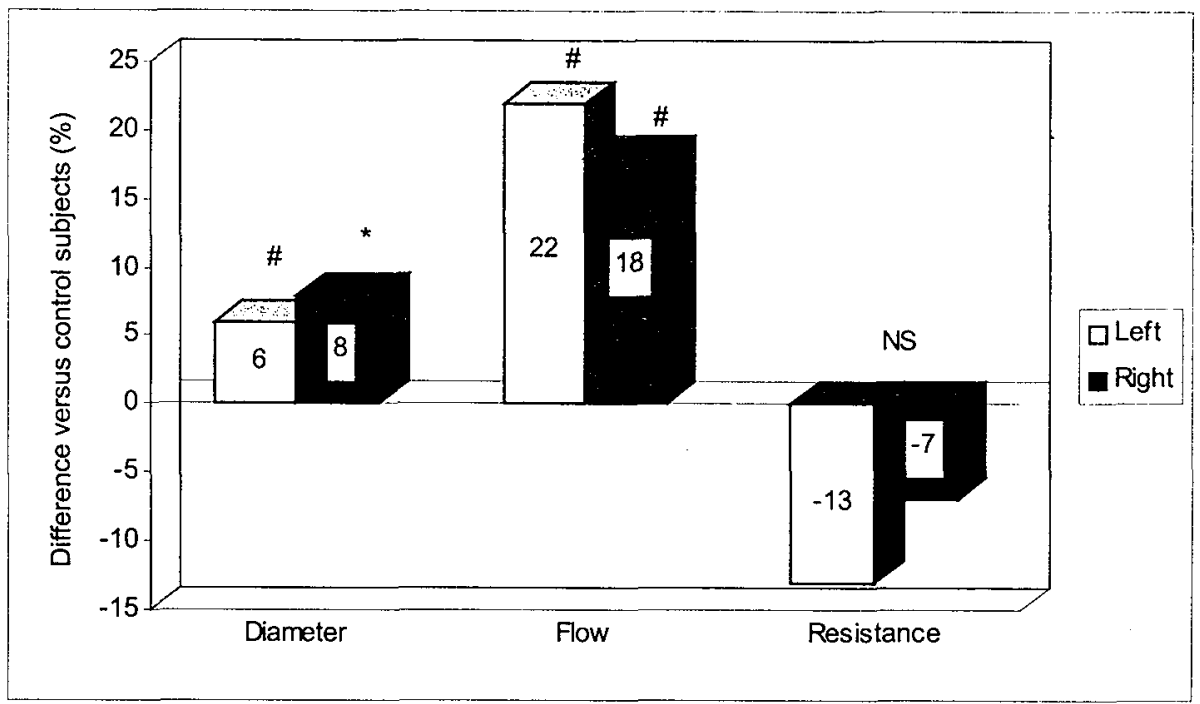

Figure 3.2 Comparison of the vascular parameters of the left and right temporal artery of migraine patients with those of control subjects. Differences are expressed as percentage difference versus control subjects. ${ }^{*} P<0.05,{ }^{*} P \leq 0.1$ and NS (no statistically significant difference) by unpaired Student's $t$-test versus control subjects.

\section{Cardiac measurements}

Cardiac output and systemic vascular resistance of control subjects $(4.8 \pm 0.1 \mathrm{l} / \mathrm{min}$ and $149 \pm 4 \mathrm{kPa} .1^{-1} . \mathrm{s}$, respectively) and non-migraineurs $\left(4.9 \pm 0.1 \mathrm{1} / \mathrm{min}\right.$ and $148 \pm 4 \mathrm{kPa} . \mathrm{l}^{-1} . \mathrm{s}$, respectively) were comparable.

\subsection{Discussion}

The present study aimed at investigating whether migraine patients display different cardiovascular properties compared to matched control subjects during the interictal period. The most striking functional and structural vascular differences between both populations were observed at the medium sized brachial artery displaying an increased 


\section{Chapter 3}

arterial stiffness and a tendency towards an increased intima-media thickness in migraine patients. In addition, migraineurs showed a larger temporal artery diameter and tended to have an increased temporal artery blood flow compared to control subjects. However, neither at the left nor at the right common carotid artery any differences were observed between both groups. Likewise, cardiac output and systemic vascular resistance did not differ.

Vascular research has frequently been performed in migraine patients and mainly aimed at investigating changes in flow and diameter $[5,6,19]$. However, most studies only report on vascular changes observed during a migraine attack and on those vascular territories involved in the pathogenesis of migraine headache. In particular, research focused on the external carotid artery and its branches, including the temporal artery [5], which largely perfuse meningeal blood vessels and are considered the pain-producing structures in migraine [2, 20, 21]. Iversen et al. [5] have previously reported that in migraine patients the temporal artery diameters of both sides do not differ during the interictal period while migraine headache is associated with an increased arterial diameter at the affected side. Accordingly, in the present study the temporal artery diameters of both sides did not differ; neither in migraine patients (between attacks) nor in control subjects. However, even between attacks, temporal artery diameter was larger in migraine patients compared to control subjects. In addition, the trend towards an increased temporal artery blood flow in migraine patients points out to differences at the level of resistance vessels as well. Taken together, these data indicate that irrespective of migraine headache, patients display changes both of conduit arteries and resistance vessels in the vascular territory which is affected during an attack. A subgroup analysis of those patients who consistently reported unilateral headache did not reveal any interictal differences between the temporal artery of the affected and unaffected sides, arguing against localised vascular changes.

At the common carotid and brachial artery both functional (vessel wall properties) and structural (intima-media thickness) vascular parameters were investigated. The functional parameters distensibility (a measure of vascular elasticity) and cross-sectional compliance (a measure of buffering capacity) refer to mechanical 
vessel wall properties and decrease with increasing arterial stiffness [22]. Distensibility and cross-sectional compliance of migraine patients and control subjects were compared at operating pressures which did not differ between both groups. The present study is the first to demonstrate that the distension and buffering capacity of the brachial artery are decreased in migraine patients. Thus, in addition to changes at the temporal artery, migraine patients are also characterised by changes at the peripheral brachial artery. However, in agreement with Barenbrock and co-workers [23], at the common carotid artery no vascular changes were observed. The different behaviour of the common carotid artery compared to the brachial artery is probably related to differences in vessel wall structure. In general, the viscoelastic properties of the vessel wall depend on a passive component due to elastic and collagenous connective tissue and on an active component due to smooth muscle activity [24, 25]. The common carotid artery is an elastic artery which has a high proportion of elastic fibres and a small quantity of vascular smooth muscle cells compared to the muscular brachial artery [24]. Thus, changes in vascular smooth muscle tone are likely to result in smaller changes of arterial stiffness in "elastic arteries" compared to "muscular arteries". At the femoral artery migraine patients display the same tendency towards an increased arterial stiffness as the one observed at the brachial artery. Although this difference did not reach statistical significance, this was likely due to a lack of power.

The increased arterial stiffness in migraine patients might be related to an increased arterial tone compared to control subjects. The regulation of arterial tone is complex and involves autonomic, humoral and endothelial mechanisms [21]. Thus, an increased arterial stiffness in migraineurs could result from a higher sympathetic output. However, the conflicting evidence of the currently available data on autonomic nervous system function in migraine patients $[26,27]$ does not allow for definite conclusions to be drawn. As far as humoral factors are concerned, serotonin (5-HT) is the most likely candidate to be involved. It probably plays an important role in the pathogenesis of migraine which is associated with low levels of 5-HT between attacks and increased levels during attacks [28, 29]. However, given the biphasic vascular response to 5-HT depending on its plasma concentration [30], it may either increase or decrease vascular tone. Still, as within the physiological range the 


\section{Chapter 3}

vasodilator effects of 5-HT predominate [31], the lower plasma concentrations in migraineurs might translate into less vasodilatation and be responsible for an increased arterial stiffness. Finally, as far as endothelial mechanisms are concerned, Joannides et al. [32] recently reported that nitric oxide (NO) contributes to the regulation of mechanical properties of peripheral conduit arteries in human. They showed that a decreased NO production results in an unexpected increase in arterial compliance. Consequently, as in the present study migraine patients displayed a decreased compliance of the brachial artery this might be related to an increased production of NO. Moreover, as previous reports suggest that the NO-pathway is activated during the headache-free period [33], this hypothesis fits well with the current opinion on NO playing a pivotal role in the pathophysiology of migraine [34]. In contrast with the effects of NO on conduit arteries, at the level of resistance vessels an increased basal production of NO results in a decreased vascular tone [35] which could explain the tendency towards an increased flow at the temporal artery.

Apart from arterial tone, arterial stiffness also depends on vessel wall structure. As the present study suggests that the intima-media thickness of the brachial artery is increased in migraine patients this might contribute to an increased arterial stiffness. The observation that intima-media thickness tends to be increased in migraine patients is very intriguing but difficult to explain if the concept of an increased basal NO production is accepted. As NO has previously been shown to be a negative regulator of vascular smooth muscle cell proliferation [36] a decreased rather than an increased intima-media thickness would be expected.

It has recently been shown that the acute intake of both $5-\mathrm{HT}_{1 \mathrm{~B} / \mathrm{D}}$-receptor agonists (de Hoon et al., Chapter 6) and ergot alkaloids [23,37] results in a transient increase in arterial stiffness. Thus, it could be argued that the vascular changes observed in the present study might not only be related to migraine itself but also to the preceding use of anti-migraine drugs. However, with the exception of ergot alkaloids, most drugs used to abort an acute migraine attack are short-acting. Even for ergot alkaloids, a drug-free period of at least 3 days should be sufficiently long for functional vascular effects to subside $[37,38]$. Although it cannot be excluded that the increased arterial stiffness is related to structural vessel wall changes due to the 
repeated exposure to anti-migraine drugs, this is very unlikely. In addition, the repeated use of ergotamine has previously been shown not to affect intima-media thickness [23].

What are the consequences of the present findings? Firstly, as vascular changes are present during the interictal period, it is tempting to speculate that drugs normalising these changes might be useful in the prophylactic treatment of migraine. Interestingly, many of the currently available prophylactic anti-migraine drugs, including calcium antagonists and selective $\beta$-blockers, have previously been shown to decrease arterial stiffness [39] and might thus normalise the vascular changes which render migraine patients at increased risk for a new attack. Secondly, as the baseline vascular characteristics of migraine patients differ from those of non-migraineurs, migraine patients may display different cardiovascular responses to the administration of vasoactive substances in general and to anti-migraine drugs in particular. Thus, the cardiovascular effects of potential anti-migraine drugs should be carefully looked at both in healthy subjects and in migraine patients. Finally, although it remains to be established whether the observed vascular changes are a primary cause of migraine or secondary to it, they do support the contention that migraine is associated with vascular abnormalities.

In conclusion, the present study is the first to demonstrate that even during the interictal period migraine patients display both cranial and peripheral vascular changes, indicating an important role of the vasculature in the pathogenesis of migraine. Although the contribution of the trigeminovascular system in migraine headache is generally accepted, migraine should not be regarded as an isolated neurovascular problem but might be part of a more generalised vascular disorder.

\subsection{References}

1. Graham JR, Wolff HG. Mechanism of migraine headache and action of ergotamine tartrate. Arch Neurol Psych 1938;39:737-763.

2. Moskowitz MA. Basic mechanisms in vascular headache. Headache 1990;8:801-815. 


\section{Chapter 3}

3. Friberg L. Cerebral blood flow changes in migraine: methods, observations and hypotheses. J Neurol 1991;238:S12-S17.

4. Olesen J. Cerebral and extracranial circulatory disturbances in migraine: pathophysiological implications. Cerebrovasc Brain Metab Rev 1991;3(1):1-28.

5. Iversen HK, Nielsen TH, Olesen J, Tfelt-Hansen $P$. Arterial responses during migraine headache. Lancet 1990;336:837-839.

6. Drummond PD, Lance JW. Extracranial vascular changes and the source of pain in migraine headache. Ann Neurol 1983;13:32-37.

7. Lafitte C, Even C, Henry-Lebras F, de Toffol B, Autret A. Migraine and angina pectoris by coronary artery spasm. Headache 1996;36:332-334.

8. Heupler FA. Syndrome of symptomatic coronary arterial spasm with nearly normal coronary arteriograms. Am J Cardiol 1980;45:873-881.

9. Miller D, Waters DD, Warnica W, Szlachcic J, Kreeft J, Theroux P. Is variant angina the coronary manifestation of a generalized vasospastic disorder? $N$ Engl $J$ Med 1981;304:763-766.

10. Zahavi I, Chagnac A, Hering R, Davidovich S, Kuritzky A. Prevalence of Raynaud's phenomenon in patients with migraine. Arch Intern Med 1984;144:742-744.

11. Carolei A, Marini C, De Matteis G. History of migraine and risk of cerebral ischaemia in young adults. The Italian National Research Council Study Group on Stroke in the Young. Lancet 1996;347:1503-1506.

12. Merikangas KR, Fenton BT, Cheng SH, Stolar MJ, Risch N. Association between migraine and stroke in a large-scale epidemiological study of the United States. Arch Neurol 1997;54(4):362-368.

13. Chang CL, Donaghy M, Poulter N. Migraine and stroke in young women: case-control study. The World Health Organisation Collaborative Study of Cardiovascular Disease and Steroid Hormone Contraception. Br Med J 1999;318:13-18.

14. Headache Classification Committee of the International Headache Society. Classification and diagnostic criteria for headache disorders, cranial neuralgias and facial pain. Cephalalgia 1988;8:1-96.

15. Kelly R, Hayward C, Ganis J, Daley J, Avolio A, O'Rourke M. Noninvasive registration of the arterial pressure pulse waveform using high-fidelity applanation tonometry. J Vasc Med Biol 1989;1(3):142-149.

16. Hoeks APG, Brands PJ, Smeets FAM, Reneman RS. Assessment of the distensibility of superficial arteries. Ultrasound Med Biol 1990;16:121-128. 
17. de Hoon JNJM, Hoeks APG, Willigers JM, Van Bortel LMAB. Non-invasive assessment of pulse pressure at different peripheral arteries in man. Neth $J$ Med 1998;52:A36.

18. Willekes C, Hoeks APG, Bots ML, Brands PJ, Willigers JM, Reneman RS. Evaluation of off-line automated intima-media thickness detection of the common carotid artery based on M-line signal processing. Ultrasound Med Biol 1999;25(1):57-64.

19. Friberg L, Olesen J, Iversen HK, Sperling B. Migraine pain associated with middle cerebral artery dilatation: reversal by sumatriptan. Lancet $1991 ; 338: 13-17$.

20. Blau JN. Migraine: a vasomotor instability of the meningeal circulation. Lancet 1978;ii:1136-1139.

21. Thomsen LL, Olesen J. The autonomic nervous system and the regulation of arterial tone in migraine. Clin Auton Res 1995;5:243-250.

22. Laurent S, Caviezel B, Beck L, Girerd X, Billaud E, Boutouyrie P, et al. Carotid artery distensibility and distending pressure in hypertensive humans. Hypertension 1994;23:878-883.

23. Barenbrock M, Spieker C, Witta J, Evers S, Hoeks APG, Rahn KH, et al. Reduced distensibility of the common carotid artery in patients treated with ergotamine. Hypertension 1996;28:115-119.

24. O'Rourke MF. Arterial function in health and disease. Edinburgh: Chirchill Livingstone; 1992.

25. Safar ME, Levy BI, Laurent S, London GM. Hypertension and the arterial system: clinical and therapeutic aspects. J Hypertens 1990;5(Suppl. 7):S113-S1 19.

26. Cortelli P, Pierangeli G, Parchi P, Contin M, Baruzzi A, Lugaresi E. Autonomic nervous system function in migraine without aura. Headache 1991;31(7):457-462.

27. Martin R, Ribera C, Molto JM, Galiano L, Matias-Guiu J. Cardiovascular reflexes in patients with vascular headache. Cephalalgia 1992;12(6):360-364.

28. Raskin NHH. Serotonin receptors and headache. N Engl J Med 1991;325:353-354.

29. Ferrari MD, Saxena PF. On serotonin and migraine: a clinical and pharmacological review. Cephalalgia 1993;13:151-156.

30. Blauw GJ, Van Brummelen P, Chang PC, Van Zwieten PA. Regional vascular effects of serotonin and ketanserin in young healthy subjects. Hypertension 1988;11:256-263.

31. Cohen RA. Adenosine nucleotides and 5-hydroxytryptamine released by aggregating platelets inhibit adrenergic neurotransmission in canine coronary artery. $J$ Clin Invest 1986;77:369-375. 
32. Joannides R, Richard V, Haefeli WE, Linder L, Lüscher TF, Thuillez C. Role of basal and stimulated release of nitric oxide in the regulation of radial artery caliber in humans. Hypertension 1995;26:327-331.

33. Gallai V, Floridi A, Mazotta G, Codini M, Tognoloni M, Vulcano MR, et al. Larginine/nitric oxide pathway activation in platelets of migraine patients with and without aura. Acta Neurol Scand 1996;94(2):151-160.

34. Olesen J, Thomsen LL, Iversen H. Nitric oxide is a key molecule in migraine and other vascular headaches. Trends Pharmacol Sci 1994;15:149-153.

35. Vallance P, Collier J, Moncada S. Effects of endothelium-derived nitric oxide on peripheral arteriolar tone in man. Lancet 1989;2:997-1000.

36. Rudic RD, Shesely EG, Maeda N, Smithies O, Segal SS, Sessa WC. Direct evidence for the importance of endothelium-derived nitric oxide in vascular remodeling. $J$ Clin Invest 1998;101(4):731-736.

37. de Hoon NNJM, Struijker-Boudier HAJ, Van Bortel LMAB. Different vascular effects of dihydroergotamine on large arteries and resistance vessels in man. $\mathrm{Br} J$ Clin Pharmacol 1999;47:470P.

38. Tfelt-Hansen P, Paalzow L. Intramuscular ergotamine: plasma levels and dynamic activity. Clin Pharmacol Ther 1985;37:29-35.

39. Van Bortel LMAB, Kool MJF, Struijker-Boudier HAJ. Effects of antihypertensive agents on local arterial distensibility and compliance. Hypertension 1995;26:531-534. 


\title{
Chapter 4
}

\section{Vascular Responsiveness to Nitric Oxide and Calcitonin Gene-Related Peptide in Migraine Patients}

\begin{abstract}
Background: As both nitric oxide (NO) and calcitonin gene-related peptide (CGRP) are considered to contribute substantially to the pathophysiology of migraine, the present study investigated the vascular responsiveness to NO, CGRP and ischaemia in migraine patients. Methods: Ten migraine patients and ten matched control subjects received intra-brachial infusions of (i) serotonin, releasing endothelial NO; (ii) sodium nitroprusside, an exogenous NO-donor and (iii) CGRP, a potent vasodilating neuropeptide. Changes in forearm blood flow (FBF) were measured using venous occlusion plethysmography and expressed as the ratio in FBF in the infused over the control arm (FBF-ratio). Flow-mediated vasodilatation of the brachial artery, depending on the endogenous release of NO, was measured using ultrasound and expressed as percentage change in diameter versus baseline. Maximal forearm vasodilator potential was assessed by plethysmography after 13 minutes of ischaemia and expressed as minimal forearm vascular resistance. Results: Basal FBF-ratio $(1.1 \pm 0.1)$ did not differ between controls and migraine patients. A dose-dependent increase $(P<0.001)$ in FBF-ratio was induced by serotonin, nitroprusside and CGRP in control subjects (to $2.8 \pm 0.3,6.7 \pm 1.4$ and $6.9 \pm 1.2$ at the highest dose, respectively) and migraine patients ( $2.5 \pm 0.4,5.6 \pm 0.8$ and $6.5 \pm 1.3$, respectively). FBF-ratios did not differ between both group. The peak increase in flow-mediated vasodilatation ( $5.8 \pm 1 \%$ versus $5.2 \pm 1 \%$, respectively) and the minimal forearm vascular resistance ( $7.5 \pm 0.8$ versus $6.2 \pm 0.6$ arbitrary units, respectively) were comparable in control subjects and migraine patients.
\end{abstract}

Based on: J.N.J.M. de Hoon $^{(1)}$, P. Smits ${ }^{(2)}$, J. Troost ${ }^{(3)}$, H.A.J. Struijker-Boudier ${ }^{(1)}$, L.M.A.B. Van Bortel $^{(1)}$. Vascular responsiveness to nitric oxide and calcitonin gene-related peptide in migraine patients. (submitted).

${ }^{(1)}$ Dept. of Pharmacol. and Toxicol., Cardiovascular Research Institute Maastricht, Maastricht Univ., Maastricht; ${ }^{(2)}$ Dept. of Pharmacol. and Toxicol. and Division of Internal Medicine, Univ. of Nijmegen, Nijmegen and ${ }^{(3)}$ Dept. of Neurology, Univ. Hospital of Maastricht, Maastricht, The Netherlands. 
Conclusions: Based on the forearm vascular responsiveness to NO, CGRP and ischaemia, migraine patients do not display generalised differences in vascular function compared to control subjects. In addition, no structural differences are present at the level of resistance vessels.

\subsection{Introduction}

The pathophysiology of migraine has been much debated over the past decades [1]. The concept of migraine being due to an inappropriate vasodilatation of cranial blood vessels as postulated by Graham and Wolff [2], has shifted towards a neurovascular theory regarding migraine as a complex disorder of the trigeminovascular system [3]. Although, this theory is generally accepted, the trigger responsible for activating this system and initiating migraine headache remains unknown.

One hypothesis, which has mainly been advocated by Olesen and co-workers [46], points to endothelial derived relaxing factor or nitric oxide (NO) as the triggering molecule for migraine attacks. They demonstrated that compared to healthy subjects, migraine patients suffer a more intense and more migraine-like headache after the administration of organic nitrates, acting as NO-donors, and histamine, stimulating the endogenous release of $\mathrm{NO}$ by the activation of endothelial $\mathrm{H}_{1}$-receptors [7, 8]. Furthermore, an increased vasodilatation of the middle cerebral artery was observed in migraine patients compared to control subjects after the administration of organic nitrates [9]. Based on these data they concluded that migraine patients display an arterial supersensitivity to NO.

Apart from NO, calcitonin gene-related peptide (CGRP) has even more convincingly been shown to be a key-player in the pathophysiology of migraine. Indeed, Goadsby and colleagues [10] provided evidence that during migraine headache the trigeminovascular system is turned on and CGRP, a potent vasodilator neuropeptide, is released into the cranial circulation. However, the question remains which are the stimuli responsible for this release. Interestingly, based on animal data, the most important emerging hypothesis states that NO plays a regulatory role in neuropeptide release from perivascular sensory nerves [11, 12]. Consequently, 
supersensitivity to NO might not only translate into an excessive vasodilatation by the direct action of $\mathrm{NO}$ on the blood vessel wall of migraine patients, but it might also translate into an excessive release of CGRP from perivascular nerves induced by NO.

The present study aims at a better understanding of the concept of supersensitivity to both endogenous and exogenous NO and the vascular reactivity to CGRP in migraine patients.

\subsection{Subjects and methods}

\section{Subjects and subject selection}

Ten migraine patients (as defined by the International Headache Society migraine criteria [13]) were compared to 10 healthy control subjects. Both groups were matched for gender, age, body mass index, blood pressure and cholesterol. Migraine patients were recruited from the neurology outpatient clinic and control subjects from among hospital and laboratory staff. Baseline characteristics of both groups are presented in Table 4.1. Based on medical history, physical examination and routine laboratory tests, all participants were in good health. Major exclusion criteria were: smoking, history of cardiovascular disease, arterial hypertension (blood pressure $>160 / 95 \mathrm{mmHg}$ ), diabetes mellitus and hyperlipidaemia (total cholesterol $>6.4$ $\mathrm{mmol} / \mathrm{l})$. Except for oral contraceptives, no regular medication was allowed. After approval by the ethics committee of the academic hospital of Maastricht this research was carried out in accordance with the Declaration of Helsinki (1989). All subjects gave written informed consent to participate.

\section{Study design}

After screening, eligible subjects were invited to return to the hospital for 2 study periods. Before each period, they were asked not to use any drugs for at least 3 days and to abstain from caffeine or alcohol-containing beverages for at least 12 hours. All measurements were performed by one investigator in a quiet, temperature controlled room and with the subject lying comfortably in the supine position. 


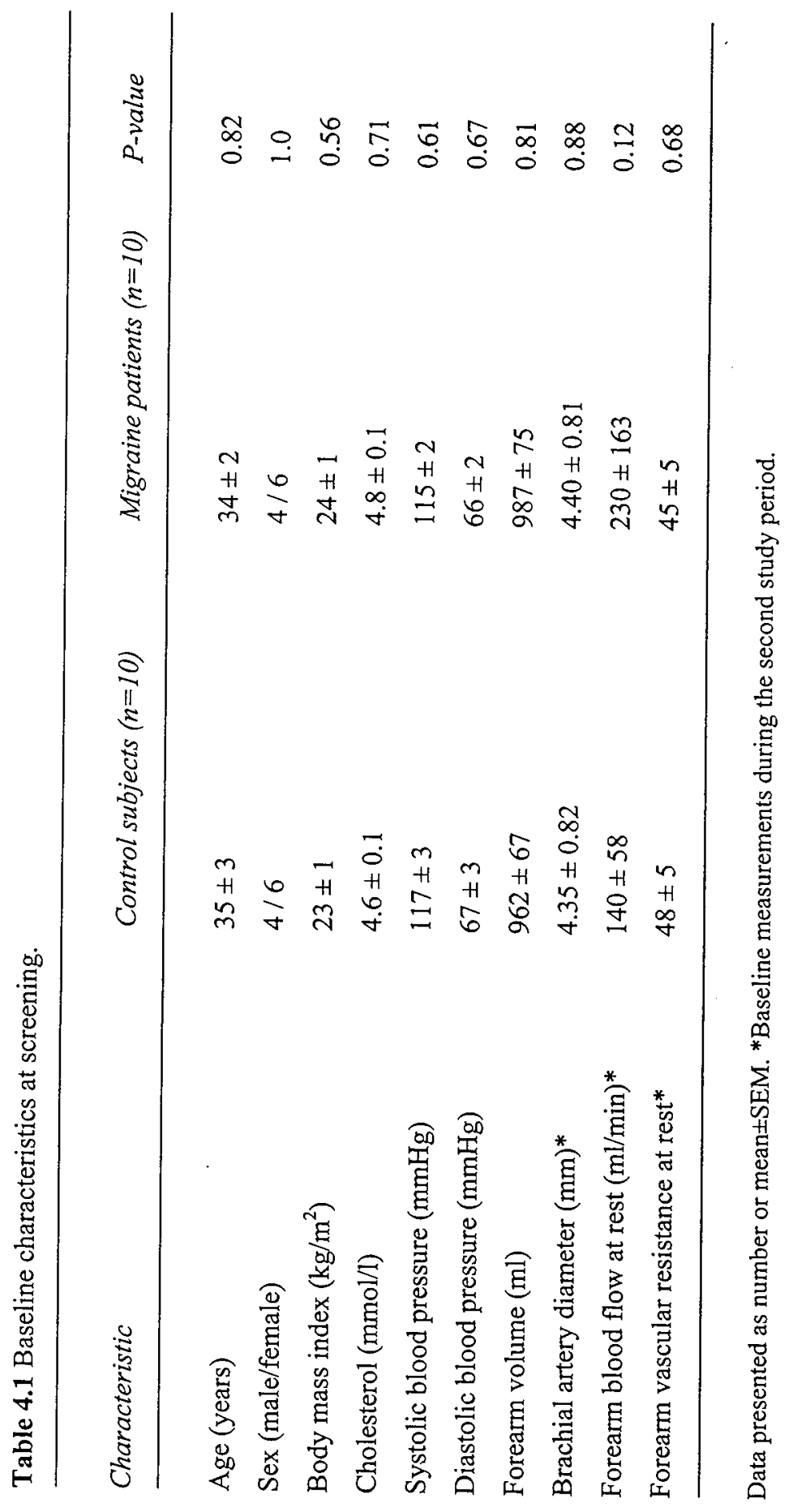




\section{First study period}

During this period, forearm vascular reactivity to serotonin (inducing an endogenous release of NO), sodium nitroprusside (SNP, an exogenous NO-donor) and CGRP was investigated using the "perfused forearm model" [14]. After local anesthesia (lidocaine $2 \%$, B. Braun, Germany) the brachial artery of the non-dominant arm was cannulated with a 20-gauge catheter (Arterial cannula, Ohmeda, U.K.) for intraarterial drug infusion (Graseby Syringe Pump 3200, Graseby Medical LTD, U.K.) and invasive blood pressure monitoring (monitor type 78201B, Hewlett Packard GmbH, Germany). Forearm arterial blood flow (FBF) was measured by ECG-triggered venous occlusion plethysmography using mercury-in-Silastic strain gauges (Periflow, Janssen Scientific Instruments, Belgium). Every 5 heart beats FBF was recorded simultaneously at both arms for 3 beats. Upper arm cuffs were intermittently and simultaneously inflated to a pressure of $45 \mathrm{mmHg}$. To ensure that FBF recordings referred predominantly to the forearm skeletal muscle resistance vessels perfusion, at least one minute before measurements were started the hand circulation was occluded by wrist cuffs inflated to $240 \mathrm{mmHg}$ [15]. Heart rate, systolic and diastolic blood pressure were recorded with every FBF measurement. Mean arterial pressure (MAP) was calculated as the electronically integrated area under the brachial artery pulsewave curve and averaged per FBF measurement.

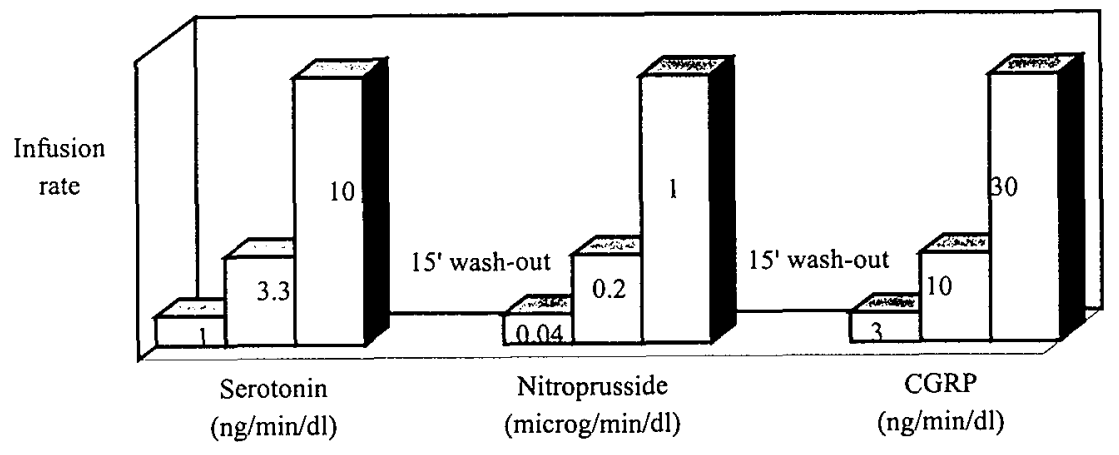

Figure 4.1 Flow chart of the first study period. 


\section{Chapter 4}

After instrumentation an equilibration period of at least 30 minutes was allowed. After equilibration, basal FBF was recorded for 5 minutes during infusion of saline $(\mathrm{NaCl} 0.9 \%)$. Baseline measurements were followed by incremental infusions of serotonin (1, 3.3 and 10 ng. $\mathrm{min}^{-1} \cdot \mathrm{dl}^{-1}$ forearm), SNP $\left(0.04,0.2\right.$ and $1 \mu \mathrm{g} \cdot \mathrm{min}^{-1} \cdot \mathrm{dl}{ }^{-1}$ forearm) and CGRP (3, 10 and $30 \mathrm{ng} \cdot \mathrm{min}^{-1} \cdot \mathrm{dl}^{-1}$ forearm) (Fig. 4.1). Each dose of serotonin and SNP was infused for 6 minutes; each dose of CGRP for 12 minutes. The mean of the measurements made during the final 2 minutes of each infusion period (i.e. at steady-state) was used in the analysis. After the highest dose of serotonin and SNP, saline was infused for at least 15 minutes to allow FBF to return to baseline. The rate of all intra-arterial infusions was kept constant at $100 \mu \mathrm{l} \cdot \mathrm{min}^{-1} . \mathrm{dl}^{-1}$ forearm volume and the dosages were normalised to forearm volume measured by water displacement. Before each experiment, all solutions were freshly prepared from commercially available vials (human-CGRP and serotonin purchased from Clinalfa Switserland) or from sterile stock solutions (SNP, provided by the hospital pharmacy). SNP was protected from light. In the analysis vascular responses to serotonin, SNP and CGRP, were expressed as the ratio in FBF in the infused over the control arm (FBF-ratio).

\section{Second study period}

During this period, after 15 minutes of supine rest, forearm vascular reactivity to ischaemia was investigated non-invasively. First, flow-mediated dilatation of the brachial artery of the right arm was measured using ultrasound (echo-tracking system). Thereafter, maximal post-ischaemic FBF of the left arm was measured using venous occlusion plethysmography. For a detailed description of how these measurements were performed and how the data were analysed, we refer to Chapter 2, sections 2.4 and 2.7. respectively. It should be mentioned however, that in the present study flow-mediated vasodilatation was measured every 30 seconds from 1 until 5 minutes after brachial artery reperfusion.

\section{Statistical analysis}

Comparison of baseline characteristics and non-serial parameters between both groups was done with the unpaired Student's $t$-test. The haemodynamic responses (FBF-ratio, 
MAP and heart rate) to incremental infusions of serotonin, SNP and CGRP within each group of subjects as well as the difference in forearm vascular response (FBFratio) between migraine patients and control subjects, were evaluated by ANOVA for repeated measures. If ANOVA showed a significant change (within a group) or difference (between groups), a post hoc Student's $t$-test was performed to determine dose dependency. Unless otherwise stated, data are expressed as mean \pm SEM; $P<0.05$ was considered statistically significant.

\subsection{Results}

\section{Subject characteristics}

Baseline characteristics of migraine patients and control subjects did not differ (Table 4.1). In both groups 2 subjects were on oral contraceptives. Migraine patients had been suffering from migraine for an average of $13 \pm 1$ years and had an attack frequency of $2.2 \pm 0.4$ each month. In most cases migraine headache was one-sided $(n=8)$, pulsatile in nature $(n=7)$ and accompanied by nausea or vomiting $(n=9)$ and photo- or phonophobia $(n=10)$. Only one patient regularly experienced migraine with aura. As an abortive drug sumatriptan ( $n=7)$ was most frequently used.

\section{First study period}

At baseline, FBF in the infused and control arm were similar within each group and did not differ between migraine patients and control subjects ( $1.8 \pm 0.3$ versus $1.7 \pm 0.1$ $\mathrm{ml} . \mathrm{min}^{-1} \cdot \mathrm{dl}^{-1}$ forearm, respectively). MAP slightly decreased $(P<0.001)$ during SNP infusion in both migraine patients (from $87 \pm 3$ at baseline to $84 \pm 3 \mathrm{mmHg}$ at the highest dose) and control subjects (from $92 \pm 3$ to $88 \pm 3 \mathrm{mmHg}$ ). In migraine patients this decrease in MAP was accompanied by a small increase $(P=0.001)$ in heart rate (from $58 \pm 3$ to $60 \pm 2 \mathrm{bpm}$ ). During the infusion of CGRP, a small increase $(P<0.001)$ in heart rate was observed both in patients (from $58 \pm 2$ to $62 \pm 3 \mathrm{bpm}$ ) and controls (from $61 \pm 2$ to $65 \pm 2 \mathrm{bpm}$ ) whereas MAP did not change $(89 \pm 3$ and $95 \pm 3 \mathrm{mmHg}$ at baseline, respectively). Although these changes in MAP and heart rate suggest a systemic vasodilator effects of SNP and CGRP, neither in migraine patients nor in 


\section{Chapter 4}

control subjects FBF in the control arm increased during any of the infusions, arguing against a systemic vasodilator effect.

A dose-dependent increase $(P<0.001)$ in FBF-ratio was induced by serotonin, SNP and CGRP (Fig. 4.2) both in control subjects (from $1.1 \pm 0.1$ to $2.8 \pm 0.3,6.7 \pm 1.4$ and $6.9 \pm 1.2$ at the highest dose, respectively) and in migraine patients (from $1.1 \pm 0.1$ to $2.5 \pm 0.4,5.6 \pm 0.8$ and $6.5 \pm 1.3$, respectively). There were no significant differences in the responses to any of the drugs between both populations.
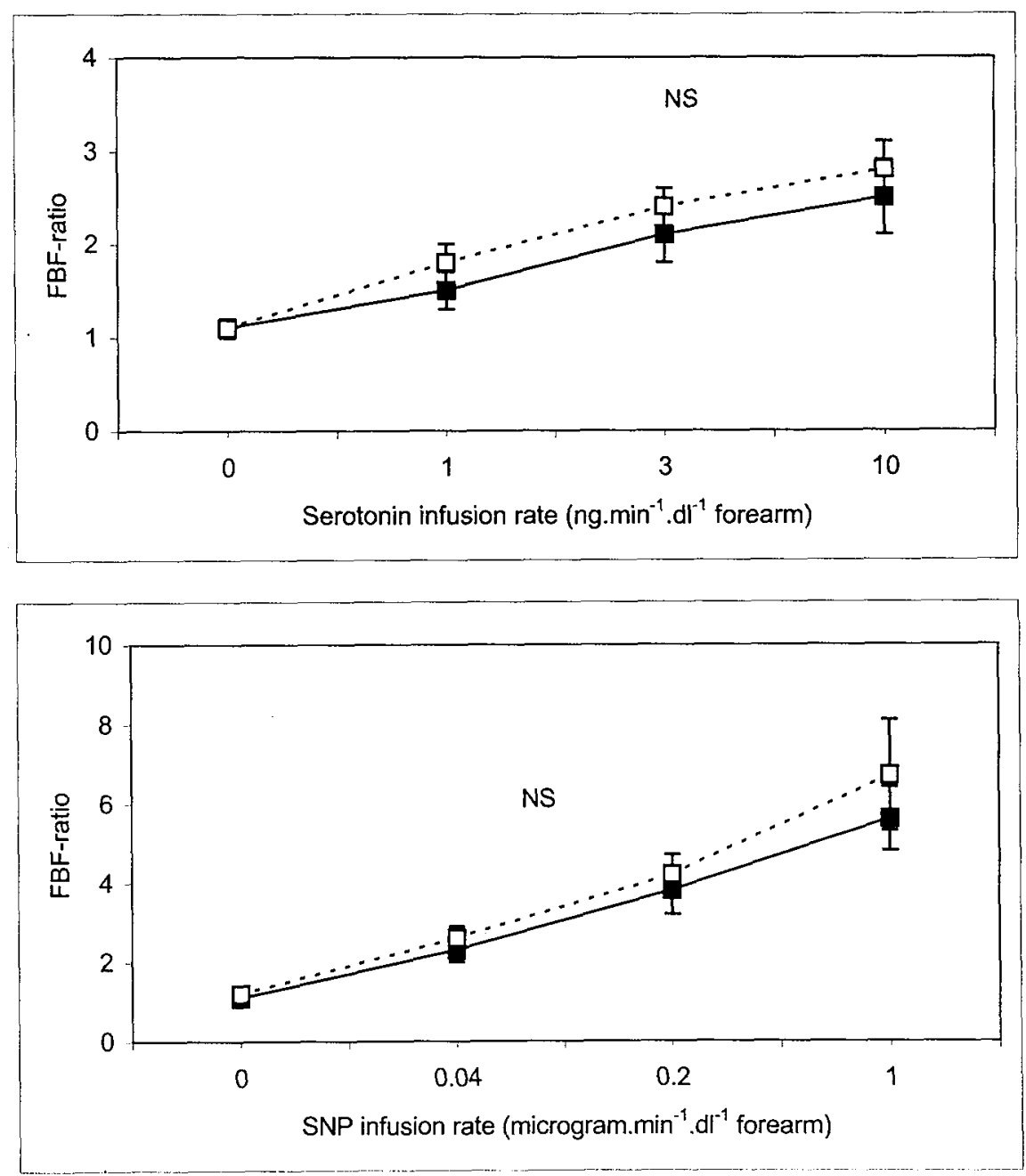


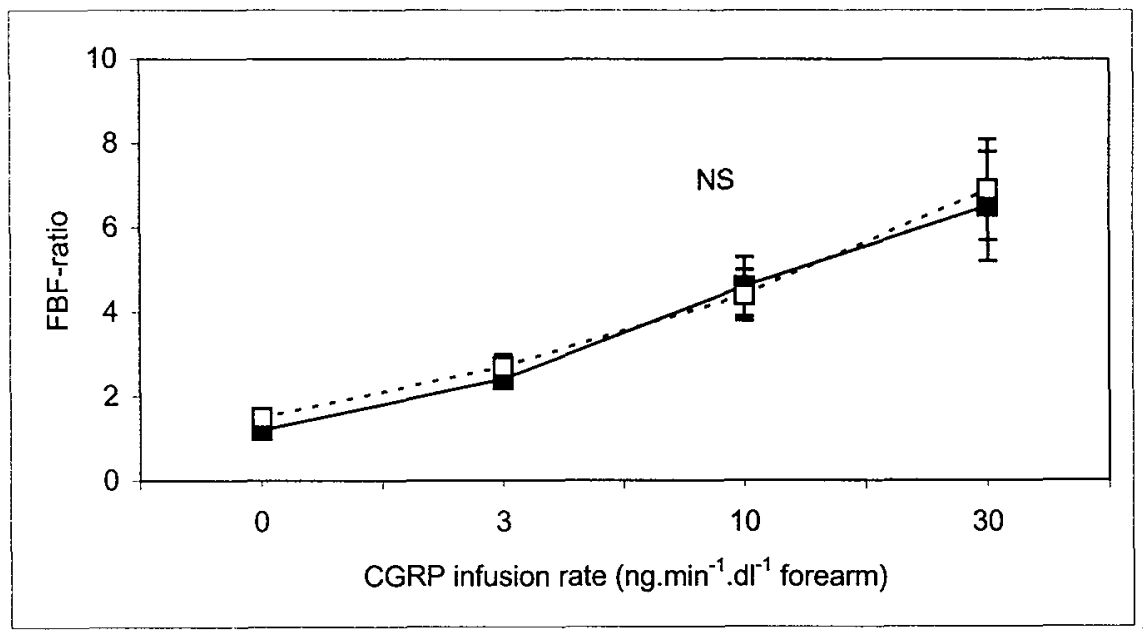

Figure 4.2 Comparison of forearm blood flow ratio (FBF-ratio) between migraine patients

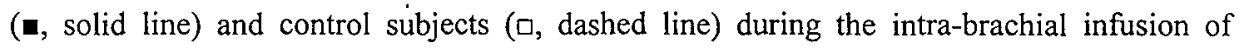
serotonin (left top), sodium nitroprusside (SNP, left bottom) and calcitonin gene-related peptide (CGRP). FBF-ratio: ratio in forearm blood flow in the infused arm over the control arm. Data are presented as mean $\pm S E M, n=10$ in each group. (NS: not statistically significant).

\section{Second study period}

The reactive hyperaemic increase in blood flow induced by 5 minutes of forearm occlusion did not differ $(P=0.054)$ between migraine patients $(476 \pm 53 \%)$ and control subjects $(608 \pm 34 \%)$. In response to this increase in flow, maximum brachial artery vasodilatation (Fig. 4.3) averaged $5.2 \pm 1.0 \%$ in migraine patients compared to $5.8 \pm 1.0$ $\%$ in control subjects $(P=0.64)$. The time-course of the flow-mediated vasodilatation expressed as $\mathrm{AUC}_{0 \rightarrow 5}$ did not differ between migraineurs and controls (370 150 $\mu \mathrm{m}$.min versus $570 \pm 147 \mu \mathrm{m}$.min, respectively, $P=0.35$ ).

Migraine patients and control subjects did not differ $(P=0.42)$ with respect to basal FBF (2.2 \pm 0.3 and $1.9 \pm 0.2 \mathrm{ml} \cdot \mathrm{min}^{-1} \cdot \mathrm{dl}^{-1}$ forearm, respectively) or maximal post-

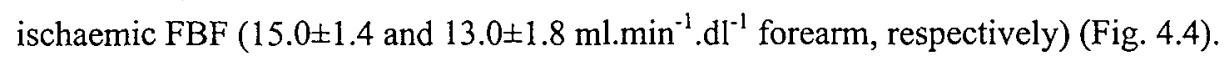




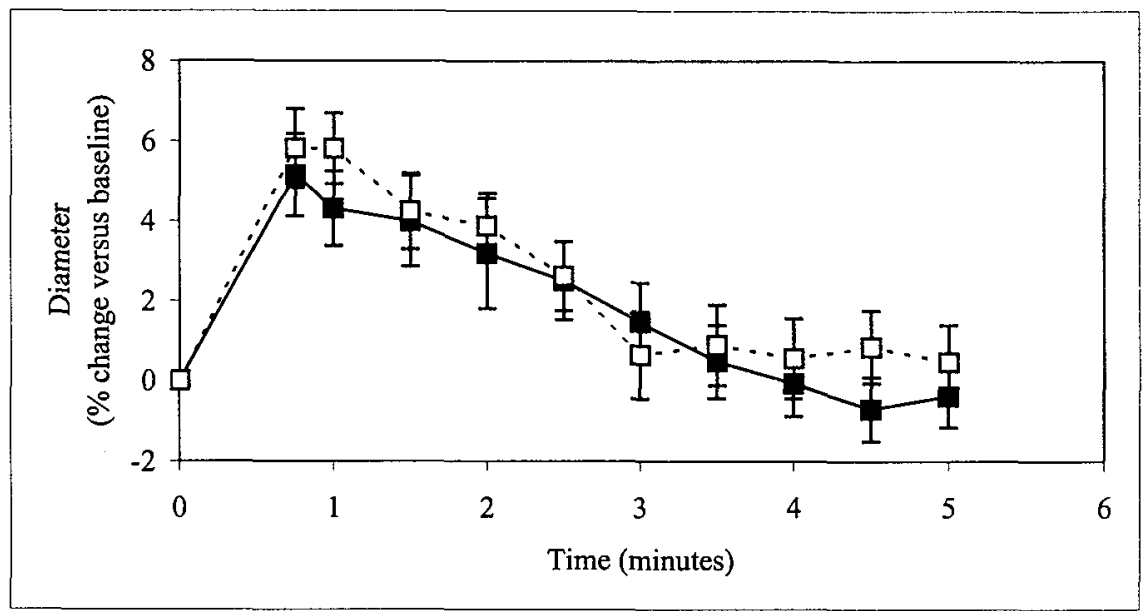

Figure 4.3 Comparison of flow-mediated vasodilatation between migraine patients ( $\mathbf{m}$, solid line) and control subjects ( $\square$, dashed line). Diameter before occlusion $(t=0)$ and from 45 seconds until 5 minutes after reperfusion. Data presented as mean \pm SEM, $n=10$ in each group.

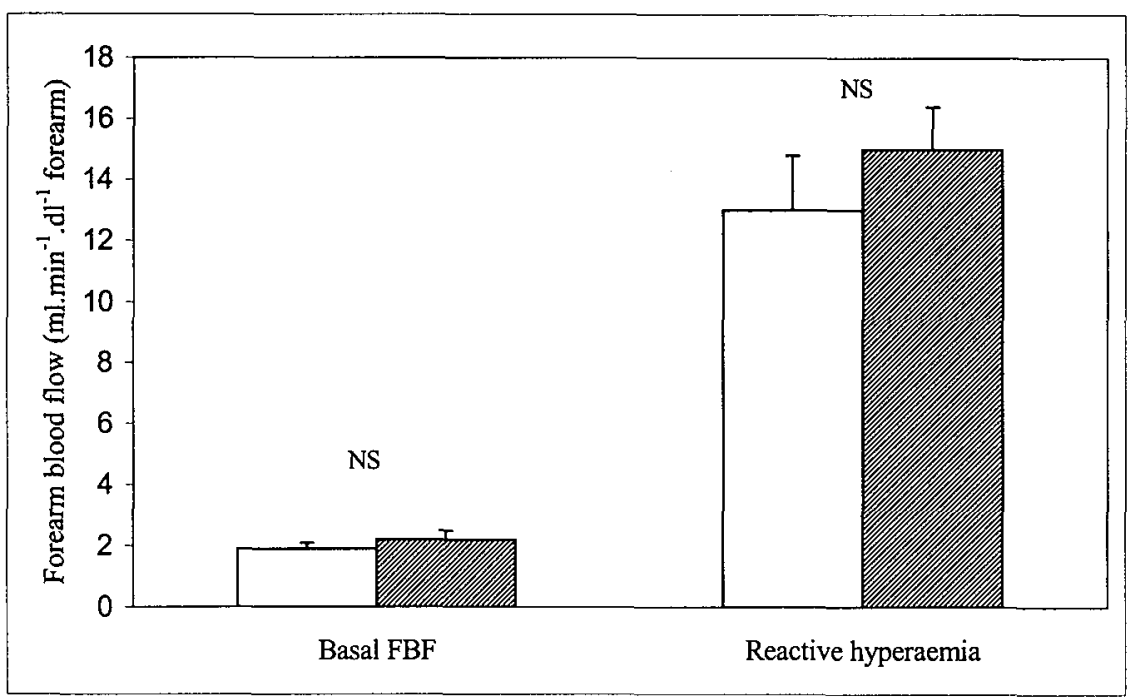

Figure 4.4 Comparison of baseline and maximal post-ischaemic forearm blood flow between migraine patients (hatched bars) and control subjects (open bars). Data are presented as mean $\pm S E M, n=10$ in each group. (NS: not statistically significant). 


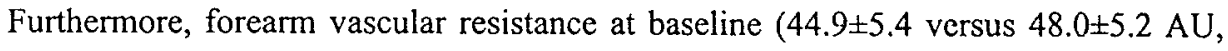
respectively) and during reactive hyperaemia (6.2 \pm 0.6 versus $7.5 \pm 0.8 \mathrm{AU}$, respectively) was comparable ( $P=0.68$ and 0.22 , respectively) in both groups. Time to reach maximal $\mathrm{FBF}$ or minimal forearm vascular resistance after reperfusion was similar $(P=0.62)$ for migraine patients and control subjects $(86 \pm 8$ and $81 \pm 7$ seconds, respectively).

\subsection{Discussion}

In vivo vascular research in migraine patients has been hampered by limited access to the cranial circulation. However, as migraine is associated with an increased incidence of Raynaud's syndrome [16] and with angina pectoris due to coronary artery vasospasm (i.e. Prinzmetal's angina) [17-19], it has been suggested to be part of a generalised vascular disorder [17]. Consequently, peripheral vascular research in migraine patients might offer an alternative approach to improve our understanding of the cranial vascular abnormalities associated with it.

The main finding of the present study is that neither for NO nor for CGRP an increased sensitivity could be demonstrated for the resistance vessels of the human forearm in migraine patients. As maximal post-ischaemic forearm blood flow was similar in both groups, there is no evidence suggesting structural differences of the resistance vessels either. In addition, flow-mediated vasodilatation did not differ between migraine patients and matched control subjects arguing against a supersensitivity to NO for conduit arteries as well. In summary, these data do not support the hypothesis of a systemic vascular supersensitivity to NO in migraine patients and do not support generalised functional vascular changes or structural changes of resistance vessels as a primary cause of the disease.

In the present study, the NO hypothesis of migraine was investigated by measuring the forearm vascular response to both the pharmacological and physiological-induced endogenous release of $\mathrm{NO}$ and to the administration of an exogenous NO-donor. The vascular response to the pharmacological release of NO was investigated by the intra-arterial infusion of serotonin. It has previously been 


\section{Chapter 4}

shown that at the dosages used in the present study, serotonin-induced vasodilatation of the human forearm is endothelium-dependent and accompanied by the release of NO $[20,21]$. The vascular sensitivity to an exogenous source of NO was investigated by the infusion of sodium nitroprusside. Like nitrates, sodium nitroprusside is known to induce an endothelium-independent vasodilatation by the release of NO upon its degradation [22]. As both endothelium-dependent and endothelium-independent NOinduced vasodilatation were comparable between migraine patients and nonmigraineurs, these findings argue against a vascular smooth muscle cell supersensitivity to NO in migraine patients.

In addition to the lack of functional differences, structural differences could not be demonstrated either. However, as venous occlusion plethysmography only measures flow changes at the level of resistance vessels, these findings do not allow us to conclude the absence of NO supersensitivity at the level of conduit arteries. Therefore, flow-mediated vasodilatation of the brachial artery was investigated. This non-invasive approach has been used frequently before to demonstrate changes in endothelial function [23-26]. It has also been shown that NO is responsible for the flow-mediated vasodilatation of human peripheral conduit arteries in vivo [27]. In the present study, neither the peak increase in brachial artery diameter nor the duration of flow-mediated vasodilatation was increased in migraine patients compared to control subjects. Consequently, at the level of the conduit artery of the human forearm our data do not support the hypothesis of supersensitivity to NO either.

What could be the explanations for the fact that the findings of the present study do not support the hypothesis of arterial supersensitivity in migraine patients as formulated by other investigators? Firstly, different vascular territories are involved. The forearm vasculature, which was investigated in the present study, might well behave differently from the cranial vasculature which is the territory of interest in migraine. Differences in receptor distribution and innervation could obviously result in a different pharmacology for both territories. Secondly, although investigated thoroughly, the earlier indications of increased arterial sensitivity to NO remain indirect [9]. Since intracranial diameter measurements cannot be obtained by current non-invasive techniques in human, vasodilatation of large intracranial arteries can only be estimated by simultaneous transcranial Doppler (TCD) and single positron 
emission computed tomography (SPECT) measurements. Based on the observation that total cerebral blood flow (measured with SPECT) is not changed during nitroglycerine-induced headache while blood velocity (measured with TCD) is decreased, rather suggests vasodilatation than providing evidence for it.

Apart from the vascular smooth muscle cell, the endothelium has also been suggested to be a likely site of the primary abnormality in migraine [28]. However, the findings of the present study indicate that endothelial function is unaffected. The preservation of the vasodilatation resulting from both serotonin and shear-stress induced endothelial release of NO, makes it very unlikely for migraine to be part of a generalised "endotheliopathy". Of course, a local, cerebral endothelial abnormality cannot be excluded. It has also been hypothesised that one of the early steps in the generation of migraine headache is the activation of endothelial $5-\mathrm{HT}_{2 \mathrm{~B}}$-receptors on meningeal blood vessels inducing the release of NO [29]. Although serotonin does induce the endothelial release of NO [21], there is no evidence indicating an increased release in migraine patients:

Although we could not demonstrate an increased sensitivity to NO in terms of an increased vascular response, the migraine-like characteristics of headache induced by nitrates do make NO a likely candidate to be involved in the pathophysiology of migraine. Consequently, one might wonder whether supersensitivity of migraine patients to NO should be interpreted in terms of an increased sensitivity of perivascular nerves to NO instead of an increased sensitivity of the blood vessel wall itself. If so, the low density of CGRP containing perivascular nerve fibres in the peripheral circulation compared to the cranial circulation [30], may explain the lack of a difference in nitroprusside-induced changes in forearm blood flow between migraine patients and control subjects in the present study. According to this vision, in migraine patients NO might result in an over-activation of the trigeminovascular system and an excessive release of CGRP involved in neurogenic inflammation [3, 7]. Firstly, this hypothesis is supported by the observation that during a genuine migraine attack plasma levels of CGRP are increased in the cranial circulation [10]. Although in healthy volunteers, nitroglycerine-induced headache was not accompanied by an increase in CGRP plasma levels [31], this does not exclude a role for trigeminal supersensitivity to NO in migraine patients. Secondly, nitrates only induce typical 
migraine headache in migraine patients after a surprisingly long latency period, suggesting that NO is involved in the initiation of a slow pathological process which eventually leads to the attack [6]. This pathological process could well be the activation of the trigeminovascular system. In addition, although nitrate-induced headache is accompanied by vasodilatation, vasodilatation as such is unlikely to be the cause of the headache. Not only because of the delay between the fast vasodilatation and the slow onset of migraine-like headache induced by nitrates, but also because other potent vasodilators including CGRP have not been reported to cause headache [32]. Finally, it should be noted that NO is involved in nociceptive processing and was recently shown to mediate vascular pain $[33,34]$. Thus, it cannot be excluded that an increased sensitivity to NO in migraine patients merely reflects a lower threshold for the noxious effects of this molecule compared to non-migraineurs.

In summary, neither peripheral resistance vessels nor conduit arteries display any differences in their vascular response to NO and the release of it between migraine patients and control subjects. Likewise, the vascular response to CGRP is not altered in migraine patients. In addition to the lack of a generalised difference in vascular function, no structural difference at the level of resistance vessels is present in migraine either. As these data do not exclude local functional or structural vascular changes, it remains to be established whether trigeminovascular supersensitivity to NO, resulting in an excessive release of CGRP, contributes to the pathogenesis of migraine.

\subsection{References}

1. Goadsby PJ. Understanding migraine pathophysiology through studying the mechanism of action of rizatriptan. Headache 1999;39(Suppl. 1):S2-S8.

2. Graham JR, Wolff HG. Mechanism of migraine headache and action of ergotamine tartrate. Arch Neurol Psych 1938;39:737-763.

3. Moskowitz MA. Basic mechanisms in vascular headache. Headache 1990;8:801-815.

4. Olesen J, Thomsen LL, Iversen H. Nitric oxide is a key molecule in migraine and other vascular headaches. Trends Pharmacol Sci 1994;15:149-153.

5. Iversen HK. Experimental headache in humans. Cephalalgia 1995;15:281-287. 
6. Olesen J, Thomsen LL, Lassen LH, Olesen 1 J. The nitric oxide hypothesis of migraine and other vascular headaches. Cephalalgia 1995;15:94-100.

7. Thomsen LL, Kruuse C, Iversen HK, Olesen J. A nitric oxide donor (nitroglycerin) triggers genuine migraine attacks. Eur J Neurol 1994;1:73-80.

8. Lassen LH, Thomsen LL, Olesen J. Histamine induces migraine via the H1-receptor. Support for the NO hypothesis of migraine. NeuroReport 1995;6:1475-1479.

9. Thomsen LL, Iversen HK, Brinck TA, Olesen J. Arterial supersensitivity to nitric oxide (nitroglycerin) in migraine sufferers. Cephalalgia 1993;13:395-399.

10. Goadsby PJ, Edvinsson L, Ekman R. Vasoactive peptide release in the extracerebral circulation of humans during migraine headache. Ann Neurol 1990;28:183-187.

11. Holzer $\mathrm{P}$, Jocic $\mathrm{M}$. Cutaneous vasodilatation induced by nitric oxide-evoked stimulation of afferent nerves in the rat. BrJ Pharmacol 1994;112:1181-1187.

12. Wei EP, Moskowitz MA, Boccalini P, Kontos HA. Calcitonin gene-related peptide mediates nitroglycerin and sodium nitroprusside-induced vasodilation in feline cerebral arterioles. Circ Res 1992;70:1313-1319.

13. Headache Classification Committee of the International Headache Society. Classification and diagnostic criteria for headache disorders, cranial neuralgias and facial pain. Cephalalgia 1988;8:1-96.

14. Benjamin N, Calver A, Collier J, Robinson B, Vallance P, Webb D. Measuring forearm blood flow and interpreting the responses to drugs and mediators. Hypertension 1995;25:918-923.

15. Lenders J, Janssen G-J, Smits P, Thien T. Role of the wrist cuff in forearm plethysmography. Clin Sci 1991;80:413-417.

16. Zahavi I, Chagnac A, Hering R, Davidovich S, Kuritzky A. Prevalence of Raynaud's phenomenon in patients with migraine. Arch Intern Med 1984;144:742-744.

17. Lafitte C, Even C, Henry-Lebras F, de Toffol B, Autret A. Migraine and angina pectoris by coronary artery spasm. Headache 1996;36:332-334.

18. Heupler FA. Syndrome of symptomatic coronary arterial spasm with nearly normal coronary arteriograms. Am J Cardiol 1980;45:873-881.

19. Miller D, Waters DD, Warnica W, Szlachcic J, Kreeft J, Theroux P. Is variant angina the coronary manifestation of a generalized vasospastic disorder? $N$ Engl $J$ Med 1981;304:763-766.

20. Cocks TM, Agnus JA. Endothelium-dependent relaxation of coronary arteries by noradrenaline and serotonin. Nature 1983;305:627-630. 
21. Brunning TA, van Zwieten PA, Blauw GJ, Chang PC. No functional involvement of 5-hydroxytryptamine $1 \mathrm{a}$ receptors in nitric-oxide dependent dilation caused by serotonin in the human forearm vascular bed. $J$ Cardiovasc Pharm 1994;24:454-461.

22. Harrison DG, Bates JN. The nitrovasodilators - new ideas about old drugs. Circulation 1993;87:1461-1467.

23. Celermajer DS, Sorensen KE, Gooch VM, Spiegelhalter DJ, Miller OI, Sullivan ID, et al. Non-invasive detection of endothelial dysfunction in children and adults at risk of atherosclerosis. Lancet 1992;340:1111-1115.

24. Hashimoto M, Akishita M, Eto M, Ishikawa M, Kozaki K, Toba K, et al. Modulation of endothelium-dependent flow-mediated dilatation of the brachial artery by sex and menstrual cycle. Circulation 1995;92:3431-3435.

25. Hayoz D, Weber R, Rutschmann B, Darioli R, Burnier M, Waeber B, et al. Postischemic blood flow response in hypercholesterolemic patients. Hypertension 1995;26:497-502.

26. Celermajer DS, Adams MR, Clarkson P, Robinson J, McCredie R, Donald A, et al. Passive smoking and impaired endothelium-dependent arterial dilatation in healthy young adults. $N$ Engl $J$ Med 1996;334:150-154.

27. Joannides R, Haefeli WE, Linder L, Richard V, Bakkali EH, Thuillez C, et al. Nitric oxide is responsible for flow-dependent dilatation of human peripheral conduit arteries in vivo. Circulation 1995;91:1314-1319.

28. Appenzeller O. Pathogenesis of migraine. Med Clin N Am 1991;75(3):763-789.

29. Schmuck K, Ullmer C, Kalkman HO, Probst A, Lübbert H. Activation of meningeal 5-HT2B receptors: an early step in the generation of migraine headache? Eur $J$ Neurosci 1996;8:959-967.

30. Zaidi M, Moonga BS, Bevis PJ, Bascal ZA, Breimer LH. The calcitonin gene peptides: biology and clinical relevance. Crit Rev Clin Lab Sci 1990;28(2):109-174.

31. Iversen HK, Jansen I, Edvinsson L, Olesen J. Calcitonin gene-related peptide levels during nitroglycerin-induced headache. Cephalalgia 1993;13(Suppl. 13):185.

32. Shekhar CY, Anand IS, Sarma R, Ferrari R, Wahi PL, Poole-Wilson PA. Effects of prolonged infusion of human alpha calcitonin gene-related peptide on hemodynamics, renal blood flow and hormone levels in congestive heart failure. Am J Cardiol 1991;67:732-736.

33. Kindgen-Milles D, Arndt JO. Nitric oxide as a chemical link in the generation of pain from veins in humans. Pain 1996;64:139-142. 


\section{Vascular responsiveness to NO and CGRP in migraine patients}

34. Meller ST, Gebhart GF. Nitric oxide (NO) and nociceptive processing in the spinal cord. Pain 1993;52:127-136. 
"Headache has a mind of its own ..."

(Charles Darwin, 1809-1882) 


\title{
Chapter 5
}

\section{Mechanism of Action of the Vasodilator response to Calcitonin Gene-Related Peptide in Human}

\begin{abstract}
Background: In vitro studies suggest that the vasodilator mechanism of action of calcitonin gene-related peptide (CGRP) involves various endothelium-dependent and endothelium-independent mechanisms. This study aimed at an in vivo analysis in humans of the contribution of nitric oxide (NO), prostaglandins, calcium-sensitive potassium channels ( $\mathrm{K}_{\text {Ca }}^{+}$-channels) and adenosine triphosphate sensitive-potassium channels ( $\mathrm{K}_{\mathrm{ATP}}^{+}$-channels) to CGRP-induced vasodilatation. Methods: CGRP (3-10-30 ng. $\mathrm{min}^{-1} \cdot \mathrm{dl}^{-1}$ forearm) was infused into the brachial artery of 40 healthy subjects. Forearm vascular responses were measured using venous occlusion plethysmography. First, dose-response curves were constructed during co-infusion of CGRP with placebo $(\mathrm{NaCl} 0.9 \%)$. After wash-out, in 5 subgroups $(\mathrm{n}=8$ each), the infusions of CGRP were repeated with: placebo (time-control experiments), $N^{G}$ monomethyl-L-arginine (L-NMMA, NO-synthase inhibitor), indomethacin (cyclo-oxygenase inhibitor), tetra-ethyl-ammonium chloride (TEA, $\mathrm{K}^{+} \mathrm{Ca}^{-}$-channel blocker) and glibenclamide

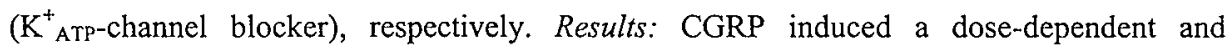
reproducible decrease $(P<0.001)$ in forearm vascular resistance. Compared to placebo, LNMMA reduced $(P<0.001)$ the decrease in forearm vascular resistance induced by CGRP ( 3 and $10 \mathrm{ng} \cdot \mathrm{min}^{-1} \cdot \mathrm{dl}^{-1}$ forearm). The absence of an inhibitory effect of L-NMMA on CGRPinduced vasodilatation at the highest dose of CGRP suggests that further mechanisms are involved. The vasodilator response to CGRP was not affected by co-infusion of either
\end{abstract}

Based on: Jan N.J.M. de Hoon ${ }^{(1)}$, Peter Pickkers ${ }^{(2)}$, Paul Smits ${ }^{(2)}$, Harry A.J. Struijker-Boudier ${ }^{(1)}$, Luc M.A.B. Van Bortel ${ }^{(1)}$. Mechanism of action of the vasodilator response to calcitonin gene-related peptide in human. (submitted).

(1)Dept. of Pharmacology and Toxicology, Cardiovascular Research Institute Maastricht, Maastricht University, Maastricht, The Netherlands and ${ }^{(2)}$ Dept. of Pharmacology and Toxicology and Division of Internal Medicine, University of Nijmegen, Nijmegen, The Netherlands. 


\section{Chapter 5}

indomethacin, TEA or glibenclamide.

Conclusions: The intra-brachial infusion of CGRP results in a dose-dependent and reproducible forearm vasodilator response. Based on the evidence presented, CGRP-induced vasodilatation is at least in part dependent on the release of NO and does not involve the release of prostaglandins or the activation of $\mathrm{K}_{\mathrm{Ca}}^{+}$or $\mathrm{K}_{\mathrm{ATP}}^{+}$-channels.

\subsection{Introduction}

Calcitonin gene-related peptide (CGRP) is a 37-amino acid neuropeptide which was first identified in 1981 by Rosenfeld and co-workers [1]. Its extensive distribution in the cardiovascular system suggests a potential role for CGRP in diverse physiological and pathophysiological processes, including: hypertension, congestive heart failure, myocardial ischaemia, Raynaud's syndrome, migraine and septic shock [2]. Although it is well established that CGRP exerts a potent vasodilating activity, its mechanism of action and contribution to local control of tissue perfusion remain a matter of debate [3].

CGRP is a neurotransmitter which is synthesised in primary sensory neurones of the dorsal root ganglia and trigeminal ganglion [4]. These neurones provide a dense perivascular network of CGRP-containing sensory nerves throughout the cardiovascular system. Activation of these nerves induces a nonadrenergicnoncholinergic (NANC) vasodilatation by the release of CGRP in a variety of vascular beds of different species [5]. CGRP exerts its vasodilating effects by interaction with CGRP-receptors which are present on both the vascular endothelium and vascular smooth muscle cells suggesting that its vascular actions involve endotheliumdependent as well as endothelium-independent mechanisms [2].

Depending on the species and tissue under investigation, at least three vasodilator mechanisms of action of CGRP have been reported. An endotheliumindependent mechanism involving vascular smooth muscle cell adenylate cyclase activation [6-8]; an endothelium-dependent mechanism accompanied by the release of nitric oxide (NO) $[9,10]$ and the activation of adenosine triphosphate-sensitive potassium channels $\left(\mathrm{K}^{+}{ }_{\text {ATP-channels }}\right.$ [11-13]. As both animal and human data on the 
vasodilator mechanism of action of CGRP mainly comprise of in vitro research on isolated blood vessels, conflicting results might be related to data obtained under high, unphysiological concentrations of CGRP. In addition, as the mechanisms involved in the in vivo and in vitro vascular responses to CGRP are not necessarily the same, further research into the vasodilator mechanism of action of CGRP in vivo is warranted.

The present study is the first to investigate in vivo in human the vasodilator mechanism of action of (patho)physiological concentrations of CGRP. To this end, the perfused forearm technique was used and the contribution of endothelial mediators (NO and prostaglandins) and $\mathrm{K}^{+}$-channels to CGRP-induced vasodilatation was investigated.

\subsection{Subjects and methods}

\section{Subjects}

After approval from the local ethics committee, 40 non-smoking subjects gave written informed consent to participate in this study. Based on a medical history and clinical examination all subjects were in good health. Their demographic data are presented in Table 5.1. Before the start of each experiment, subjects were asked not to use any drug for at least 3 days and to abstain from caffeine or alcohol-containing beverages for at least 12 hours.

\section{Study design}

All experiments were performed in a single-blind fashion in a quiet, temperaturecontrolled room $\left(23^{\circ}\right.$ to $\left.24^{\circ} \mathrm{C}\right)$. Each experiment lasted $4-5$ hours. After local anesthesia (lidocaine $2 \%$, Astra Pharmaceuticals) the brachial artery of the nondominant arm was cannulated with a 20-gauge catheter (Angiocath, Deseret Medical, Becton Dickinson) for intra-arterial drug infusion (automatic syringe infusion pump, type STC-521, Terumo) and blood pressure monitoring (monitor type 78353B, Hewlett Packard GmbH). All blood pressures mentioned were acquired from these intra-arterial measurements. 


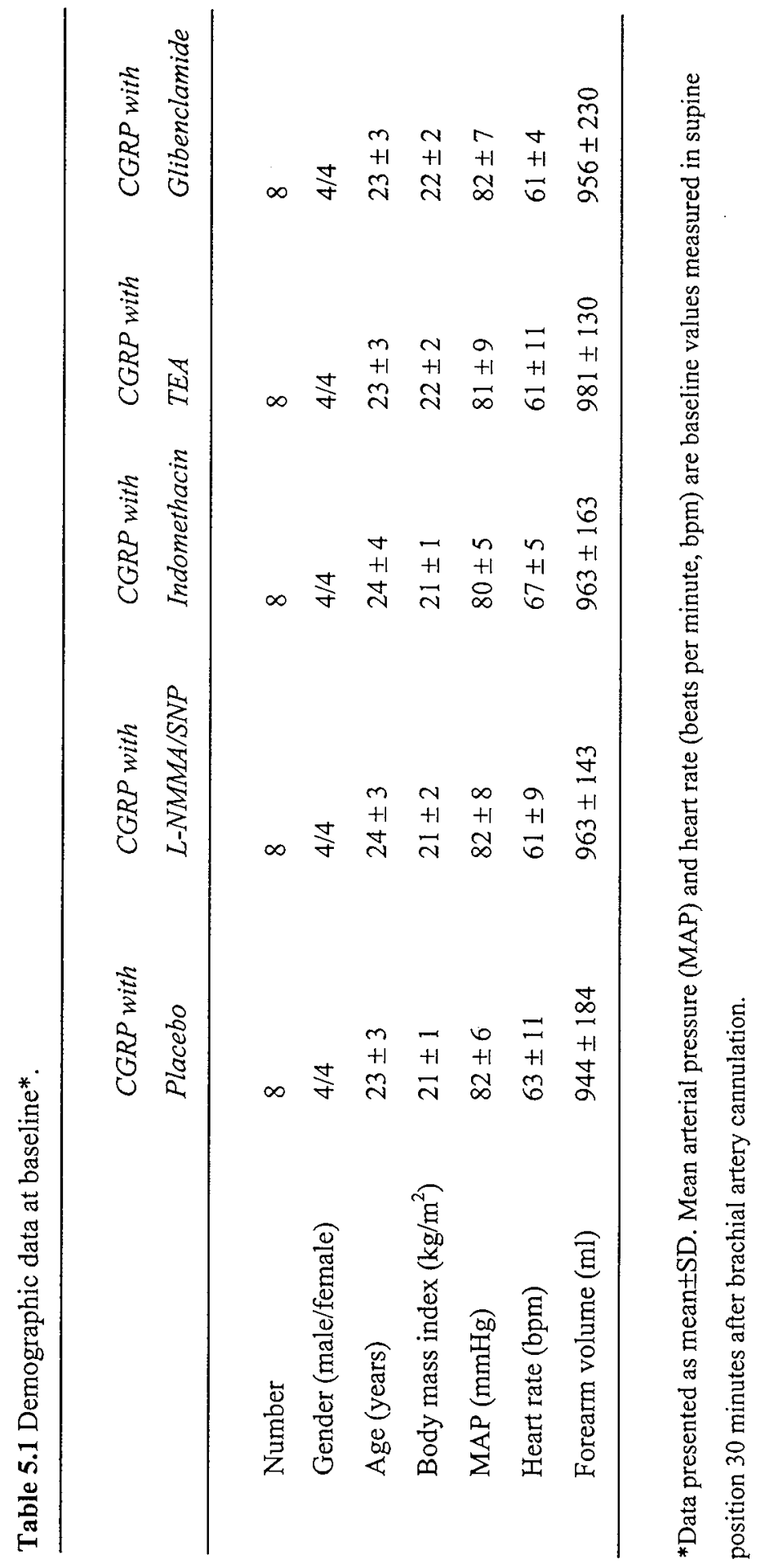


Forearm arterial blood flow (FBF) was measured by ECG-triggered venous occlusion plethysmography using mercury-in-Silastic strain gauges (Hokanson EC-4 strain gauge Plethysmograph, D.E.Hokanson Inc). FBF was measured 3 to 4 times per minute and recorded simultaneously at both arms. To ensure that recordings referred predominantly to the forearm skeletal muscle perfusion, at least one minute before FBF measurements were started the hand circulation was occluded by wrist cuffs [14]. Upper arm cuffs were intermittently and simultaneously inflated to a pressure of 45 mmHg using a rapid cuff inflator (Hokanson E-20). Heart rate, systolic and diastolic blood pressure were registered simultaneously with every FBF measurement. Mean arterial pressure (MAP) was calculated as the electronically integrated area under the brachial artery pulse-wave curve and averaged per FBF measurement.

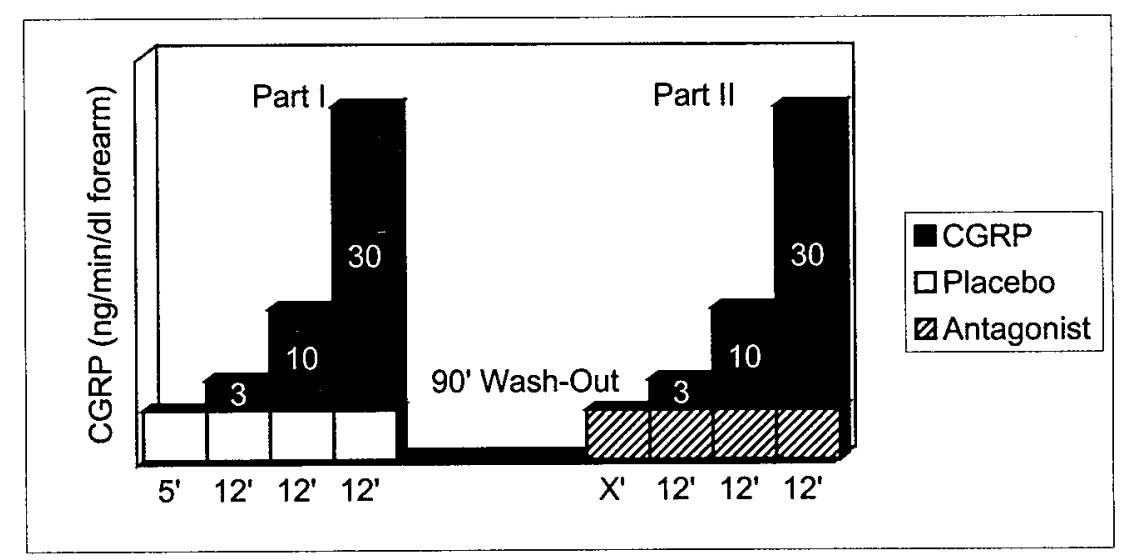

Figure 5.1 Flow chart.

After instrumentation of both arms an equilibration period of at least 30 minutes was allowed. After equilibration, each experiment started with a 5-minute period of baseline measurements (baseline 1) during the infusion of placebo ( $\mathrm{NaCl} 0.9 \%$ ) (Fig. 5.1). Thereafter, in all experiments the first series of three increasing dosages of CGRP (3, 10 and $30 \mathrm{ng} \cdot \mathrm{min}^{-1} \cdot \mathrm{dl}^{-1}$ forearm) was infused together with placebo. After a washout period of 90 minutes baseline measurements were repeated (baseline 2) for 5 minutes. Subsequently, the second series of increasing dosages of CGRP was administered either during co-infusion of placebo (subgroup $1, n=8$ ) or during co- 


\section{Chapter 5}

infusion of a specific inhibitor (subgroups 2 to $5, \mathrm{n}=8$ each). Before starting the second series of CGRP infusions the vasoactive effects of the inhibitor were evaluated. Therefore, measurements were taken just before (baseline 2) and 5 minutes after the start of the infusion of the inhibitor (15 minutes in case of indomethacin). In order to reach steady-state each dose of CGRP was infused for 12 minutes (pilot data not shown). The rate of all intra-arterial infusions was kept constant at $100 \mu 1 . \mathrm{min}^{-1} . \mathrm{dl}^{-1}$ forearm volume throughout the experiments and the dosages were normalised to forearm volume measured by water displacement.

\section{Time-control experiments}

In subgroup 1, both the first and the second series of CGRP infusions were co-infused with placebo. An antecubital vein of the infused arm was cannulated for the assessment of venous plasma levels of CGRP. Blood samples $(8 \mathrm{ml})$ were drawn at the end of baseline 1 and at the end of each dose of CGRP during the first series of infusions.

\section{The role of nitric oxide in CGRP-induced vasodilatation}

In subgroup 2, during the second series of CGRP infusion the NO-synthase inhibitor $\mathrm{N}^{\mathrm{G}}$-monomethyl-L-arginine (L-NMMA, $0.2 \mathrm{mg} \cdot \mathrm{min}^{-1} \cdot \mathrm{dl}^{-1}$ forearm) was used to block the de novo synthesis of NO $[15,16]$. The infusion of L-NMMA was accompanied by the continuous infusion of a low dose of the NO-donor sodium-nitroprusside (SNP, $0.02 \mu \mathrm{g} \cdot \mathrm{min}^{-1} \cdot \mathrm{dl}{ }^{-1}$ forearm) to "clamp" the basal NO-mediated vascular tone [17].

During these experiments, an antecubital vein of the infused arm was cannulated for assessment of the regional production of cyclic guanosine monophosphate (cGMP) and cyclic adenosine monophosphate (cAMP). Therefore, both venous and arterial blood samples $(4 \mathrm{ml})$ were drawn at the end of baseline 1 measurements and after the highest dose of CGRP.

\section{The role of prostaglandins in CGRP-induced vasodilatation}

In subgroup 3 indomethacin ( $5 \mu \mathrm{g} \cdot \mathrm{min}^{-1} \cdot \mathrm{dl}^{-1}$ forearm) was used as cyclo-oxygenase inhibitor to block the de novo synthesis of prostaglandins. To check for the inhibition of cyclo-oxygenase activity by indomethacin the ex vivo platelet thromboxane $\mathrm{B}_{2}$ 
$\left(\mathrm{TxB}_{2}\right)$ production was assessed. Therefore, an antecubital vein of the infused arm was cannulated and venous blood samples $(5 \mathrm{ml})$ were drawn just before and 15 minutes after the start of the indomethacin infusion (before starting the second series of CGRP infusions).

\section{The role of potassium channels in CGRP-induced vasodilatation}

Finally; it was investigated whether CGRP-induced vasodilatation is dependent on the activation of calcium-sensitive $\mathrm{K}^{+}$-channels $\left(\mathrm{K}_{\mathrm{Ca}}^{+}\right.$-channels, subgroup 4) and/or $\mathrm{K}^{+}{ }_{\mathrm{ATP}}-$ channels (subgroup 5). Therefore, tetra-ethyl-ammonium chloride (TEA, 0.1 mg. $\min ^{-1} \cdot \mathrm{dl}^{-1}$ forearm) was used as non-selective $\mathrm{K}^{+}{ }_{\mathrm{Ca}}$-channel blocker [18] and glibenclamide ( $2 \mu \mathrm{g} \cdot \mathrm{min}^{-1} \cdot \mathrm{dl}^{-1}$ forearm) as $\mathrm{K}_{\mathrm{ATP}}^{+}$-channel blocker [19], respectively.

\section{Laboratory assessments}

For the assessment of venous plasma concentrations of CGRP, after collection blood was immediately transferred into ice-cooled plastic tubes containing heparin $(50 \mathrm{IU} / \mathrm{ml}$ blood) and aprotinin ( $500 \mathrm{KIU} / \mathrm{ml}$ blood). CGRP was measured in duplicate using a radioimmunoassay (RIA, Peninsula Laboratories Europe, LTD.). The detection limit was $1 \mathrm{pg} / \mathrm{ml}$; intra- and inter-assay coefficients of variation $(\mathrm{n}=10)$ were $4.9 \%$ and $9.6 \%$, respectively.

For the assessment of plasma concentrations of cGMP and cAMP, after collection blood was immediately transferred into pre-chilled EDTA-tubes. Cyclic GMP and cAMP levels were each measured in duplicate using commercially available RIA kits (IBL, Hamburg). For both cGMP and cAMP the detection limit was 0.05 $\mathrm{pmol} / \mathrm{ml}$. For cGMP intra- and inter-assay coefficients of variation $(\mathrm{n}=10)$ were $4.3 \%$ and $9.5 \%$, respectively; for cAMP, $4.3 \%$ and $8.6 \%$, respectively. The local forearm spillovers of cGMP and cAMP were calculated as the product of the arteriovenous difference in plasma concentration of cGMP or cAMP and the FBF and expressed as pmol.min ${ }^{-1} . \mathrm{dl}^{-1}$ forearm [20].

For the assessment of serum $\mathrm{TxB}_{2}$ concentrations immediately after collection blood was transferred into glass tubes without additives and incubated at $37^{\circ} \mathrm{C}$ for 1 hour to allow blood clotting to take place. $\mathrm{TxB}_{2}$ concentrations were determined in duplicate by a previously described RIA using ${ }^{3} \mathrm{H}-\mathrm{TxB}_{2}$ as tracer [21]. 
Chapter 5

Drugs

Human-CGRP (Clinalfa, $50 \mu \mathrm{g}$ per vial) was dissolved in $\mathrm{NaCl} 0.9 \%$ to produce a stock solution of $500 \mathrm{ng} / \mathrm{ml}$ which was used no longer than 24 hours after preparation and stored at $4^{\circ} \mathrm{C}$. Before each experiment, CGRP solutions $(30,100$ and $300 \mathrm{ng} / \mathrm{ml})$ were freshly prepared. L-NMMA acetate (Clinalfa, $30 \mathrm{mg}$ per vial), indomethacin (Indocid PdA ${ }^{\circledR}$, Merck Sharp and Dohme, $1 \mathrm{mg}$ per ampoule) and glibenclamide (Aventis Pharma, $2 \mathrm{mg}$ per ampoule) were dissolved with $\mathrm{NaCl} 0.9 \%$ just before use. SNP (Nipride ${ }^{\circledR}$, Roche, $50 \mathrm{mg}$ per ampoule), which was dissolved with glucose $5 \%$ and further diluted with $\mathrm{NaCl} 0.9 \%$, was protected from light. TEA $(1 \mathrm{mg} / \mathrm{ml})$ was provided by the hospital pharmacy as a sterile solution.

\section{Data analysis}

Forearm vascular resistance (FVR) was calculated as MAP divided by simultaneously recorded FBF and expressed in arbitrary units (AU). Drug-induced changes in FVR were expressed as percentage change in FVR compared to the preceding FVR during placebo (i.e. baseline) or during inhibitor infusion without CGRP. Data are the mean of the measurements obtained during the last 2 minutes of each infusion period (i.e. at steady-state).

The vascular effects of CGRP during the first series of infusions were analysed by comparing the hemodynamic variables (FBF, FVR, MAP and heart rate) at baseline and at the three dose levels by ANOVA with repeated measures. Dose-response curves of the first and the second series of CGRP infusions were compared with a two-way, repeated measures ANOVA for paired data. If ANOVA showed a significant difference $(P<0.05)$, post hoc paired Student's $t$-tests (for pooled data) or Wilcoxon's matched-pairs signed-rank tests (for subgroup analyses) were performed to determine dose dependency. All data are expressed as mean \pm SEM unless specified otherwise; $P<0.05$ was considered statistically significant.

\subsection{Results}

Based on their demographic data (Table 5.1) the 5 subgroups were comparable. 


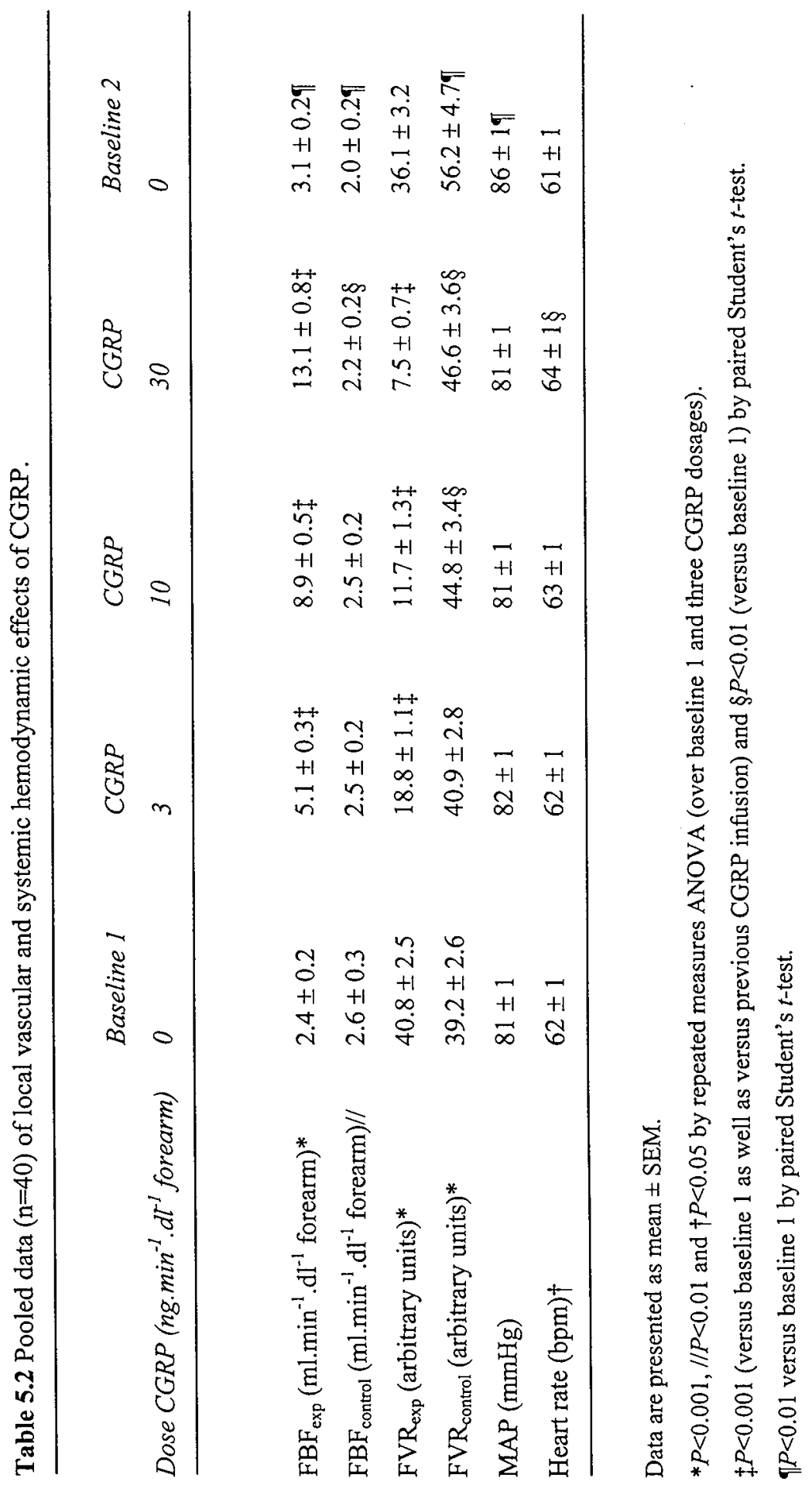




\section{Chapter 5}

\section{Vasodilator response to CGRP}

The first dose-response curves of all experiments $(n=40)$ were pooled to evaluate the vascular response to sequential infusions of CGRP with placebo (Table 5.2). CGRP induced a dose-dependent increase $(P<0.001)$ in FBF of the experimental arm $\left(\mathrm{FBF}_{\text {exp }}\right)$. This increase was for all dosages significant $(P<0.001)$ versus baseline as well as between dosages. FBF of the control arm $\left(\mathrm{FBF}_{\text {control }}\right)$ decreased $(P=0.007)$ slightly while MAP did not change throughout the experiments. Although, after washout $\mathrm{FBF}_{\text {exp }}$ had not completely returned to pre-infusion levels $(P=0.003)$, baseline 1 and baseline 2 did not differ in terms of forearm vascular resistance $\left(\mathrm{FVR}_{\mathrm{cxp}}\right)$.

During the infusion of the highest dose of CGRP, a small increase $(P=0.01)$ in heart rate was observed (Table 5.2). A comparable minor increase in heart rate was seen during the infusion of the highest dose of CGRP for each of the subgroups described below, suggesting a systemic vasodilator effect. However, as neither MAP nor $\mathrm{FVR}_{\text {control }}$ decreased systematically, alterations in heart rate did not contribute significantly to changes in FVR exp.

\section{Time-control experiments (Fig. 5.2, top)}

The first dose-response curve of CGRP during co-infusion of placebo resulted in a percentage fall in $F V R_{\text {exp }}(51 \pm 4,66 \pm 5$ and $75 \pm 5 \%$, respectively) comparable $(P=0.9)$ with that during the second dose-response curve $(43 \pm 5,68 \pm 4$ and $80 \pm 3 \%$, respectively) obtained after a wash-out period of 90 minutes. Venous plasma levels of CGRP increased from $1.2 \pm 0.1 \mathrm{pmol} / \mathrm{l}$ at baseline to $21.2 \pm 2.5,37.0 \pm 4.5$ and $78.9 \pm 15.6$ $\mathrm{pmol} / \mathrm{l}$, respectively, at the end of each dose during the first series of CGRP infusions.

Figure 5.2 (opposite page) CGRP-induced decrease in forearm vascular resistance during coinfusion of placebo ( $\mathbf{\square}$, solid line). Top, repeated co-infusion of CGRP and placebo ( $\square$, dashed line) after a 90 minutes wash-out period. Middle, co-infusion of CGRP and LNMMA/sodium nitroprusside ( $\square$, dashed line). Bottom, co-infusion of CGRP and indomethacin ( $\square$, dashed line). $P$-values refer to statistical difference by repeated measures ANOVA between first and second dose-response curve. NS: not statistically significant. ${ }^{*} P<0.05$ by Wilcoxon's matched-pairs signed-rank test between individual dosages. Data presented as mean $\pm \mathrm{SEM}, \mathrm{n}=8$ in each subgroup. 

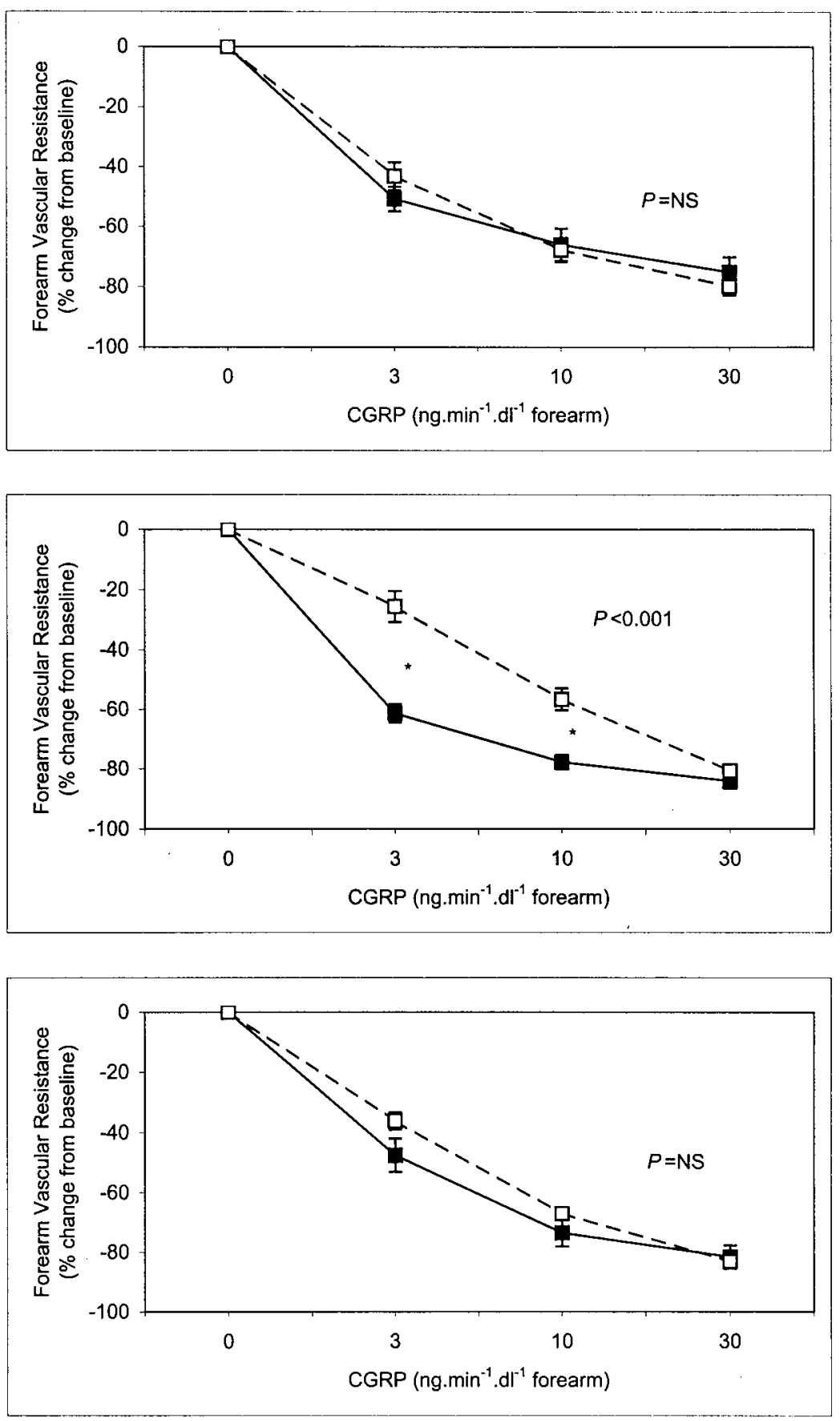


\section{Chapter 5}

The role of nitric oxide in CGRP-induced vasodilatation (Fig. 5.2, middle)

The percentage fall in $\mathrm{FVR}_{\text {exp }}$ induced by CGRP during co-infusion of placebo $(61 \pm 3$, $78 \pm 2$ and $84 \pm 3 \%$, respectively) was larger $(P<0.001)$ than during co-infusion of $\mathrm{L}$ NMMA and SNP ( $26 \pm 5,57 \pm 4$ and $81 \pm 2 \%$, respectively), due to a decreased vascular response both during the infusion of 3 and $10 \mathrm{ng} \cdot \mathrm{min}^{-1} \cdot \mathrm{dl}^{-1}$ forearm of CGRP $(P=0.012$ and 0.017 , respectively) with L-NMMA and SNP. Baseline FVR exp $(30 \pm 4 \mathrm{AU})$ did not change during co-infusion of L-NMMA and SNP without CGRP ( $35 \pm 4 \mathrm{AU})$.

Cyclic GMP spillover at baseline $\left(4.6 \pm 0.5 \mathrm{pmol} \cdot \mathrm{min}^{-1} . \mathrm{dl}^{-1}\right.$ forearm) tended to increase $(P=0.07)$ at the end of the infusion of the highest dose of CGRP

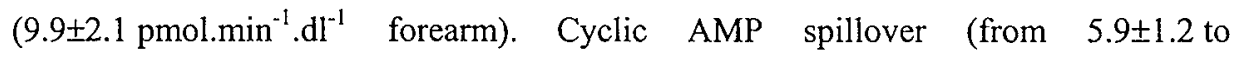
$7.6 \pm 5.0$ pmol. $\mathrm{min}^{-1} \cdot \mathrm{dl}^{-1}$ forearm) did not change $(P=0.67)$.

The role of prostaglandins in CGRP-induced vasodilatation (Fig. 5.2, bottom) The percentage fall in FVR exp induced by CGRP during co-infusion of placebo (48 \pm 6 , $74 \pm 5$ and $82 \pm 4 \%$, respectively) did not differ $(P=0.12)$ from that during co-infusion of indomethacin $\left(36 \pm 3,67 \pm 2\right.$ and $83 \pm 2 \%$, respectively). Baseline $F R_{\exp }(26 \pm 3$ AU) slightly increased $(P=0.012)$ during the infusion of indomethacin without CGRP ( $36 \pm 4$ $\mathrm{AU})$. Since, FVR control $(46 \pm 7$ versus $45 \pm 5 \mathrm{AU}$ ) did not change this suggests a vasoconstrictor effect of indomethacin in the infused arm.

The ex vivo production of $\mathrm{TxB}_{2}$ decreased $(P=0.012)$ from $235.0 \pm 25.7 \mathrm{ng} / \mathrm{ml}$ before to $3.4 \pm 0.9 \mathrm{ng} / \mathrm{ml} 15$ minutes after the start of the infusion of indomethacin.

\section{The role of $K^{+}$-channels in CGRP-induced vasodilatation}

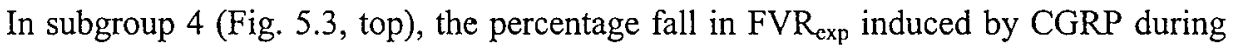
co-infusion of placebo (49 $46,66 \pm 7$ and $76 \pm 6 \%$, respectively) was comparable $(P=0.71)$ to that during co-infusion of TEA $(37 \pm 2,64 \pm 3$ and $82 \pm 2 \%$, respectively). In

subgroup 5 (Fig. 5.3, bottom), the percentage fall in FVR exp induced by CGRP during co-infusion of placebo $(49 \pm 5,64 \pm 7$ and $80 \pm 3 \%$, respectively) was comparable $(P=0.39)$ to that during co-infusion of glibenclamide $(36 \pm 3,61 \pm 3$ and $81 \pm 2 \%$, respectively). Compared to the preceding baseline, $F V R_{\exp }$ slightly increased (from $32 \pm 3$ to $38 \pm 3 \mathrm{AU}, P=0.025$ ) during the infusion of TEA without CGRP while it was 
unaffected by glibenclamide ( $41 \pm 7$ versus $41 \pm 5 \mathrm{AU})$.
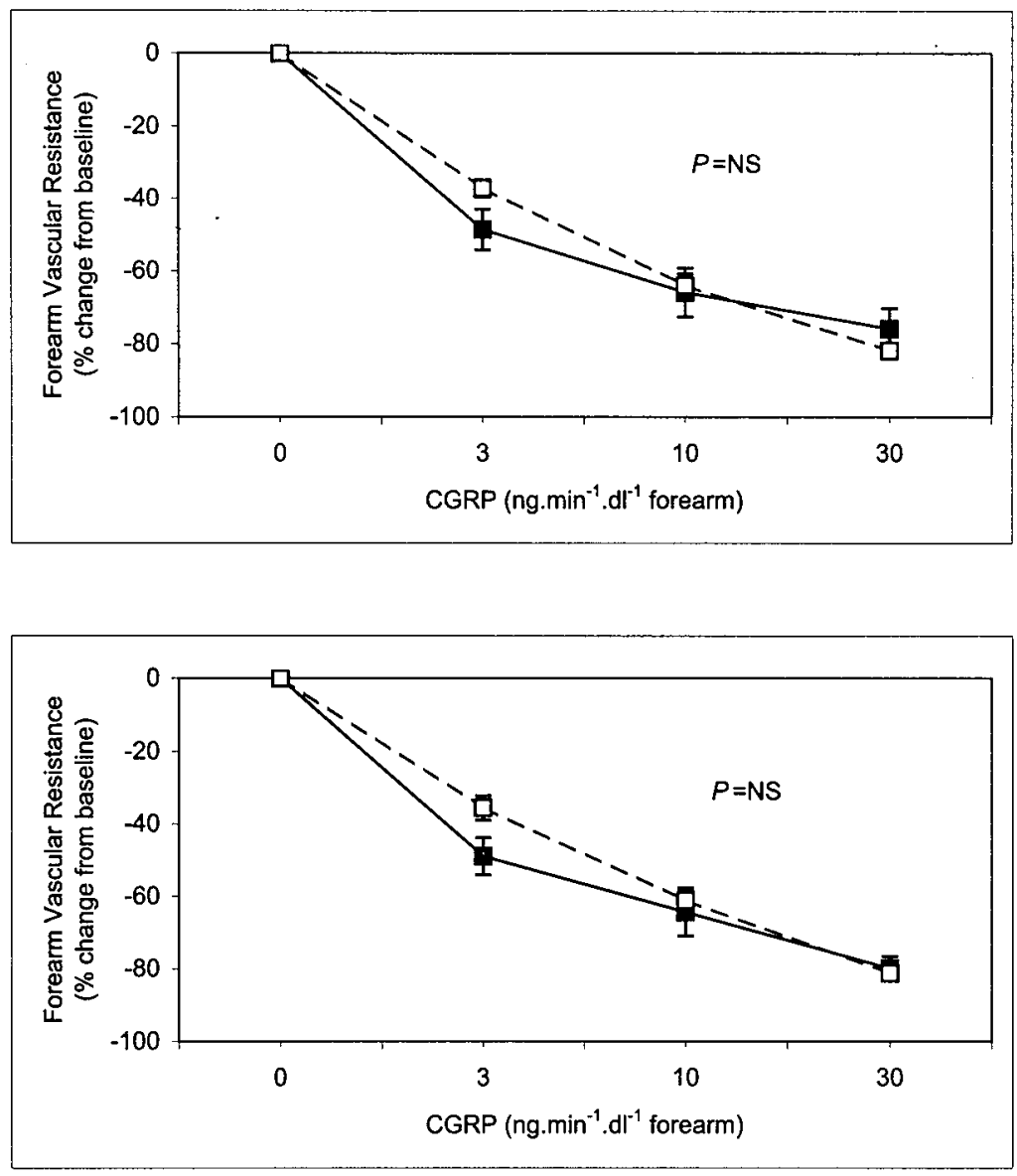

Figure 5.3 CGRP-induced decrease in forearm vascular resistance during co-infusion of placebo ( $\square$, solid line). Top, co-infusion of CGRP with tetra-ethyl-ammonium chloride ( $\square$, dashed line). Bottom, co-infusion of CGRP with glibenclamide ( $\square$, dashed line). NS: not statistically significant by repeated measures ANOVA. Data presented as mean \pm SEM, $n=8$ in each subgroup. 
Chapter 5

\subsection{Discussion}

The present study aimed to investigate in vivo in human the vasodilator mechanism of action of (patho)physiological concentrations of CGRP. Plasma levels of CGRP have been reported to range from $1 \mathrm{pmol} / 1$ in healthy subjects [2] to $110 \mathrm{pmol} / 1$ under pathological conditions (e.g. heart failure, migraine and cluster headache) $[22,23]$. During our experiments, even at the highest dose of CGRP, venous plasma levels remained within this (patho)physiological range. Consequently, the conclusions drawn from our experiments can be regarded as clinically relevant.

The CGRP-induced dose-dependent increase in forearm blood flow observed in the present study is comparable to that previously reported by other investigators $[9$, 24]. Tachyphylaxis and period-effects as possible mechanisms responsible for decreased vasodilatation upon repeated exposure to CGRP, were excluded by timecontrol experiments. These experiments clearly demonstrate that repeated infusions of CGRP with a 90-minute interval result in comparable changes in forearm vascular resistance.

\section{The role of nitric oxide in CGRP-induced vasodilatation}

The results of the present study allow us to conclude that the vasodilator effect of CGRP on the resistance arteries of the human forearm is partly mediated by the release of NO. This conclusion is based on the observation that L-NMMA, a competitive inhibitor of NO-synthase, significantly reduces the vasodilator response to CGRP. To correct for the L-NMMA-induced decrease in forearm blood flow, resulting from inhibition of the basal endothelial release of NO [15], nitroprusside was co-infused with it. Addition of this exogenous NO-donor has previously been shown to compensate for the loss of the baseline release of NO from the endothelium and to provide a useful approach for "clamping" of the basal vascular tone both in vitro and in vivo $[17,25]$. Involvement of the NO-pathway in CGRP-induced vasodilatation is further supported by our observation that cGMP spillover was doubled during the infusion of CGRP. Indeed, if CGRP exerts its vasodilator activity by the release of $\mathrm{NO}$, an increased production of its second messenger cGMP, might be expected [16]. Although the increase in CGMP spillover did not reach statistical significance, it 
should be noted that cGMP is produced at the intracellular level. Consequently, the increase in the extracellular concentration of cGMP merely reflects intracellular guanylate cyclase activation and is much smaller than the increase in forearm blood flow which is accompanied with it.

It could be argued that the CGRP-induced release of NO might have been triggered non-specifically by an increase in flow, and thus in shear stress, rather than by stimulation of endothelial CGRP-receptors. If so, L-NMMA would be expected to reduce CGRP-induced vasodilatation most prominently at the highest flow resulting in the highest shear stress. In the present study, however, during the highest flow CGRPinduced vasodilatation was not inhibited by L-NMMA. In addition, in previous studies using the same technique $[17,26]$, the infusion of L-NMMA inhibited the vasodilator effects of acetylcholine (an endothelium-dependent vasodilator) but not those of nitroprusside or verapamil (endothelium-independent vasodilators), despite achieving blood flow responses comparable to those achieved with CGRP. Both observations argue against a non-specific shear stress-induced release of NO during drug-induced changes in forearm blood flow.

Accepting the contribution of NO to CGRP-induced vasodilatation, the issue remains from which tissue NO originates. L-NMMA acts as a non-selective NOsynthase inhibitor inhibiting different isoforms of the enzyme in different tissues [16]. Although it is tempting to speculate that NO release results from the endothelial activation of NO-synthase, neuronal as well as other sources of NO cannot be excluded. Likewise, it remains to be resolved which subtype of CGRP-receptor is responsible for the CGRP-induced release of NO. As currently neither for the different CGRP-receptors nor for the different isoforms of NO-synthase selective antagonists are available for human use, it is not possible at this time to determine which subtype of each is involved.

\section{The role of prostaglandins in CGRP-induced vasodilatation}

In the present study, CGRP-induced vasodilatation was not affected by the co-infusion of indomethacin which is a reversible cyclo-oxygenase inhibitor interfering with prostaglandin synthesis. Since thromboxane $\mathrm{B}_{2}$ formation, a marker for cyclooxygenase activity [21], was completely suppressed after the infusion of 


\section{Chapter 5}

indomethacin, the absence of an inhibitory effect of indomethacin on CGRP-induced vasodilatation cannot be attributed to ineffective dosing. Consequently, prostaglandins are unlikely to be involved in CGRP-induced vasodilatation.

\section{The role of potassium channels in CGRP-induced vasodilatation}

In the present study, neither TEA nor glibenclamide affected CGRP-induced vasodilatation, indicating that TEA and glibenclamide-sensitive $\mathrm{K}^{+}$-channels are probably not involved in CGRP-induced vasodilatation unless $\mathrm{K}^{+}$-channel blockade was incomplete.

The role of $\mathrm{K}_{\mathrm{Ca}^{2}}$-channels in CGRP-induced vasodilatation was investigated using TEA. Although charybdotoxin and iberiotoxin are more selective $\mathrm{K}_{\mathrm{Ca}}^{+}$-channel blockers, they are far too toxic for human use. TEA antagonises different types of $\mathrm{K}^{+}$channels with varying degrees of potency [18], but it has been shown to selectively block single $\mathrm{K}_{\mathrm{Ca}}^{+}$-channels in arterial smooth muscle cells in vitro at concentrations comparable to those used in the present study [27]. In addition, TEA has previously been shown to inhibit the opening of $\mathrm{K}^{+}$-channels by hydrochlorothiazide in the forearm model at the same dose as the one used in the present study [28]. To investigate the role of $\mathrm{K}_{\mathrm{ATP}}^{+}$-channels in CGRP-induced vasodilatation glibenclamide was used. This drug has convincingly been shown to interact with vascular smooth muscle cell $\mathrm{K}_{\mathrm{ATP}}^{+}$-channel activity in the forearm model at a dose three times lower than the one used in the present study [19]. Therefore, the absence of an inhibitory effect of TEA and glibenclamide on CGRP-induced vasodilatation is unlikely to be due to ineffective dosing.

\section{Limitations, unanswered questions and future perspectives}

Previous in vitro studies on the mode of vasodilator action of CGRP gave conflicting results $[6-8,10-13,29,30]$. As well as discrepancies due to inter-species and intertissue differences, differences in experimental conditions may be responsible for these conflicting results. As far as the forearm model is concerned, it could be argued that the administration of CGRP into the brachial artery lumen results in an exposure which is higher for the endothelium than for the underlying vascular smooth muscle cell. This approach might result in an overestimation of the contribution of endothelial 
mechanisms compared to the physiological situation in which CGRP is released from perivascular nerves. Consequently, it cannot be excluded that in case of a perivascular release of CGRP non-endothelial mechanisms of action become more important. Therefore, our data do not entirely exclude a role for $\mathrm{K}^{+}$-channel activation by CGRP on the level of the vascular smooth muscle cell.

Although our data convincingly show that NO is involved in CGRP-induced vasodilatation of the human forearm, several questions remain. Firstly, as NO-synthase inhibition only partly attenuated CGRP-induced vasodilatation, which alternative mechanism might be involved? One of the mechanisms which has been suggested repeatedly is the activation of adenylate cyclase by the interaction of CGRP with Gprotein-coupled CGRP-receptors on the vascular smooth muscle cell $[6,7,31]$. However, as selective adenylate cyclase inhibitors are not available for human use this mechanism cannot be investigated using the forearm model. As an alternative approach the cAMP spillover was assessed as an indirect measure of local intracellular adenylate cyclase activation. Possibly due to a lack of power, the limited increase in CAMP spillover did not allow us to conclude that adenylate cyclase activation took place during the infusion of CGRP. Likewise for CGMP, it should be noted that the measurement of extracellular cAMP might not be sufficiently sensitive to assess changes at the intracellular level.

Secondly, why did NO-synthase inhibition not affect CGRP-induced vasodilatation at higher dosages of CGRP, despite the apparent involvement of NO? One possible explanation is that L-NMMA did not fully inhibit the de novo generation of NO. Although this cannot be completely excluded, it is very unlikely in view of the high dose of L-NMMA which was used and which has been reported frequently to inhibit NO formation $[15,32]$. Alternatively, NO may be bound to a carrier protein and stored in both the endothelium and the vascular smooth muscle cell [33]. The release of NO from intra-cellular stores would obviously not be inhibited by the administration of a NO-synthase blocker. To clarify the contribution of NO stores to NANC-vasodilatation in general and to CGRP-induced vasodilatation in particular, the inhibitory effect of NO-scavengers on CGRP-induced vasodilatation should be further investigated. 


\section{Chapter 5}

In summary, the results of the present study demonstrate for the first time in vivo in human that the vasodilator response to (patho)physiological concentrations of CGRP is at least in part dependent on the local release of NO. In addition, this vasodilator response appears not to be related to the release of prostaglandins or the activation of $\mathrm{K}_{\mathrm{Ca}}^{+}$-channels and $\mathrm{K}_{\text {ATP }}^{+}$-channels. Obviously, a better understanding of the vasodilator mechanism of action of CGRP may have important implications for those pathophysiological conditions where increased levels of CGRP are involved. Under these conditions not only CGRP-antagonists but also selective NO-synthase inhibitors might offer an alternative pharmacological approach for future research and drug development.

\section{Acknowledgements:}

We are greatly indebted to Prof. Dr. J. Arnout (Centre for Thrombosis and Vascular Research, University of Leuven, Belgium) for performing $\mathrm{TxB}_{2}$ assessments; to Dr. Paul Schiffers (Dept. of Pharmacology and Toxicology, Maastricht University) for performing CGRP, cGMP and cAMP assessments and to Aventis Pharma for supplying glibenclamide.

\subsection{References}

1. Rosenfeld MG, Amara SG, Roos BA. Altered expression of the calcitonin gene associated with RNA polymorphism. Nature 1981;290:63-65.

2. Bell D, McDermott BJ. Calcitonin gene-related peptide in the cardiovascular system: characterization of receptor populations and their (patho)physiological significance. Pharmacol Rev 1996;48(2):253-288.

3. Zaidi M, Moonga BS, Bevis PJ, Bascal ZA, Breimer LH. The calcitonin gene peptides: biology and clinical relevance. Crit Rev Clin Lab Sci 1990;28(2):109-174.

4. Gibson SJ, Polak JM, Glaid A, Hamid QA, Kar S, Jones PM, et al. Calcitonin generelated peptide messenger RNA is expressed in sensory neurons of the dorsal root ganglia and also in spinal motorneurons in man and in rat. Neurosci Lett 1988;91:283288.

5. Lundberg JM. Pharmacology of cotransmission in the autonomic nervous system: integrative aspects on amines, neuropeptides, adenosine triphosphate, amino acids and 
nitric oxide. Pharmacol Rev 1996;48(1):113-178.

6. Edvinsson L, Fredholm B, Hamel E, Jansen I, Verrechia C. Perivascular peptides relax cerebral arteries concomitant with stimulation of cyclic adenosine monophosphate accumulation or release of an endothelium-derived relaxing factor in the cat. Neurosci Lett 1985;58:213-217.

7. Greenberg B, Rhoden K, Barnes P. Calcitonin gene-related peptide (CGRP) is a potent non-endothelium-dependent inhibitor of coronary vasomotor tone. Br J Pharmacol 1987;92:789-794.

8. Franco-Cereceda A. Calcitonin gene-related peptide and human epicardial coronary arteries: presence, release and vasodilator effects. Br J Pharmacol 1991;102:506-510.

9. Thom SM, Hughes AD, Goldberg P, Martin G, Schachter M, Sever P. The actions of calcitonin gene-related peptide and vasoactive intestinal peptide as vasodilators in man in vivo and in vitro. BrJ Clin Pharmacol 1987;24:139-144.

10. Gray DW, Marshall I. Human alfa-calcitonin gene-related peptide stimulates adenylate cyclase and guanylate cyclase and relaxes rat thoracic aorta by releasing nitric oxide. Br J Pharmacol 1992;107:691-696.

11. Nelson MT, Huang Y, Brayden JE, Hescheler J, Standen NB. Arterial dilations in response to calcitonin gene-related peptide involve activation of $\mathrm{K}+$ channels. Nature 1990;344:770-773.

12. Kitazono T, Heistad DD, Faraci FM. Role of ATP-sensitive $\mathrm{K}+$ hannels in CGRPinduced dilatation of basilar artery in vivo. Am J Physiol 1993;34:H581-H585.

13. Luu TN, Dashwood MR, Tadjkarimi S, Chester AH, Yacoub MH. ATP-sensitive potassium channels mediate vasodilation produced by calcitonin gene-related peptide in human internal mammary but not gastroepiploic arteries. Eur $J$ Clin Invest 1997;27:960-966.

14. Lenders J, Janssen G-J, Smits P, Thien T. Role of the wrist cuff in forearm plethysmography. Clin Sci 1991;80:413-417.

15. Vallance P, Collier J, Moncada S. Effects of endothelium-derived nitric oxide on peripheral arteriolar tone in man. Lancet 1989;2:997-1000.

16. Moncada S, Palmer RMJ, Higgs EA. Nitric oxide: physiology, pathophysiology, and pharmacology. Pharmacol Rev 1991;43(2):109-142.

17. Smits P, Williams SB, Lipson DE, Banitt P, Rongen GA, Creager MA. Endothelial release of nitric oxide contributes to the vasodilator effect of adenosine in humans. Circulation 1995;92:2135-2141. 


\section{Chapter 5}

18. Langton DD, Nelson MT, Huang Y, Standen NB. Block of calcium-activated potassium channels in mammalian arterial myocytes by tetraethylammonium ions. Am J Physiol 1991;260:H927-H934.

19. Bijlstra PJ, Lutterman JA, Russel FGM, Thien T, Smits P. Interaction of sulphonylurea derivatives with vascular ATP-sensitive potassium channels in humans. Diabetologia 1996;39:1083-1090.

20. Jansen TLTA, Smits P, Tan ACITL, Thien T. Attenuated forearm vasodilator response to atrial natriuretic factor in the elderly. Hypertension 1991;18:640-647.

21. Patrono C, Ciabattoni G, Pinca E, Pugliese F, Castrucci G, De Salvo A, et al. Low dose aspirin and inhibition of thromboxane B2 production in healthy subjects. Thromb Res 1980;17:317-327.

22. Ferrari R, Panzali AF, Poole-Wilson PA. CGRP-like immunoreactivity in treated and untreated congestive heart failure. Lancet 1991;338:1084.

23. Goadsby PJ, Edvinsson L. Human in vivo evidence for trigeminovascular activation in cluster headache. Neuropeptide changes and effects of acute attacks therapies. Brain 1994;117:427-434.

24. Jernbeck J, Dalsgaard C-J, Pernow B. The effect of calcitonin gene-related peptide (CGRP) on human forearm blood flow. Clin Physiol 1990;10:335-343.

25. Koller A, Sun D, Huang A, Kaley G. Corelease of nitric oxide and prostaglandins mediates flow-dependent dilation of rat gracilis muscle arterioles. Am J Physiol 1994;267:H326-H332.

26. Rongen GA, Smits P, Thien T. Characterization of ATP-induced vasodilation in the human forearm vascular bed. Circulation 1994;40:1891-1898.

27. Stanfield PR. Tetraethylammonium ions and the potassium permeability of excitable cells. Rev Physiol Biochem Pharmacol 1983;97:1-67.

28. Pickkers $P$, Hughes AD, Russel FGM, Thien T, Smits $P$. Thiazide-induced vasodilation in humans is mediated by potassium channel activation. Hypertension 1998;32:10711076.

29. Jansen I, Mortensen A, Edvinsson L. Characterization of calcitonin gene-related peptide receptors in human cerebral vessels. Ann NY Acad Sci 1992;657:435-440.

30. Pernow J. Actions of constrictor (NPY and endothelin) and dilator (substance P, CGRP and VIP) peptides on pig splenic and human skeletal muscle arteries: involvement of the endothelium. Br J Pharmacol 1989;97:983-989.

31. Franco-Cereceda A, Rudehill A, Lundberg JM. Calcitonin gene-related peptide but not 
substance $\mathrm{P}$ mimics capsaicin-induced coronary vasodilatation in the pig. Eur $J$ Pharmacol 1987;142:235-243.

32. Cockcroft JR, Chowienczyk PJ, Brett SE, Chen CP, Dupont AG, Van Nueten L, et al. Nebivolol vasodilates human forearm vasculature: evidence for an L-arginine/NOdependent mechanism. J Pharmacol Exp Ther 1995;274(3):1067-1071.

33. Kakuyama M, Vallance $P$, Ahluwalia A. Endothelium-dependent sensory NANC vasodilatation: involvement of ATP, CGRP and a possible NO store. Br J Pharmacol 1998;123:310-316. 


\section{Part III}

\section{Vascular Effects of}

\section{Anti-Migraine Drugs}

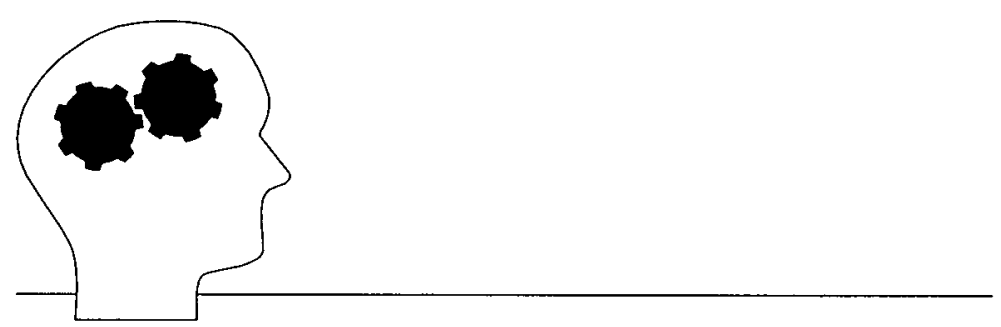


He (Grant) soaked his feet in hot water and put mustard plasters on the back of his neck.

(Ulysses S. Grant, 1822-1885) 


\title{
Chapter 6
}

\section{Vascular Effects of 5-HT $1 \mathrm{~B} / 1 \mathrm{D}-$ Receptor Agonists in Migraine Patients}

\begin{abstract}
Background: To investigate the vascular effects of selective $5-\mathrm{HT}_{1 \mathrm{~B} / 1 \mathrm{D}}$-receptor agonists. Methods: Sixteen migraine patients participated in a double-blind, placebocontrolled, 4-way cross-over study. After equipotent oral therapeutic dosages of sumatriptan $(50 \mathrm{mg})$, rizatriptan $(10 \mathrm{mg})$, zolmitriptan $(2.5 \mathrm{mg})$ or placebo measurements were performed at the common carotid, brachial and temporal artery. Using ultrasound and applanation tonometry arterial vessel wall properties, blood flow and pressure waveforms were assessed. At the brachial artery flow-mediated vasodilatation (an endothelium-dependent process) was evaluated and blood pressures were recorded. Results: Mean arterial pressure, $91 \pm 2 \mathrm{mmHg}$ after placebo, increased $(P<0.05)$ by $4-6 \%$ after each triptan. Isobaric compliance of the brachial artery, $0.077 \pm 0.010 \mathrm{~mm}^{2} / \mathrm{kPa}$ after placebo, decreased $(P<0.01)$ by $11 \pm 8,11 \pm 11$ and $23 \pm 7 \%$ after sumatriptan, rizatriptan and zolmitriptan, respectively. After zolmitriptan this decrease was larger $(P<0.05)$ than after sumatriptan. Isobaric compliance of the carotid artery, $1.31 \pm 0.10 \mathrm{~mm}^{2} / \mathrm{kPa}$ after placebo, did not change. Each drug decreased $(P<0.001)$ both brachial and carotid artery diameter whereas temporal artery diameter, 1:35 $\pm 0.06 \mathrm{~mm}$ after placebo, only decreased after zolmitriptan (by $12 \pm 3 \%, P<0.001$ ). The resistance of the vascular bed distal of the temporal artery increased after both sumatriptan (by $26 \pm 11 \%$, $P<0.05$ ) and zolmitriptan (by $40 \pm 9 \%, P=0.001$ ). Flow-mediated vasodilatation did not differ between treatments.
\end{abstract}

\footnotetext{
Based on: Jan N.J.M. de Hoon ${ }^{(1)}$, Jean M. Willigers ${ }^{(2)}$, Jaap Troost ${ }^{(3)}$, Harry A.J. Struijker-Boudier ${ }^{(1)}$,

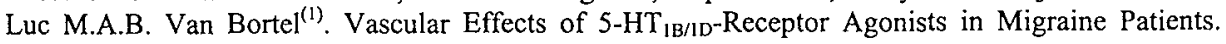
Clinical Pharmacology and Therapeutics (accepted for publication).

(1)Dept. of Pharmacology and Toxicology and (2) Dept. of Biophysics, Cardiovascular Research Institute Maastricht, Maastricht University, Maastricht, The Netherlands and ${ }^{(3)}$ Department of Neurology, University Hospital of Maastricht, Maastricht, The Netherlands.
} 


\section{Chapter 6}

Conclusions: Selective 5-HT $18 / 1 \mathrm{D}$-receptor agonists induce vasoconstriction and decrease the buffering capacity of conduit arteries. These effects are more pronounced at muscular compared to elastic arteries. Resistance is only increased at the temporal artery vascular bed, suggesting cranioselectivity for resistance vessels rather than for conduit arteries. Endothelial function is not differently affected by any of the triptans tested.

\subsection{Introduction}

The development of sumatriptan in the early 1990s was a major advance in the acute treatment of migraine [1]. It was the first selective $5-\mathrm{HT}_{1 \mathrm{~B} / 1 \mathrm{D}}$-receptor agonist to become available as an anti-migraine drug. Although sumatriptan is an effective and generally well tolerated drug, a major limitation for its use is the occurrence of chest symptoms suggestive of angina pectoris, which are reported in up to $15 \%$ of patients [2-5]. As electrocardiographic abnormalities are frequently absent, it is unlikely that these chest symptoms are always cardiac in origin. Nevertheless, the use of sumatriptan has been reported to be associated with both myocardial infarction and sudden death $[6,7]$. Furthermore, its vasoconstrictor potency both on the coronary and systemic circulation has clearly been demonstrated [8-10] and rendered the drug contraindicated in patients with cardiovascular disease. Therefore, recent research aimed at the development of anti-migraine drugs with a safer cardiovascular profile and resulted in the introduction of second-generation "sumatriptan-like" drugs (referred to as triptans).

Most second-generation triptans, including rizatriptan and zolmitriptan, are selective $5-\mathrm{HT}_{1 \mathrm{~B} / 1 \mathrm{D}}$-receptor agonists characterised by an in vitro pharmacology comparable with that of sumatriptan in terms of receptor selectivity, potency and efficacy [11]. Their vasoconstrictor activity results from activation of the vascular smooth muscle cell 5- $\mathrm{HT}_{1 \mathrm{~B}}$-receptor subtype (previously known as 5- $\mathrm{HT}_{1 \mathrm{DB}}$-receptor). This does not only apply for cranial vasoconstriction but also for coronary and peripheral vasoconstriction. Thus, from a pharmacological point of view, there is little reason to expect that second-generation triptans will display a cardiovascular profile profoundly different from that of sumatriptan. Moreover, in vitro data indicate that 
many second-generation triptans contract both human coronary and cranial arteries with a potency and maximal effect comparable with that of sumatriptan [12-15]. However, as the clinical relevance of these in vitro data remains speculative, in vivo human research is needed to better define the cardiovascular profile of these drugs by comparing their vascular effects at clinically relevant plasma concentrations.

The aim of the present study was to compare the peripheral vascular effects of sumatriptan (reference drug) with those of zolmitriptan and rizatriptan (secondgeneration triptans) in migraine patients outside a migraine attack. Therefore, druginduced changes in (i) large artery wall properties, (ii) vascular resistance and (iii) endothelial function were assessed non-invasively.

\subsection{Subjects and methods}

\section{Subjects and subject selection}

Sixteen eligible migraine patients (as defined by the International Headache Society migraine criteria [16]) were recruited from the neurology outpatient clinic. Based on medical history, physical examination, routine laboratory tests and electrocardiogram, all patients were in good health. Major exclusion criteria were: smoking, history of cardiovascular disease, arterial hypertension (blood pressure $>160 / 95 \mathrm{mmHg}$ ), diabetes mellitus, hyperlipidaemia (total cholesterol $>6.4 \mathrm{mmol} / \mathrm{l}$ ) and pregnancy or lactation. Except for oral contraceptives, no regular medication was allowed. The study was approved by the ethics committee of the academic hospital of Maastricht and conducted in accordance with the Declaration of Helsinki (Hong Kong revision 1989). All patients gave written informed consent to participate.

\section{Study design}

After screening, patients were enrolled in a randomised, double-blind, placebocontrolled, 4-way cross-over study. Study periods were separated by a wash-out period of at least 1 week. During each period a single oral dose of an anti-migraine drug (sumatriptan $50 \mathrm{mg}$, rizatriptan $10 \mathrm{mg}$ or zolmitriptan $2.5 \mathrm{mg}$ ) or placebo was 


\section{Chapter 6}

administered outside a migraine attack. Before each study period, patients were asked not to use any drugs for at least 3 days, to abstain from alcohol or caffeine containing beverages for at least 24 and 12 hours, respectively, and to remain fasted for at least 3 hours. Only the intake of water was allowed until 2 hours before drug intake. The study drug was taken with $150 \mathrm{ml}$ of water under supervision of the investigator. After drug intake, patients remained fasting until all measurements had been performed.

\section{Measurements}

Measurements started $1.5 \mathrm{~h}$ after drug intake and were consecutively performed at the common carotid artery (an elastic artery providing cranial intracerebral and extracerebral perfusion), the superficial temporal artery (a muscular artery largely providing extracerebral meningeal perfusion) and the brachial artery (a peripheral muscular artery). Unless specified otherwise measurements were always performed right sided. They lasted approximately 1 hour and were all performed by one investigator in a quiet room after the patient had been lying in the supine position for at least 15 minutes.

First, systolic blood pressure (SBP), diastolic blood pressure (DBP) and heart rate were recorded at the left upper arm for 15 minutes every 3 minutes using a semiautomated oscillometric device (Dinamap ${ }^{\circledR} 950$, Critikon Inc., Florida). The mean of these readings was used as the patient's post-drug haemodynamic parameters.

At the common carotid and brachial artery both pressure waveforms and vessel wall movements (i.e. arterial end diastolic diameter, $\mathrm{D}$ and diameter change, $\Delta \mathrm{D}$ or distension) were recorded non-invasively using an applanation tonometer (Micro-tip ${ }^{(8)}$ transducer, Millar Instruments Inc., Texas) [17] and an echo-tracking system (Wall Track System ${ }^{\circledR}$ combined with Scanner 350, Pie Medical, The Netherlands) [18], respectively. At the temporal artery only $\mathrm{D}$ was measured. In addition, using ultrasound centre stream velocity of the arterial blood flow was measured to calculate local blood flow and vascular resistance. Finally, flow-mediated vasodilatation of the brachial artery was recorded with the echo-tracking system at 45 seconds and 1.5, 2.5, 3.5 and 5 minutes after reperfusion and allowed us to calculate the area under the curve $\left(\mathrm{AUC}_{1 \rightarrow 5}\right)$ of the diameter-time curve. Flow-mediated vasodilatation was 
measured using a protocol comparable with the one described by Celermajer and collaborators [19]

At the common carotid artery vessel wall movements and pressure waveforms were recorded ipsilateral and consecutively. At the brachial artery vessel wall movements (right) and pressure waveforms (left) were recorded contralateral and simultaneously. In the analysis, the local pulse pressures $(\Delta \mathrm{P})$ of the common carotid $\left(\triangle \mathrm{P}_{\mathrm{CCA}}\right)$ and brachial artery $\left(\Delta \mathrm{P}_{\mathrm{BA}}\right)$ as well as large artery wall properties were calculated [20]. Therefore, diameter-time recordings (ultrasound) and pressure-time recordings (applanation tonometry) were simultaneously analysed off-line using a custom made Matlab ${ }^{\circledR}$ script developed by the biophysics department of the university as previously reported [20]. By constructing diameter-pressure curves, distensibility coefficients (DC) and cross-sectional compliance (CC) were calculated over the operating pressure $\triangle \mathrm{P}$. In addition, to assure that differences in vessel wall properties between treatments resulted from drug-induced changes in the pressure-diameter relation rather than from changes in arterial pressure, isobaric vessel wall properties were calculated over a pre-defined pressure interval of 85 to $95 \mathrm{mmHg}\left(\mathrm{DC}_{\text {iso }}\right.$ and $\mathrm{CC}_{\text {iso }}$ ).

For a detailed description on all the measurements and the subsequent data analysis, we refer to the methods outlined in Chapter 2.

\section{Statistical analysis}

All vascular parameters obtained after each treatment were compared by ANOVA. In case of a significant difference $(P<0.05)$ between treatments, a post-hoc paired Student's $t$-test was performed to compare treatments individually. The difference between active treatment and placebo is expressed as percentage change versus placebo. Unless specified otherwise, all data are presented as mean \pm SEM. $P<0.05$ was considered statistically significant. 


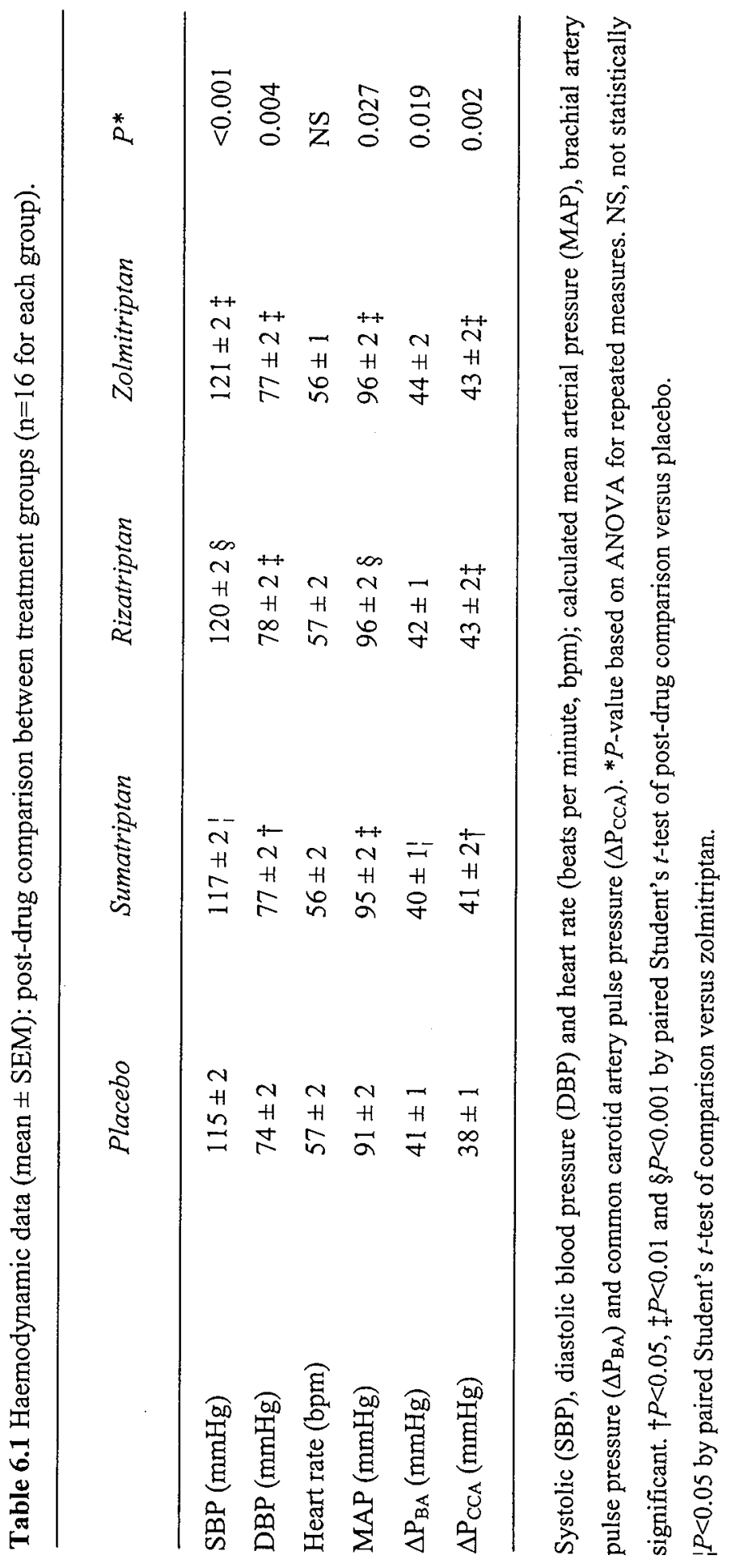




\subsection{Results}

All patients ( 3 males and 13 females) completed the study. Patients were aged 36 years (range, 23-55) and had a body mass index of 24 (range 19-29) kg/m². At screening blood pressure averaged 118 (range 102-132)/73 (range 58-89) $\mathrm{mmHg}$. Total cholesterol was 5.1 (range 3.8-6.3) $\mathrm{mmol} / \mathrm{l}$.

Patients had been suffering from migraine for $18 \pm 2$ years. One patient had a history of recurrent migraine with aura. Migraine attacks recurred with a frequency of $2.5 \pm 0.3$ per month and lasted on average $1.8 \pm 0.1$ days. In most cases headache was one-sided $(n=13)$ and pulsatile in nature $(n=9)$. In all patients it was accompanied by nausea or vomiting and both photophobia and phonophobia. As an abortive drug patients had used sumatriptan at least once before entering the study. Except for oral contraceptives $(n=7)$, no other drugs were regularly used.

\section{Haemodynamic data}

Compared to placebo each active treatment increased DBP, MAP, SBP (except for sumatriptan) and $\Delta \mathrm{P}_{\mathrm{CCA}}$ (Table 6.1). Except for a smaller $\mathrm{SBP}(P=0.027)$ and $\Delta \mathrm{P}_{\mathrm{BA}}$ $(P=0.007)$ after sumatriptan compared to zolmitriptan, the vasopressor effects did not differ between active treatments.

\section{Vascular measurements}

The elastic common carotid artery diameter was decreased by each active treatment $(P<0.001$ by ANOVA). Diameter, $6.93 \pm 0.14 \mathrm{~mm}$ after placebo, decreased to $6.65 \pm 0.16 \mathrm{~mm}$ after sumatriptan $(P=0.013$ versus placebo), $6.65 \pm 0.12 \mathrm{~mm}$ after rizatriptan $(P=0.001)$ and $6.63 \pm 0.14 \mathrm{~mm}$ after zolmitriptan $(P=0.003)$. This decrease did not differ between active treatments (Fig. 6.1, top). Drug intake did not affect distension ( $594 \pm 49 \mu \mathrm{m}$ after placebo) or distensibility; neither over operating pressure (DC) nor under isobaric conditions $\left(\mathrm{DC}_{\text {iso }}\right.$ ) (Table 6.2). Cross-sectional compliance decreased, while $\mathrm{CC}_{\text {iso }}$ did not change. Vasculare resistance $\left(703 \pm 26 \mathrm{kPa} .1^{-1} . \mathrm{s}\right.$ after placebo) was unaffected by either triptan (Fig. 6.1, bottom). 


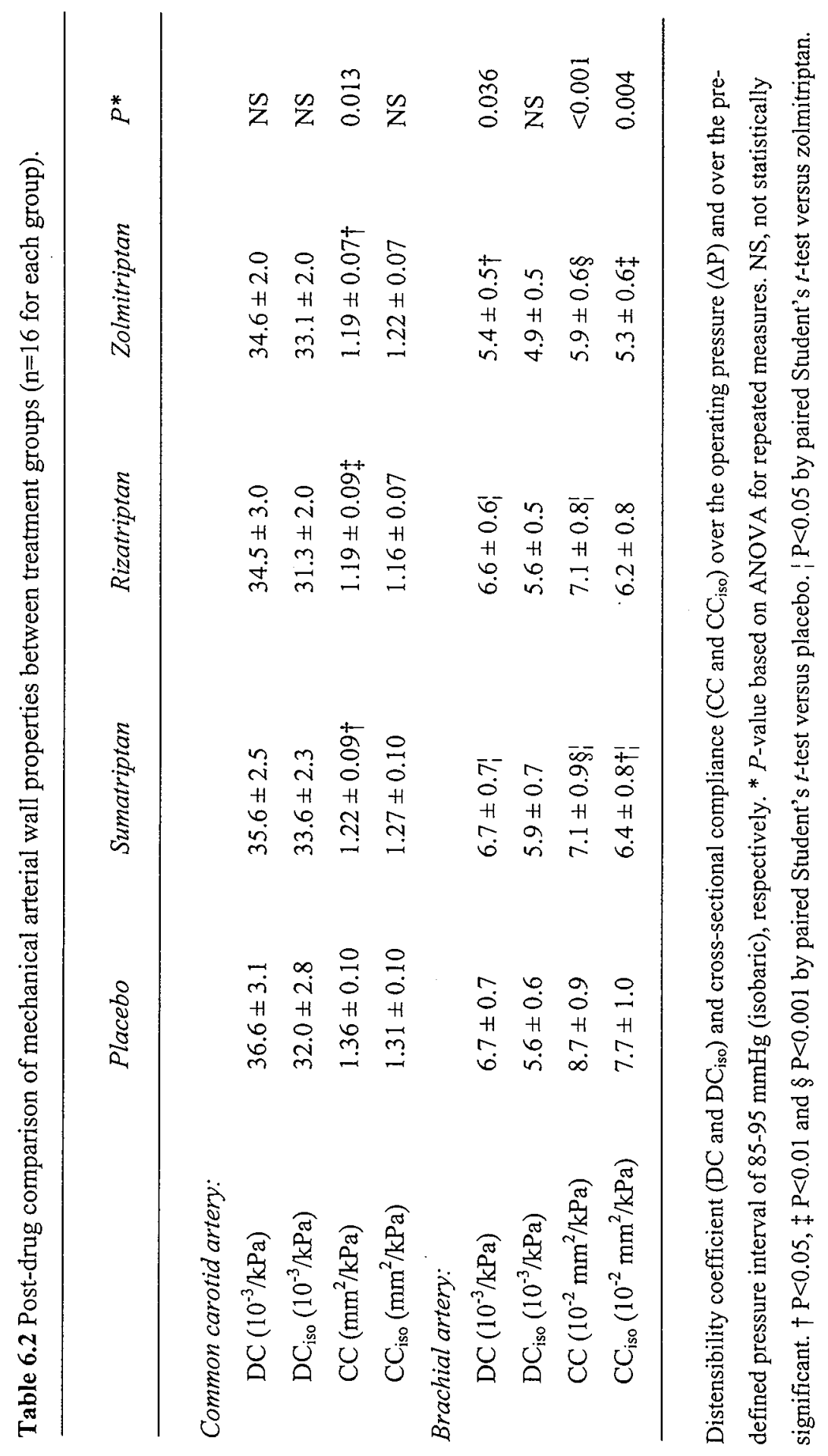



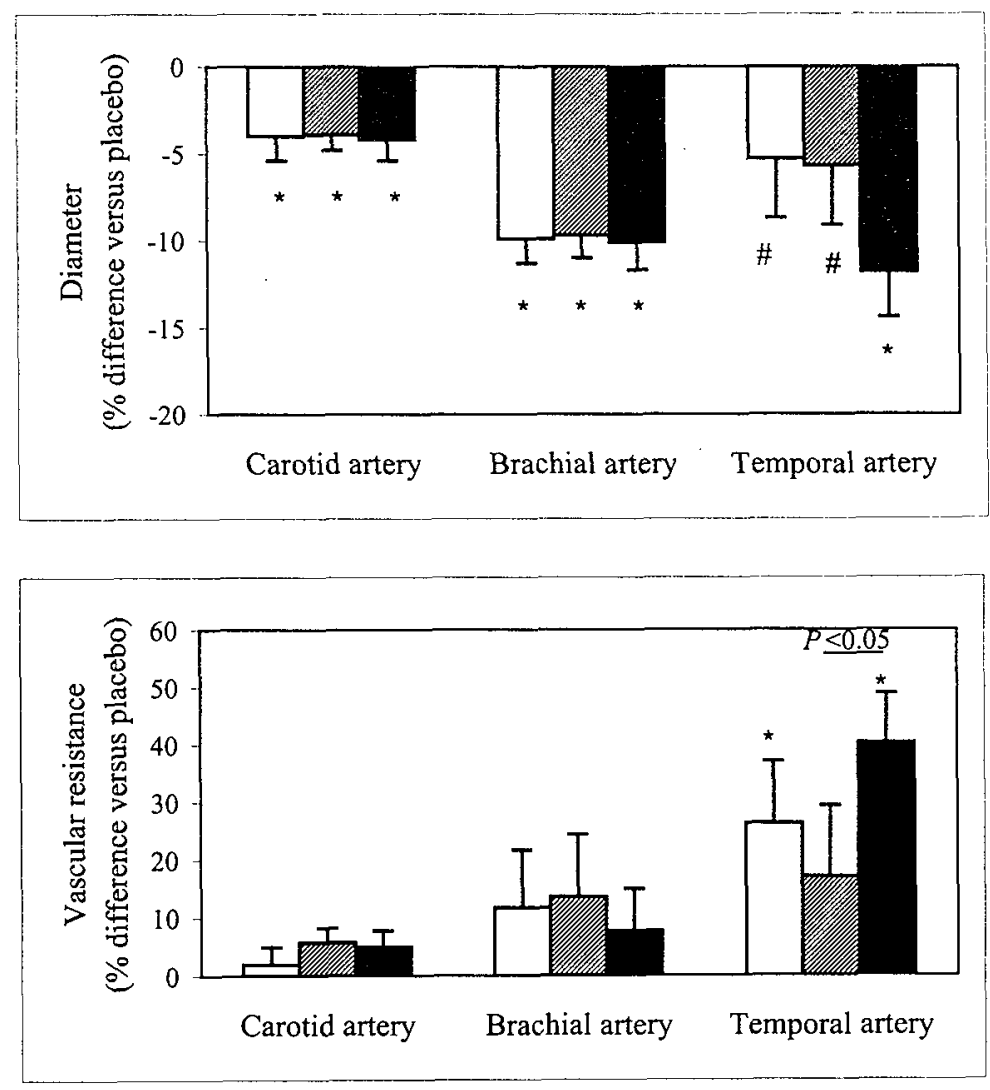

Figure 6.1 Comparison of the decrease in diameter (top) and increase in vascular resistance (bottom) of the common carotid, brachial and temporal artery after intake of sumatriptan (open bars), rizatriptan (hatched bars) and zolmitriptan (closed bars). Data presented as percentage difference versus placebo (mean $\pm \mathrm{SEM}$ ); $\mathrm{n}=16$ in each group. ${ }^{*} P<0.05$ and ${ }^{\sharp} P<0.1$ versus placebo.

The muscular brachial artery diameter was decreased by each active treatment (for each drug $P<0.001$ versus placebo). Diameter, $4.16 \pm 0.18 \mathrm{~mm}$ after placebo, decreased to $3.74 \pm 0.15 \mathrm{~mm}$ after sumatriptan, $3.75 \pm 0.15 \mathrm{~mm}$ after rizatriptan and 


\section{Chapter 6}

$3.72 \pm 0.15 \mathrm{~mm}$ after zolmitriptan. This decrease did not differ between treatments (Fig. 6.1, top). After zolmitriptan DC was smaller compared to placebo $(P=0.025)$, sumatriptan $(P=0.019)$ and rizatriptan $(P=0.03)$ (Table 6.2). Compared to placebo both $\mathrm{CC}$ and $\mathrm{CC}_{\text {iso }}$ decreased after sumatriptan $(P<0.001$ and $P=0.02$, respectively) and zolmitriptan $(P<0.001$ and $P=0.003$, respectively) while they tended to decrease after rizatriptan ( $P=0.065$ and 0.08 , respectively). Zolmitriptan decreased brachial artery $\mathrm{CC}$ to a larger extent than sumatriptan $(P=0.014)$ and rizatriptan $(P=0.04)$ did. $\mathrm{CC}_{\text {iso }}$ was smaller after zolmitriptan compared to sumatriptan $(P=0.04)$. Vascular resistance $\left(9,730 \pm 1,017 \mathrm{kPa} . \mathrm{I}^{-1} . \mathrm{s}\right.$ after placebo) did not change by active treatment (Fig. 6.1, bottom).

The muscular temporal artery, diameter ( $1.35 \pm 0.06 \mathrm{~mm}$ after placebo $)$ decreased ( $P=0.012$ by ANOVA) and vascular resistance $\left(30,738 \pm 3,374 \mathrm{kPa} . \mathrm{I}^{-1} . \mathrm{s}\right.$ after placebo) increased ( $P=0.013$ by ANOVA) after active treatment (Fig. 6.1, top). Compared to placebo, only after zolmitriptan diameter $(1.19 \pm 0.06 \mathrm{~mm}, P<0.001)$ was significantly smaller; after sumatriptan $(1.26 \pm 0.05 \mathrm{~mm})$ and rizatriptan $(1.25 \pm 0.05 \mathrm{~mm})$ it tended to be smaller $(P \leq 0.1)$. Both after sumatriptan $\left(37,007 \pm 4,264 \mathrm{kPa} .1^{-1} . \mathrm{s}, P=0.04\right)$ and zolmitriptan $\left(41,186 \pm 4,091 \mathrm{kPa} . \mathrm{l}^{-1} . \mathrm{s}, P=0.001\right)$ vascular resistance was increased compared to placebo. After rizatriptan $\left(32,515 \pm 2,610 \mathrm{kPa} . \mathrm{l}^{-1} . \mathrm{s}\right)$ the increase in resistance did not reach statistical significance and was smaller $(P=0.04)$ compared to zolmitriptan (Fig. 6.1, bottom).

The increase in flow upon ischaemia at the brachial artery resulting in flowmediated vasodilatation, did not differ between placebo $(771 \% \pm 53)$, sumatriptan $(740 \pm 52 \%)$, rizatriptan $(742 \pm 48 \%)$ and zolmitriptan $(775 \pm 48 \%)$. Flow-mediated vasodilatation (Fig. 6.2) was comparable between placebo, sumatriptan, rizatriptan and zolmitriptan both in terms of maximal vasodilatation $(5.5 \pm 1.0,6.6 \pm 1.3,5.8 \pm 0.9$ and $6.2 \pm 1.2 \%$, respectively) and in terms of $\mathrm{AUC}_{0 \rightarrow 5}(340,387,296$ and $310 \mathrm{~min} . \mu \mathrm{m}$, respectively). 


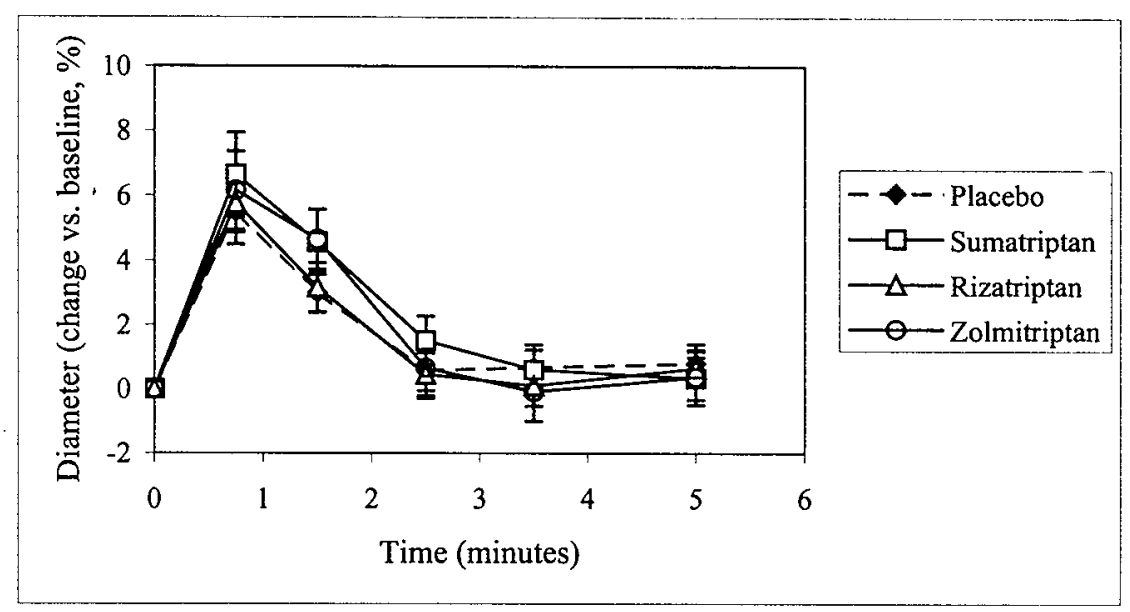

Figure 6.2 Flow-mediated vasodilatation of the brachial artery after 5 minutes of forearm occlusion. Diameter before occlusion $(t=0)$ and from 45 seconds until 5 minutes after reperfusion. Data are presented as mean $\pm \mathrm{SEM}, \mathrm{n}=16$ in each group.

\subsection{Discussion}

Most studies investigating the vascular effects of anti-migraine drugs make use of isolated blood vessels and refer to in vitro data which are sometimes obtained under clinically irrelevant concentrations [12-15]. In contrast, the results of the present study refer to in vivo data obtained in migraine patients after the intake of equally effective acute therapeutic dosages of sumatriptan, rizatriptan and zolmitriptan [21-23]. Consequently, these data allow for a fair comparison between these drugs and can be expected to represent clinical reality. Moreover, as all measurements were performed within a time frame corresponding with the time to reach maximal plasma concentrations $\left(t_{\max }\right)$ after oral drug intake [24-26], it is reasonable to assume that peak effects were observed. Still, a delayed onset of vascular effects, as previously suggested for eletriptan [27], cannot be excluded because the metabolism of both zolmitriptan and rizatriptan results in the formation of active metabolites $[26,28]$. 


\section{Chapter 6}

In accordance with previous reports sumatriptan, rizatriptan and zolmitriptan each induced a small increase in blood pressure $[10,25,29]$. The increase in mean arterial pressure is in line with previous research demonstrating an increased systemic vascular resistance after the administration of triptans $[8,9,29]$. Theoretically, the increase in mean arterial pressure could also have resulted from an increase in cardiac output due to an increase in stroke volume. Although cardiac output was not assessed, an increased stroke volume is suggested by the increase in carotid artery pulse pressure which was not accompanied by a decreased compliance. However, a change in cardiac output was not observed in previous research performing cardiac assessment after the administration of triptans $[9,27]$.

Arterial stiffness was assessed by investigating local pressure-diameter changes and calculating distensibility and cross-sectional compliance. Both distensibility, a measure of elasticity, and cross-sectional compliance, a measure of buffering capacity, are parameters which decrease with increasing arterial stiffness and refer to local mechanical vessel wall properties [30]. The present study demonstrates that each of the triptans investigated, and zolmitriptan most potently, decrease the buffering capacity of the brachial artery both at operating pressure and at isobaric values. At the common carotid artery the small decrease in buffering capacity at operating pressure can be interpreted as a passive phenomenon resulting from the increase in mean arterial pressure. Indeed, as the buffering capacity at isobaric values did not change the mechanical properties of the artery do not seem to be affected. In contrast with the common carotid artery, at the brachial artery isobaric compliance did decrease. This apparent difference in mechanical properties between the common carotid and the brachial artery after the intake of triptans, might be due to structural differences. As the common carotid artery is an elastic artery it has a higher proportion of elastic fibres and a smaller quantity of vascular smooth muscle cells [31]. Thus, a change in smooth muscle tone is likely to result in a small increase in stiffness of "elastic arteries" compared to "muscular arteries". Taken together, these data demonstrate that the intake of both sumatriptan and second-generation triptans results in a comparable systemic vasopressor effect and a decreased buffering capacity of muscular arteries. 
These vascular effects are regarded as undesirable and implicate that triptans should be used with caution in patients at increased risk for cardiovascular events.

Each of the active treatments decreased the diameter of both the common carotid and the brachial artery without affecting vascular resistance. As neither for the carotid nor for the brachial artery vasoconstriction was different between treatments this argues against an increased cranial selectivity of second-generation triptans compared to sumatriptan. At the temporal artery however, zolmitriptan most potently decreased arterial diameter and increased vascular resistance. As each of the triptans was equally effective in decreasing brachial artery diameter, these data do suggest an increased cranioselectivity for zolmitriptan. However, this does not translate into a more favourable cardiovascular profile as zolmitriptan also most potently affected brachial artery wall properties. Although it cannot be excluded that the changes at the temporal artery induced by sumatriptan and rizatriptan did not reach statistical significance due to a lack of power, these data do indicate that triptans can differently affect the same vascular territory. Obviously, these effects can be expected to be dose-dependent.

Thus within the cranial circulation selective $5-\mathrm{HT}_{1 \mathrm{~B} / 1 \mathrm{D}}$-receptor agonists, and most convincingly zolmitriptan, result in arterial and arteriolar vasoconstriction of the vascular territory supplied by the external carotid artery. Interestingly, studies on the pathophysiology of migraine have focussed on the dilatation and increased pulsations of the external carotid artery and its branches, including the temporal artery [32, 33]. Moreover, dilated meningeal blood vessels are considered the pain-producing structures in migraine $[34,35]$ and are largely perfused by the external carotid artery. Consequently, the vascular changes observed at the temporal artery might be useful surrogate markers indicative of anti-migraine activity.

Although cranial vasoconstriction is considered a prerequisite to yield a 5- $\mathrm{HT}_{1 \mathrm{~B} / \mathrm{ID}}$-receptor agonist with anti-migraine activity [11], it is tempting to speculate that increasing vessel wall stiffness might be equally important. The pulsatile nature of migraine headache suggests that increased vascular pulsations are sensed by stretch receptors, resulting in the activation of perivascular nerve endings [34]. If so, increasing vessel wall stiffness per se, without obligatory inducing vasoconstriction, might sufficiently temper the activation of stretch receptors and render efficient anti- 


\section{Chapter 6}

migraine drugs with a reduced risk of coronary vasoconstriction. Besides selective 5-HT $\mathrm{T}_{\mathrm{B} / \mathrm{ID}}$ receptor agonists, also ergot alkaloids have previously been reported to decrease arterial compliance $[36,37]$, supporting the idea that decreasing the activation of perivascular nerves by increasing arterial stiffness might contribute to the efficacy of anti-migraine drugs.

Whether or not patients are at risk for unwanted coronary vasoconstriction after the exposure to 5-HT-receptor agonists has been related to endothelial function [38, 39]. As $5-\mathrm{HT}_{\mathrm{IB} / \mathrm{D}}$ receptor agonists interact with endothelial receptors mediating the release of vasodilator substances, including nitric oxide, their vascular effect is supposed to be the balanced result of vasoconstriction, mediated by smooth muscle receptors and vasodilatation, mediated by endothelial receptors [38]. Consequently, in patients with coronary artery disease, which has been associated with endothelial dysfunction [40], the vasoconstrictor effects of triptans might remain unopposed and render them at increased risk for untoward cardiovascular events. If the endothelium plays a pivotal role in providing a counteractive mechanism, the intake of triptans should not interfere with endothelial function. This was investigated by measuring flow-mediated vasodilatation of the brachial artery which has previously been shown to be dependent on the endothelial release of NO [41] and correlates well with coronary endothelial function [42]. In the present study, flow-mediated vasodilatation of the brachial artery did not differ between the triptans and placebo, arguing against an interference with endothelial function. However, as the brachial artery baseline diameter after the intake of a triptan was smaller than after placebo, these data have to be interpreted with caution. As previous studies have shown that flow-mediated vasodilatation dilates small arteries more than it does larger ones [43], placebo and active treatment groups cannot be directly compared [44]. Nevertheless, it can be concluded that none of the active treatments interfered differently with flow-mediated vasodilatation.

In summary, the data of the present study demonstrate that after the intake of equipotent therapeutic dosages, both sumatriptan and second-generation triptans induce vasoconstriction and decrease the buffering capacity of conduit arteries. These effects are more pronounced at muscular compared to elastic arteries. In contrast, 
vascular resistance is only increased at the temporal artery vascular bed, suggesting cranioselectivity of triptans for resistance arteries rather than for conduit arteries. Zolmitriptan most potently affects the vascular territory of the temporal artery, but also induces the largest decrease in brachial artery buffering capacity. Endothelial function, as assessed by flow-mediated vasodilatation, is not differently affected by the triptans.

\section{Acknowledgement:}

This study was supported by AstraZeneca, Zoetermeer, The Netherlands.

\subsection{References}

1. Humphrey PPA, Feniuk W. Mode of action of the anti-migraine drug sumatriptan. Trends Pharmacol Sci 1991;12:444-446.

2. Visser WH, Jaspers NMWH, de Vriend RHM, Ferrari MD. Chest symptoms after sumatriptan: a two-year clinical practice review in 735 consecutive migraine patients. Cephalalgia 1996;16:554-559.

3. Ottervanger JP, Van Witsen TB, Valkenburg HA, Grobbee DE, Stricker BHC. Adverse reactions attributed to sumatriptan. A post-marketing study in general practice..Eur $J$ Clin Pharmacol 1994;47:305-309.

4. Brown EG, Endersby CA, Smith RN, Talbot JC. The safety and tolerability of sumatriptan: an overview. Eur Neurol 1991;31:339-344.

5. Plosker GL, McTavish D. Sumatriptan: a reappraisal of its pharmacology and therapeutic efficacy in the acute treatment of migraine and cluster headache. Drugs 1994;47:622-651.

6. Main ML, Ramaswamy K, Andrews TC. Cardiac arrest and myocardial infarction immediately after sumatriptan injection. Ann Intern Med 1998;128:874.

7. Ottervanger JP, Paalman HJ, Boxma GL, Stricker BH. Transmural myocardial infarction with sumatriptan. Lancet 1993;341:861-862.

8. MacIntyre PD, Bhargava B, Hogg KJ, Gemmill JD, Hillis WS. The effect of I.V. sumatriptan, a selective 5-HT1-receptor agonist on central haemodynamics and the coronary circulation. Br J Clin Pharmacol 1992;34:541-546. 


\section{Chapter 6}

9. MacIntyre PD, Bhargava B, Hogg KJ, Gemmill JD, Hillis WS. Effects of subcutaneous sumatriptan, a selective $5 \mathrm{HTl}$ agonist, on the systemic, pulmonary, and coronary circulation. Circulation 1993;87:401-405.

10. Hood S, Birnie D, Hillis S. The haemodynamic effects of subcutaneous sumatriptan, a 5HT1-receptor agonist. Br J Clin Pharmacol 1997;43:327-328.

11. Pauwels PJ, John GW. Present and future of 5-HT receptor agonists as antimigraine drugs. Clin Neuropharmacol 1999;22:123-136.

12. Maassen van den Brink A, Reekers M, Bax WA, Ferrari MD, Saxena PR. Coronary side-effect potential of current and prospective antimigraine drugs. Circulation 1998;98:25-30.

13. Maassen van den Brink A, Van den Broek RWM, De Vries R, Saxena PR. Human middle meningeal and coronary artery contraction to eletriptan and sumatriptan. Cephalalgia 1999;19:399.

14. Longmore J, Hargreaves RJ, Razzaque Z, Schofield WN, Shaw D, Smith D, et al. Rizatriptan selectively contracts human isolated middle meningeal artery over coronary artery: comparisons with sumatriptan. Cephalalgia 1997;17:388.

15. Longmore J, Razzaque Z, Shaw D, Davenport AP, Maguire J, Pickard JD, et al. Comparison of the vasoconstrictor effects of rizatriptan and sumatriptan in human isolated cranial arteries: immunohistological demonstration of the involvement of 5HT1B-receptors. Br J Clin Pharmacol 1998;46:577-582.

16. Society HCCotIH. Classification and diagnostic criteria for headache disorders, cranial neuralgias and facial pain. Cephalalgia 1988;8:1-96.

17. Kelly R, Hayward C, Ganis J, Daley J, Avolio A, O'Rourke M. Noninvasive registration of the arterial pressure pulse waveform using high-fidelity applanation tonometry. J Vasc Med Biol 1989;1(3):142-149.

18. Hoeks APG, Brands PJ, Smeets FAM, Reneman RS. Assessment of the distensibility of superficial arteries. Ultrasound Med Biol 1990;16:121-128.

19. Celermajer DS, Adams MR, Clarkson P, Robinson J, McCredie R, Donald A, et al. Passive smoking and impaired endothelium-dependent arterial dilatation in healthy young adults. $N$ Engl $J$ Med 1996;334:150-154.

20. de Hoon $\mathbb{N J M}$, Hoeks APG, Willigers JM, Van Bortel LMAB. Non-invasive assessment of pulse pressure at different peripheral arteries in man. Neth $J$ Med 1998;52:A36.

21. Goadsby PJ. A triptan too far? J Neurol Neurosurg Psychiatry 1998;64:143-147. 
22. Solomon GD, Cady RK, Klapper JA, Earl NL, Saper JR, Ramadan NM. Clinical efficacy and tolerability of $2.5 \mathrm{mg}$ zolmitriptan for the acute treatment of migraine. Neurology 1997;49:1219-1225.

23. Visser HW, Terwindt GM, Reines SA, Jiang K, Lines CR, Ferrari MD. Rizatriptan versus sumatriptan in the acute treatment of migraine. Arch Neurol 1996;53:1 132-1137.

24. Fowler PA, Lacey LF, Thomas M, Keene ON, Tanner RJN, Baber NS. The clinical pharmacology, pharmacokinetics and metabolism of sumatriptan. Eur Neurol 1991;31:291-294.

25. Sciberras DG, Polvino WJ, Gertz BJ, Cheng H, Stepanavage M, Wittreich J, et al. Initial human experience with MK-462 (rizatriptan): a novel 5-HT1D agonist. Br J Clin Pharmacol 1997;43:49-54.

26. Seaber E, On N, Phillips S, Churchus R, Posner J, Rolan P. The tolerability and pharmacokinetics of the novel antimigraine compound $311 \mathrm{C} 90$ in healthy male volunteers. Br J Clin Pharmacol 1996;41:141-147.

27. Muir D, McCann GP, Swan L, Clark AL, Hillis WS. Hemodynamic and coronary effects of intravenous eletriptan, a 5-HT1B/1D-receptor agonist. Clin Pharmacol Ther 1999;66:85-90.

28. Beer M, Middlemiss D, Stanton J, Heald M, Hanoford E, Stagg A, et al. An in vitro pharmacological profile of rizatriptan. Cephalalgia 1997;17:390.

29. Dixon RM, Meire HB, Watt H, On N, Posner J, Rolan PE. Peripheral vascular effects and pharmacokinetics of the antimigraine compound, zolmitriptan, in combination with oral ergotamine in healthy volunteers. Cephalalgia 1997;17:639-646.

30. Laurent S, Caviezel B, Beck L, Girerd X, Billaud E, Boutouyrie P, et al. Carotid artery distensibility and distending pressure in hypertensive humans. Hypertension 1994;23:878-883.

31. O'Rourke MF. Arterial function in health and disease. Edinburgh: Chirchill Livingstone; 1992.

32. Iversen HK, Nielsen TH, Olesen J, Tfelt-Hansen P. Arterial responses during migraine headache. Lancet 1990;336:837-839.

33. Drummond PD, Lance JW. Extracranial vascular changes and the source of pain in migraine headache. Ann Neurol 1983;13:32-37.

34. Moskowitz MA. Basic mechanisms in vascular headache. Headache 1990;8:801-815.

35. Blau JN. Migraine: a vasomotor instability of the meningeal circulation. Lancet 1978;ii:1136-1139. 
36. Barenbrock M, Spieker C, Witta J, Evers S, Hoeks APG, Rahn KH, et al. Reduced distensibility of the common carotid artery in patients treated with ergotamine. Hypertension 1996;28:115-119.

37. de Hoon JNJM, Struijker-Boudier HAJ, Van Bortel LMAB. Different vascular effects of dihydroergotamine on large arteries and resistance vessels in man. $\mathrm{Br} \mathrm{J} \mathrm{Clin}$ Pharmacol 1999;47:470P.

38. Golino P, Piscione F, Willerson JT, Cappelli-Bigazzi M, Focaccio A, Villari B, et al. Divergent effects of serotonin on coronary-artery dimensions and blood flow in patients with coronary atherosclerosis and control patients. N Engl J Med 1991;324:641-648.

39. Ellwood AJ, Curtis MJ. Mechanism of actions of sumatriptan on coronary flow before and after endothelial dysfunction in guinea-pig isolated heart. $\mathrm{Br} J$ Pharmacol 1997;120:1039-1048.

40. Vanhoutte PM, Shimokawa H. Endothelium-derived relaxing factor and coronary vasospasm. Circulation 1989;80:1-9.

41. Joannides R, Haefeli WE, Linder L, Richard V, Bakkali EH, Thuillez C, et al. Nitric oxide is responsible for flow-dependent dilatation of human peripheral conduit arteries in vivo. Circulation 1995;91:1314-1319.

42. Anderson TJ, Uehata A, Gerhard MD, Meredith IT, Knab S, Delagrange D, et al. Close relation of endothelial function in the human coronary and peripheral circulations. $J \mathrm{Am}$ Coll Cardiol 1995;26:1235-1241.

43. Celermajer DS, Sorensen KE, Gooch VM, Spiegelhalter DJ, Miller OI, Sullivan ID, et al. Non-invasive detection of endothelial dysfunction in children and adults at risk of atherosclerosis. Lancet 1992;340:1111-1115.

44. Hashimoto M, Akishita M, Eto M, Ishikawa M, Kozaki K, Toba K, et al. Modulation of endothelium-dependent flow-mediated dilatation of the brachial artery by sex and menstrual cycle. Circulation 1995;92:3431-3435. 


\title{
Chapter 7
}

\section{Dihydroergotamine: Discrepancy Between Arterial,}

\section{Arteriolar and Pharmacokinetic Data}

\begin{abstract}
Background: To investigate the peripheral vascular effects and pharmacokinetics of dihydroergotamine (DHE) $0.5 \mathrm{mg}$ after a single subcutaneous administration. Methods: A double-blind, placebo-controlled, two-way cross-over study was performed in 10 healthy male subjects. A wash-out period of 2 weeks separated the two study periods. During each period, just before and at regular time intervals after drug administration, vascular measurements were performed and venous blood samples drawn. At the brachial artery, vessel wall properties were assessed by ultrasound and applanation tonometry. Blood pressure and heart rate were recorded with an oscillometric device. Forearm blood flow was measured with venous occlusion plethysmography. For all parameter-time curves the area under the curve (AUC) was calculated. Differences in AUC after placebo and DHE ( $\triangle A U C)$ were analysed and the time-course of the difference assessed. DHE plasma concentrations were fitted to a tri-exponential equation consistent with a two-compartment open model. Results: AUC for blood pressure, heart rate and forearm vascular resistance did not change after DHE. Brachial artery diameter and compliance decreased $(P<0.01) ; \triangle$ AUC $(95 \%$ confidence interval) equalled $-8.81 \mathrm{~mm} \cdot \mathrm{h}(-12.97 /-4.65)$ and $-0.98 \mathrm{~mm}^{2} \cdot \mathrm{kPa}^{-1} \cdot \mathrm{h}(-1.61 /-0.34)$, respectively. Diameter decreased $(P<0.05)$ from 1 until $24 \mathrm{~h}$ after DHE (peak decrease $9.7 \%$ at $10 \mathrm{~h}$ ); compliance from 2 until $32 \mathrm{~h}(24.8 \%$ at $2 \mathrm{~h})$. Time to reach maximum plasma concentration of DHE averaged $0.33 \pm 0.08 \mathrm{~h}$ ( \pm SEM); terminal half-life was $5.63 \pm 1.15 \mathrm{~h}$.
\end{abstract}

Based on: J.N.J.M. de Hoon, K.A. Poppe, H.H.W. Thijssen, H.A.J. Struijker-Boudier, L.M.A.B. Van Bortel. Dihydroergotamine: discrepancy between arterial, arteriolar and pharmacokinetic data. (submitted).

Department of Pharmacology and Toxicology, Cardiovascular Research Institute Maastricht, Maastricht University, Maastricht, the Netherlands. 


\section{Chapter 7}

Conclusions: As DHE decreases diameter and compliance of the brachial artery whereas forearm vascular resistance remains unchanged, it acts on conduit arteries without affecting resistance vessels. Furthermore, a discrepancy was demonstrated between the plasma concentrations of DHE which rapidly reach peak levels and quickly decline, and its long lasting vasoconstrictor activity.

\subsection{Introduction}

Migraine is a common and debilitating neurological disorder for which effective and safe treatment is needed. The ergot alkaloids ergotamine and dihydroergotamine (DHE) were the first compounds reported to be successful in the acute treatment of migraine [1]. Ergotamine was isolated in 1918 from the fungus Claviceps purpurea and reported effective as an anti-migraine drug in 1926. However, because of its unfavourable side effect profile the dihydrogenated derivative DHE was developed [2]. DHE differs form ergotamine in that it is less toxic, less emetic, devoid of uterotonic activity and it displays a decreased peripheral vasoconstrictor activity [2, 3]. In particular, DHE preferentially constricts venous capacitance vessels and arteriovenous anastomoses while being a much less potent arterial vasoconstrictor [4, 5]. However, it is not entirely clear how this vascular selectivity is obtained as both drugs are non-selective pharmacological agents interacting with serotonergic $\left(5-\mathrm{HT}_{1}\right.$ and 5-HT $\mathrm{H}_{2}$-receptors), adrenergic ( $\alpha_{1}$ and $\alpha_{2}$-receptors) and dopaminergic receptors $\left(\mathrm{D}_{2}\right.$-receptors) $[2,6]$.

The venoconstrictor activity of DHE has been investigated extensively whereas data on its arterial and arteriolar effects are limited. Both in animal [7] and in human [8-10] a discrepancy has been reported between the long lasting venoconstrictor activity of DHE and its plasma concentration profile showing rapidly increasing plasma levels which quickly decline. With respect to arterial effects, in vitro data show that ergotamine and DHE induce a sustained contraction of human arteries [11, 12]. For ergotamine both long lasting arterial contractions and a discrepancy between plasma concentrations and arterioconstrictor activity have also been reported in human [13]. In contrast, based on indirect measurements Andersen et al. [14] concluded that 
DHE lacks peripheral arterial effects. Direct assessments of the arterial effects of DHE in man have never been performed.

These conflicting results between in vitro and in vivo data and the unexpected difference between the vascular effects of ergotamine and DHE, led us to investigate the vascular effects of DHE in vivo in human. Moreover, as the use of DHE in the acute treatment of migraine can be expected to increase because of the commercial availability of a nasal spray, a better knowledge of its vascular effects is warranted. In the present study, the peripheral vascular effects (arterial and arteriolar) of DHE. over time and the pharmacokinetics of DHE were investigated simultaneously after the administration of a single subcutaneous injection of DHE to healthy subjects.

\subsection{Subjects and methods}

\section{Subjects and study design}

Ten non-smoking, male subjects (age $23 \pm 2$ years (mean $\pm \mathrm{SD}$ ), weight $72 \pm 8 \mathrm{~kg}$ and height $182 \pm 7 \mathrm{~cm}$ ) entered and completed the study. Based on their medical history, clinical examination, routine laboratory tests and electrocardiogram all subjects were in good health. The study was approved by the ethics committee of the academic hospital of Maastricht and conducted in accordance with the Declaration of Helsinki (Hong Kong revision 1989). All patients gave written informed consent to participate.

A double-blind, randomised, placebo-controlled, two-way cross-over design was used. A wash-out period of at least 2 weeks separated the two study periods. During one period $0.5 \mathrm{mg}$ dihydroergotamine mesylate (Dihydergot ${ }^{\circledR}$, Novartis Pharma, 1 $\mathrm{mg} / \mathrm{ml}$ ) was administered, during the other $0.5 \mathrm{cc} \mathrm{NaCl} 0.9 \%$ as placebo. Both were administered subcutaneously at the level of the thigh. On each occasion the drug was administered after overnight fasting and subjects remained fasting until 4 hours after drug administration. Before drug administration, subjects were asked to abstain from alcohol-containing beverages for at least 24 hours. Until all measurements had been performed (i.e. 32 hours after drug administration) alcohol and caffeine-containing beverages were not allowed. 


\section{Chapter 7}

\section{Pharmacodynamic assessments}

All measurements were performed by one investigator in a quiet room with the subject lying comfortably in the supine position for at least 15 minutes before measurements were started. Just before $(0 \mathrm{~h})$ and at $0.5,1,2,4,6,8,10,24$ and 32 hours after drug administration, pharmacodynamic assessments were performed. These consisted of non-invasive measurements of (i) vessel wall movements and pressure wave recordings of the brachial artery, (ii) forearm blood flow with and without wrist occlusion and (iii) blood pressure and heart rate.

\section{Brachial artery wall properties}

Using an echo-tracking system as described by Hoeks et al. [15] (Wall Track System ${ }^{\circledR}$ and Scanner 350, Pie Medical, The Netherlands) end diastolic diameter (D) and diameter changes $(\Delta \mathrm{D}$, distension) of the right brachial artery were measured. Using applanation tonometry (Micro-tip ${ }^{(1)}$ transducer, Millar Instruments Inc., Texas) [16], pressure waveforms of the left brachial artery were recorded simultaneously with vessel wall movements. At each point in time at least 3 measurements were performed.

Both before and after vessel wall movement/pressure waveform recordings, diastolic blood pressure (DBP), systolic blood pressure (SBP) and heart rate were each measured 3 times with a 1-minute interval. These measurements were performed at the right upper arm using an oscillometric device (Dinamap ${ }^{\$}$, Critikon Inc., Florida). At each point in time the mean of these recordings was taken as the subject's reading.

In the analysis, mean arterial pressure (MAP), brachial artery pulse pressure $\left(\triangle \mathrm{P}_{\mathrm{BA}}\right)$ and large artery wall properties were calculated. Therefore, after pressure wave calibration, diameter-time recordings (ultrasound) and pressure-time recordings (applanation tonometry) were simultaneously analysed off-line using a custom made Matlab ${ }^{\circledR}$ script developed by the biophysics department of the university [17]. By constructing pressure-diameter curves, distensibility coefficients (DC) and crosssectional compliance $(\mathrm{CC})$ were calculated over the operating pressure $\left(\Delta \mathrm{P}_{\mathrm{BA}}\right)$ according to the equations outlined in Chapter 2. In addition, to assure that changes in vessel wall properties resulted directly from drug-induced changes rather than indirectly from changes in blood pressure, isobaric vessel wall properties were 
calculated over a pre-defined pressure interval of 85 to $95 \mathrm{mmHg}$ (isobaric distensibility, $\mathrm{DC}_{\text {iso }}$ and isobaric compliance, $\mathrm{CC}_{\text {iso }}$ ). For a detailed description on all the measurements which were performed and the subsequent data analysis, we refer to the methods outlined in Chapter 2.

\section{Forearm blood flow and vascular resistance}

Using ECG-triggered venous occlusion plethysmography forearm blood flow (FBF) of the left forearm was measured with mercury-in-Silastic strain gauges (Periflow, Janssen Scientific Instruments, Belgium) [18]. Both before and after occlusion of the hand circulation, by inflation of a wrist cuff to $240 \mathrm{mmHg}, \mathrm{FBF}$ was recorded for 2 minutes. Because of instability of blood flow after wrist occlusion, hand circulation was occluded at least 1 minute before FBF measurements were repeated. FBF was recorded for 3 heart beats every 5 beats by intermittent inflation of an upper arm cuff to a pressure of $45 \mathrm{mmHg}$. FBF measurements obtained without occlusion of the hand circulation refer to total $\mathrm{FBF}\left(\mathrm{FBF}_{\text {total }}\right)$. FBF recordings obtained during occlusion of the hand circulation refer predominantly to the forearm skeletal muscle perfusion $\left(\mathrm{FBF}_{\text {muscle }}\right)[19]$.

Total $\left(\mathrm{FVR}_{\text {total }}\right)$ and muscular forearm vascular resistance $\left(\mathrm{FVR}_{\text {muscle }}\right)$ were calculated as MAP divided by $\mathrm{FBF}_{\text {total }}$ and $\mathrm{FBF}_{\text {muscles }}$ respectively, and expressed as arbitrary units (AU).

\section{Pharmacokinetic assessments}

Just before drug administration $(0 \mathrm{~h})$, at 10, 20, 30 and 45 minutes and at 1, 2, 3, 4, 6, $8,10,24$ and 32 hours after drug administration, venous blood samples $(8 \mathrm{ml})$ were collected in heparinised tubes from an antecubital vein of the left forearm. Within 2 hours after collection, plasma was separated by centrifugation (10 minutes at $1500 \mathrm{~g}$ ), frozen at $-20^{\circ} \mathrm{C}$ and stored at $-80^{\circ} \mathrm{C}$ until analysis.

DHE plasma concentrations were measured in duplicate using a specific radioimmunoassay (RIA) as previously described [20]. The lower limit of quantification was determined to be $50 \mathrm{pg} / \mathrm{ml}$. The slopes of the standard curves were consistent with correlation coefficients $>0.995$. The variability of the calibration standards was less than $5 \%$. 


\section{Chapter 7}

According to Schran et al. [21], after subcutaneous administration, at each point in time ( $\mathrm{t}$ ) DHE plasma concentration $C(\mathrm{t})$ can be described by a tri-exponential function: $C(\mathrm{t})=\mathrm{A} \cdot \mathrm{e}^{-\alpha . \mathrm{t}}+\mathrm{B} \cdot \mathrm{e}^{-\beta . t}-(\mathrm{A}+\mathrm{B}) \cdot \mathrm{e}^{-\mathrm{k} . \mathrm{t}}$ where $\mathrm{A}$ and $\mathrm{B}$ are coefficients referring to fictitious plasma concentrations of DHE at time zero and $k_{a}, \alpha$ and $\beta$ are rate constants referring to the absorption of DHE and the rapid and slow phase of decline in plasma concentration, respectively. The equation was fitted to the experimental data to obtain the relevant pharmacokinetic constants of each subject. The pharmacokinetic software program MW/PHARM (Medi/Ware, Centre of Pharmacy, University of Groningen, The Netherlands) was used for the model fitting. Peak plasma concentration $\left(C_{\max }\right)$ and time to reach $C_{\max }\left(t_{\max }\right)$ were determined from the plasma concentration-time curve of each subject. Half-lives of absorption $\left(t_{1 / 2, \text { abs }}\right)$, distribution $\left(t_{1 / 2, \alpha}\right)$ and elimination $\left(t_{1 / 2, \beta}\right)$ were calculated as $0.693 / \mathrm{k}_{\mathrm{a}}, 0.693 / \alpha$ and $0.693 / \beta$, respectively. The total area under the plasma concentration-time curve (AUC) was calculated by the linear trapezoidal method and extrapolation to infinity. Assuming complete absorption from the injection site, plasma clearance $(\mathrm{CL})$ and volume of distribution $\left(V_{\beta}\right)$ of DHE were calculated as dose/AUC and $C L / \beta$, respectively.

\section{Statistical analysis}

All pharmacodynamic parameters were plotted as a function of time and the area under the parameter time-curves after placebo and after DHE were compared using a paired Student's $t$-test. The differences in AUC after placebo and DHE ( $\triangle A U C)$ are presented as $95 \%$ confidence intervals $(95 \% \mathrm{CI})$. In case of a significant difference $(P<0.05)$, post hoc paired Student's $t$-tests were performed to determine the time course of the difference. Data are presented as mean \pm SEM.

\subsection{Results}

Six subjects reported that the subcutaneous injection of DHE was painful (mild to moderate). Two subject reported minor gastro-intestinal side effects (nausea, watery stools and flatulence) which were probably drug related and resolved spontaneously. After placebo no adverse events were reported. 


\section{Pharmacokinetic data}

DHE $(0.5 \mathrm{mg})$ was rapidly absorbed $\left(t_{1 / 2, \text { abs }} 0.11 \pm 0.03 \mathrm{~h}\right)$ and reached a maximum plasma concentration of $1,419 \pm 88 \mathrm{pg} / \mathrm{ml}\left(C_{\max }\right)$ at 20 minutes $\left(t_{\max }=0.33 \pm 0.08 \mathrm{~h}\right)$ after subcutaneous injection (Fig. 7.1A). The half-lives of distribution $\left(t_{1 / 2, a}\right)$ and elimination $\left(t_{1 / 2, \beta}\right)$ averaged $0.92 \pm 0.16$ and $5.63 \pm 1.15 \mathrm{~h}$, respectively. Mean $\mathrm{CL}, \mathrm{V}_{\beta}$ and AUC were $95 \pm 9 \mathrm{l} / \mathrm{h}, 739 \pm 1141$ and $5825 \pm 667 \mathrm{pg} \cdot \mathrm{ml}^{-1} . \mathrm{h}$, respectively.

\section{Haemodynamic parameters}

Pre-drug SBP (112 $\pm 3 \mathrm{mmHg})$, DBP $(59 \pm 2 \mathrm{mmHg})$, MAP $(80 \pm 2 \mathrm{mmHg})$, pulse pressure $(52 \pm 2 \mathrm{mmHg})$ and heart rate $(58 \pm 2 \mathrm{bpm})$ were comparable during both study periods. The area under the parameter-time curves after placebo and DHE did not differ (Table 7.1). The time course of the haemodynamic parameters (Fig. 7.1B) was similar after placebo and DHE.

\section{Brachial artery wall properties}

Pre-drug diameter $(4.698 \pm 0.096 \mathrm{~mm})$, distension $(179 \pm 14 \mu \mathrm{m}), \mathrm{DC}_{\text {iso }}(9.39 \pm 1.01$ $\left.10^{-3} / \mathrm{kPa}\right)$ and $\mathrm{CC}_{\text {iso }}\left(0.167 \pm 0.016 \mathrm{~mm}^{2} / \mathrm{kPa}\right)$ did not differ between both study periods. After DHE, the AUC for diameter, distension and cross sectional compliance decreased (Table 7.1). Compared to placebo, diameter decreased $(P<0.05)$ from 1 until $24 \mathrm{~h}$ after DHE (Fig. 7.1C); a maximum difference of $462 \pm 60 \mu \mathrm{m}(9.7 \%$, $P<0.001)$ was measured $10 \mathrm{~h}$ after drug administration. Distension decreased from 2 until $8 \mathrm{~h}$ after DHE whereas $\mathrm{CC}_{\text {iso }}$ decreased from 2 until $32 \mathrm{~h}$ (Fig. 7.1D). Compared to placebo, a maximum difference in distension $(34 \pm 7 \mu \mathrm{m}$ or $17.5 \%, P=0.002)$ and $\mathrm{CC}_{\text {iso }}\left(3.91 \pm 1.3410^{-2} \mathrm{~mm}^{2} / \mathrm{kPa}\right.$ or $\left.24.8 \%, P=0.017\right)$ was observed 6 and $2 \mathrm{~h}$ after drug administration, respectively.

\section{Forearm vascular resistance}

Pre-drug $\mathrm{FVR}_{\text {total }}(15.0 \pm 1.8 \mathrm{AU})$ and $\mathrm{FVR}_{\text {muscle }}(30.4 \pm 3.1 \mathrm{AU})$ were similar during both study periods. The area under the parameter-time curves after placebo and DHE did not differ statistically (Table 7.1). The time course of the forearm vascular resistance was comparable after placebo and DHE (Fig. 7.1E). 

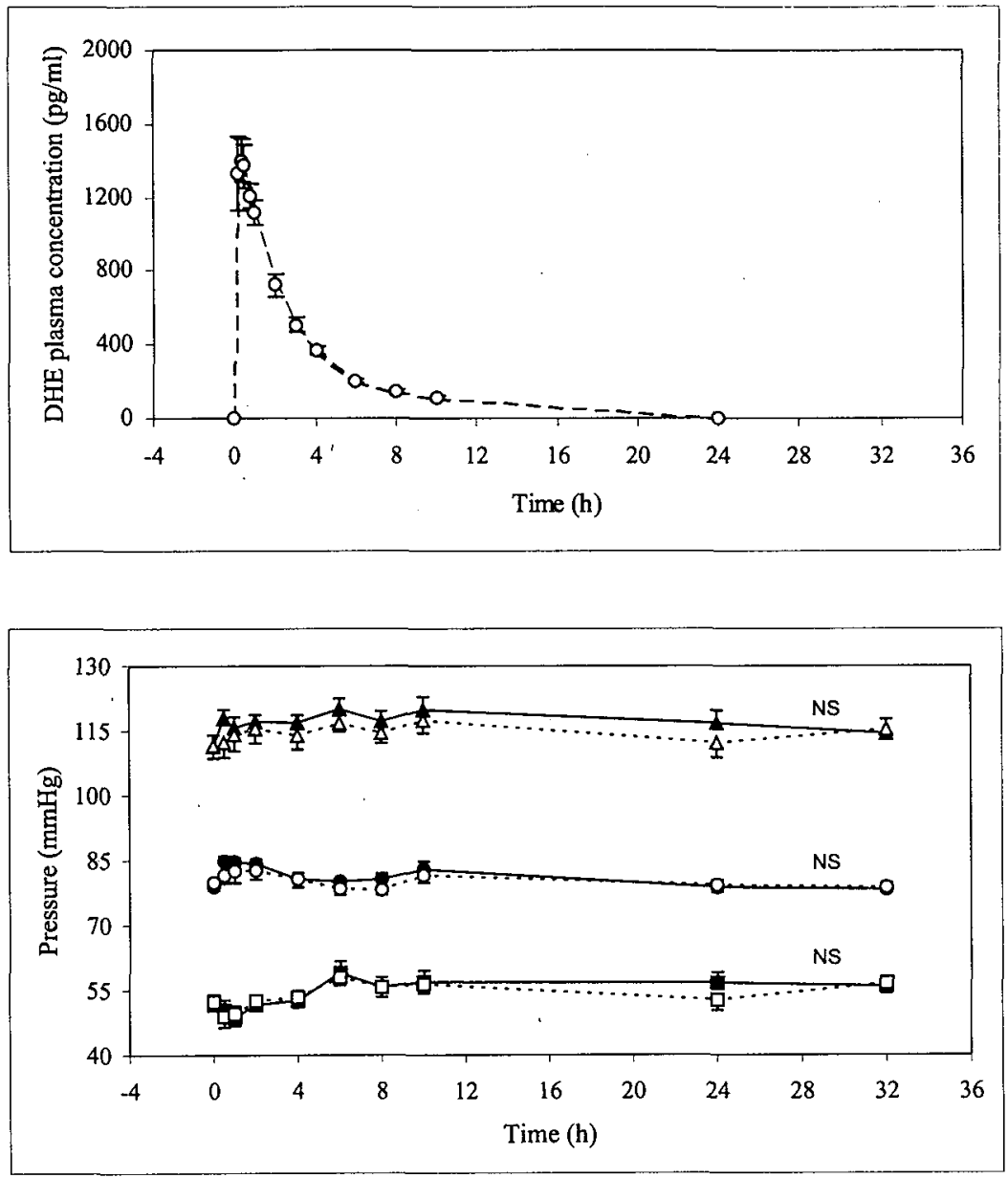

Figure 7.1 Top left: the plasma-concentration time curve of dihydroergotamine (DHE) after a single subcutaneous administration of $0.5 \mathrm{mg}$. Bottom left: time course of systolic blood pressure $(\Delta, \mathbf{A})$, mean arterial pressure $(\circ, \bullet)$ and pulse pressure $(\square, \boldsymbol{\Sigma})$ after placebo (open symbols, dashed line) and DHE (closed symbols, solid line); Time course of brachial artery diameter (top right) and isobaric compliance (middle right) after placebo ( $\square$, dashed line) and DHE ( $\square$, solid line). Bottom right: time course of total forearm vascular resistance after

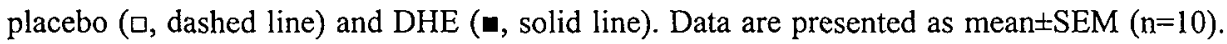
*Points in time with $P<0.05$ for difference between DHE and placebo; NS: no statistically significant difference. 
Dihydroergotamine: vascular effects and pharmacokinetics
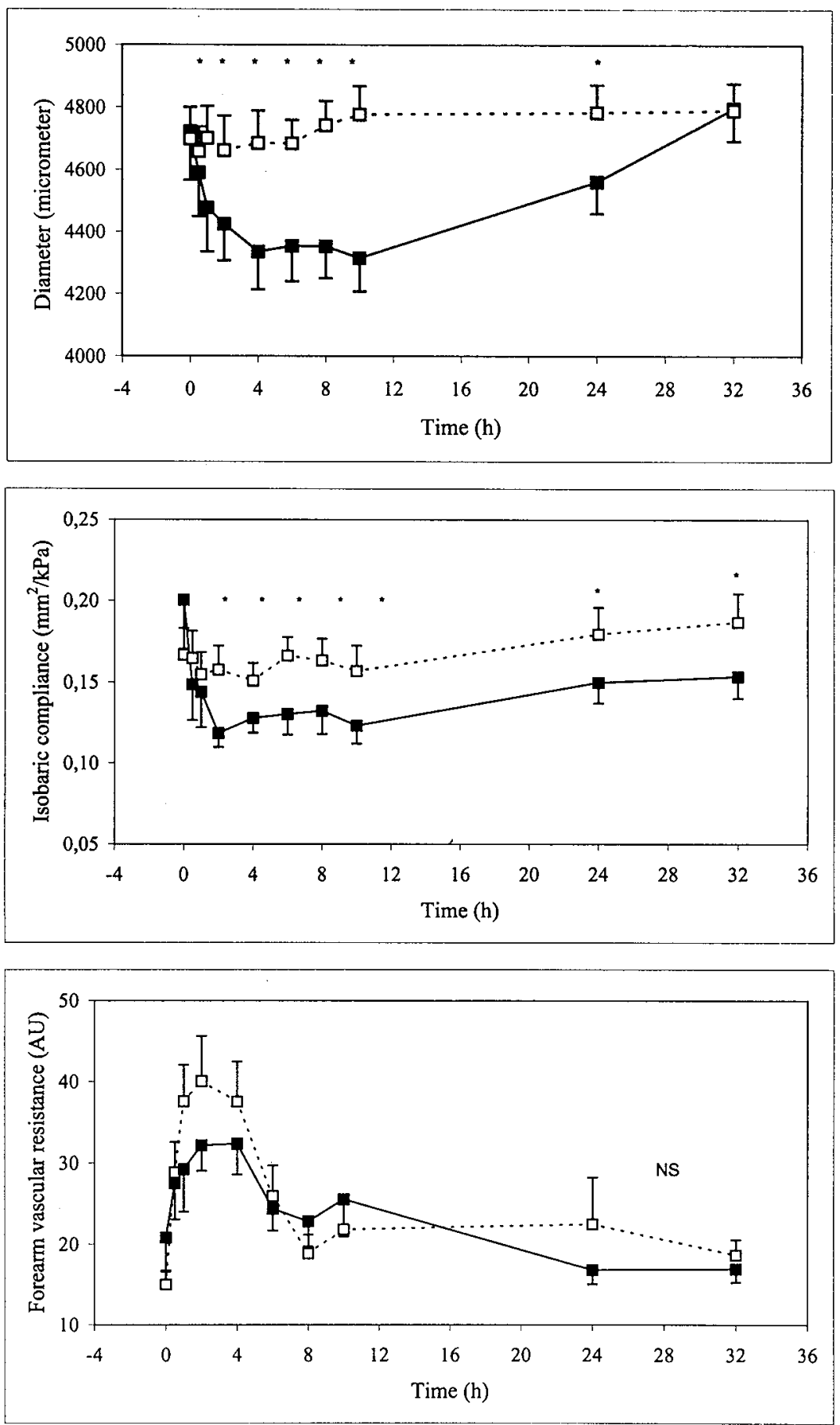
Chapter 7

Table 7.1 Pharmacodynamic data $(n=10)$.

$\triangle A U C(95 \% C I) \quad P$-value*

Haemodynamic parameters

$\begin{array}{lll}\text { Systolic blood pressure (mmHg.h) } & 90(-11 / 191) & 0.07 \\ \text { Diastolic blood pressure (mmHg.h) } & 47(-40 / 133) & 0.26 \\ \text { Mean arterial pressure (mmHg.h) } & 17(-63 / 96) & 0.65 \\ \text { Pulse pressure (mmHg.h) } & 43(-23 / 110) & 0.18 \\ \text { Heart rate (bpm.h) } & 31(-71 / 134) & 0.51\end{array}$

Brachial artery wall properties

$$
\begin{aligned}
& \text { Diameter }(\mathrm{mm} \cdot \mathrm{h}) \\
& \text { Distension }(\mu \mathrm{m} \cdot \mathrm{h}) \\
& \mathrm{DC}_{\text {iso }}\left(10^{-3} \cdot \mathrm{kPa}^{-1} \cdot \mathrm{h}\right) \\
& \mathrm{CC}_{\text {iso }}\left(\mathrm{mm}^{2} \cdot \mathrm{kPa}^{-1} \cdot \mathrm{h}\right)
\end{aligned}
$$

$\begin{array}{ll}-8.812(-12.97 /-4.650) & 0.001 \\ -790(-1359 /-222) & 0.012 \\ -17.5(-47.7 / 12.6) & 0.22 \\ -0.98(-1.61 /-0.34) & 0.007\end{array}$

$-62(-246 / 121)$

0.46

$52(-94 / 199)$

Pharmacodynamic data after the subcutaneous administration of $0.5 \mathrm{mg}$ DHE. Data are presented as mean difference between the area under the parameter-time curve after placebo and after DHE $(\triangle \mathrm{AUC}) .95 \% \mathrm{CI}$ : 95\% confidence interval. $\mathrm{DC}_{\text {iso }}$ (isobaric distensibility coefficient) and $\mathrm{CC}_{\text {iso }}$ (isobaric cross-sectional compliance) calculated within a pre-defined pressure interval of $85-95 \mathrm{mmHg} . F \mathrm{FR}_{\text {total }}$ and $\mathrm{FVR}_{\text {musclc: }}$ total and muscular forearm vascular resistance. * $P$-value of treatment differences by paired Student's $t$-test. 


\subsection{Discussion}

The vascular effects of ergot alkaloids depend on the dose and route of administration, the species and tissue under investigation and the pre-existing vascular tone [4]. In the present study both the arterial and arteriolar effects of DHE were investigated at the level of the forearm after the administration of $0.5 \mathrm{mg}$, which is regarded a clinically relevant dose and is being used in the acute treatment of migraine [22]. Following drug administration, both brachial artery diameter and cross sectional compliance, slowly decreased (from 1 to 2 hours after drug administration) and remained decreased for at least 24 hours. These data do not support the contention of DHE being a selective venoconstrictor and argue against DHE lacking peripheral arterial effects as reported by Andersen et al [14]. However, their data should be interpreted with caution. Andersen et al. assessed arterial effects indirectly by measuring changes in toe-arm systolic blood pressure gradients whereas the present data refer to direct measurements at the brachial artery. Consequently, regional differences between the upper and lower extremities in vascular reactivity to DHE might have contributed to these conflicting results. In addition, it should be noted that in contrast with the present study, the previous study was not placebo-controlled and did not feature a double-blind design.

In contrast with the effects of DHE on conduit arteries, at resistance vessels no drug-induced changes were observed in the present study. Neither total nor muscular forearm vascular resistance were affected by DHE and blood pressure did not change, indicating the absence of both local and systemic vasoconstriction of resistance vessels. These findings are in agreement with previous research demonstrating that DHE does not affect skeletal muscle perfusion [23]. Finally, although blood pressure is often reported to rise in response to DHE [4], the absence of a systemic vasopressor effect under experimental conditions similar to those of the present study is not exceptional $[10,24]$ and is likely due to the low dose of DHE administered. Taken together our data demonstrate that at the dose used, DHE induces a potent and longlasting arterial vasoconstriction and decreases compliance without affecting resistance vessels of the forearm. These data illustrate the well known potential of vasoactive drugs to act selectively at one vascular territory without affecting the other and remind 
of a complexity which should be kept in mind when the vascular effects of drugs are being investigated [25].

The pharmacokinetic parameters observed in the present study are comparable with those previously reported after the parenteral administration of DHE [21, 26, 27]. After subcutaneous administration DHE was quickly taken up into the systemic circulation and reached peak plasma concentrations within 30 minutes. Following absorption, DHE plasma levels rapidly declined in a biphasic fashion, suggesting fast tissue distribution into a peripheral compartment before being eliminated. Although the terminal half-life observed in the present study is in agreement with several previous reports $[21,27,28]$, others disagree and report a much slower elimination [24]. Different results are probably related to different analytical assays used to determine DHE plasma concentrations and to different dosages of the drug. Because of the relative low dose of DHE administered in the present study and despite the use of a validated RIA, from $24 \mathrm{~h}$ after drug administration plasma levels were below the detection limit. Consequently, it cannot be excluded that terminal half-life was underestimated.

In accordance with its potent and long lasting venoconstrictor activity reported by Aellig et al. $[8,10]$, the arterial effects of DHE observed in the present study are also characterised by a slow onset and long duration of action which correlates poorly with plasma levels. How can the discrepancy between the pharmacokinetics of DHE and its prolonged vascular activity be explained? The long terminal half-life of DHE as reported by some investigators [24] provides one explanation. Alternatively, the extensive metabolism of DHE results in the formation many active metabolites [29]. The main metabolite, 8 'hydroxy-dihydroergotamine, occurs in plasma in concentrations 5 to 7 times higher than the parent drug and has previously been shown to have potent and long lasting venoconstrictor activity in man [30]. Although these arguments provide a possible explanation for the prolonged vascular activity of DHE in vivo, they do not explain the sustained vasoconstrictor activity of ergot alkaloids in vitro which persists even after repeated washing [11, 12]. Therefore, tight tissue binding resulting in slow diffusion from the receptor biophase is likely to contribute substantially to these effects. This is also suggested by the large volume of distribution. As ergotamine displays a comparable discrepancy between 
pharmacokinetics and long lasting arterial vasoconstriction [13] as well as an increase in arterial stiffness [31], these properties seem to be a common characteristic of the ergot alkaloids as a class.

How do these vascular effects translate into the therapeutic use of DHE which is indicated in the treatment of orthostatic hypotension and acute migraine? In orthostatic hypotension the beneficial effects of DHE are believed to result from the constriction of venous capacitance vessels thereby promoting venous return and subsequently increasing cardiac output [4]. In migraine however, many mechanisms have been proposed, including constriction of large cranial extracerebral arteries and closure of arteriovenous anastomoses [2]. It is tempting to speculate that at the cranial arteries ergot alkaloids display the same long lasting vascular effects as at peripheral arteries. If so, this might explain why headache recurrence after the initially successful treatment of acute migraine is far less frequent after the use of DHE compared to the use of short acting 5-HT $\mathrm{HB}_{1 \mathrm{1} / \mathrm{D}}$-receptor agonists such as sumatriptan [32].

In summary, DHE decreases brachial artery diameter and compliance, while forearm vascular resistance remains unchanged. Consequently, DHE acts on large arteries without affecting resistance vessels. Furthermore, a discrepancy was demonstrated between the plasma concentrations of DHE which rapidly reach peak levels and quickly decline, and its long lasting vasoconstrictor activity.

\section{Acknowledgements:}

We are greatly indebted to G. Kalafsky and D. Katzgrau (Novartis Pharmaceuticals Corporation, Drug Metabolism and Pharmacokinetics, East Hannover, New Jersey, U.S.A.) for performing dihydroergotamine plasma concentration assessments.

\subsection{References}

1. Silberstein SD, Young WB. Safety and efficacy of ergotamine tartrate and dihydroergotamine in the treatment of migraine and status migrainosus. Neurology 1995;45:577-584.

2. Silberstein SD. The pharmacology of ergotamine and dihydroergotamine. Headache 1997;37:S15-S25. 
3. The Dihydroergotamine Nasal Spray Multicentre Investigators. Efficacy, safety and tolerability of dihydroergotamine nasal spray as monotherapy in the treatment of acute migraine. Headache 1995;35:177-184.

4. Clark BJ, Chu D, Aellig WH. Actions on the heart and circulation. In: Berde B, Schild HO, editors. Ergot alkaloids and related compounds. Berlin, Heidelberg, New York: Springer-Verlag; 1978. p. 321-420.

5. Muller-Schweinitzer E. What is known about the action of dihydroergotamine on the vasculature in man? Int J Clin Pharmacol Ther Toxicol 1984;22(12):677-682.

6. Saxena PR, Den Boer MO. Pharmacology of antimigraine drugs. $J$ Neurol 1991;238:S28-S35.

7. Muller-Schweinitzer E, Rosenthaler J. Ex vivo studies after oral treatment of the beagle with dihydroergotamine. Eur J Pharmacol 1983;89:1-8.

8. Aellig WH. A new technique for recording compliance of human hand veins. $\mathrm{Br} J \mathrm{Clin}$ Pharmacol 1981;11:237-243.

9. de Marees H, Welzel D, de Marees A, Klotz U, Tiedjen KU, Knaup G. Relationship between the venoconstrictor activity of dihydroergotamine and its pharmacokinetics during acute and chronic oral dosing. Eur J Clin Pharmacol 1986;30:685-689.

10. Aellig WH, Rosenthaler J. Venoconstrictor effects of dihydroergotamine after intranasal and intramuscular administration. Eur J Clin Pharmacol 1986;30:581-584.

11. Ostergaard JR, Mikkelsen E, Voldby B. Effects of 5-hydroxytryptamine and ergotamine on human superficial temporal artery. Cephalalgia 1981;1:223-228.

12. Maassen van den Brink A, Reekers M, Bax WA, Ferrari MD, Saxena PR. Coronary sideeffect potential of current and prospective antimigraine drugs. Circulation 1998;98:2530.

13. Tfelt-Hansen P, Paalzow L. Intramuscular ergotamine: plasma levels and dynamic activity. Clin Pharmacol Ther 1985;37:29-35.

14. Andersen AR, Tfelt-Hansen P, Lassen NA. The effect of ergotamine and dihydroergotamine on cerebral blood flow in man. Stroke 1987;18:120-123.

15. Hoeks APG, Brands PJ, Smeets FAM, Reneman RS. Assessment of the distensibility of superficial arteries. Ultrasound Med Biol 1990;16:121-128.

16. Kelly R, Hayward C, Ganis J, Daley J, Avolio A, O'Rourke M. Noninvasive registration of the arterial pressure pulse waveform using high-fidelity applanation tonometry. $J$ Vasc Med Biol 1989;1(3):142-149.

17. de Hoon JNJM, Hoeks APG, Willigers JM, Van Bortel LMAB. Non-invasive assessment of pulse pressure at different peripheral arteries in man. Neth J Med 1998;52:A36. 
18. Benjamin N, Calver A, Collier J, Robinson B, Vallance P, Webb D. Measuring forearm blood flow and interpreting the responses to drugs and mediators. Hypertension 1995;25:918-923.

19. Lenders J, Janssen G-J, Smits P, Thien T. Role of the wrist cuff in forearm plethysmography. Clin Sci 1991;80:413-417.

20. Rosenthaler J, Munzer H, Voges R, Andres H, Gull P, Bolliger G. Immunoassay of ergotamine and dihydroergotamine using a common $3 \mathrm{H}$-labelled ligand as tracer for specific antibody and means to overcome experienced pitfalls. Int $\mathrm{J} \mathrm{Nucl} \mathrm{Med} \mathrm{Biol}$ 1984;11(1):85-89.

21. Schran HF, Tse FLS. Pharmacokinetics of dihydroergotamine following subcutaneous administration in humans. Int J Clin Pharmacol Ther Toxicol 1985;23(1):1-4.

22. Report of the Quality Standards Subcommittee of the American Academy of Neurology. Practice parameter: appropriate use of ergotamine tartrate and dihydroergotamine in the treatment of migraine and status migrainosus. Summary statement. Neurology 1995;45:585-587.

23. Mellander S, Nordenfelt I. Comparative effects of dihydroergotamine and noradrenaline on resistance, exchange and capacitance functions in the peripheral circulation. Clin Sci 1970;39:183-201.

24. Wyss PA, Rosenthaler J, Nuesch E, Aellig WH. Pharmacokinetic investigation of oral and IV dihydroergotamine in healthy subjects. Eur J Clin Pharmacol 1991;41:597-602.

25. Van Bortel LM, Spek JJ, Balkestein EJ, Sardina M, Struijker Boudier HA. Is it possible to develop drugs that act more selectively on large arteries? J Hypertens 1999;17:701705.

26. Schran HF, Bitz DW, DiSerio FJ, Hirsch J. The pharmacokinetics and bioavailability of subcutaneously administered dihydroergotamine, heparin and the dihydroergotamineheparin combination. Thromb Res 1983;31(1):51-67.

27. Humbert H, Cabiac M-D, Dubray C, Lavene D. Human pharmacokinetics of dihydroergotamine by nasal spray. Clin Pharmacol Ther 1996;60:265-275.

28. Schran HF, Tse FLS, Chang C-T, Hunt TL, Saxe MA, Ventura DF, et al. Bioequivalence and safety of subcutaneously and intrámuscularly administered dihydroergotamine in healthy volunteers. Cur Ther Res 1994;55(12):1501-1508.

29. Muller-Schweinitzer E. Pharmacological actions of the main metabolites of dihydroergotamine. Eur J Clin Pharmacol 1984;26:699-705. 
Chapter 7

30. Maurer G, Frick W. Elucidation of the structure and receptor binding studies of the major primary, metabolite of dihydroergotamine in man. Eur J Clin Pharmacol 1984;26:463470.

31. Barenbrock M, Spieker C, Witta J, Evers S, Hoeks APG, Rahn KH, et al. Reduced distensibility of the common carotid artery in patients treated with ergotamine. Hypertension 1996;28:115-119.

32. Winner P, Ricalde O, Le Force B, Saper J, Margul B. A double-blind study of subcutaneous dihydroergotamine versus subcutaneous sumatriptan in the treatment of acute migraine. Arch Neurol 1996;53:180-184. 


\section{Part IV}

\section{Discussion \& Synopsis}

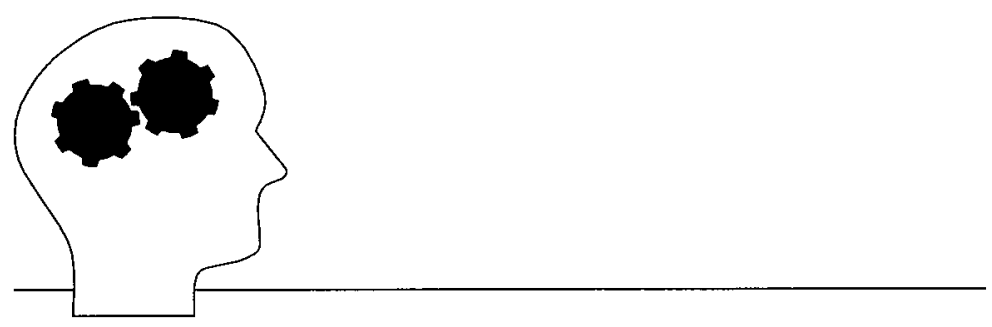


"I suspect the Tartar sauce I had for lunch ...

... disagreed with me."

(Sigmund Freud, 1856-1939) 


\section{Chapter 8}

\section{General Discussion and Conclusions}

\subsection{Interictal functional and structural arterial changes in migraine patients}

The objective of the present thesis was to study migraine and its treatment by investigating migraine pathophysiology and acute anti-migraine drugs from a cardiovascular point of view (Chapter 1). Although migraine has repeatedly been associated with peripheral vascular disorders [1-3], structural and functional extracranial vascular research has hardly ever been performed in migraine patients. Therefore, our first aim was to make an inventory of cardiovascular properties of migraine patients outside a migraine attack.

As described in Chapter 3, it was demonstrated that compared to matched control subjects during the interictal period migraine patients display both cranial and peripheral arterial changes. The most striking functional and structural vascular differences between both populations were observed at the medium sized muscular brachial artery displaying an increased stiffness and a tendency towards an increased intima-media thickness in migraine patients. In addition, migraineurs showed a larger temporal artery diameter and tended to have an increased temporal artery blood flow compared to control subjects.

What might be the cause of the changed vascular properties of peripheral conduit arteries in migraine patients? The contribution of arterial tone to vessel wall stiffness was already extensively discussed in Chapter 3. However, as both functional (arterial stiffness) and structural (intima-media thickness) changes were observed, alternative explanations should be considered. As CGRP has previously been demonstrated to be involved in the pathogenesis of migraine headache [4], it is tempting to speculate about its putative contribution to interictal vascular changes as well. CGRP has a 


\section{Chapter 8}

physiological role in the regulation of vascular tone and was shown to inhibit proliferation of cultured smooth muscle cells $[5,6]$. Consequently, a deficient basal release of CGRP could explain (i) an increased interictal arterial stiffness related to an increased vascular tone and (ii) intima-media thickening due to smooth muscle cell proliferation. This hypothesis is supported by the observation that migraine is associated with an increased incidence of Raynaud's Syndrome in which CGRP was shown to be deficient in digital cutaneous perivascular nerves $[7,8]$. Although the interictal plasma concentration of CGRP in migraine patients is similar to that in control subjects [4], based on the wide physiological range of circulating plasma concentrations of CGRP and the short half-life of the peptide [9], a decreased basal release cannot be excluded. Likewise, a decreased basal CGRP release does not exclude a paroxysmal excessive release of it as observed during acute migraine [4, $10]$.

It remains speculative as to what extent the peripheral vascular changes in migraine patients parallel changes at the level of the intra-cranial arteries. If so, one might wonder whether increased arterial wall stiffness can be regarded as a defence mechanism against unwanted vasodilatation and is meant to prevent the perivascular stimulation of supersensitive stretch receptors activating the trigeminovascular system during the interictal period.

\subsection{Migraine pathophysiology: a unifying hypothesis on CGRP and NO}

One of the intriguing and unanswered questions in migraine pathophysiology relates to the trigger initiating a migraine attack [11]. Although it is generally accepted that migraine is a neurovascular disorder [12], it remains a matter of debate whether perivascular nerve activation is responsible for secondary vasodilatation or vice versa (Chapter I). Regarding this issue NO and CGRP are considered to play a pivotal role. In order to better define the contribution of these molecules to the pathogenesis of migraine, the vascular responsiveness to both was further investigated in migraine patients (Chapter 4). 
Olesen and collaborators provided evidence indicating that migraine patients display an arterial supersensitivity to NO [13,14]. To improve our understanding of the concept of supersensitivity to NO, we compared the vascular responsiveness to both endogenous and exogenous NO between migraine patients and matched control subjects at the level of the forearm. The main finding was that neither for resistance arteries nor for conduit arteries the responsiveness to endogenous or exogenous NO was changed in migraine patients (Chapter 4). Likewise, the vascular responsiveness to CGRP did not differ between migraineurs and control subjects. Taken together these data do not support the hypothesis of a systemic vascular supersensitivity to NO in migraine patients and argue against a generalised change in vascular responsiveness as a primary cause of the disease. Obviously, the major limitation of our approach is the fact that the forearm vasculature might well behave differently compared to the cranial vasculature which is the territory of interest in acute migraine. As differences in receptor distribution and innervation could result in a different pharmacology for both territories our data do not exclude NO-supersensitivity at the cranial level. Alternatively, one might wonder whether supersensitivity to NO may be interpreted in terms of an increased sensitivity of perivascular nerves to NO instead of an increased sensitivity of the blood vessel wall itself (vide infra). If so, the lack of a difference in nitroprusside, 5-HT and flow-induced changes in forearm blood flow between migraine patients and control subjects in the present study may be explained by the low density of CGRP containing perivascular nerve fibres in the peripheral circulation compared to the cranial circulation [15].

As for CGRP, it is well established that this neuropeptide is a potent vasodilator involved in the pathogenesis of migraine $[4,10]$. However, its mechanism of action remains a matter of debate $[9,15]$. Depending on the species and tissue under investigation, at least three vasodilator mechanisms of action have been reported some of which are endothelium-independent [16-21] whereas others are endotheliumdependent $[22,23]$. Chapter 5, presents the first study in man investigating the vasodilator mechanism of action of (patho)physiological concentrations of CGRP in vivo. To this end, the "perfused forearm model" was used and the contribution of endothelial mediators (NO and prostaglandins) and potassium channels (ATP and 


\section{Chapter 8.}

calcium-sensitive $\mathrm{K}^{+}$-channels) to CGRP-induced vasodilatation was investigated. The results of this study allow to conclude that CGRP-induced vasodilatation of the resistance vessels of the human forearm is at least in part mediated by the release of NO whereas prostaglandins or $\mathrm{K}^{+}$-channels do not seem to contribute substantially.

The discrepancy between the results of the present study (Chapter 5) and some previously reported in vitro data might be related to (i) inter-species, (ii) experimental and (iii) inter-tissue differences. As far as inter-species differences are concerned, in relation to (patho)physiology, human data are obviously more relevant than animal data. With regard to experimental differences, most data on the vasodilator mechanism of action of CGRP refer to research on isolated blood vessels $[16,17,19$, $22,23]$. Consequently, conflicting results might be related to data obtained under clinically irrelevant concentrations of CGRP or might be due to differences between in vivo and in vitro responses [22]. Regarding the "perfused forearm model", it must be recognised that the infusion of CGRP into the brachial artery lumen might result in an overestimation of the contribution of endothelial mechanisms compared to the physiological situation in which CGRP is released by perivascular nerves from the abluminal site. Finally, for inter-tissue differences, it is unknown to what extent the pharmacology of the forearm vasculature can be applied to the cranial vasculature implicating that extrapolation should be regarded as speculative.

Assuming that CGRP-induced vasodilatation is similar in peripheral and cranial vascular beds, what would be the implications of our findings in relation to migraine? Firstly, based on the observation that CGRP-induced vasodilatation in migraine patients is virtually identical to that induced in control subjects (Chapter 4), it is reasonable to expect that the vasodilator mechanism of action of CGRP is the same in both groups. Secondly, the fact that CGRP-induced vasodilatation is at least in part dependent on the release of NO (Chapter 5) whereas it has previously been shown that $\mathrm{NO}$ is involved in the regulation of neuropeptide release [24], suggests that the contribution of NO and CGRP to the pathophysiology of migraine might be reconciled in a unifying hypothesis. Indeed, Olesen's hypothesis on arterial NO supersensitivity [13] may not have to be interpreted as an increased responsiveness to NO of the vessel wall strictu sensu, but rather as an over-activation of perivascular 
nerves in response to a potentially noxious molecule. This over-activation would result in (i) a local process of neurogenic vasodilatation due to an excessive release of neuropeptides and (ii) the central transmission of a stimulus responsible for the sensation of pain. This hypothesis fits well with Moskowitz theory [25] of the trigeminovascular system playing a pivotal role in the pathogenesis of migraine and explains the increase in CGRP during a migraine attack as reported by Goadsby and

\section{UNKNOWN TRIGGER}

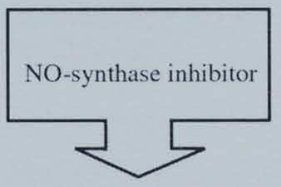

\section{MIGRAINE}

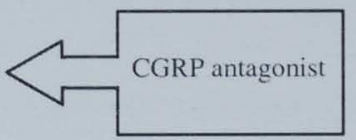

CGRP release
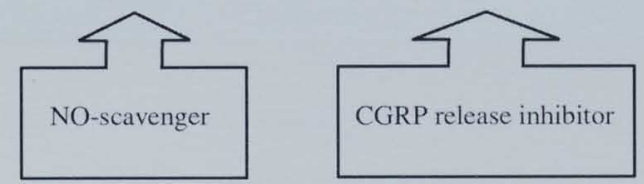

Fig. 8.1 Scheme illustrating a unifying hypothesis on the pathophysiology of migraine. An acute migraine attack is initiated by an unknown trigger releasing NO and/or CGRP which stimulate each others release and maintain a process of local vasodilatation. Based on the premise that this vicious circle should be interrupted in order to treat migraine, theoretical approaches for the future development of potential anti-migraine drugs are indicated. 


\section{Chapter 8}

collaborators [4]. Following our findings, CGRP would in turn stimulate the release of NO resulting in (i) a vasodilatation which might be interpreted as a defence mechanism of the brain to eliminate potentially noxious stimuli and (ii) a continuation of perivascular nerve activation, CGRP release and central pain transmission. This view is also supported by the fact that nitrates only induce typical migraine headache in migraine patients after a surprisingly long latency period [26], suggesting that NO is involved in the initiation of a slow pathological process which eventually leads to the attack [14]. In addition, although nitrate-induced headache is accompanied by vasodilatation, vasodilatation as such is unlikely to be the cause of the headache. Not only because of the delay between the fast vasodilatation and the slow onset of migraine-like headache induced by nitrates, but also because other potent vasodilators including CGRP have not been reported to cause headache [27].

In summary, it is suggested that migraine might be the consequence of a vicious circle resulting from interactions between NO and CGRP. Both a primary neurogenic or vascular event might cause the activation of this circle. However, once acute migraine is established, the stimulus initiating the onset of these neurovascular changes is only of secondary importance and treatment should be aimed at interrupting the process responsible for its continuation (Fig. 8.1).

\subsection{Cardiovascular effects of anti-migraine drugs}

In vitro data indicate that all currently available acute anti-migraine drugs contract both human coronary and cranial arteries with a potency and maximal effect comparable with that of sumatriptan [28-31]. For ergotamine, a non-selective compound, and sumatriptan, the first selective $5-\mathrm{HT}_{1 \mathrm{~B} / 1 \mathrm{D}}$ agonist which became available for the acute treatment of migraine, this vasoconstrictor potency has been confirmed in vivo [32-36]. Moreover, the use of both drugs has been associated with both myocardial infarction and sudden death [37-39] and rendered their use contraindicated in patients at increased risk for cardiovascular events. Therefore, recent research aimed at the development of anti-migraine drugs with a safer cardiovascular 
profile and resulted in the introduction of second-generation triptans. However, as the clinical relevance of the in vitro data on the vascular effects of these drugs remain speculative, in vivo human research was needed to better define their cardiovascular profile at clinically relevant plasma concentrations.

The research presented in Chapters 6 and 7 aimed at investigating the vascular effects of the most frequently used commercially available acute anti-migraine drugs: dihydroergotamine (DHE), sumatriptan (reference drug) and the second generation triptans rizatriptan and zolmitriptan. The data of these studies demonstrate that after the intake of equipotent therapeutic dosages, both DHE and selective $5-\mathrm{HT}_{1 \mathrm{~B} / \mathrm{DD}^{-}}$ receptor agonists induce a comparable vasoconstriction (about 10\%) and a similar decrease in compliance (about 20\%) of the brachial artery without affecting resistance vessels of the human forearm. For the triptans, for which these effects were also investigated at the carotid and temporal artery, the changes in arterial diameter and compliance are more pronounced at muscular compared to elastic arteries. In contrast with their effects on conduit arteries, triptans only increase vascular resistance in the vascular bed distal of the temporal artery, suggesting cranioselectivity for resistance vessels rather than for conduit arteries. Although zolmitriptan most potently affects the vascular territory of the temporal artery, this does not necessarily translate into a more favourable cardiovascular profile as it also most potently affected brachial artery wall properties.

Taken together, these data demonstrate that the intake of both ergot alkaloids and selective $5-\mathrm{HT}_{1 \mathrm{~B} / \mathrm{ID}}$-receptor agonists results in vascular effects (vasoconstriction and increased arterial stiffness) which are regarded as undesirable. Therefore, all currently available acute anti-migraine drugs should be used with caution in patients at increased risk for cardiovascular events.

Although cranial vasoconstriction is considered a prerequisite to yield a $5-\mathrm{HT}_{1 \mathrm{~B} / \mathrm{LD}}$-receptor agonist with anti-migraine activity [40], it is tempting to speculate that increasing vessel wall stiffness might be equally important. The pulsatile nature of migraine headache suggests that increased vascular pulsations are sensed by stretch receptors, resulting in the activation of perivascular nerve endings and the release of CGRP [41]. If so, increasing vessel wall stiffness per se, without obligatorily inducing 


\section{Chapter 8}

vasoconstriction, might sufficiently temper the activation of stretch receptors and render efficient anti-migraine drugs with a reduced risk of coronary vasoconstriction. Interestingly, both selective $5-\mathrm{HT}_{1 \mathrm{~B} / \mathrm{D}}$ receptor agonists and ergot alkaloids decrease arterial compliance (Chapters 6 and 7) [42], supporting the idea that decreasing the activation of perivascular nerves by increasing arterial stiffness might contribute to the efficacy of anti-migraine drugs. If so, it is tempting to speculate that a decrease in brachial artery compliance might be a useful surrogate marker for anti-migraine efficacy as it can be measured non-invasively in the early development of new potential anti-migraine drugs. By selecting those compounds which efficiently increase arterial stiffness without causing vasoconstriction at clinically relevant plasma concentrations, the cardiovascular safety of future drugs might be increased.

\subsection{From facts to future}

What are the implications of the finding that migraine patients display interictal functional and structural vascular changes compared to matched control subjects? Firstly, this supports the hypothesis of migraine being part of a generalised vascular disorder and indicates that at present the importance of the role of the vasculature might well be underestimated in the pathogenesis of migraine. Secondly, it is tempting to speculate that drugs normalising the interictal increase in arterial stiffness in migraine patients might be useful prophylactic agents. Interestingly, many of the currently available prophylactic anti-migraine drugs, including calcium antagonists and selective $\beta$-blockers, have indeed been shown to decrease arterial stiffness [43]. Thirdly, as the baseline vascular characteristics of migraine patients differ from those of non-migraineurs, migraine patients may display a different response to the administration of vasoactive substances in general and to anti-migraine drugs in particular. Thus, the cardiovascular effects of potential anti-migraine drugs should be carefully looked at both in healthy subjects and in migraine patients.

Regarding the future development of anti-migraine drugs, there is little reason to expect that any selective $5-\mathrm{HT}_{1 \mathrm{~B} / 1 \mathrm{D}}$-receptor agonist will be devoid of undesirable 
cardiovascular side effects. Due to their interaction with 5-HT $1 \mathrm{~B}^{\mathrm{B}}$-receptors, which are negatively coupled with adenylate cyclase activity, vasoconstriction can be regarded as a class effect of the triptans. Consequently, new avenues should be explored to develop effective and yet cardiovascular safe anti-migraine drugs. A possible future approach might be based on the well established release of CGRP during migraine headache, the putative role of $\mathrm{NO}$ and our findings on the interaction between both. Therefore, the development of CGRP-receptor antagonists, NO-synthase inhibitors or NO-scavengers seems to provide the most rational approach to tackle the problem (Fig. 8.1). In this context the efficacy results of the first non-peptide CGRP-receptor antagonist BIBN4096SB, which is currently being evaluated in the acute treatment of migraine [44], are being awaited with great expectations.

Unfortunately however, many issues remain unresolved, some of which might be elegantly investigated using the "perfused forearm model". Firstly, different CGRPreceptors have been identified and it is unsettled at present which receptor should be targeted to render an effective anti-migraine drug. Secondly, different constitutional and inducible isoforms of NO-synthase have been isolated but the isoform involved in CGRP-induced vasodilatation is unknown. Last but not least, as both CGRP and NO are involved in the regulation of vascular tone, it cannot be excluded that a compound interfering with either mediator will be bestowed with unwanted cardiovascular side effects. If so, history is likely to repeat itself and after the "triptan war" of the $20^{\text {th }}$ century, the $21^{\text {th }}$ century will become a new battlefield ...

\subsection{References}

1. Lafitte C, Even C, Henry-Lebras F, de Toffol B, Autret A. Migraine and angina pectoris by coronary artery spasm. Headache 1996;36:332-334.

2. Heupler FA. Syndrome of symptomatic coronary arterial spasm with nearly normal coronary arteriograms. Am J Cardiol 1980;45:873-881.

3. Miller D, Waters DD, Warnica W, Szlachcic J, Kreeft J, Theroux P. Is variant angina the coronary manifestation of a generalized vasospastic disorder? $N$ Engl $J$ Med 1981;304:763-766. 
4. Goadsby PJ, Edvinsson L, Ekman R. Vasoactive peptide release in the extracerebral circulation of humans during migraine headache. Ann Neurol 1990;28:183-187.

5. Portaluppi F, Vergnani L, Margutti A, Ambrosia MR, Bondanelli M, Transforini G, et al. Modulatory effect of the renin-angiotensin system on the plasma levels of CGRP in normal man. $J$ Clin Endocrinol Metab 1993;77:816-820.

6. Fiscus RR. CGRP inhibits proliferation of cultured bovine aortic smooth muscle cellspotential anti-atherogenic action of CGRP. FASEB 1993;7:791.

7. Zahavi I, Chagnac A, Hering R, Davidovich S, Kuritzky A. Prevalence of Raynaud's phenomenon in patients with migraine. Arch Intern Med 1984;144:742-744.

8. Bunker CB, Terenghi G, Springall DR, Polak JM, Dow DM. Deficiency of CGRP in Raynaud's phenomenon. Lancet 1990;336:1530-1533.

9. Bell D, McDermott BJ. Calcitonin gene-related peptide in the cardiovascular system: characterization of receptor populations and their (patho)physiological significance. Pharmacol Rev 1996;48(2):253-288.

10. Edvinsson L, Goadsby PJ. Neuropeptides in migraine and cluster headache. Cephalalgia 1994;14:320-327.

11. Moskowitz MA. Neurogenic versus vascular mechanisms of sumatriptan and ergot alkaloids in migraine. Trends Pharmacol Sci 1992;13:307-311.

12. Moskowitz MA, Macfarlane R. Neurovascular and molecular mechanisms in migraine headaches. Cerebrovasc Brain Metab Rev 1993;5(3):159-177.

13. Olesen J, Thomsen LL, Iversen H. Nitric oxide is a key molecule in migraine and other vascular headaches. Trends Pharmacol Sci 1994;15:149-153.

14. Olesen J, Thomsen LL, Lassen LH, Olesen IJ. The nitric oxide hypothesis of migraine and other vascular headaches. Cephalalgia 1995;15:94-100.

15. Zaidi M, Moonga BS, Bevis PJ, Bascal ZA, Breimer LH. The calcitonin gene peptides: biology and clinical relevance. Crit Rev Clin Lab Sci 1990;28(2):109-174.

16. Edvinsson L, Fredholm B, Hamel E, Jansen I, Verrechia C. Perivascular peptides relax cerebral arteries concomitant with stimulation of cyclic adenosine monophosphate accumulation or release of an endothelium-derived relaxing factor in the cat. Neurosci Lett 1985;58:213-217.

17. Greenberg B, Rhoden K, Barnes P. Calcitonin gene-related peptide (CGRP) is a potent non-endothelium-dependent inhibitor of coronary vasomotor tone. $\mathrm{Br} J$ Pharmacol 1987;92:789-794. 
18. Nelson MT, Huang Y, Brayden JE, Hescheler J, Standen NB. Arterial dilations in response to calcitonin gene-related peptide involve activation of $\mathrm{K}^{+}$channels. Nature 1990;344:770-773.

19. Franco-Cereceda A. Calcitonin gene-related peptide and human epicardial coronary arteries: presence, release and vasodilator effects. $B r J$ Pharmacol 1991;102:506-510.

20. Kitazono T, Heistad DD, Faraci FM. Role of ATP-sensitive $\mathrm{K}^{+}$channels in CGRPinduced dilatation of basilar artery in vivo. Am J Physiol 1993;34:H581-H585.

21. Luu TN, Dashwood MR, Tadjkarimi S, Chester AH, Yacoub MH. ATP-sensitive potassium channels mediate vasodilation produced by calcitonin gene-related peptide in human internal mammary but not gastroepiploic arteries. Eur $J$ Clin Invest 1997;27:960-966.

22. Thom SM, Hughes AD, Goldberg P, Martin G, Schachter M, Sever P. The actions of calcitonin gene-related peptide and vasoactive intestinal peptide as vasodilators in man in vivo and in vitro. Br J Clin Pharmacol 1987;24:139-144.

23. Gray DW, Marshall I. Human alfa-calcitonin gene-related peptide stimulates adenylate cyclase and guanylate cyclase and relaxes rat thoracic aorta by releasing nitric oxide. Br J Pharmacol 1992;107:691-696.

24. Wei EP, Moskowitz MA, Boccalini P, Kontos HA. Calcitonin gene-related peptide mediates nitroglycerin and sodium nitroprusside-induced vasodilation in feline cerebral arterioles. Circ Res 1992;70:1313-1319.

25. Moskowitz MA, Reinhard JFJ, Romero J, Melamed E, Pettibone DJ. Neurotransmitters and the fifth cranial nerve: Is there a relationship to the headache phase of migraine? Lancet $1979 ; 2: 883-885$.

26. Thomsen LL, Kruuse C, Iversen HK, Olesen J. A nitric oxide donor (nitroglycerin) triggers genuine migraine attacks. Eur J Neurol 1994;1:73-80.

27. Shekhar CY, Anand IS, Sarma R, Ferrari R, Wahi PL, Poole-Wilson PA. Effects of prolonged infusion of human alpha calcitonin gene-related peptide on hemodynamics, renal blood flow and hormone levels in congestive heart failure. Am $J$ Cardiol $1991 ; 67: 732-736$.

28. Maassen van den Brink A, Reekers M, Bax WA, Ferrari MD, Saxena PR. Coronary side-effect potential of current and prospective antimigraine drugs. Circulation 1998;98:25-30. 
Chapter 8

29. Maassen van den Brink A, Van den Broek RWM, De Vries R, Saxena PR. Human middle meningeal and coronary artery contraction to eletriptan and sumatriptan. Cephalalgia 1999;19:399.

30. Longmore J, Hargreaves RJ, Razzaque Z, Schofield WN, Shaw D, Smith D, et al. Rizatriptan selectively contracts human isolated middle meningeal artery over coronary artery: comparisons with sumatriptan. Cephalalgia 1997;17:388.

31. Longmore J, Razzaque Z, Shaw D, Davenport AP, Maguire J, Pickard JD, et al. Comparison of the vasoconstrictor effects of rizatriptan and sumatriptan in human isolated cranial arteries: immunohistological demonstration of the involvement of 5-HT1B-receptors. Br J Clin Pharmacol 1998;46:577-582.

32. Clark BJ, Chu D, Aellig WH. Actions on the heart and circulation. In: Berde B, Schild HO, editors. Ergot alkaloids and related compounds. Berlin, Heidelberg, New York: Springer-Verlag; 1978. p. 321-420.

33. Muller-Schweinitzer E. What is known about the action of dihydroergotamine on the vasculature in man? Int J Clin Pharmacol Ther Toxicol 1984;22(12):677-682.

34. MacIntyre PD, Bhargava B, Hogg KJ, Gemmill JD, Hillis WS. The effect of I.V. sumatriptan, a selective 5-HT1-receptor agonist on central haemodynamics and the coronary circulation. Br J Clin Pharmacol 1992;34:541-546.

35. MacIntyre PD, Bhargava B, Hogg KJ, Gemmill JD, Hillis WS. Effects of subcutaneous sumatriptan, a selective 5HT1 agonist, on the systemic, pulmonary, and coronary circulation. Circulation 1993;87:401-405.

36. Hood S, Birnie D, Hillis S. The haemodynamic effects of subcutaneous sumatriptan, a 5HT1-receptor agonist. Br J Clin Pharmacol 1997;43:327-328.

37. Galer BS, Lipton RB, Solomon S, Newman LC, Spierings ELH. Myocardial ischemia related to ergot alkaloids: a case report and literature review. Headache 1991;31:446451.

38. Ottervanger JP, Paalman HJ, Boxma GL, Stricker BH. Transmural myocardial infarction with sumatriptan. Lancet 1993;341:861-862.

39. Main ML, Ramaswamy K, Andrews TC. Cardiac arrest and myocardial infarction immediately after sumatriptan injection. Ann Intern Med 1998;128:874.

40. Pauwels PJ, John GW. Present and future of 5-HT receptor agonists as antimigraine drugs. Clin Neuropharmacol 1999;22:123-136.

41. Moskowitz MA. Basic mechanisms in vascular headache. Headache 1990;8:801-815. 
42. Barenbrock M, Spieker C, Witta J, Evers S, Hoeks APG, Rahn KH, et al. Reduced distensibility of the common carotid artery in patients treated with ergotamine. Hypertension 1996;28:115-119.

43. Van Bortel LMAB, Kool MJF, Struijker-Boudier HAJ. Effects of antihypertensive agents on local arterial distensibility and compliance. Hypertension 1995;26:531-534.

44. Doods H, Hallermayer G, Wu D, Entzeroth M, Rudolf $K$, Engel W, et al. Pharmacological profile of BIBN4096BS, the first selective small molecule CGRP antagonist. Br J Pharmacol 2000;129:420-423. 
A migraine is not a headache, An anti-migraine drug is not a headache pill.

(London-Underground, 2000) 


\section{Chapter 9}

\section{Summary - Samenvatting}

\subsection{Summary}

After summarising the epidemiology, clinical features and diagnostic criteria of migraine, Chapter 1 provides a historical overview on the pathophysiology of the disorder. Both the primary vascular and neuronal theory are discussed and reconciled in a unifying hypothesis regarding migraine as a neurovascular disease. The triggers which might be involved in initiating an acute migraine attack are summarised. Subsequently, a review is given of the currently available acute anti-migraine drugs. This review focuses on the mode of action and cardiovascular effects of these drugs and elaborates on recent research aimed at the development of safer compounds. Finally, the arguments suggesting a relation between migraine and cardiovascular disease in general are being commented on.

Chapter 2 discusses the methods for haemodynamic assessments used in this thesis. Ultrasound technology and venous occlusion plethysmography constituted the main techniques to assess large artery wall properties, tissue perfusion and endothelial function both in an invasive (the "perfused forearm model") and in a non-invasive setting. For the assessment of large artery wall properties, a "novel" approach is out-lined consisting of: (i) the use of a robotic arm for fixing the ultrasound probe during measuring vessel wall movements, (ii) the calculation of local pulse pressures and (iii) the combined analysis of diameter-time and pressure-time recordings. 


\section{Chapter 9}

The objective of the present thesis is to study migraine and its treatment by performing human in vivo cardiovascular research on migraine pathophysiology and acute antimigraine drugs. The specific Aims are: 1. to make an inventory of both the structural and functional cardiovascular properties of migraine patients during the interictal period, 2 . to investigate the vasodilator mechanism of action of calcitonin gene-related peptide (CGRP) which is regarded to contribute substantially to the pathophysiology of migraine, and 3. to study the cardiovascular effects of therapeutic dosages of acute anti-migraine drugs in human.

It has frequently been suggested that migraine might be part of a more generalised vascular disorder. This hypothesis was challenged in Chapter 3 by comparing the cardiovascular properties of migraine patients with or without aura during the interictal period with those of matched control subjects. Using ultrasound, large artery wall properties of the common carotid, temporal, brachial and femoral artery were measured and cardiac parameters were assessed. The most striking functional and structural vascular differences between both groups were observed at the medium sized brachial artery displaying an increased arterial stiffness and a tendency towards an increased intima-media thickness in migraine patients. In addition, migraineurs showed a larger temporal artery diameter and tended to have an increased temporal artery blood flow compared to control subjects. These data demonstrate that even outside the headache phase, migraine patients display vascular changes which extend beyond the cranial circulation pointing to the potential importance of the vasculature in the pathogenesis of migraine.

Nitric oxide (NO) and CGRP are probably involved in the pathophysiology of acute migraine headache. Chapter 4 explores the hypothesis of migraine patients displaying a changed vascular responsiveness to NO, CGRP and ischaemia during the interictal period. Ten migraine patients and ten matched control subjects participated in this study in which both invasive (part I) and non-invasive (part II) techniques were applied. In part 
$I$, the "perfused forearm model" was used and the vascular responsiveness to intrabrachial infusions of (i) serotonin, (ii) sodium nitroprusside, and (iii) CGRP were assessed. In part II, flow-mediated vasodilatation of the brachial artery and maximal forearm vasodilator potential were measured. Neither for NO nor for CGRP a changed vascular responsiveness was demonstrated at the level of resistance vessels of the human forearm in migraine patients. As maximal post-ischaemic forearm blood flow was similar in both groups, there is no evidence suggesting structural differences at the level of resistance vessels either. In addition, flow-mediated vasodilatation did not differ between migraine patients and matched control subjects arguing against a supersensitivity to NO for conduit arteries as well. Taken together, these data do not support the hypothesis of a systemic vascular supersensitivity to NO in migraine patients and do not support generalised functional vascular changes as a primary cause of the disease. In addition, no structural differences are present at the level of peripheral resistance vessels either.

Depending on the species and tissue under investigation in vitro studies show that the vasodilator mechanism of action of CGRP involves endothelium-dependent and/or endothelium-independent mechanisms. Chapter 5 presents the first study to address the vasodilator mechanism of action of clinically relevant plasma concentrations of CGRP in vivo in human. It aimed at investigating the contribution of endothelial mediators (NO and prostaglandins) and $\mathrm{K}^{+}$-channels (calcium-sensitive potassium channels, $\mathrm{K}^{+} \mathrm{Ca}^{-}$ channels and adenosine-5'-triphosphate sensitive-potassium channels, $\mathrm{K}^{+}{ }_{\mathrm{ATP}}$-channels) to CGRP-induced vasodilatation. To this end, the "perfused forearm model" was used and the forearm vascular responses to increasing dosages of CGRP during co-infusion of either placebo (saline) or a selective inhibitor were investigated. The repeated co-infusion of CGRP with placebo (time-control experiments) demonstrated a dose-dependent and reproducible forearm vasodilator response to CGRP. Compared to placebo, the NOsynthase inhibitor $\mathrm{N}^{\mathrm{G}}$-monomethyl-L-arginine (L-NMMA) reduced the increase in forearm blood flow induced by CGRP. The absence of an inhibitory effect of L-NMMA on CGRP-induced vasodilatation at the highest dose of CGRP suggests that still other 
mechanisms are involved. The vasodilator response to CGRP was not affected by coinfusion of the cyclo-oxygenase inhibitor indomethacin, the $\mathrm{K}^{+} \mathrm{Ca}_{\mathrm{a}}$-channel blocker tetraethyl-ammonium chloride or the $\mathrm{K}_{\mathrm{ATP}}^{+}$-channel blocker glibenclamide. Based on these findings it can be concluded that in vivo in human the vasodilator response to CGRP is at least in part dependent on the local release of NO whereas it appears not to be related to the release of prostaglandins or the activation of $\mathrm{K}_{\mathrm{Ca}}^{+}$and $\mathrm{K}_{\text {ATP-Channels. }}^{+}$

Chapter 6 compares the vascular effects of sumatriptan, the first selective $5-\mathrm{HT}_{1 \mathrm{~B} / 1 \mathrm{D}^{-}}$ receptor agonist used in the acute treatment of migraine, with those of the secondgeneration triptans rizatriptan and zolmitriptan in migraine patients outside a migraine attack. Sixteen migraine patients participated in a double-blind, placebo-controlled, 4-way cross-over study. After the oral intake of equipotent therapeutic dosages of sumatriptan $(50 \mathrm{mg})$, rizatriptan $(10 \mathrm{mg})$, zolmitriptan $(2.5 \mathrm{mg})$ or placebo, measurements were performed at the common carotid, brachial and temporal artery. Triptan-induced changes in (i) large artery wall properties, (ii) tissue perfusion and (iii) endothelial function were assessed using ultrasound. Compared to placebo both sumatriptan and second-generation triptans caused a small blood pressure increase, induced arterial vasoconstriction and decreased the buffering capacity of conduit arteries. These effects were more pronounced at muscular compared to elastic arteries. In contrast with large artery wall properties, vascular resistance was only increased at the vascular bed distal of the temporal artery and suggests cranioselectivity of triptans for resistance vessels rather than for conduit arteries. Zolmitriptan most potently affected the vascular territory of the temporal artery, but also induced the largest decrease in brachial artery buffering capacity. Endothelial function, as assessed by flow-induced vasodilatation, did not differ between active treatments. Given the fact that the changes in large artery wall properties observed after the intake of sumatriptan and second-generation triptans were comparable, they can be regarded as a class effect of the triptans. Moreover, as these changes are generally considered as undesirable these data support the contention that triptans should be used with caution in patients at increased risk for cardiovascular events. 
The research presented in Chapter 7 was initiated because of the conflicting results between in vitro and in vivo data on the vascular effects of dihydroergotamine (DHE). Changes in brachial artery wall properties and forearm vascular resistance resulting from DHE ( $0.5 \mathrm{mg}$ subcutaneously) were assessed by comparing parameter-time curves after placebo and DHE. In addition, DHE pharmacokinetics were assessed using a twocompartment open model with an absorption phase. The study was performed in 10 healthy, male volunteers and featured a randomised, double-blind, placebo-controlled, cross-over design. DHE induced no changes in blood pressure, heart rate and forearm vascular resistance. Brachial artery diameter and compliance decreased from 1 until $24 \mathrm{~h}$ and from 2 until $32 \mathrm{~h}$ after DHE, respectively. In contrast, time to reach maximum plasma concentration of DHE averaged only about 20 minutes. Consequently, at the level of the forearm, DHE acts on conduit arteries without affecting resistance vessels. In addition, a discrepancy was demonstrated between the plasma concentrations of DHE, which rapidly reach peak levels and quickly decline, and its long lasting arterial effects.

By reconciling the results presented in the individual chapters, in Chapter $\mathbf{8}$ following hypotheses are discussed: (i) whether CGRP contributes to the interictal vascular changes observed in migraine patients, (ii) whether acute migraine results from a vicious circle driven by the actions of NO and CGRP, and (iii) whether drugs increasing arterial stiffness without causing vasoconstriction might be effective anti-migraine drugs with an improved cardiovascular safety profile. Finally, suggestions for future research and potential surrogate markers in the early development of both prophylactic and acute antimigraine drugs are made.

\subsection{Samenvatting}

Naast een samenvatting van de epidemiologie, klinische kenmerken en diagnostische criteria van migraine, geeft Hoofdstuk 1 een historisch overzicht van de pathofysiologie 


\section{Chapter 9}

van deze aandoening. Zowel de primair vasculaire als de primair neuronale theorie worden besproken en verenigd in een overkoepelende hypothese die migraine beschouwt als een neurovasculaire ziekte. De uitlokkende factoren die mogelijk betrokken zijn bij het ontstaan van een acute migraineaanval worden samengevat. Vervolgens wordt een overzicht gegeven van de thans beschikbare geneesmiddelen voor de acute behandeling van migraine. Hierbij wordt aandacht geschonken aan het werkingsmechanisme en de cardiovasculaire effecten van anti-migraine geneesmiddelen en wordt dieper ingegaan op recent onderzoek gericht op de ontwikkeling van veiliger geneesmiddelen. Tenslotte worden de argumenten besproken die er voor pleiten dat er mogelijk een verband bestaat tussen migraine en hart-vaatziekten.

Hoofdstuk 2 bespreekt de methoden voor het meten van hemodynamische effecten die in dit proefschrift gebruikt werden. Ultrageluid technieken en veneuze occlusie plethysmografie vormden de belangrijkste methoden voor het meten van vaatwandeigenschappen, weefsel doorbloeding en endotheelfunctie en dit zowel in een invasieve (het "geperfundeerde onderarmsmodel") als in een niet-invasieve benadering. Voor de meting van vaatwandeigenschappen van grote slagaders wordt een nieuwe aanpak beschreven bestaande uit: (i) het gebruik van een statief voor het stabilizeren van de ultrageluid probe tijdens het meten van de vaatwandbeweging, (ii) het berekenen van de lokale polsdruk en (iii) het gelijktijdig analyseren van diameter-tijd en druk-tijd registraties.

Het Doel van dit proefschrift bestaat erin om de pathofysiologie van migraine en de effecten van acute anti-migraine geneesmiddelen in vivo te bestuderen bij de mens met behulp van cardiovasculaire onderzoekstechnieken. De specifieke doelstellingen zijn de volgende: 1 . het evalueren van zowel de functionele als structurele eigenschappen van het hart-vaatstelsel van migrainepatiënten tijdens de interictale periode, 2. het onderzoeken van het vaatverwijdende mechanisme van calcitonin gene-related peptide (CGRP) dat wellicht een belangrijke rol speelt in de pathofysiologie van migraine, en 3 . het 
bestuderen van de cardiovasculaire effecten van acute anti-migraine geneesmiddelen na de toediening van een therapeutische dosis.

Er wordt vaak gesuggereerd dat migraine deel uitmaakt van een meer veralgemeende vasculaire aandoening. Om deze hypothese te toetsen werden in Hoofdstuk 3 de cardiovasculaire eigenschappen van migrainepatiënten, met of zonder aura, gedurende de interictale periode vergeleken met deze van een vergelijkbare groep controlepersonen. Met behulp van ultrageluid werden de vaatwandeigenschappen van de arteria carotis communis, arteria temporalis, arteria brachialis en arteria femoralis gemeten. De meest opvallende functionele en structurele verschillen tussen migrainepatiënten en controlepersonen werden vastgesteld ter hoogte van de arteria brachialis die een toegenomen stijfheid vertoonde evenals een tendens tot een toegenomen intima-media dikte. Bovendien hadden migrainepatiënten ter hoogte van de arteria temporalis een grotere diameter en een tendens tot toegenomen doorbloeding. Deze gegevens tonen aan dat migrainepatiënten, zelfs buiten een periode van hoofdpijn, vasculaire veranderingen vertonen die zich uitstrekken buiten het vaatgebied van het hoofd en wijzen op het potentiële belang van het vaatstelsel in de pathofysiologie van migraine.

Stikstofmonoxide (NO) en CGRP spelen wellicht een belangrijke rol in de pathofysiologie van migraine. Hoofdstuk 4 toetst de hypothese die stelt dat migrainepatiënten tijdens de interictale periode een gewijzigde vasculaire gevoeligheid vertonen voor NO, CGRP en ischemie. Tien migrainepatiënten en 10 vergelijkbare controlepersonen namen deel aan deze studie waarin zowel invasieve (deel 1) als nietinvasieve (deel 2) technieken gebruikt werden. In deel 1 , werd het "geperfundeerde onderarmsmodel" gebruikt om de vaatverwijding te bestuderen als gevolg van de intrabrachiale infusie van (i) serotonine, (ii) natrium nitroprusside en (iii) CGRP. In deel 2, werden de vaatverwijding van de arteria brachialis uitgelokt door toegenomen doorbloeding en de maximale onderarmsdoorbloeding gemeten. Noch voor NO, noch voor CGRP werd er een gewijzigde gevoeligheid vastgesteld ter hoogte van de 


\section{Chapter 9}

weerstandsvaten van de onderarm bij migrainepatiënten. Aangezien de maximale onderarmsdoorbloeding (na ischemie) vergelijkbaar was in beide groepen, is er evenmin een reden om aan te nemen dat er structurele verschillen zijn ter hoogte van de weerstandsvaten. Bovendien werd er geen verschil vastgesteld in de vaatverwijding van de arteria brachialis uitgelokt door een toename in doorbloeding, wat pleit tegen een overgevoeligheid voor NO ter hoogte van grote slagaders. Samengevat bevestigen deze gegevens niet de hypothese van een systemische vasculaire overgevoeligheid voor NO bij migrainepatiënten of van veralgemeende functionele veranderingen als primaire oorzaak van de aandoening. Structurele veranderingen op het niveau van perifere weerstandsvaten werden evenmin aangetoond.

Afhankelijk van de diersoort en het weefsel dat onderzocht wordt, toont in vitro onderzoek aan dat het vaatverwijdende mechanisme van CGRP zowel endotheelafhankelijk als endotheel-onafhankelijk verloopt. Hoofdstuk 5 beschrijft het eerste in vivo onderzoek bij de mens dat het vaatverwijdende mechanisme van CGRP bestudeert bij klinisch relevante plasmaconcentraties. De bijdragen van endotheliale mediatoren (NO en prostaglandines) en kalium-kanalen (calcium-gevoelige kalium-kanalen, $\mathrm{K}_{\mathrm{Ca}^{-}}^{+}$ kanalen en adenosine-5'-trifosfaat-gevoelige kalium-kanalen, $\mathrm{K}^{+}{ }_{\mathrm{ATP}}$-kanalen) aan de vaatverwijding veroorzaakt door CGRP werden onderzocht. Met behulp van het "geperfundeerde onderarmsmodel" werd de onderarmsdoorbloeding tijdens de infusie van toenemende doses CGRP samen met placebo (fysiologisch zout) of met een selectieve inhibitor gemeten. De herhaalde infusie van CGRP samen met placebo (tijdscontrole-experimenten) toonde aan dat CGRP leidt tot een dosis-afhankelijke en reproduceerbare toename in onderarmsdoorbloeding. In vergelijking met placebo, verminderde de NO-synthase inhibitor $\mathrm{N}^{\mathrm{G}}$-monomethyl-L-arginine (L-NMMA) de toename in onderarmsdoorbloeding door CGRP. Het ontbreken van een remmend effect van L-NMMA op de vaatverwijding veroorzaakt door de hoogste dosis CGRP, suggereert dat nog andere mechanismen een rol spelen. Het vaatverwijdende effect van CGRP werd niet beïnvloed door de gelijktijdige infusie van de cyclo-oxygenaseremmer 
indomethacine, de $\mathrm{K}_{\mathrm{Ca}^{-}}^{+}$-kanaalblokker tetra-ethyl-ammoniumchloride of de $\mathrm{K}_{\mathrm{ATP}^{-}}$ kanaalblokker glibenclamide. Op basis van deze bevindingen kan besloten worden dat in vivo bij de mens de vaatverwijding door CGRP ten minste gedeeltelijk berust op de lokale vrijstelling van $\mathrm{NO}$ en niet op de vrijstelling van prostaglandines of de activatie van $\mathrm{K}_{\mathrm{Ca}}^{+}$of $\mathrm{K}_{\text {ATP-kanalen. }}^{+}$

Hoofdstuk 6 vergelijkt bij migrainepatiënten tijdens de interictale periode de vasculaire effecten van sumatriptan, de eerste selectieve $5-\mathrm{HT}_{1 \mathrm{~B} / 1 \mathrm{D}}$-receptor agonist voor de behandeling van een acute migraineaanval, met deze van de tweede-generatie triptanen rizatriptan en zolmitriptan. Zestien migrainepatiënten namen deel aan een dubbel-blind, placebo-gecontroleerd, 4-weg cross-over onderzoek. Na de orale inname van doses met een vergelijkbare klinische efficaciteit (sumatriptan $50 \mathrm{mg}$, rizatriptan $5 \mathrm{mg}$, zolmitriptan $2,5 \mathrm{mg}$ ) of placebo werden, met behulp van ultrageluid, metingen verricht ter hoogte van de arteria carotis communis, arteria temporalis en arteria brachialis. Veranderingen in (i) vaatwandeigenschappen, (ii) weefseldoorbloeding en (iii) endotheelfunctie ten gevolge van de inname van triptanen werden onderzocht. In vergelijking met placebo resulteerden zowel sumatriptan als de tweede-generatie triptanen in een kleine bloeddruktoename, een arteriële vaatvernauwing en een afname van het bufferend vermogen van grote slagaders. Deze effecten waren duidelijker aanwezig ter hoogte van musculaire dan ter hoogte van elastische vaten. In tegenstelling tot de vaatwandeigenschappen nam de weerstand uitsluitend toe ter hoogte van het vaatbed van de arteria temporalis. Dit suggereert een cranioselectiviteit van triptanen voor weerstandsvaten eerder dan voor grote slagaders. Zolmitriptan had de meest potente effecten op het vaatgebied van de arteria temporalis, maar veroorzaakte eveneens de meest uitgesproken afname in het bufferend vermogen van de arteria brachialis. De vaatverwijding van de arteria brachialis, die veroorzaakt wordt door een toename in doorbloeding en welke gebruikt werd als maat voor endotheelfunctie, was niet verschillend voor de onderzochte triptanen. Gegeven het feit dat de veranderingen in vaatwand-eigenschappen veroorzaakt door sumatriptan en tweede-generatie triptanen vergelijkbaar waren, kunnen zij beschouwd worden als een 


\section{Chapter 9}

klasse-effect van de triptanen. Aangezien deze vasculaire veranderingen algemeen beschouwd worden als ongunstig, dragen deze bevindingen bij tot de stelling dat triptanen met de nodige voorzichtigheid dienen gebruikt te worden bij patiënten met een verhoogd cardiovasculair risico.

Het onderzoek in Hoofdstuk 7 werd uitgevoerd naar aanleiding van de discrepantie tussen de in vivo en in vitro resultaten van de vasculaire effecten van dihydroergotamine (DHE). Veranderingen in arteria brachialis vaatwand-eigenschappen en onderarmsweerstand ten gevolge van de toediening van DHE (0,5 mg subcutaan) werden gemeten door het vergelijken van het parameter-tijd verloop na placebo en DHE. Tevens werd de farmacokinetiek van DHE bepaald aan de hand van een open, tweecompartimentmodel met een absorptie fase. Aan dit dubbel-blind, placebo-gecontroleerd, cross-overonderzoek namen 10 gezonde mannelijke vrijwilligers deel. DHE veroorzaakte geen veranderingen in bloeddruk, hartfrequentie en onderarmsweerstand: De diameter en het bufferend vermogen van de arteria brachialis namen respectievelijk af van 1 tot 24 en van 2 tot 32 uur na DHE. Echter de maximale plasmaconcentratie van DHE werd gemiddeld reeds bereikt na 20 minuten. Bijgevolg heeft DHE ter hoogte van de onderarm een belangrijk effect op grote slagaders zonder de weerstandsvaten te beïnvloeden. Bovendien werd een discrepantie aangetoond tussen het plasmaconcentratie-verloop van DHE, dat snel piekwaarden bereikt en snel weer afneemt, en de langdurende arteriële effecten ervan.

In Hoofdstuk 8 worden door het samenvoegen van de onderzoeksresultaten van de individuele hoofdstukken, volgende hypothesen besproken: (i) of CGRP bijdraagt tot de interictale veranderingen van het vaatstelsel zoals we die bij migrainepatiënten hebben vastgesteld, (ii) of een acute migraineaanval het resultaat is van een vicieuze cirkel die in stand gehouden wordt door de effecten van NO en CGRP, en (iii) of medicijnen die de stijfheid van de vaatwand van grote slagaders doen toenemen, zonder vaatvernauwing te veroorzaken, effectieve en veilige anti-migraine medicijnen zouden kunnen zijn. 
Tenslotte worden suggesties gedaan in verband met toekomstig onderzoek en potentieel nuttige parameters in de vroege ontwikkeling van zowel preventieve als acute antimigraine geneesmiddelen. 
De weg is het doel.

(vrij naar de Koran) 


\section{Dankwoord - Acknowledgement}

Toen ik in 1995 als "naïf" arts-onderzoeker de toenmalige Vakgroep Farmacologie binnenwandelde op een zonnige nazomerse ochtend, kon ik me onmogelijk de omvang inbeelden van de opdracht die me te wachten stond. Het doel was duidelijk -het behalen van een doctorstitel- maar de weg die daartoe moest leiden was bijzonder vaag. Nu, zowat 5 jaar later, ben ik me er meer dan ooit van bewust dat ik zonder de leiding, steun en hulp van een groot aantal mensen nooit in deze opdracht zou geslaagd zijn. Alhoewel namen noemen het risico inhoudt dat sommigen vergeten worden, wens ik toch enkele mensen speciaal te vermelden.

Mijn promotoren, Prof. dr. H. Struijker-Boudier en Prof. dr. J. Troost, en co-promotor, Dr. L. Van Bortel, dank ik voor hun vertrouwen en voor de kans die ze me gegeven hebben om me als klinisch farmacoloog te ontplooien. Harry, je aanwezigheid was zelden prominent maar werd zeer gewaardeerd op beslissende momenten. Luc, je hebt me niet alleen een vorming als wetenschapper gegeven maar tevens een voorbeeld van "management beyond data-management". Ik hoop oprecht dat de voorbije jaren slechts het begin geweest zijn van een duurzame samenwerking in de toekomst.

Ing. J. Willigers wil ik bijzonder bedanken voor zijn zeer gewaardeerde hulp, gaande van het oplossen van de meest idiote technische problemen tot het uitwerken van gecompliceerde software. Jean, als technicus en als mens had ik me geen betere bio(psycho)fysicus kunnen bedenken.

Voor de onderzoeken beschreven in dit proefschrift, werd beroep gedaan op meer dan 200 vrijwilligers zonder wiens medewerking mijn werk onmogelijk zou zijn geweest. Yvonne, Lilian, Peter, Jacques en Leo zijn slechts enkele collega's die hun hart- 
vaatstelsel meermaals ter beschikking stelden van de wetenschap. Zij zijn er het levende bewijs van dat frequente blootstelling aan ultrageluid geen schadelijke effecten heeft. Ook Simone, Diana (zeer moedig), Lou en Peter van het laboratorium biochemie van het Akademisch Ziekenhuis Maastricht, behoorden tot de "vaste staf" (min of meer) gezonde controlepersonen. Onder de migrainepatiënten was het enthousiasme van enkele opvallende "slachtoffers" waaronder Loekie, Kim, Daniëlle, Peter en Erik een aangename stimulans in moeilijke perioden.

Prof. dr. P. Smits dank ik van harte voor het onderzoek dat op de afdeling Farmacologie en Toxicologie van de Katholieke Universiteit Nijmegen mocht plaatsvinden. Paul, dankzij jouw gastvrijheid en met de hulp van Peter Pickkers kreeg ik de kans om me op korte tijd de techniek van het onderarmsmodel eigen te maken.

De professoren P. Kitslaar, J. De Mey, P. Goadsby, A. Hoeks en P. Saxena ben ik zeer erkentelijk voor de beoordeling van mijn manuscript. In het bijzonder dank ik Arnold, voor de subtiele opmerking dat "scares" misschien wel hetzelfde klinkt als "scarce", maar toch net iets anders betekent.

De onderzoeksassistentes van de divisie klinische farmacologie: Mirjam, Carla en Karin vormden een onvergetelijk trio dat ik dank voor de prettige samenwerking. Mirjam, de ochtenduren wil ik hierbij even buiten beschouwing laten.

Al waren de sociale kontakten met de meesten van de Vakgroep Farmacologie beperkt, toch zal ik velen herinneren als bijzondere collega's. Matthijs, gedoodverfd als vlaaienvreter -al was zijn BMI nauwelijks hoog genoeg om aan klinische studies te mogen deelnemen- herinner ik als mijn eerste kamergenoot met wie ik het beginnersleed kon delen. Gregorio, Chris en Jan als back-up providers van de laatste hoop in geval van "a fatal error has occurred" en verwante obstakels. Jo, als pendelcompagnon tussen Mol en Maastricht met wie ik inspirerende uren doorbracht in de auto. Mia en Els, als een 
vrolijk duo secretaressen dat je problemen al opgelost had voor ze geformuleerd waren. Paul, als sportman steeds op zoek naar een nieuw record indoor-snelwandelen (enkel Jos vormt een ernstige concurrent), die een massa bio-analytische bepalingen verrichtte. Henk tenslotte, als senior farmacokineticus met wie zelfs negatieve interacties positief verliepen. Allen, bedankt voor je hulp en gezelschap.

I greatly appreciate the comments made on my thesis by Dr. P. Williams, Dr. M. Thomas and Dr. V. Libri from the clinical pharmacology unit of GlaxoWellcome in Greenford. Pauline, Malcolm and Vincenzo, each of you contributed to the final touch of this manuscript.

Mijn paranımfen, de dames P. Eekers en A. Maassen van den Brink, dank ik voor de zware verantwoordelijkheid die ze op zich hebben willen nemen om me moreel bij te staan tijdens de laatste hindernissen van mijn promotie-parcours. Patricia en Antoinette, na mijn promotie gaan we eens over andere dan hoofd-zaken brain-stormen (contradictio in terminis).

Mijn ouders dank ik voor de vrijheid die ze me gegeven hebben bij de keuze van mijn studies en hun steun tijdens mijn -in hun ogen- eeuwigdurende carrière als student. Ook mijn schoonouders dank ik voor hun interesse in mijn werk. Leo, bij het squashen kan ik je verslaan, maar voor de spelling van de Nederlandse taal sta ik graag de eer af aan jou.

Tenslotte, Ann. Elke uitspraak zou tekort doen aan jouw bijdrage tijdens mijn promotieperiode. Dat we samen van mijn doel onze weg konden maken, heb ik aan jou te danken ... 
"I took some cocaine, watched the migraine vanish at once, ..."

(Sigmund Freud, 1856-1939) 


\section{Curriculum vitae}

Jan de Hoon was born on the $8^{\text {th }}$ of May 1964 in Turnhout, Belgium. After finishing secondary school in 1982 (Sint Jozefcollege, Turnhout, Belgium) he studied chemistry at the university of Limburg (Limburgs Universitair Centrum, Diepenbeek, Belgium) and at the university of Antwerp (Universitaire Instelling Antwerpen, Antwerp, Belgium) where he obtained his scientific degree in chemical sciences on the $7^{\text {th }}$ of July 1986 with the highest distinction. In the same year he was awarded by the Flemish Chemical Society for his research project entitled "Contrast enhancement in nuclear magnetic resonance imaging: the coupling of proteins to paramagnetic ions and their influence on relaxation time" which was performed at the department of organic chemistry under the supervision of Prof. dr. F.C. Alderweireldt at the university of Antwerp. From 1986 until 1992 he studied medicine at the university of Leuven (Katholieke Universiteit Leuven, Leuven, Belgium) and got his degree as a medical doctor on June $30^{\text {th }} 1992$ with the highest distinction. Thereafter, he started his internship for internal medicine at the University Hospital Gasthuisberg of Leuven and affiliated hospitals. From 1995 until 1999 he was part-time appointed as an assistant in internal medicine at the department of General Internal Medicine (head Prof. dr. H. Bobbaers) of the University Hospital. During the same period he worked part-time as a research assistant at the department of Pharmacology and Toxicology at the University of Maastricht in The Netherlands. Under the guidance of Prof. dr. H.A.J. Struijker-Boudier and dr. L.M.A.B. Van Bortel he worked on a project entitled "Migraine and anti-migraine drugs: focus on cardiovascular aspects". On the $1^{\text {st }}$ of November 1998 he was registered as a clinical pharmacologist in The Netherlands and on the $16^{\text {th }}$ of August 1999 as a specialist in general internal medicine in Belgium. Since August 1999 he is appointed as a supervising clinical research physician at the Centre for Clinical Pharmacology of the University Hospital Gasthuisberg in Leuven. $\mathrm{He}$ is currently detached to the clinical pharmacology unit of GlaxoWellcome at Greenford in the United Kingdom where he is involved with early drug development in general and with research on new anti-migraine drugs in particular. He is married to Ann Van Hoof who is due to have their first child in November. 



\section{Bibliography}

\section{Full papers}

1. de Hoon J, Van Wijngaerden E, Peetermans W. Pneumocystis carinii pneumonie. Tijdschrift voor Geneeskunde 1996; 52 (2): 117-123.

2. J.N. de Hoon, W.E. Peetermans, H.J. Bobbaers. Pneumocystis carinii pneumonia: review of 32 cases in immunocompromised hosts. Acta Clin Belg 1997; 52 (1): 19-26.

3. L.M.A.B. Van Bortel, J.N.J.M. de Hoon, M.J.F. Kool, J.A.G. Wijnen, C.I.M. Vertommen, L.G.M. Van Nueten. Pharmacological properties of nebivolol in man. Eur J Clin Pharmacol 1997; 51 (5): 379-384.

4. J.N.J.M. de Hoon, F.H.M. Vanmolkot, L.L.M. van de Ven, L.M.A.B. Van Bortel: Quality of life comparison between bisoprolol and nifedipine retard in hypertension. Cardiovasc Drugs Ther 1997; 11: 465-471.

5. J.N.J.M. de Hoon, H.H.W. Thijssen, A.J.M.M. Beysens, L.M.A.B. Van Bortel: No effect of short-term omeprazole intake on acenocoumarol pharmacokinetics and pharmacodynamics. Br J Clin Pharmacol 1997; 44: 399-401.

6. F.H.M. Vanmolkot, J.N.J.M. de Hoon, L.L.M. van de Ven, L.M.A.B. Van Bortel. Impact of antihypertensive treatment on quality of life: comparison between bisoprolol and bendrofluazide. J Hum Hypertens 1999; 13: 559-563.

7. Jan N.J.M. de Hoon, Jean M. Willigers, Jaap Troost, Harry A.J. Struijker-Boudier, Luc M.A.B. Van Bortel. Vascular Effects of 5-HT $1 \mathrm{~B} / 1 \mathrm{D}-$ Receptor Agonists in Migraine Patients. Clinical Pharmacology and Therapeutics (accepted for publication). 
8. J.N.J.M. de Hoon, K.A. Poppe, H.H.W. Thijssen, H.A.J. Struijker-Boudier, L.M.A.B. Van Bortel. Dihydroergotamine: discrepancy between arterial, arteriolar and pharmacokinetic data. Submitted.

9. Jan N.J.M. de Hoon, Peter Pickkers, Paul Smits, Harry A.J. Struijker-Boudier, Luc M.A.B. Van Bortel. Mechanism of action of the vasodilator response to calcitonin gene-related peptide in human. Submitted.

10. J.N.J.M. de Hoon, J.M. Willigers, J. Troost, H.A.J. Struijker-Boudier, L.M.A.B. Van Bortel. Migraine patients display interictal changes in large artery wall properties. Submitted.

11. J.N.J.M. de Hoon, P. Smits, J. Troost, H.A.J. Struijker-Boudier, L.M.A.B. Van Bortel. Vascular responsiveness to nitric oxide and calcitonin gene-related peptide in migraine patients. Submitted.

\section{Abstracts}

1. J.N. de Hoon, M.J. Kool, J.A. Wijnen, C.I. Vertommen, L.G. Van Nueten, L.M. Van Bortel: Nebivolol: its pharmacological profile in man. Arch Int Pharmacodyn Ther 1996; 331(3): 330-331.

2. J.N.J.M. de Hoon, H.H.W. Thijssen, A.J.M.M. Beysens, L.M.A.B. Van Bortel: Pharmacokinetic and pharmacodynamic interaction study between omeprazole and acenocoumarol. Fundam Clin Pharmacol 1997; 11: 148.

3. Jan de Hoon, Floris Vanmolkot, Louis van de Ven, Luc Van Bortel: La qualité de vie sous bisoprolol et nifédipine retard. Arch Mal Coeur Vaisseaux 1996; 89(Suppl. Résumé XVI ${ }^{\mathrm{es}}$ Journées de l'Hypertension Artérielle): 35.

4. J.N.J.M. de Hoon, F.H.M. Vanmolkot, L.L.M. van de Ven, L.M.A.B. Van Bortel: Hypertension and quality of life: bisoprolol versus nifedipine retard. Neth $J$ Med 1997; 50(5): A29. 
5. J.N.J.M. de Hoon, H.H.W. Thijssen, A.J.M.M. Beysens, L.M.A.B. Van Bortel: Study on the interaction between omeprazole and acenocoumarol. Neth J Med 1997; 50(5): A9.

6. J. de Hoon, H. Thijssen, A. Beyssens, L. Van Bortel: Interaction study between omeprazole and acenocoumarol. Eur J Clin Pharmacol 1997; 52 (Suppl.): A130.

7. J.N.J.M. de Hoon, P. Pickkers, P. Smits, L.M.A.B. Van Bortel: Is calcitonin generelated peptide induced vasodilation endothelium-dependent in man? Br J Clin Pharmacol 1998; 46: 621P-622P.

8. J.N.J.M. de Hoon, A.P.G Hoeks, J.M. Willigers, L.M.A.B. Van Bortel: Non-invasive assessment of pulse pressure at different peripheral arteries in man. Neth J Med 1998; 52(4): A36.

9. J.N.J.M. de Hoon, P. Pickkers, P. Smits, L.M.A.B. Van Bortel: Calcitonin generelated peptide induced vasodilation in man is endothelium-dependent. Fundam Clin Pharmacol 1998; 12: 650.

10. J.N.J.M. de Hoon, H.A.J. Struijker-Boudier, L.M.A.B. Van Bortel: Different vascular effects of dihydroergotamine on large arteries and resistance vessels in man. Br J Clin Pharmacol 1999; 47: 470P.

11. J.N.J.M. de Hoon, P. Pickkers, P. Smits, H.A.J. Struijker-Boudier, L.M.A.B. Van Bortel: Calcitonin gene-related peptide induced vasodilation in man: endotheliumdependent? Hypertension 1998; 32(4): 790.

12. J.N.J.M. de Hoon, P. Pickkers, P. Smits, H.A.J. Struijker-Boudier, L.M.A.B. Van Bortel: Calcitonin gene-related peptide induced vasodilation in man. Fundam Clin Pharmacol 1999; 13: 130.

13. J.N.J.M. de Hoon, H.A.J. Struijker-Boudier, L.M.A.B. Van Bortel: Vascular effects of dihydroergotamine on large arteries and resistance vessels in man. Fundam Clin Pharmacol 1999; 13: 516. 
14. J.N.J.M. de Hoon, P. Pickkers, P. Smits, H.A.J. Struijker-Boudier, L.M.A.B. Van Bortel: Calcitonin gene-related peptide induced vasodilation in man: the contribution of potassium channels. Br J Clin Pharmacol 1999: 48: 774P.

15. J.N.J.M. de Hoon, P. Pickkers, P. Smits, H.A.J. Struijker-Boudier, L.M.A.B. Van Bortel: Calcitonin gene-related peptide induced vasodilation is nitric oxide dependent. Neth J Med 1999; 54(5): A59.

16. J.N.J.M. de Hoon, L.M.A.B. Van Bortel, H.A.J. Struijker-Boudier: The effects of dihydroergotamine on large arteries and resistance vessels in man. $J$ Hypertens 1999; 17(Suppl. 3): S96-S97.

17. J.N.J.M. de Hoon, P. Pickkers, P. Smits, H.A.J. Struijker-Boudier, L.M.A.B. Van Bortel: Calcitonin gene-related peptide induced vasodilation does not depend on the activation of potassium channels in man. $J$ Hypertens 1999; 17(Suppl. 3): S107-S108.

18. J.N.J.M. de Hoon, P. Pickkers, P. Smits, H.A.J. Struijker-Boudier, L.M.A.B. Van Bortel: Calcitonin gene-related peptide induced vasodilation is nitric oxide dependent in man. J Hypertens 1999; 17(Suppl. 3): S160-S161.

19. J.N.J.M. de Hoon, H.A.J. Struijker-Boudier, L.M.A.B. Van Bortel: Acute vascular effects of dihydroergotamine in man. Cephalalgia 1999; 19(4): 356-357.

20. J.N.J.M. de Hoon, P. Pickkers, P. Smits, H.A.J. Struijker-Boudier, L.M.A.B. Van Bortel: Calcitonin gene-related peptide induced vasodilation does not involve the activation of potassium channels in man. Cephalalgia 1999; 19(4): 397.

21. J.N.J.M. de Hoon, P. Pickkers, P. Smits, H.A.J. Struijker-Boudier, L.M.A.B. Van Bortel: Calcitonin gene-related peptide induces vasodilation by nitric oxide. Cephalalgia 1999; 19(4): 315-316.

22. L.M.A.B. Van Bortel, J.N.J.M. de Hoon, P. Pickkers, P. Smits, H.A.J. StruijkerBoudier: Calcitonin gene-related peptide induced vasodilation does not depend on the activation of potassium channels in man. Eur Heart J 1999; 20(Suppl.): 39 (P401). 
23. L.M.A.B. Van Bortel, J.N.J.M. de Hoon, P. Pickkers, P. Smits, H.A.J. StruijkerBoudier: Calcitonin gene-related peptide induced vasodilation depends on the release of nitric oxide. Eur Heart $J$ 1999; 20(Suppl.): 132.

24. J.N.J.M. de Hoon, P. Pickkers, P. Smits, H.A.J. Struijker-Boudier, L.M.A.B. Van Bortel: Does calcitonin gene-related peptide induced vasodilation in man involve potassium channel activation? Hypertension 1999; 34: 705.

25. J.N.J.M. de Hoon, L.M.A.B. Van Bortel, H.A.J. Struijker-Boudier: Disparate effects of dihydroergotamine on large arteries and resistance vessels in man. Hypertension 1999; 34: 705.

26. J.N.J.M. de Hoon, P. Smits, J. Troost, H.A.J. Struijker-Boudier, L.M.A.B. Van Bortel: Exploring vascular function and structure in migraine patients. $\mathrm{Br} \mathrm{J} C l i n$ Pharmacol (in press).

27. L.M.A.B. Van Bortel, J. Troost, P. Smits, H.A.J. Struijker-Boudier, J.N.J.M. de Hoon: Exploring the vascular function and structure in migraine patients. Neth $J$ Med 2000; 56(5): A12-13.

28. L.M.A.B. Van Bortel, J.N.J.M. de Hoon, P. Smits, J. Troost, H.A.J. StruijkerBoudier: Vascular responsiveness and structure in migraine patients. $J$ Hypertens 2000; 18(Suppl. 2): S182.

29. J. de Hoon, J. Troost, H. Struijker-Boudier, L. Van Bortel: Vascular effects of 5-

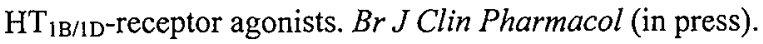

30. J.N.J.M. de Hoon, H.A.J. Struijker-Boudier, L.M.A.B. Van Bortel: Vascular effects of dihydroergotamine. BrJ Clin Pharmacol (in press).

31. J. de Hoon, J. Troost, P. Smits, H. Struijker-Boudier, L. Van Bortel: Vascular function in migraine patients. Br J Clin Pharmacol (in press). 



\section{List of Abbreviations}
A, B
fictitious plasma concentrations at time zero
$\alpha, \beta$
rate constants referring to the rapid $(\alpha)$ and slow $(\beta)$ phase of decline in plasma concentration, respectively
$\mathrm{ACh}$ acetylcholine
ANOVA
analysis of variance
ATP
adenosine-5'-triphosphate
AU
arbitrary units
AUC
area under the curve
$\triangle \mathrm{AUC}$
change/difference in AUC
CACN $\alpha 1 \mathrm{~A}$
$\alpha_{1 A}$-subunit of a brain specific voltage gated P/Q-type calcium channel
cAMP
cyclic adenosine-5'-monophosphate
$\mathrm{CC}$
cross-sectional compliance (over the operating pressure)
$\mathrm{CC}_{\text {iso }}$ isobaric $\mathrm{CC}$; $\mathrm{CC}$ over a pre-defined pressure interval
cGMP cyclic guanosine-5'-monophosphate
CGRP calcitonin gene-related peptide
$95 \% \mathrm{CI}$
$\mathrm{CL}$ $95 \%$ confidence interval
$C_{\max }$
CSA $\triangle \mathrm{CSA}$ plasma clearance maximum plasma concentration arterial end diastolic cross-sectional area change in arterial cross-sectional area during the cardiac cycle cortical spreading depression plasma concentration at time $\mathrm{t}$ coefficient of variation
$\mathrm{D}$ arterial end diastolic diameter
DBP change in arterial diameter during the cardiac cycle; distension
DC diastolic blood pressure distensibility coefficient (over the operating pressure) 
$\mathrm{DC}_{\text {iso }}$

DHE

dl

ECG

EDRF

EDTA

eNOS

FBF

$\mathrm{FBF}_{\text {control }}$

$\mathrm{FBF}_{\text {exp }}$

FBF-ratio

fMRI

FVR

FVR $_{\text {control }}$

FVR $_{\text {exp }}$

$\mathrm{FVR}_{\text {muscle }}$

FVR total

h

${ }^{3} \mathrm{H}$

5-HIAA

5-HT

IMT

IU

$\mathrm{k}_{\mathrm{a}}$

$\mathrm{K}_{\text {ATP-channels }}^{+}$

$\mathrm{K}^{+}$Ca-channels

$\mathrm{K}_{\mathrm{i}}$

KIU

$\mathrm{kPa}$

1 isobaric DC; DC over a pre-defined pressure interval

dihydroergotamine

deciliter

electrocardiogram

endothelium derived relaxing factor

ethylene-diaminetetraacetic acid

endothelial nitric oxide synthase

forearm blood flow

forearm blood flow in the control arm

forearm blood flow in the experimental/infused arm

ratio in FBF in the infused over the control arm

functional magnetic resonance imaging

forearm vascular resistance

forearm vascular resistance in the control arm

forearm vascular resistance in the experimental/infused arm

muscular forearm vascular resistance

total forearm vascular resistance

hour

tritium

5-hydroxyindole-3-acetic acid

5-hydroxytryptamine; serotonin

intima-media thickness

international units

rate constant referring to absorption

ATP-sensitive potassium channels

calcium-sensitive potassium channels

the concentration of competing ligand in a competition assay that would occupy $50 \%$ of the receptors if no radioligand were present

kallikrein inhibitor units

kilo pascal

liter 


$\begin{array}{ll}\text { L-NMMA } & \mathrm{N}^{\mathrm{G}} \text {-monomethyl-L-arginine } \\ \text { LogD } & \text { parameter referring to lipophilicity of drugs (see Table 1.3) } \\ \mathrm{MAP} & \text { mean arterial pressure } \\ \mathrm{mg}, \mu \mathrm{g} & \text { milligram, microgram } \\ \mathrm{MHz} & \text { mega hertz } \\ \text { min } & \text { minute } \\ \mathrm{ml}, \mu \mathrm{l} & \text { milliliter, microliter } \\ \mathrm{mm} & \text { millimeter } \\ \mathrm{mmHg} & \text { millimeters of mercury } \\ \text { mmol } & \text { millimole } \\ \mathrm{n} & \text { number } \\ \mathrm{NANC} & \text { nonadrenergic-noncholinergic } \\ \mathrm{NAV} & \text { not available } \\ \mathrm{ND} & \text { not determined } \\ \mathrm{ng} & \text { nanogram } \\ \mathrm{NK}-\mathrm{receptor} & \text { neurokinin-receptor } \\ \mathrm{NKA} & \text { neurokinin A } \\ \mathrm{NMDA} & \text { N-methyl-D-aspartaat } \\ \text { NO } & \text { nitric oxide } \\ \text { NOS } & \text { NO-synthase } \\ \text { NOS III } & \text { identical to eNOS } \\ \mathrm{NSAID} & \text { non-steroidal anti-inflammatory drug } \\ P & \text { level of significance } \\ \Delta \mathrm{P} & \text { pulse pressure } \\ \Delta \mathrm{P}_{\mathrm{BA}} & \text { brachial artery } \Delta \mathrm{P} \\ \Delta \mathrm{P}_{\text {cal }} & \text { calculated } \Delta \mathrm{P} \\ \Delta \mathrm{P}_{\mathrm{CCA}} & \text { common carotid artery } \Delta \mathrm{P} \\ \Delta \mathrm{P}_{\mathrm{FA}} & \text { femoral artery } \Delta \mathrm{P} \\ \Delta \mathrm{P}_{\text {tono }} & \text { absolute } \Delta \mathrm{P} \text { as measured with tonometry } \\ \mathrm{PET} & \text { positron emission tomography } \\ \text { pg } & \text { picogram } \\ \mathrm{pK} & \end{array}$




$\begin{array}{ll}\text { pmol } & \text { picomole } \\ \text { RC } & \text { repeatability coefficient (Bland-Altman) } \\ \text { rCBF } & \text { regional cerebral blood flow } \\ \text { RF } & \text { radio frequency } \\ \text { RIA } & \text { radioimmuno-assay } \\ \text { SBP } & \text { systolic blood pressure } \\ \text { SD } & \text { standard deviation } \\ \text { SEM } & \text { standard error of the mean } \\ \text { SNP } & \text { sodium nitroprusside } \\ \text { SP } & \text { substance } \mathrm{P} \\ \text { SPECT } & \text { single positron emission computed tomography } \\ \text { SSOFRA } & \text { selective serotonin-1-F-receptor agonist } \\ \text { SVR } & \text { systemic vascular resistance } \\ t_{1 / 2, a b s} & \text { absorption half-life } \\ t_{1 / 2, a} \text { and } t_{1 / 2, \beta} & \text { distribution and elimination half-life } \\ t_{1 / 2,2} & \text { terminal half-life } \\ \text { TCD } & \text { transcranial Doppler sonography } \\ t_{\max } & \text { time to reach } C_{\text {max }} \\ \text { TEA } & \text { tetra-ethyl-ammonium chloride } \\ \text { TxB } & \text { thromboxane } B_{2} \\ \mathrm{~V}_{\beta} & \text { volume of distribution }\end{array}$

